\title{
DADOS DIGITAIS DO SATÉLITE SPOT E DE RADIOMETRIA DE CAMPO NO ESTUDO DA CULTURA DO EEIJOEIRO (Phaseolus vulgaris I.) IRRIGADO
}

\author{
ATHADEU FERREIRA DA SILVA
}

Orientador: Prof. Dr. CARLOS ALBERTO VETTORAZZI

\footnotetext{
Tese apresentada is Escola Superior de Agrioulture "Iuiz de Queiroz", da Untrersidade de săo Paulo, para obtençăo do titalo de Doutor m Agronamia, irea de concentração: Irrigaçăo - Drenagean.
}

P I R A C I C A B A

Estado de São Paulo - Brasil

Agosto - 1995 
CATALOBACAO HA FUELICAGAO

DIVISAO DE BIELJOTECA E DOCUMEHTAGAD - CAMFUS "LUII DE BUEJROI"/USF

Silva. Athadeu Ferreira da Dados dioitais do satélite spot e de radiometria de camo no estudo da cultura do fejjoeiro (Phaseolus vulgaris l. irrigado. Piracicaba. 1995. $118 p$.

TeEE - ESALB

Bibliografiz.

1. Aqua de irrjoaczo - Defarda 2. Fejizo - Irrioacăo - Monitoramento 3. Sensoriasento remoto 1. Escola Sugerior de Agricultura Luiz de Gueiroz. Piracicaba

$\operatorname{CDD} \quad 635,652$ 


\section{DADOS DIGITAIS DO SATÉLITE SPOT}

$E$ DE RADIOMETRIA DE CAMPO NO ESTUDO DA CUITURA DO EEIJOEIRO (Phaseolus vulgaris I.) IRRIGADO

Aprovada em: $08 \cdot 08 \cdot 1995$

Comissão julgadora:

Prof. Dr. Carlos Alberto Vettorazzi

USP

Prof. Dr. Gilberto José Garcia

Prof. Dr. Herminio Hideo Suguino

CODEVASE

Prof. Dr. Hilton Thadeu Zarate do Couto

USP

Prof. Dr. Tarlei Ariel Botrel

USP

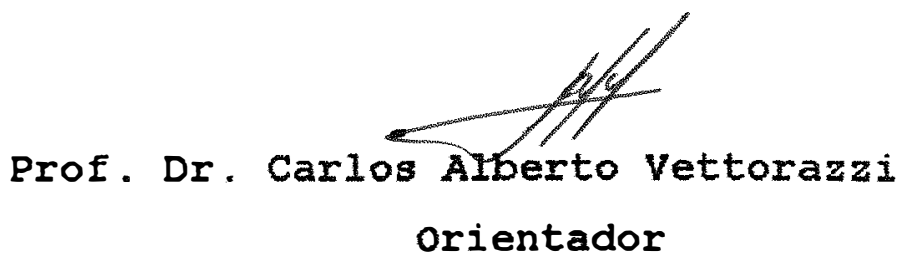




\section{Aos meus inesqueciveis pais Erancisco de Paula e Maria Aparecida Silva (in memoriam) pela árdua luta sócio-econômica travada sob condiçôes adversas, em pról da formação de cidadania dos Eilhos, ofereço.}

A minha esposa Piva, Aos meus Eilhos Athila, Athalita, Achiles e Artur, Aos meus irmãos Antônio e Jorcelina. dedico.

h̀s pessoas que vêm no conhecimento e no saber o caminho para o desenvolvimento de um povo, congratulo. 


\section{$\begin{array}{llllllllllllll}A & G & R & A & D & E & C & I & M & E & N & T & O & S\end{array}$}

A Companhia de Desenvolvimento do Vale do São Erancisco - CODEVASE, pela nossa liberaçăo para participar do curso de Pós-Graduação em Irrigação e Drenagem, nível de Doutorado.

A Escola Superior de Agricultura "Luiz de Queiroz"ESALQIUSP, por intermédio do Departamento de Engenharia Rural, pela oportunidade concedida.

Ao Conselho Nacional de Pesquisa - CNPq pela ajuda de custos fornecida.

Ao Professor Doutor Carlos Alberto Vettorazi pela orientação, apoio e amizade dispensados no desenvolvimento do trabalho.

Ao Professor Doutor Rubens Angulo filho pela assistência que deu na condução do trabalho, como co-orientador, por ocasião da estada do professor orientador fora do Pais, e também pela amizade e sugestoes complementares.

À 1 . Superintendência Regional da CODEvase (Montes Claros/MG) pelo apoio logístico à execuçăo dos serviços de campo.

Ao SRGRAPH CODEVASE (Brasilia/DE) pela contribuição logistica e técnica dispensadas, através do Engenheiros Carlos Alcebiades Barros Cavalcanti e Aristóteles Eernandes de Melo.

Ao Professor Doutor Hilton Thadeu Zarate do Couto (Departamento de Ciências Elorestais da ESALQ/USP Piracicaba'SP) e Professor Eduardo Ereitas da Silva (Departamento de Estatistica da Universidade de Brasilia - UnB) pelo auxilio na analise estatistica dos dados. 
Aos professores e Euncionários do Departamento de Engenharia Rural da ESRLQ/USP pela amizade cultivada no decorrer do comvivio acadêmico.

Ao Engenheiro Agrônomo José Eduardo Borella pelo incentivo, colaboração e apoio na etapa de finalização do trabalho.

A todos que, direta ou indiretamente, contribuiram para a realização deste trabalho. 


\section{página}

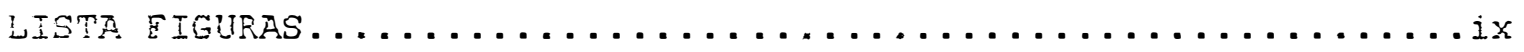

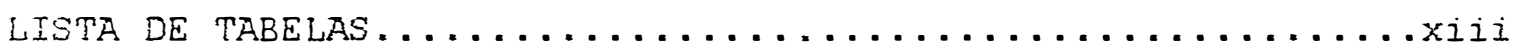

LISTA DE ABREVIATURA E SIMBOLOS..................

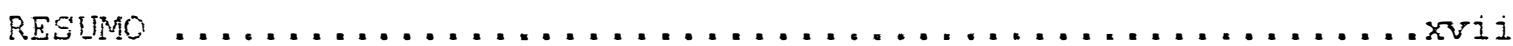

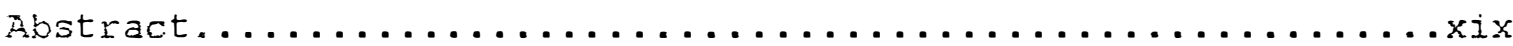

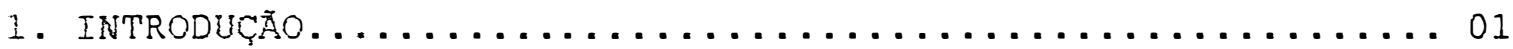

2. REVISÃO DE LITERATURA...................... .

2.1. Conceitos e considerações sobre sensoriamento remoto........................... 04

2.2. Sensoriamento remoto e agricultura irrigada.........07 2.2.1. Aspectos técnicos e operacionais...........08

2.2.1.1. Imagens de satélite...........08

2.2.1.1.1. Sistema Spot.........10

2.2.1.2. Radiometria...............12

2.2.1.3. Parametros Eitotécnicos.........14

2.2.2. Trabalhos desemolvidos baseados em imagens

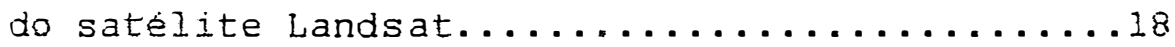

2.2.3. Trabalhos desenvolvidos com base em imagens

do satélite spot..................22

2.3. Trabalhos que relacionam radiometria de campo com dados digitais de imagens de satélites e índices de

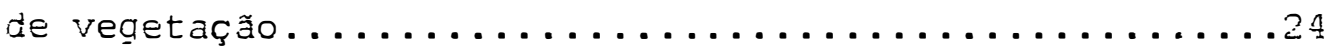

2.4. Fatores inerentes à resposta espectral caracterís-

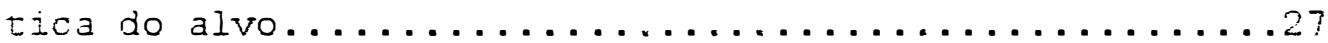


3. MATERIAIS E MÉTODOS...........................

3.1. Localização da área de estudo................... 35

3.2. Caracterização da região.....................

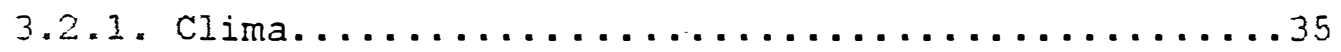

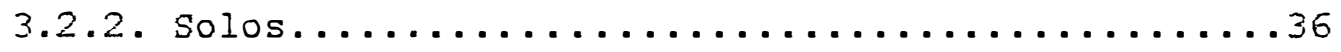

3.2.3. Recursos hidricos....................... 37

3.3. Informações do projeto Jaíba .................. 37

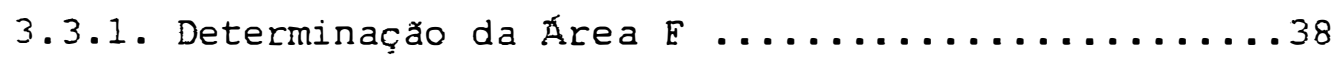

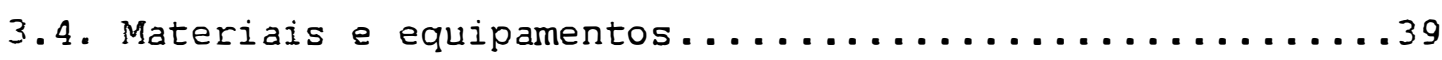

3.4.1. n cultura base do trabalho.................39

3.4.2. Localização das áreas de trabalho............39

3.4.3. Dados culturais......................40

3.4.4. Dados orbitais da área de estudo...........A1

3.4.5. Equipamentos empregados nas mediçôes

radiométricas.....................

3.4.6. Equipamentos empregados no tratamento de

imagens.......................42

3.5. Métodos............................. 4

3.5.1. Açoes de campo....................44

3.5.1.1. Coleta de dados................44

3.5.1.2. Dados Eitotécnicos.............45

3.5.1.3. Leituras radiométricas e tratamentos de dados................49

3.5.1.4. Tratamentos de imagens de satélite e obtenção de dados............51

3.5.1.5. Análise dos dados..............52

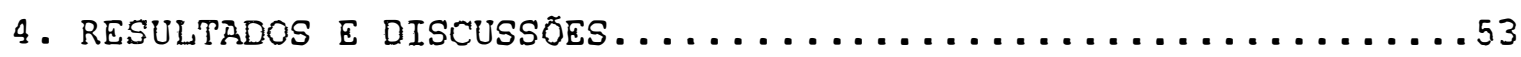

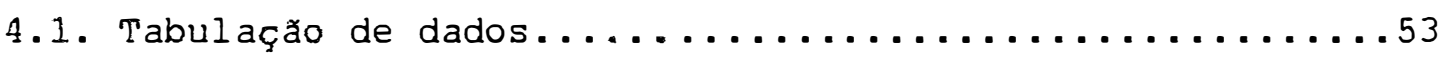

4.2. Análise estatística dos valores de reflectância......57

4.2.1. Análise estatística dos valores temporais de reflectância.........................

4.2.1.1. Análise de variância - Teste "E"....57

4.2.1.2. Discussão de resultados.........60

4.2.2. Análise estatistica dos valores temporais

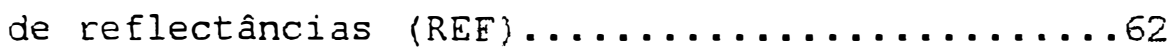


viii.

4.2.2.1. Análise de variância - Teste "E".....63

4.2.2.2. Teste de Tukey..............63

4.2.2.3. Discussão de resultados..........64

4.2.3. Análise estatistica dos valores temporais

de reflectância (RAD) .................

4.2.3.1. Análise de variância - Teste "E"....65

4.2.3.2. Teste de Tukey para as médias

das interaçŏes................ 65

4.2.3.2. Discussão de resultados.........67

4.3. Avaliaçăo gráfica das curvas dos valores de re-

Electância temporal (REE e RAD).................

4.3.1. Discussão de resultados ...............70

4.4. Avaliação gráfica das curvas dos valores de re-

Electância em Eunção de dados Eitotecnicos...........1

4.4.1. Curvas de reflectância em Eunção da cober-

tura vegetal...................... 72

4.4.1.1. Discussão de resultados.........75

4.4.2. Curvas de reflectància função do indice

de área foliar.......................

4.4.2.1. Discussáo de resultados...........79

4.4.3. Tratos culturais...................... 80

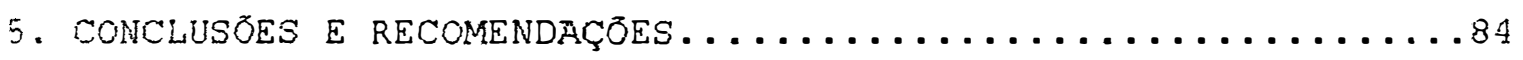

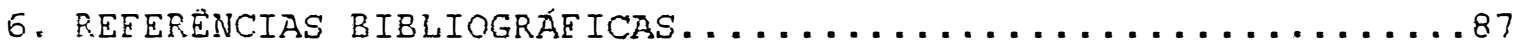

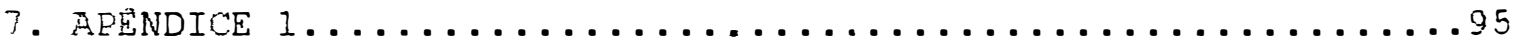

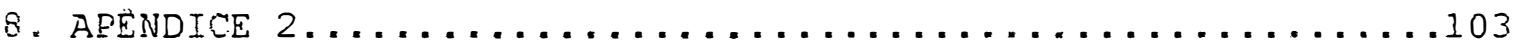

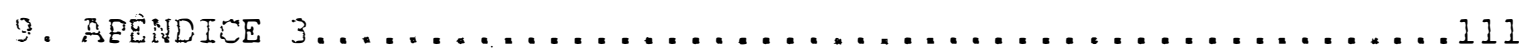




\section{I TA DE FIURA S}

\section{Eiguras}

Página

1. Regióes do espectro óptico..................... 07

2. Kepresentaçåo esquemática de um sistema de varredura

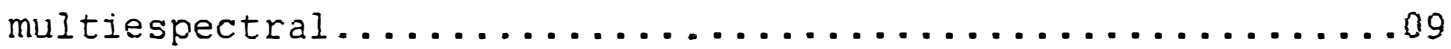

3. Possibilidade de visadas dos sensores HRV.............11

4. Componentes básicos de um radiometro................13

5. Estrutura morfológica de uma folha normal.............28

6. Principais características da resposta espectral das

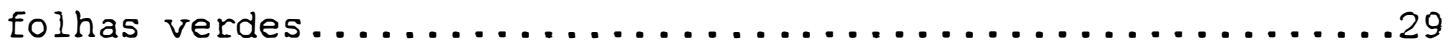

7. Efeito da reflectância espectral, causado pela infiltração de água nos espaços intracelulares de

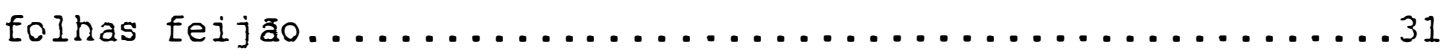

8. Ilustração esquemática das três grandes fases do ciclo Eenológico de uma cultura agrícola, quanto aos principais componentes do sistema a influenciar na

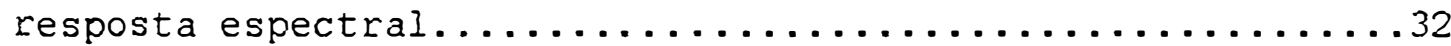

9. Diagrama de montagem dos elementos ópticos do

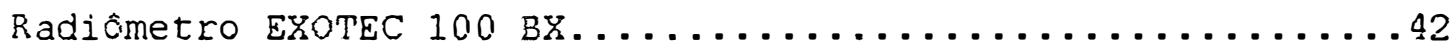

10. Configuração do hardware de um sistema de processa-

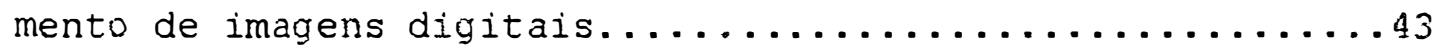

11. Esquema de para obtençåo do valor de " $C$ " no campo.......46

12. Estratégia de coleta de dados na planta.............4

13. Curvas de reflectancias médias dos 7 lotes estuda-

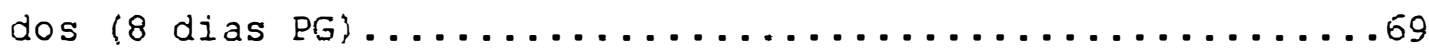

14. Curvas de reflectâncias médias dos 7 lotes estudados $\{50$ dias $P G\}$. 
15. Curvas médias de reflectâncias em funçăo da cobertura vegetal (8 dias gG)....................

16. Curvas médias de refiectâncias em função da cobertura vegetai $(50$ dias $P G) \ldots \ldots \ldots \ldots \ldots \ldots \ldots \ldots \ldots$

17. Curvas medias de reflectâncias em funçăo do ındice de área foliar $(8$ dias $E G) \ldots \ldots \ldots \ldots \ldots \ldots \ldots \ldots$

18. Curvas médias de refiectâncias em funçăo do indice de area foliar (50 dias gG) ................

19. Imagem spot da área de trabalho do periodo referente a 50 dias pos-germinação cultura de

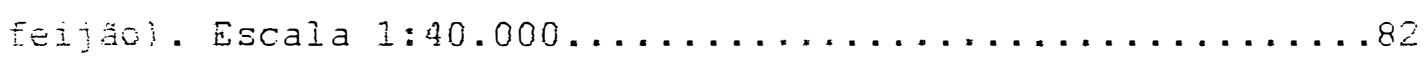

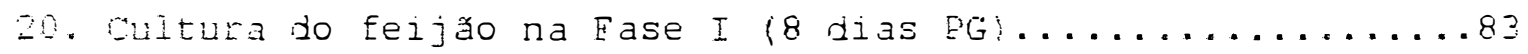

21. Culura do feijão na fase II (8 dias $P G) \ldots \ldots \ldots \ldots \ldots . \ldots$.

1... Curvas de reflectâncias do lote $I$ ( 8 dias $P G\} \ldots . . \ldots \ldots .96$

1E. Cumas de reflectâncias do lote $I(50$ dias PG)..........5

1. Cunfas de refiectancias do lote II $\{8$ dias PG ............

1D. Curas de reflectâncias do lote II 150 dias PG) . . . . . . .

1E. Gurrá de reflectancias do lote III 8 dias FGi........98

IF. Curvas de reflectancias do lote III (50 dias PG) ........8

1G. Curras de reflectancias do lote IV $\{8$ dias QG $\} \ldots . . . \ldots .99$

14. Curvas de reflectâncias do lote IV (50 dias PG) . . . . . . 99

1F. Curvas de reflectâncias do lote $v(8$ dias $E G) \ldots \ldots \ldots \ldots . .100$

1.]. Curvas de reflectancias do lote $v(50$ dias EG).........100

1L. Curras de reflectancias do lote vI $(8$ dias PG)...........

M. Uuras de reflectâncias do lote VI $(50$ dias $E G) \ldots \ldots \ldots \ldots 101$

iN. Lunas de reflectâncias do lote YII 8 dias fG)........102

1. Curvas de refiectancias do lote VII (50 dias PG).......102

27. Curvas de reflectancias em funçăo da cobertura veqetal

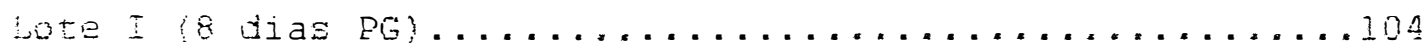

28. Curvas de refiectôncias em função da cobertura vegetai

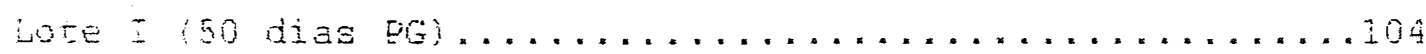

20. Cumas de reflectäncias em funçăo da cobertura veqetal Lote II 8 dias $f g$..........................

-D. Curas de reflectancias em funço da cobertura vegetal

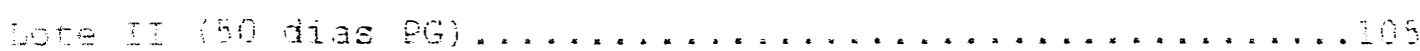


2E. Curvas de reflectancias em funçăo da cobertura vegetal

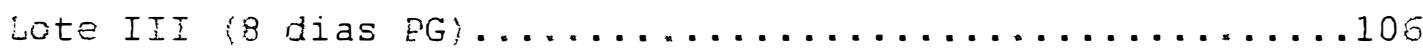

$2 \mathrm{~F}$. Curvas de reflectâncias em Eunção da cobertura vegetal Lote III $(50$ dias EG) ........................ 106

2G. Curvas de reflectâncias em Eunção da cobertura vegetal

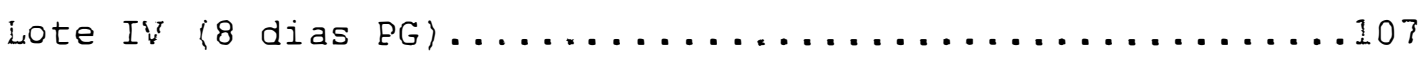

$2 \mathrm{H}$. Curvas de reflectâncias em Eunção da cobertura vegetal

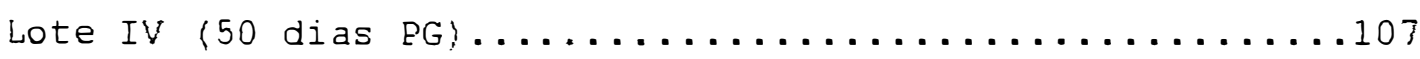

2I. Curvas de reflectâncias em Eunção da cobertura vegetal

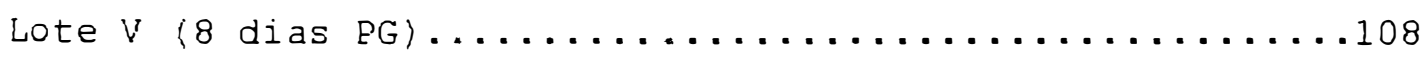

23. Curvas de reflectâncias em Eunção da cobertura vegetal

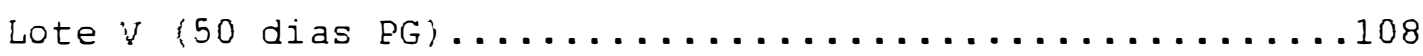

2L. Curvas de reflectâncias em Eunção da cobertura vegetal Lote VI $(8$ dias $E G) . . \ldots \ldots \ldots \ldots \ldots \ldots . \ldots \ldots$

$2 M$. Curvas de reflectâncias em Eunção da cobertura vegetal

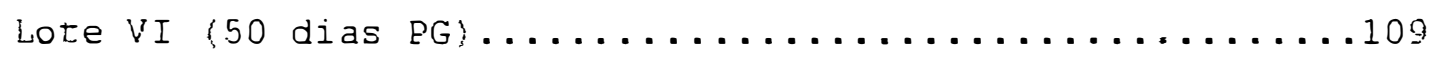

$2 \mathrm{~N}$. Curvas de reflectâncias em função da cobertura vegetal Lote VII $(8$ dias PG) ........................ 110

20. Curvas de reflectâncias em Eunção da cobertura vegetal Lote VII ( 8 dias PG) ...................... 110

3A. Curvas de reflectâncias em função da cobertura vegetal

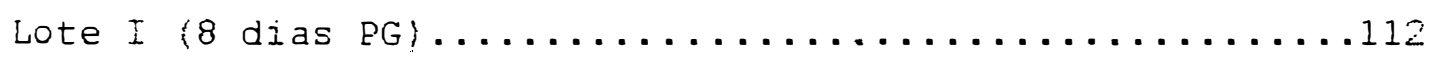

$3 B$. Curras de reflectâncias em função da cobertura vegetal

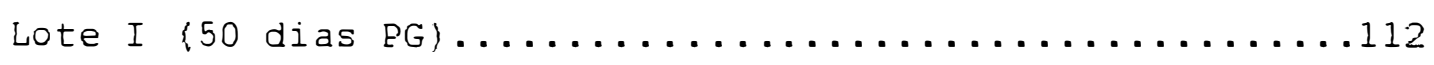

$3 C$. Curvas de reflectancias em função da cobertura vegetal

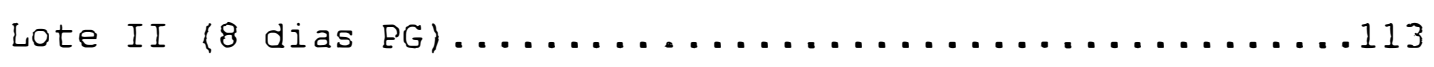

3D. Curvas de reflectâncias em função da cobertura vegetal

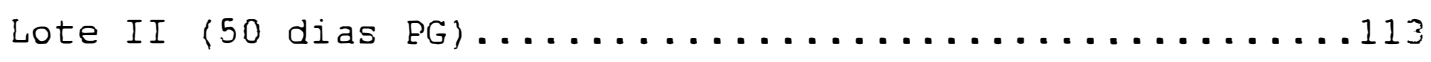

$3 E$. Curvas de reflectâncias em função da cobertura vegetal

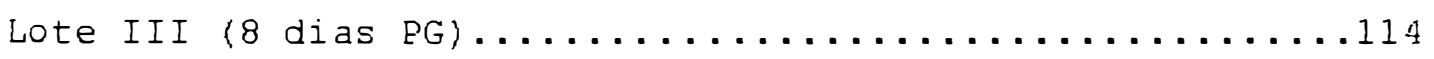

$3 E$. Curras de reflectâncias em função da cobertura vegetal

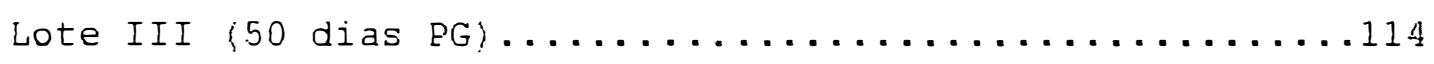

3.G. Curvas de reflectâncias em Eunção da cobertura vegetal

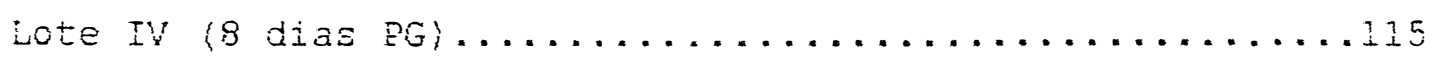


xii.

3H. Curvas de reflectâncias em funçăo da cobertura vegetal

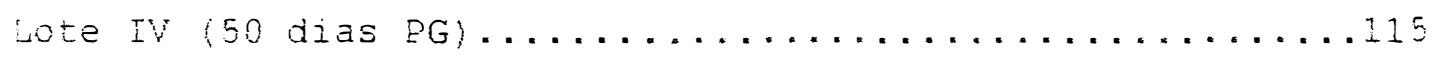

3I. Curvas de reflectâncias em Eunção da cobertura vegetal

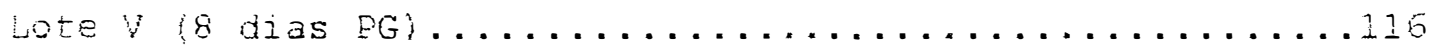

s.t. Guras de reflectancias em funça da cobertura vegetal

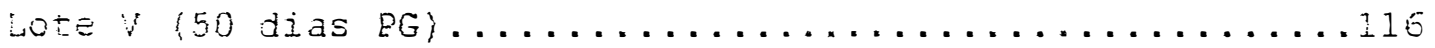

3i. Cunas de reflectâncias em Eunçäo da cobertura vequetal

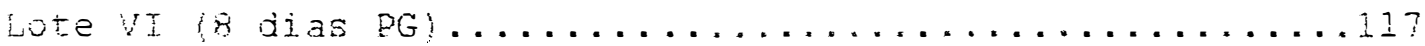

TM. Curvas de reflectâncıas em Eunçăo da cobertura vegetal

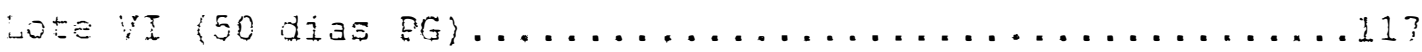

3N. Curvas de reflectâncias em Eunça da cobertura vegetal Loce VII 8 dias PG ........................

30. Curvas de reflectancias em funçä́ da cobertura vegetal

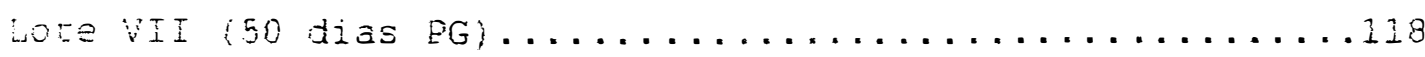


xiii.

I I S T A DE TA B E L A

Tabelas

Rágina

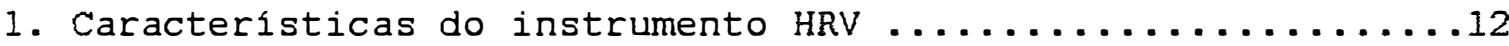

2. Dados climatológicos do posto de Mocambinho (Projeto

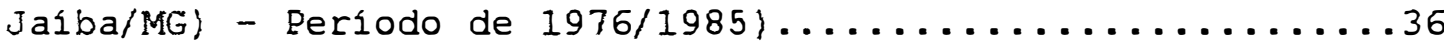

3. Valores de reflectâncias obtidas a partir de dados extraidos de imagens do satélite spot..............54

4. Valores de reflectancia obtidos a partir de radiome-

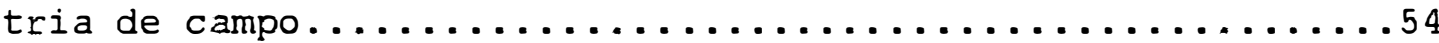

5. Dados médios de índice de área foliar.................55

6. Dados médios de cobertura vegetal da cultura............56

7. Teste "E" para as médias das interaçơes...............58

8. Teste de Tukey: variável METODO..................58

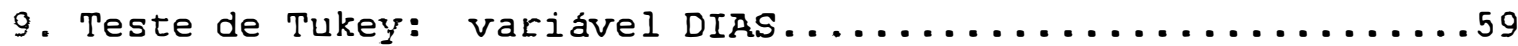

10. Teste "E" para as médias das interaçøes................59

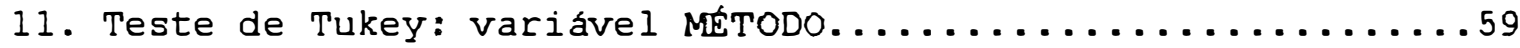

12. Teste de Tukey: variável DIAS. ....................... 59

13. Teste "E" para as médias das interaçסes..............60

14. Teste de Tukey: variável METODO..................60

15. Teste de Tukey: variável DIAs.....................60

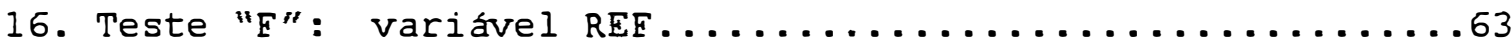

17. Teste de Tukey: variável REF...................64

18. Teste de Tukey: variável BANDA...................64

19. Teste de Tukey para as médias das interaçסes..........66

20. Teste de Tukey: variável RAD...................66 
21. Teste de Tukey: variável Bandas................66

22. Dados médios de reflectância (REF, RAD) .............68

23. Dados médios temporais de cobertura vegetal (COV) e de reflectância (RAD, REE) da lavoura de feijão.......73

24. Resultado da correlação de dados fitotécnicos e de reflectâncias.............................

25. Dados temporais médios de indice de área foliar (IAF) e reflectância (RAD, REF) da lavoura de feijão...........................

26. Resultado da correlaçăo de dados fitotécnicos e de reflectâncias.......................... 80 


\section{$\begin{array}{lllllllllllllllllll}I & I & S & \mathrm{~T} & \mathrm{~A} & \mathrm{D} & \mathrm{E} & \mathrm{A} & \mathrm{B} & \mathrm{R} & \mathrm{E} & \mathrm{V} & \mathrm{I} & \mathrm{A} & \mathrm{T} & \mathrm{U} & \mathrm{R} & \mathrm{A} & \mathbf{S}\end{array}$

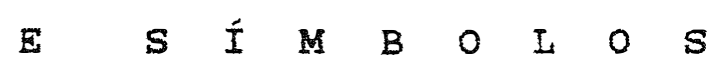

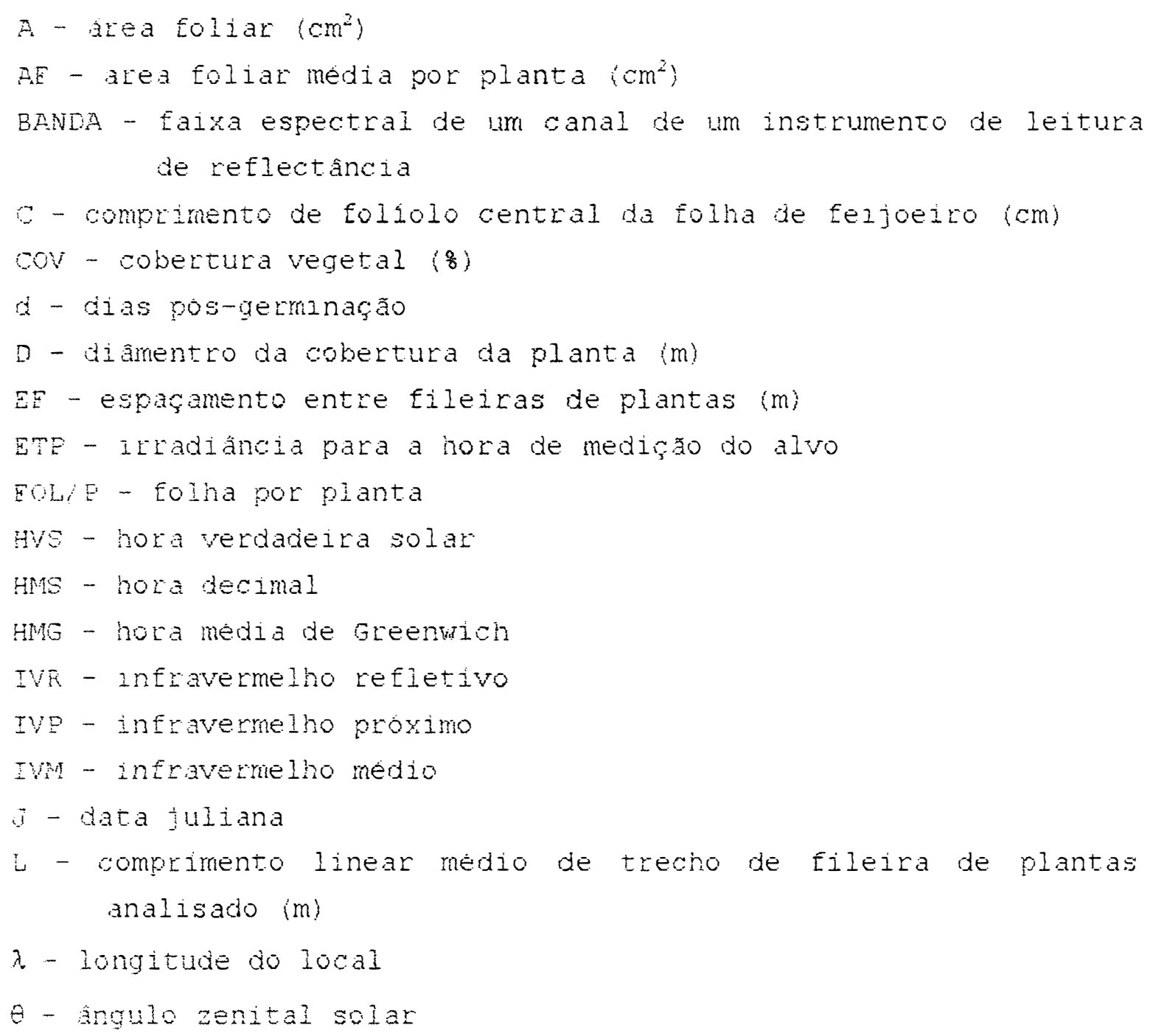


xvi.

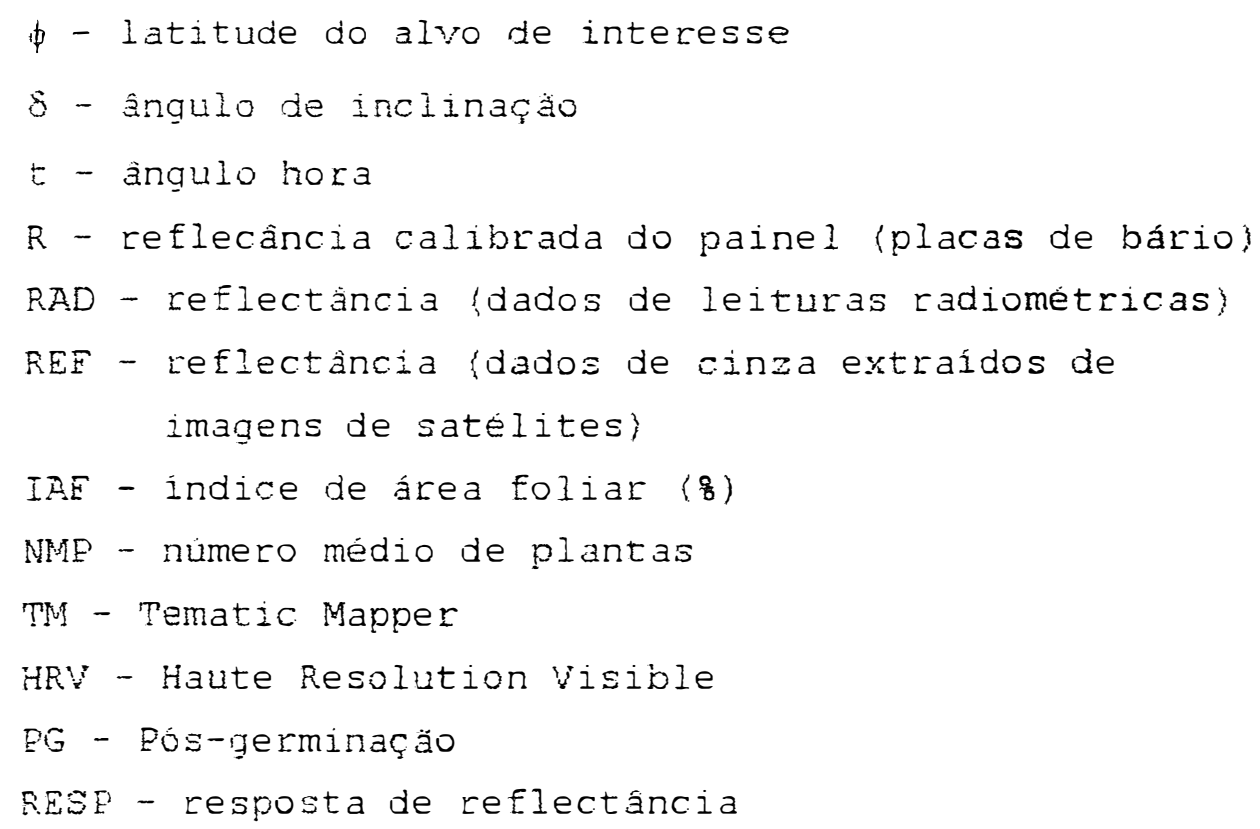




\title{
DADOS DIGITAIS DO SATÉIITE SPOT E DE RADIOMETRIA DE CAMPO NO ESTUDO DA CULTURA DO EEIJOEIRO (Phaseolus vulgaris I.) IRRIGADO
}

\author{
Autor: ATHADEU FERREIRA DA SIIVA \\ Orientador: PROE. DOUTOR CARLOS ALBERTO VETTORAZZI
}

RESUMO

Otrabaho teve cono objetivo testar a aplicaca de imagene digtals do atelite spot e dados radiometricos coletados emi camoo, no cadastamento de áreas com culturas de feija carzoda phasedus valuaris i.) sob regime de irriagán. Numa abordagem mais ampla, objetivou-se identificar a especie cultivada entre outras, precisar a dimensăo da gleba para subsidiar o discipinamento de uso da água de uma fonte hidrica, ou seja, o gerenciamento de recursos hidricos. Earte-se da hipötese que existe estreita correlação entre a reflectancia dos dados de cinza extraídos da imagem de satélite e os dados radiometricos coletados no campo. Em razão disso o monitoramento e levantamento de culturas irrigadas podem ser feitos empregandose sensoriamento remoto digital, interagidos com dados básicos de campo, calibrados para grupos de especies vegetais distintos. o estudo foi conduzido no municipio de laiba - MG, numa área de colonzzaçăo (lotes irrigados com area media individual de 5 ha) com a cultura do feijăo, durante um ciclo agrícola. os dados destinajos ao estudo foram coletados em três ciclos da cultura, sendo elez dados fitotécnicos, dados de radiometria de campo e dados digitais extraídos de imagens do satelite spot. A pesquisa 
xviii.

\begin{abstract}
permitiu concluir que, sob as condiçoes estudadas, não existe correlação satisfatória entre dados radiométricos e digitais orbitais; e o cadastramento e identificaça de culturas de ciclo anual exploradas em área agrícolas sob regime de irrigaçăo exige serviços de apoio de campo sistemático. Recomendam-se novos estudos do gènero para aprimorar os resultados ora alcançados.
\end{abstract}




\section{SPOT SATELIITE DIGITAI DATE AND RADIOMETER FIEID DATE FOR STUDYING IRRIGATED BEANS CROPS DATA (Phaseolus vulgaris $I$. )}

Author: ATHADEU FERREIRA DA SILVA

Adviser: PROE. DOUTOR CARLOS ALBERTO VETTORAZZI

Abstract

The work had the objective to test application of spot satellite digital images and radiometer field data in the mapping of areas cultivated with carioca beans phaseojus vuigaris L.) under irrigation. In a broad way, the work tried to identify the cultivated specie among others, to precise the area dimension to subsidise the reguiation of water use, in other iwords, the management of water resources. The hypothesis of this work was that exists a narrow correlation between satellite image digital data and radiometer data collected in the field. Due to this Eact the monitoring and surveying of irrigated crops an be done using digital remote sensing interacted with basic field data cailorated Eor distinct group of plant species. The study area inas zmolemented in Jaiba Irrigation Eroject (municipal distict of jaiba/MG), in a colonization area (irrigated plotz with average area of 5 hal, cultivated with beans, during an agricultural cycie. The data for the study, collected in tree pnases of veqerative culture cicle, were phytotechnical data, Field radiometry and digital data extracted from the satelite images. The results aliowed to conciude that under the studied condituns, there was no satisfactory correiation berween 
radiometer and orbital digital data: annual crops surveying, in irrigated areas, needs sistematic field support. It is recommended new similar studies to improve the results now obtained. 


\section{INTRODUÇÄO.}

A Inadequaça do uso dos recursos hidricos as multipias lininas demandadas aos interesses da soriedade, tem acarretado conflitos entre as partes envolvidas a niveis cada vez mazs consideráreis e preocupantes. O grau de dificuldades em arminıstrar essa situaçao avaņ̧a proporcionalmente à evolução oopuiacional de uma regiao, devido às necessidades geradas à sobrevivencia humana. Entre os vários segmentos beneficiarios do nnsumo, esta 0 de irrigaça, cuja área expandiu-se zignificativamente no pais nos dez luitimos anos, à margem de orzentaçoes de politzcas disciplinadoras do uso da aqua. Em consecuencia, passou a sofrer desajustes operacionazs graves, compromentendo os projetos de irrigaça implantados ao longo da fonte hidrica. Para situaçoes localizadas, onde ha poucos projetos, o problema pode ser sontrolado sem maiores diflculdades. Quando trata-se de extensoes maiores; com grande concentraç㐅 de produtores envolvidos na atividade, e onde o processo de uso da agua é alterado constantemente lentrada de novas areas em operação e/ou alternâncias de turnos de regas das areas com culturas em desenvolvimento desordenado), faz-se necessario a regulamentaçăo de Uso (DAEE, 1990).

Destacam-se como parämetros necessários ao desenvoivimento de uma metodologia de trabalho, os seguintes: a) informaçoes climatologicas; b) estudos de geologia e de solos (levantamentos); c) dados historicos de hidrologia; d) uuantificaça da área cultivada; e e) tipos de culturas exploradas.

os dois últimos itens, "quantificaçåo da area irrigada" e "tipos de culturas exploradas", tem-se caracterizado pela dificuldade em precisar-se as informaçðes face às variaçues 
Erequentes ocorridas no campo e ao empirismo metodológico praticado na obtenção dos dados:

Regiões semi-áridas, de poucas variações no decorrer do ano (temperaturas médias altas e escassêz de chuva), propiciam, graças à irrigaçăo, praticar-se explorações agrícolas de ciclo curto, diversificadas, orientadas pelo mercado consumidor, praticamente em todas as estações do ano. As glebas encontram-se distribuidas irregularmente ao longo das margens de mananciais de vazões reduzidas, normalmente isoladas (registramse casos de pólos de irrigaçăo), com dimensóes variando de 0,50 na (olericultura) até Eaixas maiores que 100,00 ha (a maioria das glebas agrícolas está compreendida entre 2,00 ha e 5,00 ha). As áreas apresentam formato irregular e são de difícil acesso (geograficamente e/ou dificultado pelo proprietário). O interesse básico em identificar-se a exploração agricola, e dai o seu uso consultivo, em um universo tão diversificado entre os pares, é fundamental à proposta maior desejada (gerenciamento hidrico).

O monitoramento de recursos naturais através de imagens de satélite coloca várias informações de interesses multiplos à disposição de segmentos distintos, em Eunção do dinamismo requerido. A agricultura serve-se dessas informações para levantamentos de fronteiras agrícolas, estimativa de safras, monitoramentos, etc. A maioria dos trabalhos refere-se ao cadastramento de extensas áreas de monocultivos de reservas florestais; de lavouras agricolas de ciclos perene (Eruticultura), semi-perene (cana-de-açúcar) e/ou de culturas anuais (caso do cultivo de soja e de arroz). Apoiado em informaçŏes complementares de campo, o trabalho é complementado com niveis de precisão satisfatórios. Já os monitoramentos envolvendo pequenas glebas agrícolas, como no caso em questão, os resuitados não tem mostrados com o grau de satisfação desejado. Em alguns casos, há dificuldade até em precisar-se a dimensão da área.

Iste trabalho teve como objetivo correlacionar vaiores digitais extraicios da imagem de satélite spot e de radiometria de campo provenientes do cadastramento temporal da 
lavroura irrigada de feijăo. Numa evolução sequencial espera-se cadastrar as áreas com culturas irrigadas, identificar a espécie cultivada e precisar a dimensão da gleba, empregando imagens de satelite spot, com apoio de operaçöes de campo, viabilizando, a partir daí, estimar o uso consuntivo da lavoura (demanda de áqua requerida pela atividade). Espera-se com isso atingir resultados em tempos menores, a graus de precisăo satisfatorios e custos reduzidos, com a eliminação de etapas da operação de cadastramento em campo.

Assumiram-se as sequintes hipóteses:

- existe estreita correlação entre os valores de niveis de cinza extraidos da imagem de satélite e as leituras de radiometria coletadas no campo.

- o levantamento e o monitoramento de culturas irrigadas podem ser Eeitos empregado-se sensoriamento remoto orbital interagido com dados básicos de campo calibrados para grupos de espécies vegetais distintos.

- Os valores de níveis de cinza extraídos de imagens de satélites de uma área agrícola definem características vegetativas de um cultivar.

- Não há diferenças significativas entre o comportamento espectral dos alvos obtidos através das leituras radiométricas e dos valores de níveis de cinza da imagem de satélite.

- Tratos culturais e fatores fitotécnicos interferem nas respostas espectrais. 


\section{REVISÄO DE IITERATURA}

\subsection{Conceitos e considerações sobre sensoriamento remoto.}

Diversos sao os conceitos dados para sensoriamento remoto, cuja essencia das redaçes converge para uma ideia comum sobre 0 fenómeno. Entre esses, citaremos a definicao de Novo $(1989):$

- "Sensoriamento Remoto é a utilizaço conjunta de modernos sensores, equipamentos para transmissa de dados, aeronave, espaçonaves, etc, com o objetivo de estudar o ambiente terrestre através do registro e análise das interaçes entre radiação eletromagnética e as substâncias do planeta Terra em suas mais diversas manifestaçes". MENDonç⿸ (1981) faz algumas obsemaçbes sobre o tema: "Colocando-se dispositivos sensores em iviös ou satélites, com objetivo de obter informaçes acerca de objetos com o meio ambiente, o sensorzamento remoto apresenta tres importantes caracteristicas: rapidez, repetitividade e poder de analise espectral".

De acordo com LARS (Laboratory for Agricultural Remote sensing, 1968), citado por MEDonÇA (1981), o sensoriamento remoto tem sido aplicado a agricultura para atender a très objetivos básicos: 1) identificar, de acordo com os padroes de resposta espectral, as diversas categorias de culturas agricolas; $2)$ estabelecer para essas diversas categorias de culturas a faixa de melhor discriminaça do espectro eletromagetico; e, 3\} determinar em funça do estágio de desenvolvimento das culturas, de acordo com as variacoes temporais e as diferentes condiçes de solo, os padroes de resposta multiespectral para os diferentes grupos ou categorias de cultura.

- apoio ao mapeamento de areas agricolas atraves 
da interpretação de imagens LANDAST, ainda segundo MENDONÇA (1981), oferece bons resultados, desde que cuidados básicos sejam observados por ocasião da seleção das datas de passagem do satelite sobre os locais desejados, como: ausencia de nuvens; repetição da operação em séries temporais, acompanhando as etapas de desenvolvimento da cultura (em épocas de acentuado contraste espectral com a vegetação nativa); repetição da operação por mais de uma safra, na mesma regiào, para maior segurança nas ınformações obtidas.

A repeito desse assunto, MISRA \& WHEELER (1978), utilizando dados espectrais do MSS (Multispectral Scanner Subsystem) do LANDSAT, afirmam que a noção de resposta espectral, tomada como base exclusiva para classificação das culturas e necessário associar as variaçŏes espectrais e temporaiz.

KOFFLER (1982) comenta as seguintes consideraçoes: Quando a radiaçào eletromagnetica atinge a matéria, ocorrem alguns fenomenos físicos:

- uma parte da energia retorna ao espaço que contém a fonte de radiação: é a reflexão;

- uma segunda parte entra na matéria e desaparece em seu interior: é a absorção;

- uma terceira e iltima parte atravessa a matéria: é a transmissão.

- Interessa ao sensoriamento a reflexão, que é examinada sob duas variáveis: albedo, que é a relação entre toda a luz refletida pela superficie e toda luz incidente; e reflectância, que é a razăo entre a radiação refletida em uma direção especifica e a radiaçăo incidente a um determinado comprimento de onda".

Segundo VETTORAzzI (1992) a Eaixa espectral que se estende de $0,3 \mu \mathrm{m}$ a $15,0 \mu \mathrm{m}$ é a mais usada em sensoriamento remoto. E conhecida como ESPECTRO ÓPTICO, pois se conseguem informaçôes com aparelhos dotados de lentes: máquinas fotográficas, radiômetros, etc) - Eigura 1, cujas principais regibes e respectivos comprimentos de onda ( $\lambda \mathrm{m})$ são: 
a) Regiăo do Espectro Refletivo $(0,38 \mu \mathrm{m}$ a $3,0 \mu \mathrm{m})$ : e chamada de porçăo refletida do espectro em razảo da energia detectada nessa região ser basicamente originada da reflexäo da energia solar pelos objetos postados na superficie terrestre. o espectro refletivo divide-se em três sub-regiöes:

- Visivel $(0,38 \mu m$ a $0,72 \mu m)$ : corresponde à região em que o olho humano é capaz de responder à radiaçăo eletromagnética. Também é conhecida como região das cores primarias - azul, verde e vermelho -, responsáveis pelas demais matızes. O assunto voltará a ser enfocado em 2.4.

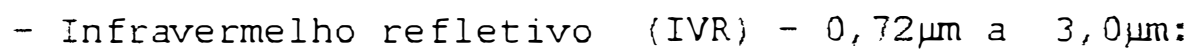

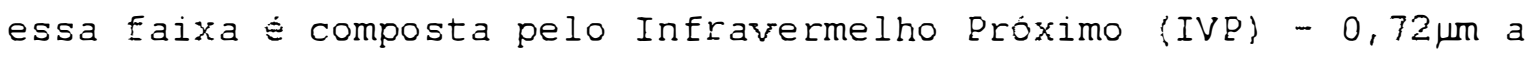
1.3um - e Infravermelho Médio (IVM) - 1,3um a 3,0

b) Regiăo Nåo Definida $(3,0 \mu m$ a $7,0 \mu m)$ : esta região caracteriza-se pela interferência de efeitos atmosféricos na interpretação dos dados de radiação, limitando a utilização destes comprimentos de onda em aplicaçôs de sensoriamento remoto orbital.

c) Região Infravermelho Distante $(7,0 \mu m$ a $15 \mu m)$ : é conhecida também como regiåo termal ou emissiva. Segundo GARCIA \{1982\}, a grande utilidade desta faixa seria no estudos de biomassa para fins energeticos. Para interpretar os resultados exige-se conhecimentos dos processos fisicos que controlam a interaçäo entre a energia termal e a materia, bem como as propriedades termais da materia: capacidade térmica (cal/g C), 
ESPECTRO ÓTINO

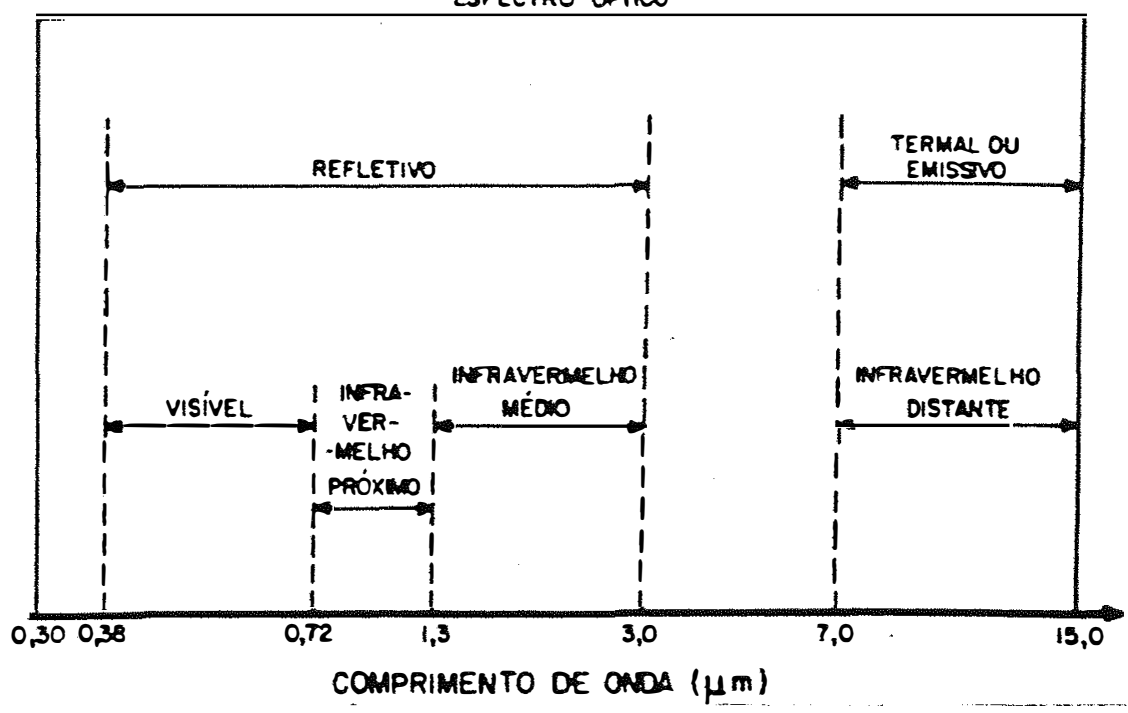

Figura 1 - Regioes do espectro óptico. Fonte: SWAIN \& DAVIS, (1978).

condutividade térmica (cal/cm.seg. $\left.{ }^{\circ} \mathrm{C}.\right)$, inércia térmica (cal $\left./ \mathrm{cm}^{2} \cdot \operatorname{seg}^{1 / 2} \cdot{ }^{\circ} \mathrm{C}\right\rangle$ e difusibilidade térmica $\left(\mathrm{cm}^{2} / \mathrm{seg}\right)$. 0 sensoriamento remeto através do infravermelho termal utiliza-se da radiaçăo emitida e nåo da refletida por objetos, na superficie terrestre.

\subsection{Sensoriamento remoto e agricultura irrigada}

Os trabalhos relacionados ao assunto utilizam informaçöes obtidas através de sensoriamento remoto (imagens de satélite e radiometria de campo), parâmetros fitotécnicos e práticas culturais adotadas nas lavouras sob observaçăo, interagindo-as ou não, entre si, com o propósito de aprimorar a qualidade final perseguida. Torna-se importante, pelos motivos 
expostos, comentar sôbre o procedimento técnico/operacional dos topicos.

\subsubsection{Aspectos técnicos e operacionais}

\subsubsection{Imagens de satélite}

De acordo com VETTORAZzI (1991), as imagens dos satélites Landsat e Spot são obtidas por sensores que se enquadram no grupo dos sistemas imageadores elétrico-ópticos, que registram os dados coletados na forma de sinais elétricos, possibilitando transmissão à distância. Compōem-se de Sistema óptico e Detector.

o Sistema óptico focaliza e direciona a energia refletida ou emitida do objeto em foco para o detector, onde há processamento dos sinais elétricos, de acordo com a intensidade de radiação recebida. Os sensores de imageamento eletro-óptico dividem-se em Sensores de Quadro ("Erame") e Sensores de varredura.

Os "Erame"(Vidicons) originados do sistema de televisão, viabilizam a conversão de uma imagem eletrônica sôbre uma superficie fotosletrica, em sinais elétricos que podem ser transmitidos, ou registrados e mais tarde rearranjados para reproduzir a imagem da cena original. Ocorre a decodificação dos sinais ao serem recebidos a recepção de um aparelho de televisão é un exemplo\}.

O sistema de Varredura Multiespectral ("scanner"), mede a radiancia da superficie terrestre ao longo de uma linha perpendicular à linha de vôo da aeronave ou órbita do satélite. Como a plataforma que conduz o sensor movimenta-se à Erente, medições contínuas de radiância permitem a formação de uma imagem bidimencional. O imageamento dá-se através de uma faixa.

Curran \{1985\}, citado por VETTORAZZI \{1991\}, diz que $\circ$ varredor multiespectral compoe-se de coletores e registradores. Seu funcionamento seque a seguinte ordenação, orientando-se pela Figura 2: 
- a radiação proveniente da superficie terrestre passa de um telescópio (1), para ser focalizada sobre um espelho rotativo(2), que a reflete sôbre um conjunto óptico (3), sendo dal enviada para um sistema em radiação refletida e emitida (4);

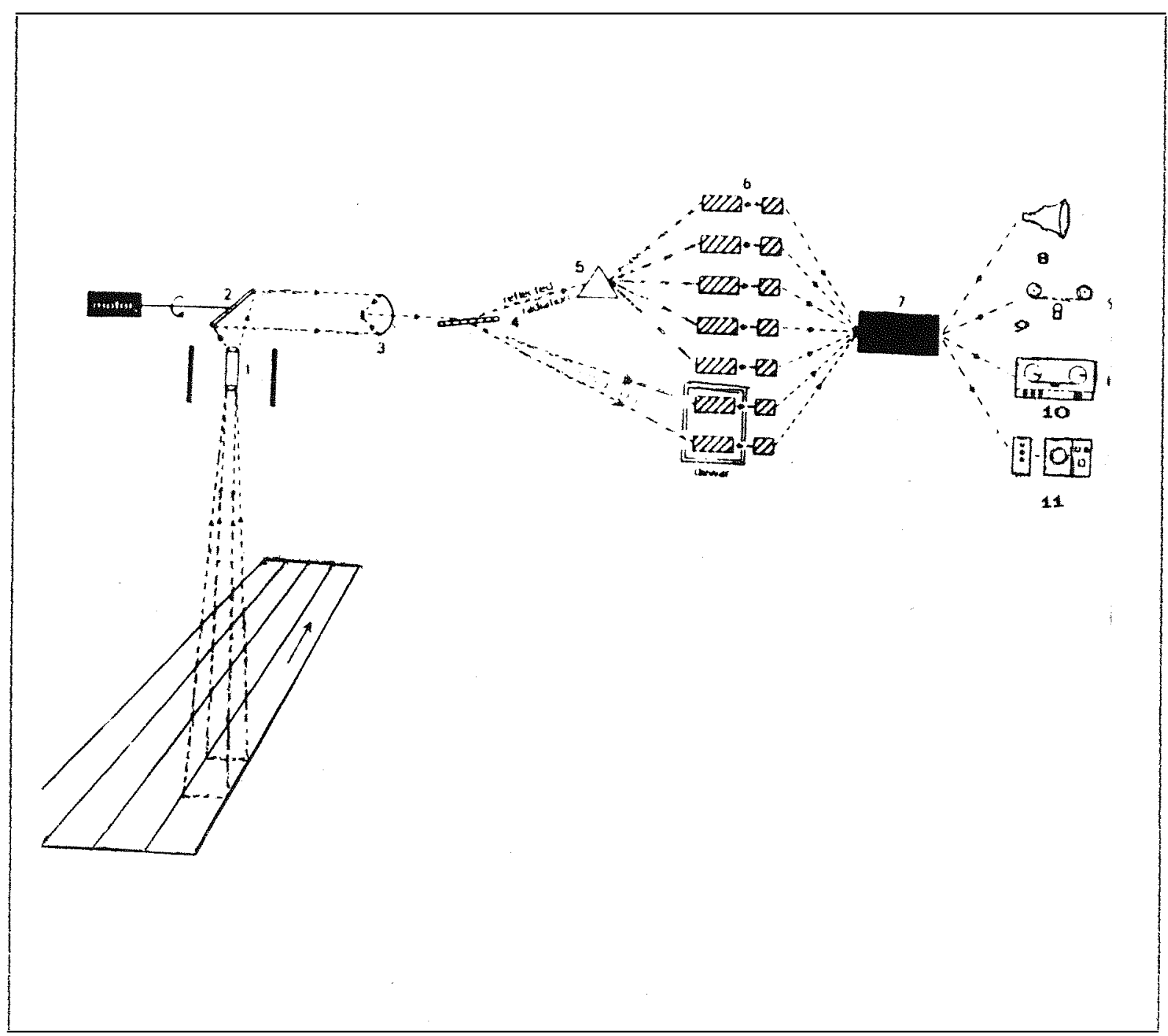

Eigura 2 - Representaçăo esquemática de um sistema de varredura multiespectral. Fonte: CURRAN, 1985.

a radiaçăo refletida é dividida, através de um prisma (5), em seus componentes espectrais, que såo detectados e amplificados por detectores e pró-amplificadores (6); a radiaçao emitida vai direto para os registradores termais e pré-amplificadores (6). Todas informações eståo na forma eletronica e são controlados 
pelo console eletronico (7), ao qual podem ser ligados varios sistemas de sardas $(8,9,10$ e 11$\}$.

Entre esses aparelhos registrados de imagens adequados a fornecrmento de informaçoes ao trabalho em tela, utilizou-se imagens do Satelite pour L'observation de la Terre SEOT, cujas características serão abordadas a sequir.

\subsection{Sistema SPOT}

A série SPOT, de acordo com UETTORAZZI (1992), teve inicio com lançamento do SPOTl em 1985, hoje semi-desativado. Em 1990 e 1993 foram lançados respectivamente as unidades SPor2 e SPOT3. Ảs principais caracteristicas do sistema sPOT săo a săo a alta resoluçăo espacial no modo multiespectral (20m x 20m) e no pancromatico $(10 \mathrm{~m} X 10 \mathrm{~m})$ e a capacidade imageamento obliquo (offnadir), permitindo o aumento da repetitividade da cobertura e a obtençào de pares estereoscópicos (Eigura 3). Os sensores tèm ànqulo de visada variável e são programáveis através de comandos da estaçăo terrestre. Săo capazes de imagear qualquer porçăo do terreno compreendida por uma Eaixa distante de até $475 \mathrm{~km}$ em cada um dos lados da órbita em que se encontra o satélite. Isso permite observaçoes orbitais adjacentes da área de interesse no período entre uma passagem e outra do satelite no local (NOVO, 1989), através do sistema de varredura "push broom".

Ainda segundo VETTORAzzI (1992) a órbita do satélite SPOT é similar a do Landsat: circular, sol-sincrona e quase polar; opera numa altitude de $830 \mathrm{~km}$, ângulo de inclinaçăo de

98, $7^{\circ} ;$ o período de cobertura de faixa săo de 104,4 minutos, dando $145 / 26$ volta em 24 horas e passando pelo equador (15 de junho) às 10:30 horas; necessita de 369 passagens para a cobertura total. E composto por unidades de sensores 

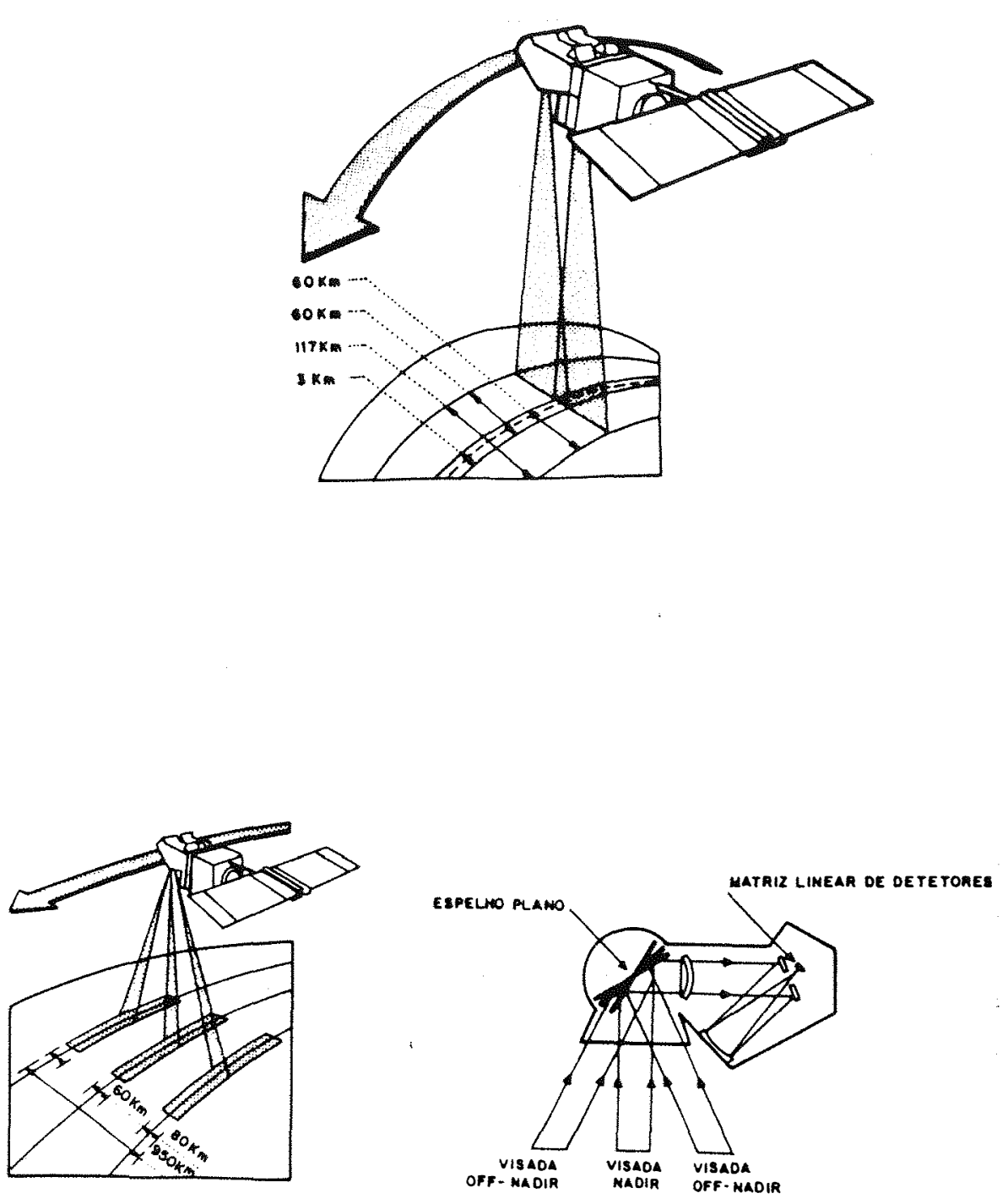

Eigura 3 - Possibilidade de visadas dos sensores HRV Eonte: Citado por VETTORAZZI (1992).

especiais HRV (Haute Resolution Visible); 2 registradores de dados de fitas magnéticas; e um conjunto de telemetria para a transmissão de dados para a Terra. O HRV opera nas regioes do visível e do infravermelho do espectro eletromagnético, nos modos Pacromático (PAN) e Multiespectral (XS) (Tabela 1)

No Brasil a imagem spot é comercializada pela IMAGEM GEOSISTEMAS (Så José dos Campos/SP) com repetitividade de 
25 dias no Nadir e até 10 vêzes no mês em inclinaçăo lateral sentido oeste-leste.

Tabela 1 - Caracteristicas do instrumento HRV.

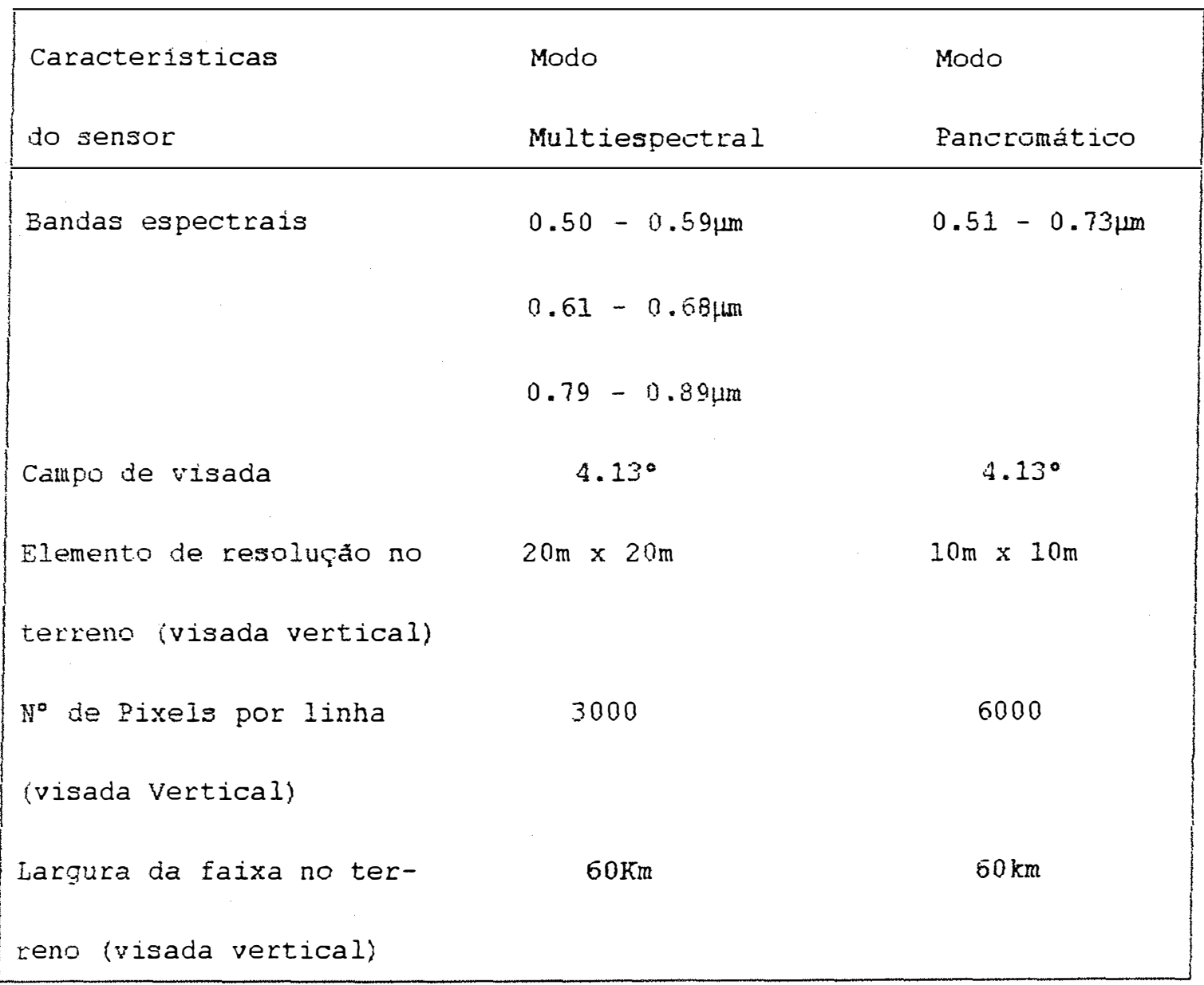

EONTE: VETTORAZZI (1992).

\subsubsection{Radiometria}

Radiometria é o conjunto das técnicas utilizazadas para a medida das quantidades de energia radiante e os sistemas para a mediçăo dessas quantidades são denominadas radiometros (STEEFEN et alii, 1981). As mediçoes de campo são feitas instalando-se o aparelho sobre a cultura, por exemplo, em local representativo da área, procedendo as leituras provenientes das radiaçoes de ondas curtas incidentes nas plantas e das 
radiaçóes de ondas longas refletidas por elas, dando a resposta em leitura eletrônica digital, que acusa o resultado entre as partes. Estas informações devem ser registradas no campo em sincronismo com a passagem do satélite pela área de estudos para que, quando analisadas, interagidas às imagens obtidas pelo aparelho, via programa de computadores, obtenha níveis de respostas bem correlacionadas e satisfatórias na identificação do alvo em foco (VERDIN \& SILVA, 1989).

Os componentes básicos de um radiômetro, de acordo com a Eigura 4, segundo VETTORAZZI (1992), são:

- Sistema óptico: tem função de captar o fluxo de

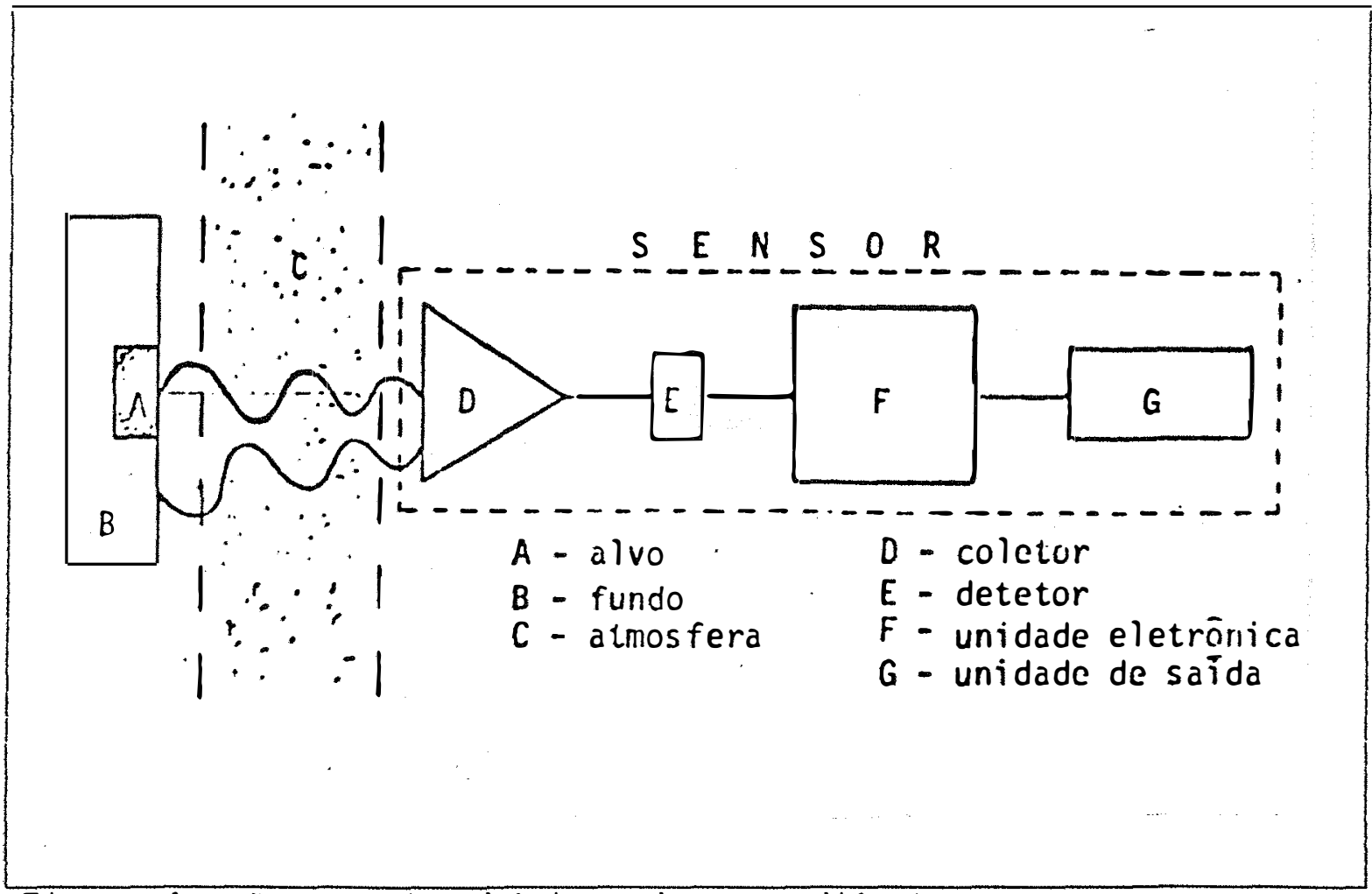

Figura 4 - Componentes básicos de um radiômetro. Fonte: VETTORAZZI (1992).

energia radiante proveniente de um alvo, dentro de ângulo de visada fixo, e concentrá-lo sobre o sistema de dispersão.

- Sistema de dispersão: decompõe a radiação em diferentes comprimentos de ondas (Eaixas de operação do sensor). 
- Detector: responsável pela conversão de dada quantidade de energia radiante incidente sôbre o radiômetro, em sinal elétrico proporcional.

- Erocessador: transforma os sinais eletricos gerados pelo detector em dados, que podem ser fornecidos ao usuário sob forma de números ou gráficos.

\subsubsection{Paràmetros fitotécnicos}

Os dados fitotécnicos, conforme VERDIN \& SILVA (1989), constituem indicativos auxiliares importantes à caracterização de um padrăo refletivo de uma espécie vegetal, em suas fases distintas: plantas de ciclo perene alteram o aspecto, na maioria das vêzes, com as estaçres do ano; as de ciclo anual mostram as modificaçðes nas fases distintas da vida da planta.

o deservolvimento vegetativo sadio de uma cultura, que the propicie um desempenho satisfatorio (arquitetura; cobertura vegetal; indice de área foliar; etc...) caracterizando bem a espécie, emitirá reflectâncias em comprimento de ondas com poucas variaçoes dentro da mesma lavoura, no mesmo estágio. Isso possibilita a obtençåo de respostas espectrais de boa qualidade. Essa condiçăo otima, entretanto, é funçăo de diversos fatores implicitos, cuja inobservância pode comprometer o padrå desejado, tais como tratos culturais e fitossanitários dispensados a lavoura. Entre os tratos culturais alguns trabalhos dao relevância ao aspecto nutricional do vegetal:

- AL ABBAS et alii (1974) comentam que a deficiência de minerais afeta principalmente o conteúdo da clorofila e possivelmente a estrutura anatomica das folhas.

- A clorose provocada pela deficiencia de ferro afeta a reflectancia da folha na regiåo do visivel (MOREAU et ali.i., 1981).

- A deficiência de nitrogênio muda toda reflectŝncia espectral. Na faixa do visivel há um incremento de reflectancia atribuida ao baixo conteúdo de clorofila; e decresce na Eaixa de dominio do Infravermelho Próximo e Infravermelho 
Médio atribuido a diminuição do número de camadas de células (THOMAs et alii, 1972). Debita-se a insuficiencia desses dois elementos na composição dos nutrientes à disposição da cultura a maloria dos casos de nutrientes à disposição da cultura na maioria dos casos de ocorrência do fenômeno clorose.

A proliferaça na cultura de pragas e doenças, por descuidos com os tratos fitossanitários, tráz consequências danosas às plantas, no enfoque em discussão:

- Segundo Moreau et alii (1981) a mudança na pigmentaçăo da folha, como o amarelecimento precoce por exemplo, aEEta as propriedades ópticas na região do visivel. Induz à Érmạ̧ăo de necroses. A reflectância de partes necrosadas podem ser confundidas com as folhas em fase de senescència.

- KEEGAN et alii (1981\} dizem que o fenomeno induz outros pigmentos, que podem aumentar ou diminuir a reflectancia em diferentes partes do espectro. Modifica a taxa de transpiração da folha sem mudar suas propriedades ópticas. Neste caso a temperatura radiativa da folha é mudada e o efeito da doença ou ataque de pragas pode ser detectado na região do infravermelho termal.

- CASTRO (1974) analisou o crescimento do amendoinceiro (Rachis hypogea $L$.) com relaça a influencia de pragas, empregando as Érmuias de BLACKMAN \& WILSON (1951), para calcuiar:

\section{Indice de Area Foliar}

$I A F=A / S$

A/: - razăo, area foliariárea euperficie do terreno em uma mesma colheita.

Relaçăo de Área Foliar

$$
\begin{gathered}
\mathrm{RAF}=\mathrm{A} / \mathrm{P} \mathrm{dm}^{2} / \mathrm{g} \\
\text { h/E - tazão àrea foliari peso seco de uma mesma colheita. }
\end{gathered}
$$


Taxa de Assimilação Aparente (TAA)

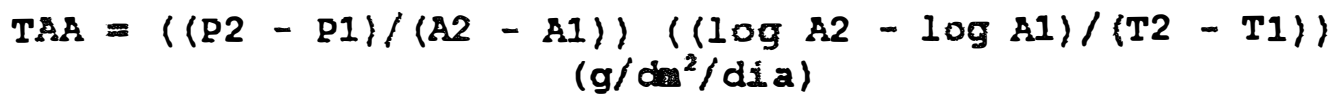

P2 - P1 - diferença de peso geco em qramas, entre duas amostras.

\$2 - 1 - diferença de área foliar, em dm², entre as mesmas amostras.

T2 - T1 - tempo trangcorrido em dias, entre as colheitas.

Taxa de Crescimento Relativo (TRC)

$$
\mathrm{TRC}=(\log \mathrm{P} 2-\log \mathrm{P} 1) /(\mathrm{T} 2-\mathrm{T} 1) \mathrm{g} / \mathrm{g} / \mathrm{dia}
$$

Entre as conclusoes obtidas do trabalho, cita-se:

- os danos provocados por pragas do amendoinzeiro diminuem o indice foliar da cultura;

- Populaçoes mais altas de pragas promovem decréscimo na relaçăo de área foliar na cultura do amendoinzeiro.

Metodologia para calcular indices de área foliar. aiell lu ilanailu le CASTRO (19/4), cilam-se as desenvolvidas por EPIPHANIO (1988) \& GOMIDE \& CÄSTRO NETO (1989).

No seu trabalho EPIPHANIO (1988) empregou as fórmulas BLACKMAN \& WILSON (1951) para determinar o indice de área foliar das culturas de feijåo e trigo.

\section{IAF $=($ MMP X AF $) / E F$}

NTP - número módio de plantas/m linear

AF - area foliar média por planta $\left(\mathrm{m}^{2}\right)$

EF - espaço medio entre fileira (m)

IAF - indice de área foliar (u)

Para determinar a area foliar do feija as folhas das plantas foram decalcadas em papel e posteriormente a area foi medida com planimetro; no caso do trigo assumiu-se a forma da folha como sendo semelhante a um retangulo, e com a multipliaçăo das medidads dos lados obtinha-se diretamente a área foliar media da planta. 
GOMIDE \& CASTRO NETO (1989) desenvolveram trabalho para determinar a área foliar "in vitro" no feijoeiro, sem destruição da Eolha, colhendo os dados diretamente no campo, sem qualquer prejuizo físico para a planta.

Pela metodologia utilizada concluiu-se que a determinaçăo da área foliar pode ser feita pelos métodos do retângulo e do círculo circunscrito, sendo êste último mais prático de operar no campo por ser necessário apenas medir o comprimento de um foliolo de cada folha.

$$
\mathrm{A}=1,1286 \mathrm{c}^{2}
$$

A - area foliar $\left(\mathrm{cm}^{2}\right)$

[- comprimento do foliolo central do feijoeiro (cm)

Em Eunção dos resultados obtidos, os pesquisadores assumiram que:

- Não exite diferença entre as áreas dos foliolos de uma mesma folha de um feijoeiro, cultivar Eriparza.

- Não existe diferença entre as áreas calculadas pelo metodo de circulo, método do retângulo e a área rél.

- A área de uma folha de feijoeiro, cultivar Eriaparaa pode ser obtida a partir da equaçăo $A=1,1286 \mathrm{C}^{2}$.

A determinação da área foliar de maneira destrutiva, dependendo das circunstancias, pode ser inconveniente e/ou dificultada por motivos diversos: o proprietário da lavoura não permite que se arranquem as plantas; o campo instalado destina-se a mais de um segmento de pesquisa, cuja ação "predatória" não é desejável; etc. Nesta situação a metodologia de GOMIDE \& CAsTRO (1989) constitui numa alternativa muito oportuna. 


\subsubsection{Trabalhos desenvolvidos baseados en imagens do télite Landsat.}

Os primeiros trabalhos desenvolvidos para cadastramento agricolas de modo geral, empregando imagens orbitais, utilizaram dados Landsat, por ter sido o primeiro satélite de recursos naturais colocado em órbita na década de 70 .

Mendonça et alii (1978), citado por MENDONÇA (1981), realizaram um estudo comparativo de interpretação automática e visual em imagens Landsat, visando à identificação da cultura de cana-de-açúcar. Utilizaram-se dados do LANDSAT-MSS de diferentes datas de passagens do satélite, conseguindo identificar a cultura de cana-de-açúcar numa área de 1814,20 ha, através dos métodos de análise automática e visual. O estudo foi desenvolvido no município de Jardinópolis (SP) e fez parte do Projeto de Estatísticas Agricolas (EAGRI) do INPE. Fatores relacionados a própria cultura, tais como variedades cultivadas, época de plantio, estágio de desenvolvimento e época de colheita, influenciaram decisivamente na resposta espectral. Várias outras referências são apresentadas pelos pesquisadores no mencionado trabalho, evidenciando a importancia das informações fornecidas pelos trabalhos de apoio de campo, como auxilio complementar no processo de interpretaçâo de imagens.

WININGS et alii (1982), visando melhorar o monitoramento temporal de culturas anuais (milho e soja), nos Estados de Illinois e Iowa (EUA), utilizaram o DCLC (Domestic Crops and Land Cover) dentro do AgRISTARS (Agriculture and Resource Inventory Survery Through Aeroespace Remote Sensing Program\}, chegando a resultados próximos da projeçăo estipulada para a safra de fato colhida, usando somente imagens do satélite uandsat. 
$\mathrm{Na}$ região egípcia do delta do Nilo, HADY et alii (1983), com imagens digitais Landsat-MSS, procuraram identificar áreas agricolas e estimar a superficie irrigada em cada estrato. Distinguiram com eficiência lavouras, terra arada, áreas desérticas, pântanos e áreas urbanas. Trabalharam com as bandas 1,2 e 3 . Nas áreas menores que 2,0 ha os autores tiveram dificuldades de identificação através dos dados do satélite.

THIRUVENGADACHRI (1983), empregou imagens de satélite Landsat em estudos desenvolvidos no sul da India (Vale Cumbum, Estado de Tamil Nadu), para identificar glebas irrigadas e orientar o delineamento racional da irrigação. Usou a banda 7 . - estrato de culturas irrigadas era heterogêneo (lavouras de algodão; arroz; sorgo; milheto; banana; cana-de-açúcar; amendoim; e legumes), a exemplo do que ocorre na região semi-árida brasileira, distribuido em glebas variando de 0,2 hectare a 4 hectares (moda 1 hectare). A base cartográfica usada foi de escalas de 1:50.000 e 1:250.000. A identificação só foi eficaz para as lavouras plantadas em áreas de maiores dimensóes, caso das culturas de arroz e algodão. A esse respeito, como em de outros trabalhos acessados, GIMBARZEVISKY (1974) já comentava que as imagens fornecidas pelo satélite Landsat apresentam tanto vantagens como desvantagens: "a pequena escala, por exemplo, proporciona uma visão global excelente para análises de áreas extensas em apenas uma imagem, mas impede 0 mapeamento de detalhes importantes". SILVA (1989) cadastrando áreas irrigadas com imagens Landsat/TM (bandas 2,3 e 4), no Vale Gorutuba (Janaúba/Porteirinha/MG), ao tentar trabalhar com maiores ampliaçðes das imagens, visando melhorar a identificação das glebas, nåo obteve resultados animadores. Ao passar da escala 1:50.000 (escala que ofereceu melhor resposta) para a escala de $1: 25.000$, os resultados gerados perdiam significativamente a nitidez, tornando-se difusos.

VALERIO EILHO (1986), em trabalho desenvolvido no município de Guaíra (SP), visando a identificação de áreas irrigadas através de imagens digitais Landsat/TM, deixa claro o 
grande apoio que essa metodologia pode prestar ao segmento de manejo dos mananciais, principalmente aqueles de vazões reduzidas e demandas intensas, atendendo Eins distintos, inclusive agricultura irrigada.

Nos Estados Unidos, com uso de imagens Landsat/TM, THELIN \& HEIMES (1987) procederam ao mapeamento das áreas irrigadas, para determinação do uso da água do planalto aquífero em partes dos Estados do Colorado, Kansas, Nebraska, Novo México, Oklahoma, South Dakota, Texas e Wyoming. Na primeira Ease, Eizeram uma análise com dados obtidos da imagem de satélite Landsat/MSS de 1978, levantando-se a bacia do aquífero e avaliando o potencial disponível. Na segunda fase (1990) usaram 59 imagens obtidas nas estações de primaveraiverão para indentificar as áreas irrigadas com maiores estimativas de safra. Entre estas amostraram-se algumas, simulando estimativa de consumo de água para as demandas, montando um modelo de uso adequado ao potencial de áqua do aquífero.

ERIPHANIO (1988), usou dados digitais Landsat/TM, das culturas de Eeijåo e trigo (região de Barretos/SP), gravados em Eitas magnéticas compativeis com computador, para desenvolver estudos sôbre o comportamento espectral das espécies durante o ciclo vital da lavoura. Através da análise gráfica dos valores pode-se avaliar o desenvolvimento das culturas e suas alteraçóes espectrais nos diferentes comprimentos de ondas e durante o ciclo da cultura. Fêz-se avaliação da influência dos fatores agronômicos (espaçamento, cobertura do solo, arquitetura foliar) exercidos sôbre o comportamento espectral, concluindo que a caracterização (comportamento espectral típico de vegetação) ocorre respectivamente após a germinação, 20 a 30 dias para a cultura do trigo e 40 a 50 dias para a cultura de Eeijão. No mesmo trabalho o autor avaliou estatisticamente a potencialidade de cada banda para diferenciar áreas de feijão e de trigo; fez correlaçôes entre índice de área foliar e percentagem de cobertura de solo (constatou que no início do ciclo da cultura ocorre maior sig̣nificância de resultados). 
VALERIO FILHO et alii (1988) utilizaram imagem do satélite Landsat-5 para mapear áreas de concentraçoes agrícolas em toda regiâo Centro Sul do Brasil, com objetivo de subsidiar o planejamento de agricultura irrigada. Adotou-se técnicas de interpretação visual, gerando 25 mapas temáticos na escala de 1:100.000, contendo distribuiçăo das classes de concentraçoes agricolas e informaçoes regionais relevantes. Nestas classes, o produto final do trabalho mostra que, em conformidade com o relevo do terreno e tradiçôes culturais locais, perpetuam-se tipos de lavouras que vem sendo exploradas nas mesmas regioes há anos passados. As novas fronteiras com cultivos de soja e algodão säo proeminentes nas regioes Norte do Estado do Paraná, Noroeste de São Paulo e Mato Grosso.

SILVA (1989) enfoca a necessidade de dinamizar o processo de cadastramento de áreas irrigadas, através de imagens de satélites, fotografias, aéreas, etc., a niveis de detalhe que permitam a identificação segura da área das glebas e também do grupo de culturas em exploração.

MOREIRA (1990) estudou as contribuiçoes de dados do satélite Landsat/TM para estimar áreas das culturas do método de expansão direta. O trabalho foi realizado no Distrito Federal, abrangendo área de $5184 \mathrm{~km}^{2}$, em 135 unidades de produção dispersas na região. Utilizou-se imagens em composição colorida, das bandas 3,4 e 5 do senso TM, na escala de 1:100.000 (passagens $01 / 02 / 89$ e $06 / 04 / 89$ ). Os resultados da interpretação visual foram utilizados no método de expansão direta para estimar a area total destas culturas no Distrito Federal. Os resultados da pesquisa satisfizeram o esperado. As áreas mensuradas pelo processo equivaleram-se aos valores cadastrados no campo pelo Instituto Brasileiro de Geografia e Estatistica (IBGE). 0 conhecimento adquirido com o trabalho recomenda para a necessidade de proceder acompanhamento multitemporal no decorrer de um ano agricola com o objetivo de melhor caracterizar as fases da lavoura. 
ROCHA (1993) desenvolveu trabalho na Região de Campinas (SP) visando determinar as áreas nas principais classes de uso agrícola do solo, utilizando-se imagens do satélite Landsat/TM e mapas digitalizados de amostras de dados colhidos no campo. Envolveu uma área de $54 \mathrm{~km} \times 63 \mathrm{~km}$. Utilizou-se a imagem da data de $16 / 08 / 1987$ como base de serviço. A classificação da imagem foi feita pelo método de máxima verossimilhança e a precisão de classificação foi determinada estatisticamente com dados da imagem classificada e dos mapas digitalizados com os dados de campo. os resultados mostraram uma precisão de classificação de 658 .

\subsubsection{Trabalhos desenvolvidos com base en imagens do satélite spoT.}

Os satélites da série SPOT, cujo lançamento da primeira versão ocorreu em 1986, têm sido os mais recomendados no apoio dos serviços de cadastramentos agricolas para fins multiplos, em relação ao Landsat, por apresentar melhor resolução espacial (resolução espacial do Landsat: $79 \mathrm{~m} \times 79 \mathrm{~m}$ no MSS e $30 \mathrm{~m} \times$ $30 \mathrm{~m}$ no TM; resolução espacial do SPOT: $20 \mathrm{~m} \times 20 \mathrm{~m}$ no $\mathrm{XS}$ e $10 \mathrm{~m} \times$ $10 \mathrm{~m}$ no PAN). Isso permite maior definição de informações nas pequenas áreas agrícolas por exemplo, onde os trabalhos apoiados em imagens geradas pelo satélite Landsat não têm atingido a espectativa desejada, conforme trabalhos de HADY et alii e de THIRUVENGADACHARI desenvolvidos em 1983 (vide 2.2.2).

BATISTA et alii (1986) com imagens SPOT de regioes agrícolas do sul do Brasil, desenvolveram trabalho visando avaliar a resolução espacial e caracteristicas de dados dos sensores HRV ("Haute Resolution Visible") do SPOT para discriminação de culturas, com atenção especial nas visadas OFFNADIR. Analizaram-se campos de trigo, café, cana-de-açúcar e pastagem, em áreas expressivas. A exemplo de MENDONÇA (1981) e de 
5EIFHANIO (1388), consideraram como parametros de estudos a influência dos Eatores agronômicos na resposta espectral: área, variedade, data de plantio; estágio fenológico; altura da planta; espaçamento entre linha e planta; porcentagem de cobertura do solo (indice de área Eoliar, aspecto da cultura - sanidade); topografia; e características dos solos. Constatou-se que a banda do ineravermelho proximo (banda 3 para o SPOT e 4 para TM) é informativa; as 2 bandas do visivel mostraram-se altamente correlacionadas na análise conjunta de todos tipos de cobertura; năo houve diferença significativa em relaçăo aos diferentes ângulos de inclinação e data de aquisição do material; decilvidades de $0 \%$ a $5 \%$ analisadas, näo influenciaram no resultado Einal.

HOWARD \& LANTIERI (1986), no Kenia (ÄErica), numa area de $1800 \mathrm{~km}^{2}$, conduziram trabalho para classificação e mapeamento de vegetação e tipo de solo, usando dados spot muitispectrais, sequindo hierarquia aproximada para classificaça de vegetaçăo desenvolvida pelo Centro de Sensoriamento Remoto da EAOO. Consequiram mapear propriedades agricolas por tipos de solos, por tamanho de áreas (5 classes), por densidades de áreas e terrenos irrigados e não irrigados. O mapeamento do tipo de agricultura obteve melhor aperfeiçoamento quando foi feito com apoio de indicadores já conhecidos, como: tipos de classes (tamanho da área), etc.

LEPOUTRE \& CAVEDON (1987) mostram os trabalhos realizados no sudoeste da Erança, para cadastramento de áreas irrigadas, objetivando a obteção de um mapa de uso de ocupação atual, a partir de informaçóes Eornecidas pelo satélite SPOT. 


\subsection{Trabalhos que relacionam radiometria de campo com dados} digitais de imagens de satélites e indices de vegetaçăo.

Os assuntos mencionados neste tópico estáo relacionados a trabalhos que tratam da identificaçăo de coberturas do solo; de testes de indices de vegetaçăo; e outras investigaçós básicas, com auxilio de recursos de sensoriamento remoto. Os resultados alcançados servem de subsidios técnicos para execusăo de trabalhos práticos de natureza similar, como: monitoramento de lavouras agrícolas; orientar turnos de regras através da determinaçăo de estresse hidrico; avaliar biomassa de reservas florestais; estimar cultivos, e outras aplicaçôes distintas.

Os propósitos da presente pesquisa de identificar espécies cultivadas relacionando dados de radiometria de campo, dados digitais de imagens de satélite e parâmetros fitotécnicos, também encontram respaldos científicos nesta linha de raciocinio. Alguns estudos do gênero săo o testemunho desses comentários.

PINTO et alii (1982) desenvolveram trabalho na busca de uma metodologia de aquisição de dados radiométricos de diferentes tipos de cobertura de solo, visando ao estabelecimento de correleçåo entre cobertura vegetal efetiva do solo e niveis de cinza em imagens Landsat, na Bacia do Ribeiråo Anhumas, SW do Estado de Såo Paulo. A base do trabalho foi a cobertura natural do terreno (capim coloniăo, macega e solo exposto). A coleta dos dados radiométricos foi feita pelo fotômetro/radiômetro digital, Modelo 820 da Gamma Scientific, Incorporated (Earth Ground Truth - EGT), que opera nas mesmas Eaixas do Landsat/MSS; e a aquisiçăo dos niveis de cinza nas imagens Landsat/MSS foi realizada através do Analisador de Imagens Multiespectrais (IMAGE 100). Fez-se a correlaçăo entre os dados colhidos direto do campo e os valores dos niveis de cinza nos canais 5 e 7 , por serem mais usualmente utilizados para estudos de diferentes coberturas. O coeficiente 
da correlação para os dados do canal 5 mostrou mais eficiente, embora com indice baixo.

Entre as conclusoes, destaca-se a baixa correleção entre os dados radiométricos, obtidos zo nivel de campo, com os valores de níveis de cinza obtidos a partir dos dados orbitais. Isto é explicado pela interferencia de Eatores ambientais e de tomadas de dado; a sensibilidade do sistema MSS é insuficiente para registrar, de modo preciso, as variações entre "pixels" similares no terreno; os resultados indicam que a faixa do espectro mais eficiente para avaliar diferenças na densidade de cobertura é a referente ao canal 5, tanto para dados de radiometria quanto para dados orbitais (niveis de cinza).

Três trabalhos desenvolvidos no Distrito Federal aproximam-se muito dos interesses do tema de tese aqui desenvolvido:

Num estudo de técnicas de monitoramento de queimadas em pastagens nativas na região de cerrado (Brasilia/DE), as curvas de reflectancia das gramineas Capim gordura (Melinis minutifloral apresentam assinaturas espectrais distintas, 0 que permitiu separá-las com relativa facilidade, na faixa situada entre 450 e $850 \mathrm{~nm}$ (ADAMOLI et alii, 1982). Os estudos iniciaramse a partir da rebrota da vegetação pós-queimada. Em bases de trabalhos definidos, realizou coleta de dados em 3 estágios de desenvolvimento da vegetação, para observar a evolução temporal: analise de dados de fitomassa e radiometricos (utilizaram o espectro radiômetro ABE-SEKKEI). Como referencial a situação anterior a queimada, foi Eeita uma análise densitométrica dos niveis de cinza, obtidos a partir de uma imagem fotográfica na região do infravermelho próximo (canal 3 do Landsat). 0 relacionamento destas variáveis, através das colonias de vegetação extintas pelo incèndio.

MADEIRA NETO et alii (1982) desenvolveram pesquisas para determinar características de $\frac{a}{y}$ variedades de soja, sob 
condiçoes de irrigação e de estresse hídrico, em campo experimental. O registro das reflectâncias espectrais foi feita com um espectro-radiômetro portátil ABE-SEKKEI em cada campo de variedade de soja, a partir do $50^{\circ}$ dia pós-germinação, em 4 oportunidades, espaçadas de 3 semanas. Concomitantemente a essa operação, foram determinados indices de área foliar. 0 correlacionamento entre os índices de área e índices de reflectância mostraram-se satisfatórios em relação a diferenciação de cultivares, mas nåo o foram na detectção do efeito de déficite hídrico.

COHEN (1991) avaliou a resposta de indice de vegetação para variação de estresse na folha, em dois experimentos, em condiçôes de laboratório. Para o primeiro experimento usou ramos de pinus (pinus contorta), concluindo que o potencial de agua na folha apresentou alta correlaçăo com os indices NVDI (Indice de Vegetação de Diferença Normalizada), near-infrared/red (infravermelho próximo sôbre vermelho), II (índice de Infravermelho) e o MSI (indice de Estresse de Umidade), em relação ao LWCI (Indice de Conteúdo de Agua na Folha), IM (Taxa de Infravermelho Médio), ou quando analisada individualmente nas bandas TM. As reflectâncias foram medidas com radiometro portatil nas bandas TM3, TM4, TM5 e TM6.

No segundo experimento usou três tipos de plantas (Pinus coulteri; cenothus crassifolius; salvia mellifera). Avaliou-se os indices do trabalho anterior $e$ os indices brightness e greenness, e umidade no TM Talessed Cap, cujas respostas de estresse hidrico mostraram diferenças no RWC (Conteúdo Relativo de Agua na Eolha) em relação ao WC (Conteúdo de Agua na Eolha) nas três espécies de plantas analisadas e indicaram dependencias de análises associadas. Na análise separada das espécies o LWCI (Indice de Conteúdo de Agua na Eolha), mostrou altos indices de correlação de contraste para o RWC e WC conjuntamente, seguido do II, MSI e Umidade. Apenas o LWCI apresentou-se altamente correlacionado para $\circ$ RWC $e$ WC quando as espécies foram analisadas conjuntamente. O LWCI das 
três espécies, em conjunto, apresentou alto indice de correleção apenas para o RWC, enquanto que O II, MSI, Infraverme ho Medio e Umidade tiveram altos indices de correlação com o WC. Utilizou-se um espectômetro (Beckman UV-5240) para medição das reflectâncias na Eaixa de $0,4 \mu m$ a $2,5 \mu m$.

MELLo et aIii \{I9̣9) desenvoiveram estudos básico de monitoramento de lavouras irrigadas na Bacia do Rio Verde Grande (Região Norte do Estado de Minas Gerais) através de informaçòes de imagens digitais de satélite (imagens spot de 03/07/88 e Landsat de 26/08/90) / e dados de radiometria de campo $(04 / 03 / 90$ e 26/08/90). Na região localiza-se um latente conflito pelo uso de água em razáo da alta demanda requerida pelos vários projetos particulares de irrigação instalados e a limitada oferta do insumo. Os resultados mostram-se satisfatorios aos propósitos traçados. As imagens spot mostraram-se mais apropriadas à natureza do trabalho que as imagens Landsat. As informaçoes radiometricas foram de suma importancia dentro do contexto interpretativo de resultados.

Esse trabalho, ao lado de outros do gênero, visa à montagem de um banco de dados e a busca de um modelo prático de trabalho, para apoiar as açŏes de serviços da CODEVASE em gerir recursos hidricos da Bacia do Rio São Francisco a contento.

\subsection{Eatores inerentes à resposta espectral caracteristica do alvo.}

A reflectancia de uma cultura depende do dossel vegetal que, segundo COLWEL (1983) constitui no parâmetro cultural de máximo interesse na interação com a radiação eletromagnetica que leva as informações da cultura até os sensores remotos. E constituído por todos os componentes da vegetação.

$\mathrm{Na}$ composiçáo do dossel a Eolha constitui num dos principais elementos sôbre as propriedades espectrais do vegetal, por ser a componente de maior expressão. Orientando-se pela Eigura 5, detalhes da estrutura foliar (BUNNIK, 1978), enten- 


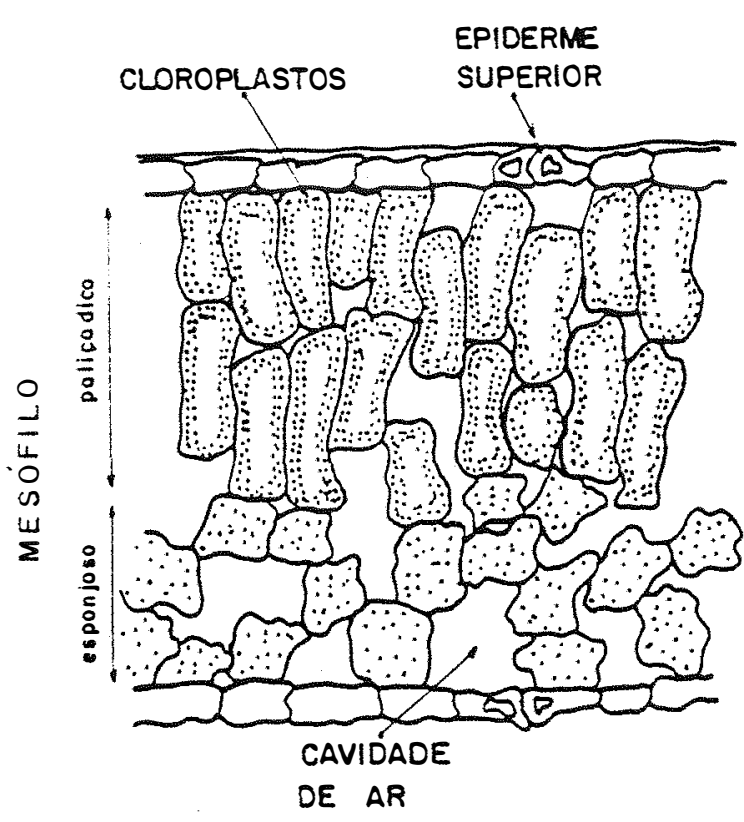

Figura 5 - Estrutura morfologica de uma folha normal (Adaptado de Bunnik(1978), citado por FORMAGGIO, 1989).

de-se melhor o assunto. A folha é recoberta externamente (face dorsal e ventral) pela epiderme; na parte interna encontra-se o mesófilo foliar, constituido pelo tecido do paliçádico (próximo a regiåo ventral) e do tecido esponjoso (apegado à regiåo dorsal). - tecido esponjoso é constituído por cavidades de paredes irregulares, cheias de ar e vapor d'água. O tecido paliçádico contém cloroplastos verdes (clorofila) e também caratenóides que, em ausência de clorofila, têm a função de determinar a cor da Eolha. Em funçåo disso, de acordo com o esquema representativo da da Figura 5, e com os pesquisadores GATES et alii (1955), HOFFER \& JOHANNSEN (1969), HOFFER (1978) e BAUER et alii (1980), a reflectância de uma folha em estado fitossanitário normal, 


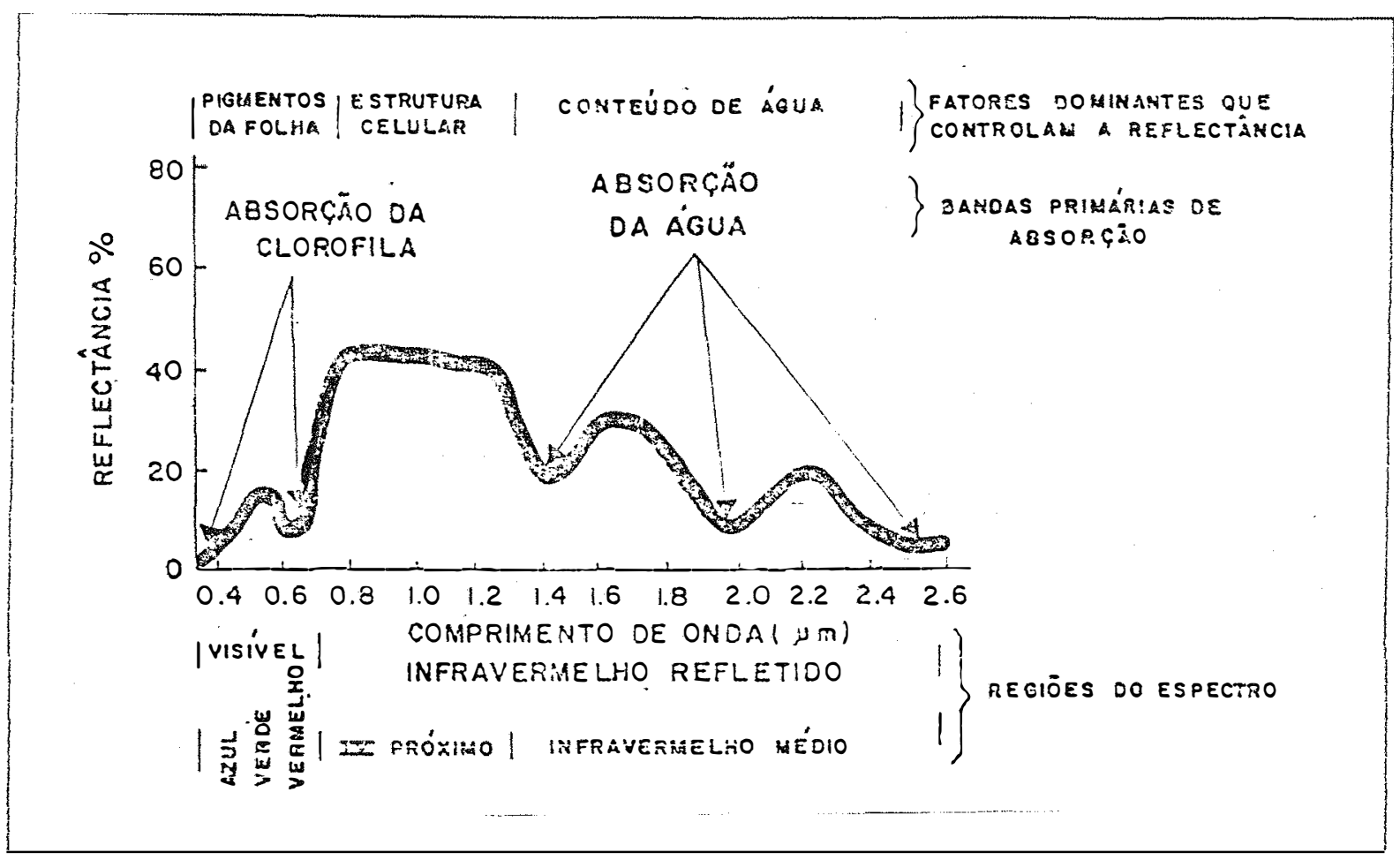

Figura 6 - Principais caracteristicas da resposta espectral das folhas verdes. Hoffer (1978), citado por FORMAGGIO (1989).

dentro do comprimento de onda considerado $(0,4 \mu \mathrm{m}$ a $2,6 \mu \mathrm{m})$, apresenta as seguintes Eaixas:

- Faixa do Visivel $(0,40 \mu \mathrm{m}$ a $0,70 \mu \mathrm{m})$ : compre-se das cores azul, verde e vermelho.

A faixa do visivel caracteriza-se pela reflectância e alta absortancia atribuidos à presença de pigmentos carotenóides e xantofilicos. Verifica-se, porém, aumentos de reflectância nas regioes medianas do visivel $(0,55 \mu \mathrm{m})$ em decorrência da menor absorção de radiação, refletindo o verde.

- Faixa do Infravermelho Próximo $(0,7 \mu m$ a $1,4 \mu m)$ : nesta região a vegetação incidente ao interagir com a vegetação sadia apresenta uma maior porcentagem de energia refletida e 
transmitida, em uma menor porcentagem de radiação absorvida, quando comparada com a região do visível. Assume-se que a estrutura interna da folha é a grande responsável pelo fenomeno: as radiaçôs, ao incidirem na estrutura foliar, são espalhadas pela cuticula e epiderme para as células do mesófilo e cavidades de ar (ar e vapor d'água), onde sofrem novo espalhamento seguidos de reflexões e refrações múltiplas devido à diferença de indices de refração entre $\circ$ ar $(1, \quad e$ as paredes celulares hidratadas $(1,4)$. Como as estruturas internas das folhas variam de uma espécie vegetal para outra, isso explica a razão da maior reflectância normalmente observada no infravermelho que na regiåo do visivel. Essa faixa de comprimento de onda é a mais indicada para identificação de culturas.

Segundo EORMAGGIO (1989), as propriedades de reflectância, transmitância e absortância pelas folhas dependem da concentração de pigementos e de água, além da estrutura interna que é função das espécies. Estas entidades fisiológicas e morfológicas dependem do tipo de folha, estágio de maturação e da senescência. $\dot{A}$ proporção que as folhas amadurecem, sua reflectancia no visivel diminui; no infravermelho próximo aumenta.

BATISTA et alii (1986) em trabalho de identificação de culturas, afirmam que a análise do conjunto de informações

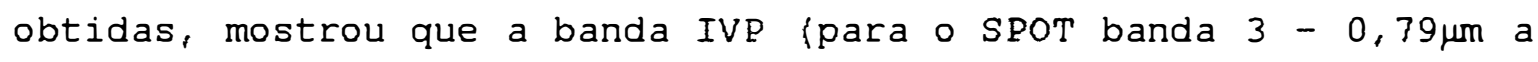
$0,89 \mu \mathrm{m}$ - e Landsat/TM banda $4-0,76 \mu \mathrm{m}$ a $0,90 \mu \mathrm{m}$ ) são mais informativas. As 2 bandas do visivel correlacionaram satisfatoriamente quando todos tipos de cobertura foram analisados conjuntamente.

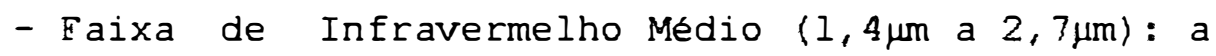
reflectância da vegetação verde é dominada pela forte absorção pela água, que influencia reflexăo proporcionalmente ao teor de umidade da folha (BAUER et alii, 1980). Esse conceito foi confirmado por THIRUVENGADACHRI (1983) que, ao cadastrar áreas 
irrigadas, trabalhando com a banda 7 Landsat/TM $(2,08 \mu \mathrm{m}$ a $2,35 \mu \mathrm{m})$, identificou com sucesso culturas de arroz entre as demais. Isso pode ser atribuído à turgescência do tecido foliar da cultura irrigada sob regime de inundação permanente (Eigura ?)

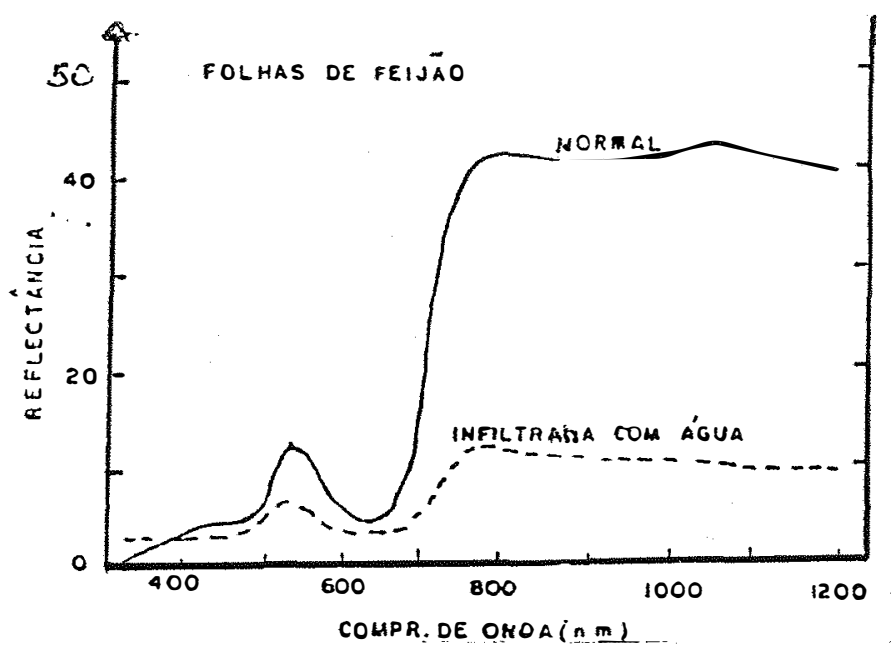

Eigura 7 - Efeito da reflectancia espectral, causado pela infiltração de água nos espaços intracelulares de folhas de feijão. Eonte: KNIPLING (1970).

HADY et alii (1983) também chegaram a resultados semelhantes confirmando a influência da umidade presente na estrutura foliar na absorção da radiação eletromagnética a partir de comprimentos de onda de $1,3 \mu m$, usando imagens Landsat/TM.

A cultura, ao longo de seu ciclo, pode ser divida em três Eases fenologicas distinta, de acordo com a Eigura 8 (FORMAGGIO, 1989):

- Fase I: Ease de plantio e germinaçăo inicial, em que a cultura não cobre totalmente o solo. Há maior predominància de terreno desnudo que de vegetação. 
- Figura II: é a Ease vegetativa própriamente dita, advindo em sequinda o florescimento e a maturação. Há formação do dossel "telhado" da lavoura numa visada vertical sôbre a cultura). A presença ada cobertura verde da cultura interage com as radiaçôes eletromagnéticas.

- Fase III: é o estágio final do ciclo da cultura pós-amadurecimento dos Erutos. Caracteriza-se pelo secamento e queda das folhas, voltando a predominância de solo em relação 30 dossel.

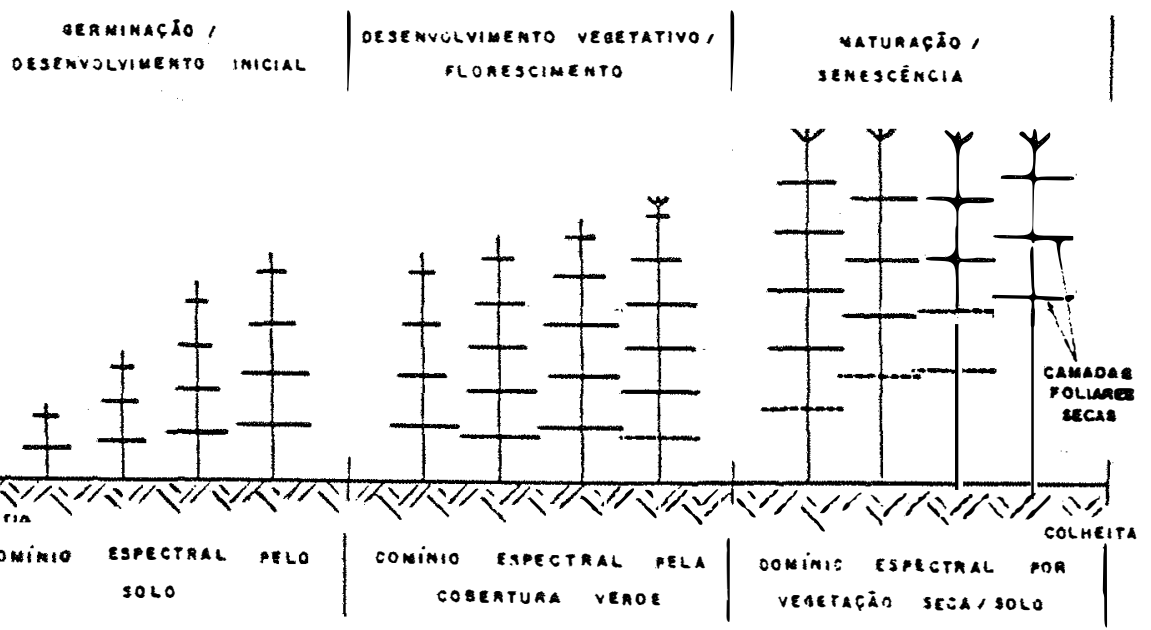

Figura 8 - Ilustração esquemática das três grandes fases do ciclo fenológico de uma cultura agricola, quanto aos principais componentes do sistema a influenciar na resposta espectral. Eonte: FORMAGGIO (1989).

Outra variável importante na análise do comportamento espectral de uma vegetação é a contribuição radiométrica do solo exposto. 
HUETE (1987) afirma que um dos problema do emprego de técnicas de sensoriamento remoto para medir a Eitomassa vegetal em condiçסes de cobertura vegetal incompleta é a resposta de refletância fornecida pela superficie do solo. E Eundamental entender o sinal do solo para melhor relatar o espectro de cobertura com as propriedades das plantas. Para separar as variações espectrais associadas do solo daquelas vegetativas, o pesquisador usou um modelo interativo de Eluxo radiante de planta-solo, associado a diversos indices de vegetação. A técnica Eundamenta-se na interação dos fluxos de radiâncias provenientes da cobertura vegetal e da superficie do solo:

- Tomou como base o espectro da cultura de algodão sôbre 4 tipos de solos inseridos alternadamentre sôbre a copa das piantas, registrando em radiômetro. Considerou-se nesta operação 2 parâmetros distintos: a Eunção planta isolada e outra, representada pela interação que combinou a influência do solo e as propriedades espectrais vegetativas.

Analisando as informações, através do citado mode10, foi possível detectar a componente solo, devido a semelhança da resposta espectral da vegetação verde, graças a dispersão e transmitância das propriedades sôbre a cobertura vegetal. Verificou-se que os 2 parâmentros objetos de estudos foram influenciados pelas propriedades espectrais da cobertura vegetal e todos indices de vegetação testados apresentaram resultados satisfatórios em razão da sensibilidade às influências espectrais de ambos Eatores (planta e planta-solo). Os resultados também mostraram que a mistura de assinaturas espectrais proveniente do soìo, dentro de vários indices de vegetação, inibem a confiabilidade de discriminação vegetativa.

CLEVER (1988) adotou a derivação do modelo de reElectância para a estimativa do IAF, exatamente para contornar a influência exercida pela reflectância do solo. 
Apesar de informaçóes da literatura atestarem que os fatores de reflectância na faixa do IVP serem mais apropriados para estimar o IAF, aquele pesquisador observou que isso nå se tem mostrado eficiente em se tratando de análise multiespectral. - fenômeno se deve ao fato de o solo não se manter sob uma constante umidade ao longo das estaçôes do ano, cujas variaçôes de água no seu conteúdo terem grande influencia na reflectância.

A correção para cobertura do solo tem sido feita verificando a relação entre reflectâncias e características de cobertura vegetal. A reflectância corrigida registrada na região do IV é calculada subtraindo-se a contribuição proveniente do solo úmido: assumindo que existe uma razão constante entre a reflexão do solo descoberto nas bandas espectrais para una dada cobertura de solo, independente da umidade no solo, possibilita que a reflectancia IV corrigida seja calculada sem conhecer a reflectância do solo. Esse valor obtido - IV corrigido - é utilizado na estimativa do IAF através de função empirica. 


\section{MATERIAIS E MÉTODOS.}

\subsection{Localização da área de estudo.}

O trabalho foi desenvolvido no Projeto Jaiba, zıtuado na Região Nordeste do Estado de Minas Gerais, municipio de Jaiba, entre os rios São Francisco e Verde Grande - Regiào do Médio São Erancisco, com coordenadas geográficas entre $14^{0} 33^{\prime}$ e $15^{\circ} 28^{\prime}$ de latitude sul e entre $43^{\circ} 29^{\prime}$ e $44^{\circ} 06^{\prime}$ longitude oeste de Greenwich e altitude entre $450 \mathrm{~m}$ e $500 \mathrm{~m}$. As ações foram conduzidas em uma gleba do projeto de Irrigação do Jaiba denominada "Ảrea $E^{\prime \prime}$, em lotes agricolas previamente selecionados.

\subsection{Caracterização da região.}

\subsubsection{Clima}

A regiaao encontra-se no Polígono das Secas, apresentando clima quente, regime térmico estável e alto poder evaporante. As chuvas concentram-se no Einal da primavera e verào. De acordo com a classificação de Köppen o clima enquadrase no tipo AW. Apresenta temperaturas médias máximas de $31,5^{\circ} \mathrm{C}$ e minimas de $18,3^{\circ} \mathrm{C}$ (valores máximos ocorrem em outubro: $40^{\circ} \mathrm{C}$ ); umidade relativa média: $30 \%$ (época seca: 30\%; época chuvosa: 85z); baixa nebulosidade (média de hora de sol anual: 3000h); velocidade média do vento: $2,2 \mathrm{~m} / \mathrm{s}$ (predomina vento $\mathrm{SE} / \mathrm{E}$ ); evapotranspiraçăo: 4, 6mm/dia. A Tabela 2 detalha os dados.

'AREA " $E$ " é composta de 342 lotes agrícolas irrigados, de 5 ha cada, destinada ao assentamento de colonos. 
Tabela 2 - Dados climatologicos do posto de Mocambinho

(Projeto Jaiba/MG) - Periodo de 1976/1985.

\begin{tabular}{|c|c|c|c|c|c|c|c|c|}
\hline \multirow[t]{2}{*}{ MES } & \multicolumn{3}{|c|}{ TEMPERATURA $\quad{ }^{\circ} \mathrm{C}$} & \multirow{2}{*}{$\begin{array}{l}\text { UR } \\
\frac{8}{6}\end{array}$} & \multirow{2}{*}{$\begin{array}{r}\text { VENTO } \\
(\mathrm{m} / \mathrm{s})\end{array}$} & \multirow{2}{*}{$\begin{array}{c}\mathrm{PP} \\
\text { (mm) }\end{array}$} & \multirow{2}{*}{$\begin{array}{c}\text { EVAP } \quad \star \star \\
(\mathrm{mm})\end{array}$} & \multirow{2}{*}{$\begin{array}{l}\text { INSOL } \\
\text { (HrS) }\end{array}$} \\
\hline & $\mathrm{AR}$ & MAX & MIN & & & & & \\
\hline JAN & 25.9 & 30.9 & 20.5 & 78.0 & $\mathrm{NE} / \mathrm{N} 2.0$ & 243.2 & 85.0 & $182 .{ }^{\circ}$ \\
\hline FEV & 26.6 & 31.9 & 20.3 & 74.1 & $\mathrm{NE} / \mathrm{SE} 2.1$ & 107.4 & 89.5 & 219.5 \\
\hline MAR & 26.8 & 31.8 & 20.5 & 75.3 & $\mathrm{E} / \mathrm{NE} 1.8$ & 132.2 & 91.9 & 227.4 \\
\hline$A B R$ & 26.3 & 31.2 & 17.9 & 73.6 & $\mathrm{SE} / \mathrm{e} 1.9$ & 60.3 & 83.4 & 241.0 \\
\hline MAI & 25.2 & 31.0 & 17.5 & 70.3 & $\mathrm{SE} / \mathrm{E} 2.0$ & 13.5 & 115.5 & 258.7 \\
\hline JUN & 24.2 & 30.2 & 15.2 & 66.5 & $\mathrm{SE} / \mathrm{E} 2.0$ & 13.0 & 124.3 & 263.1 \\
\hline JUL & 21.1 & 30.4 & 14.3 & 66.9 & $\mathrm{SE} / \mathrm{E} 2.5$ & 0.2 & 142.6 & 284.2 \\
\hline AGO & 25.8 & 32.1 & 15.1 & 60.6 & $\mathrm{SE} / \mathrm{E} 2.6$ & 180.5 & 295.1 & 295.1 \\
\hline SET & 27.1 & 33.0 & 17.3 & 60.6 & $\mathrm{SE} / \mathrm{E} 2.1$ & 17.9 & 181.7 & 237.1 \\
\hline DUT & 27.4 & 32.9 & 19.8 & 64.3 & $\mathrm{SE} / \mathrm{E} 2.4$ & 92.7 & 147.0 & 209.0 \\
\hline NOV & 26.4 & 31.4 & 20.5 & 73.2 & $\mathrm{~N} / \mathrm{SE} 2.2$ & 163.9 & 96.5 & 166.8 \\
\hline DEZ & 26.3 & 31.4 & 20.7 & 76.2 & $\mathrm{NE} / \mathrm{SE} 1.9$ & 176.3 & 85.9 & 191.7 \\
\hline MED & 26.0 & 31.5 & 18.3 & 69.8 & $\mathrm{SE} / \mathrm{E} 2.2$ & $1013.2^{*}$ & $1538.4^{*}$ & $2775.6^{*}$ \\
\hline
\end{tabular}

Fonte: Instituto Nacional de Meteorologia/Ministério da Agricultura $(1986)$.

\subsubsection{Solos}

Segundo EPAMIG/ EMPRAPA(1936) ocorrem na área os seguintes tipos de solo:

- Latossolo Vermelho-Amarelo; Latossolo Vermelho Escuro; Cambissolos; Planossolos; Aluviais; Areias Quartzoliticas; Vertissolos; e Litólicos.

Os Latossolos Vermelho-Amarelos representam mais de 508 da área do Projeto, caracterizando-se pela baixa fertilidade; pH muito ácido; $O$ relevo apresenta-se plano e suavemente ondulado, verificando-se grande ocorrencias de murundus ${ }^{2}$; elevada taxa de infiltraçåo; predomina a vegetaçăo caatinga (hipo e hiperxerofila) e florestas caducifolias.

\footnotetext{
${ }^{2}$ Murundus são elevaçōes do relevo (tipo cupim), construídos por insetos extintos na superficie do terreno, com solos dos diversos horizontes do perfil, que atingem de $1 \mathrm{~m}$ a $2 \mathrm{~m}$ de altura e diâmetro de base de $5 \mathrm{~m}$ a $10 \mathrm{~m}$. Podem existir até 30 murundus/ha.
} 
As Areias Quartzosas, em segundo plano, correspondem a 25ㅇa da área. Tem baixo teor de argila, baixa fertilidade, textura extremamente arenosa e excessiva infiltração. A vegetação predominante é a caatinga arbustivo-arbórea. O relevo é plano e suavemente ondulado.

\subsubsection{Recursos hidricos}

O projeto Jaiba prevê uma demanda máxima de $80 \mathrm{~m}^{3} / \mathrm{s}$ de água, tendo como Eonte supridora o Rio São Erancisco, cuja potencialidade de fluxo garante com segurança as necessidades hidricas do empreendimento, dentro das projeçóes de vida útil estabelecidas. Além da vazão mínima de $500 \mathrm{~m}^{3} / \mathrm{s}$, registrada pela Barragem de Três Marias (Três Marias - MG) postada no Rio São Erancisco a $500 \mathrm{~km}$ à montante da captação do projeto, o rio, neste trecho (Barragem de Três Marias - Projeto Jaíba), recebe contribuiçoes significativas de pelo menos 5 afluentes (Rios Abaeté, das Velhas, Paracatú, Urucuri e Jequitai).

De acordo com estudos conduzidos pela TECNOSOLO ${ }^{3}$, face às condições de solos da região, constatou-se a inexistência de potencialidade natural do ecoamento superficial. Praticamente não existe fluxo superficial. O deflúvio médio é da ordem de $0,51 / \mathrm{s} / \mathrm{km}^{2}$.

\subsection{Informaçōes do Projeto Jaíba}

Projeto Jaiba objetiva irrigar 100.000 ha, distribuidos em 4 patamares distintos, em funçao do relevo do terreno, destinados a 3043 irrigantes distribuidos em lotes agricolas de 5ha a 90ha, acoplados a um complexo agroindustrial. - publico alvo constitui-se de colonos, pequenos e médios produtores e empresas.

3 TECNOSOLO. Estudo de viabilidade técnica do Projeto Jaíba. CODEVASF/RURALMINAS, 1980. 


\subsubsection{Detalhamento da Área F}

A "Área F", onde foi desenvolvido o trabalho, apresenta a seguinte ficha técnica:

- Área total: 2336 ha;

- Area irrigada: 1928 ha

- Número de lotes: 342

- Área por lote: 5 ha

- Vazão unitária: 1,06 1/s/ha

- Extensão total de:

- canais de adução: 5,6 km

- rede de distribuição: $57 \mathrm{~km}$

- drenos: 2,8 km

- estradas de serviços: $8,4 \mathrm{~km}$

- estradas de serviços secundárias: 70,5 km

A Área " $F "$ é subdividida em 8 SISTEMAS (quadras), compostos por números variáveis de lotes (média de 40 lotes/ SISTEMA), irrigados pelo sistem de apersão convencional. A pressurização da água é feita por $q$ estações de bombeamento estratégicamente distribuidas na área, que através de uma demanda controlada, atende os 8 SISTEMAS. A condução da água, a partir de uma derivação secundária até as estaçôes de bombeamentos, dá-se através de canais revestidos de concreto, por gravidade. A maior parte da Area "E" é coberta por Latossolo Vermelho-Amarelo distrófico (textura média e argilosa) e Latossolo Vermelho Amarelo Eutrófico (textura média), que, pelas caracteristicas distintas, exigem práticas agricolas eficientes para um aproveitamento racional. 


\subsection{Materiais e equipamentos.}

\subsubsection{A cultura base do trabalho.}

A cultura base para os trabalhos de campo foi a do feijoeiro, variedade carioquinha.

Essa cultura, apesar da oscilação dos preços no mercado consumidor e dos baixos retornos econômicos em relação a outros produtos agrícolas (caso da fruticultura), sob regime de irrigação, é ainda responsável pela ocupação da maioria das áreas irrigadas da região no decorrer de um ano agrícola. É normal colherem-se 2 safras/ano na mesma gleba. Eoi por essa importância sócio-enconômica que se decidiu pela cultura de Eeijão como base para trabalho.

A planta tem a nomenclatura científica de Fhaseolus vulgaris L. e assim é descrita por ZIMMERMANN et ali1(1988): "As folhas såo compostas, trifoliatas (têm três foliolos uniformes dentro de cada variedade e tamanho variável segundo o cultivar), ásperos, esparsamente cobertos de pêlos, sendo o folíolo central simétrico, com peciolo contendo duas estipulas, e os dois laterais assimétricos, opostos, com peciolos geralmente glabros, apresentando cada uma estipela linear. Os foliolos são inteiros, com forma ovalada ou triangular. O peciolo é caniculado, com a pigmentação variando igualmente com o caule".

\subsubsection{Localização das áreas de trabalho}

Os trabalhos foram desenvolvidos na Área "F" do Projeto Jaiba em 5 SISTEMAS, dentro de 7 lotes agrícolas representativos, selecionados ao acaso entre aqueles plantados com feijåo na mesma data e/ou em datas mais próximas possiveis, com o objetivo de acompanhar todo ciclo vegetativo da cultura. Os lotes selecionados foram: LlO-III; L37-IV; L13-II; L40-I; L36-V; L26-VI e LI5-VII (respectivamente lotes I, II, III, IV, V, VI e

4 "LI0-III" = Lote $n^{\circ} .10$ do SISTEMA III. 
VII - nomeclatura adotada para o trabalho). Dentro de cada lote delimitou-se 3 bases de trabalhos com áreas individuias de $100 \mathrm{~m}^{2}$ (10m $x$ 10m) para coleta dos dados fitotécnicos e realização das leituras radiométricas.

E oportuno informar que embora os lotes tenham área em torno de 5ha, isso não implica que em toda gleba ocorra o piantio da cultura de Eeijão - a característica do perfil desse produtor (colonos) é de diversificação, distribuindo na parcela até 6 tipos de cultura 10 módulo de trabalho ficou em torno de 2,5 ha).

No campo orientou-se pela planta cartográfica fundiária da Área "E" (Esc. 1:10.000).

\subsubsection{Dados culturais}

O preparo de solo para o plantio, nos lotes em destaque, consistiu apenas na operação de gradagem (grade aradora), que contribuiu para corrigir imperfeiçóes do relevo. A profundidade de corte atingida pelo equipamento foi superficial (em média $15 \mathrm{~cm}$ ) apesar da área estar sob cultivo contínuo.

os lotes, na sua maioria, têm baixo teor de matéria orgânica; exceto o lote II que tem solo arenoso, os demais são de Latossolo Vermelho-Amarelo.

o plantio foi feito com plantadora mecanizada (tracionada por trator agricola) e manual ("matraca"), com variações do espaço entrelinhas de $40 \mathrm{~cm}$ a $50 \mathrm{~cm}$ e densidade de plantio de 13 a 18 plantas por metro linear. As áreas plantadas com plantadora manual apresentaram melhor "stand" (são mais uniformes) e as com equipamentos mecanizados, por Ealta de habilidade do operador, apresentam-se falhadas e com alinhamento tortuoso.

o plantio de todas as áreas alvos da pesquisa foi feito com "caroço" de feijão (sementes comuns). Apenas no lote L36-V foram Eeitas as adubaçoes recomendadas e os tratos fitossanitários necessários. Nos demais só foi feita a adubação de cobertura e tratos fitossanitarios incompletos. 
A elininaçåo de ervas daninhas da lavoura foi feita com capinas manuais até o fechamento da cultura. Na maioria das áreas isso ocorreu a partir dos 50 dias pós-germinaçăo e em poucas situaçóes deu-se a partir dos 40 dias. A prática, neste estágio, é suspensa devido ao abafamento do mato provocado pela cobertura da lavoura e também para evitar estragos na carga de flores e de frutos que prosperam.

A irrigação, pelo sistema de aspersão convencional, é feita em turnos de 2 em 2 dias, sendo 2 horas por posiçăo, aplicando lâmina de água de valor constante.

\subsubsection{Dados orbitais da área de estudo.}

o imageamento da área de estudos foi realizado pelo satélite Spot, Satélite Pour Lobservation de la Terre" (vide 2.2.1.1.1.), acompanhando a evolução temporal da safra entre as áreas irrigadas e a vegetaçăo nativa (nessa época ocorre estiagem prolongada na regiåo). As imagens HRV-Spot datam de 22/05/92 e $03 / 07 / 92$.

\subsubsection{Equipamentos empregados nas mediçóes radiométricas}

Para este serviço foram utilizados equipamentos do SRGRAPH/CODEVASE, assim discriminados:

- RADIOMETRO EXOTEC - modelo $100 \mathrm{BX}$, composto por 4 canais compactos (CHA; $\mathrm{CH} B ; \mathrm{CH} C ; \mathrm{CH} D)$, projetados para uso de campo. Possui filtros opticos removiveis (Eigura 9), podendo ser adaptados e utilizados para qualquer comprimento de onda no intervalo de $0,4 \mu m$ a $1,1 \mu m$ para adaptaçăo aos satélites spot (HRV) e LANDSAT (MSS e TM).

- pAINel - placa de sulfato de bário utilizada na calibração do radiômetro.

- COLETOR DE DADOS - Modelo 516-C-64-A com capacidade de $32 \mathrm{~K}$ de memória. Possui 4 funçós: gravar dados; armazenar dados coletados para transferência a um microcomputador ou impressora; 
executar cálculos; monitorar e integrar dados de outros instrumentos sensor.

- MATERIAIS DE APOIO - mastro de quatro metros de altura (sustenta o radiometro para as leituras); mesa portatil; trena de 20 metros; nivel de pedreiro; nivel de bolha (verticalizar o mastro); cabos sobressalentes de ligaçăo entre o radiômetro e o coletor de dados.

Detalhes a respeito do principio de funcionamento do radiômetro estão em 2.2.1.2.

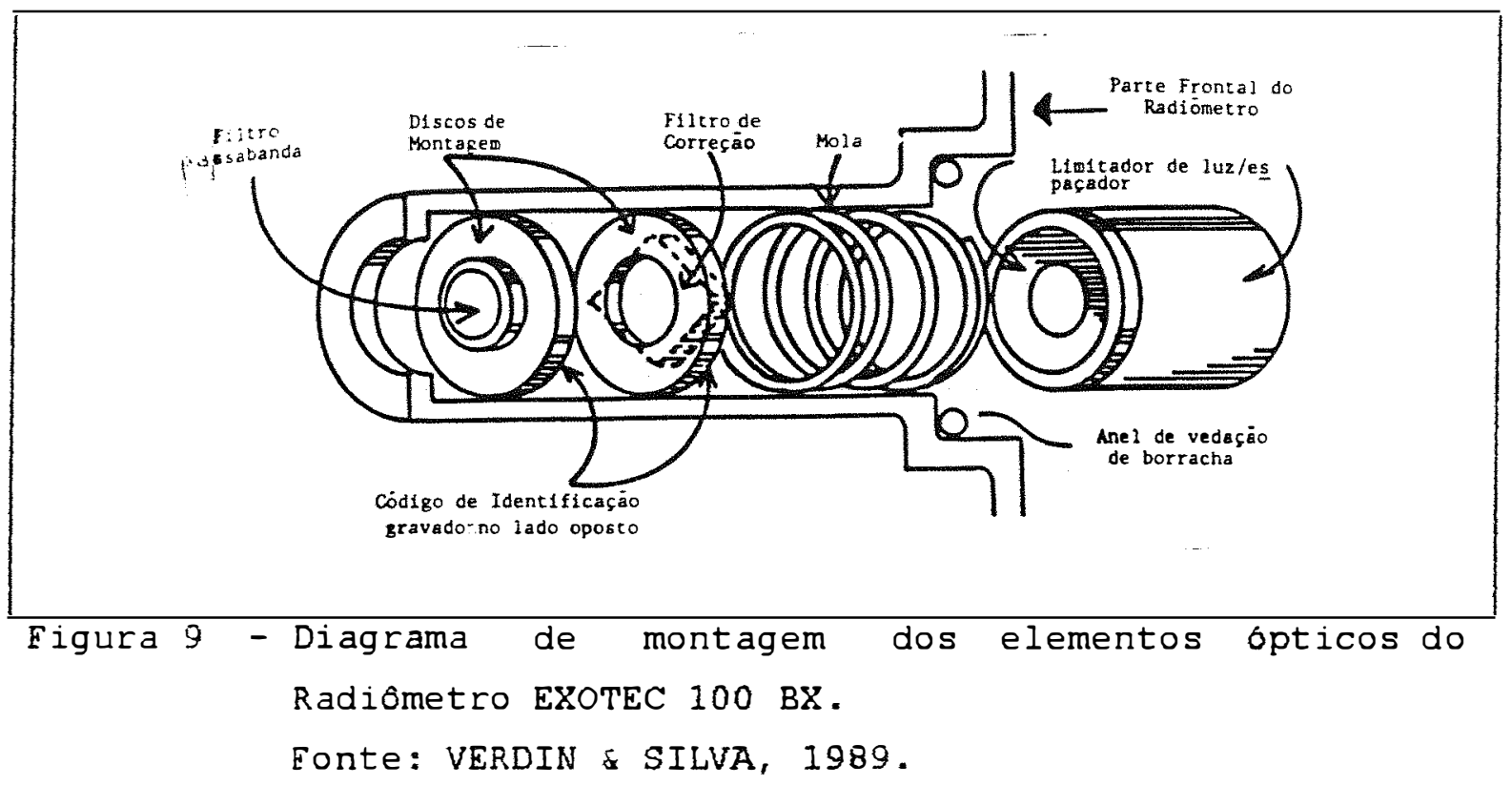

\subsubsection{Equipamentos empregados no tratamento de imagens.}

O processamento de imagens digitais desenvolveuse no SRGRAPH/CODEVASF (Brasilia - DE) empregando o sistema ERDAS (Companhia ERDAS, Atlantic City/EUA), para tratamento e extração de valores digitais. Esse sistema permite manipular numéricamente as informações da cena em Eoco.

o hardware do sistema de processamento de imagens digitais utilizado foi um SPARC STATION IPC (Figura 10, ilustraçåo típica) composto pelas seguintes unidades: uma Unidade de Eita Magnética (Eita rolo); um winchester (3 Gigabytes) e 


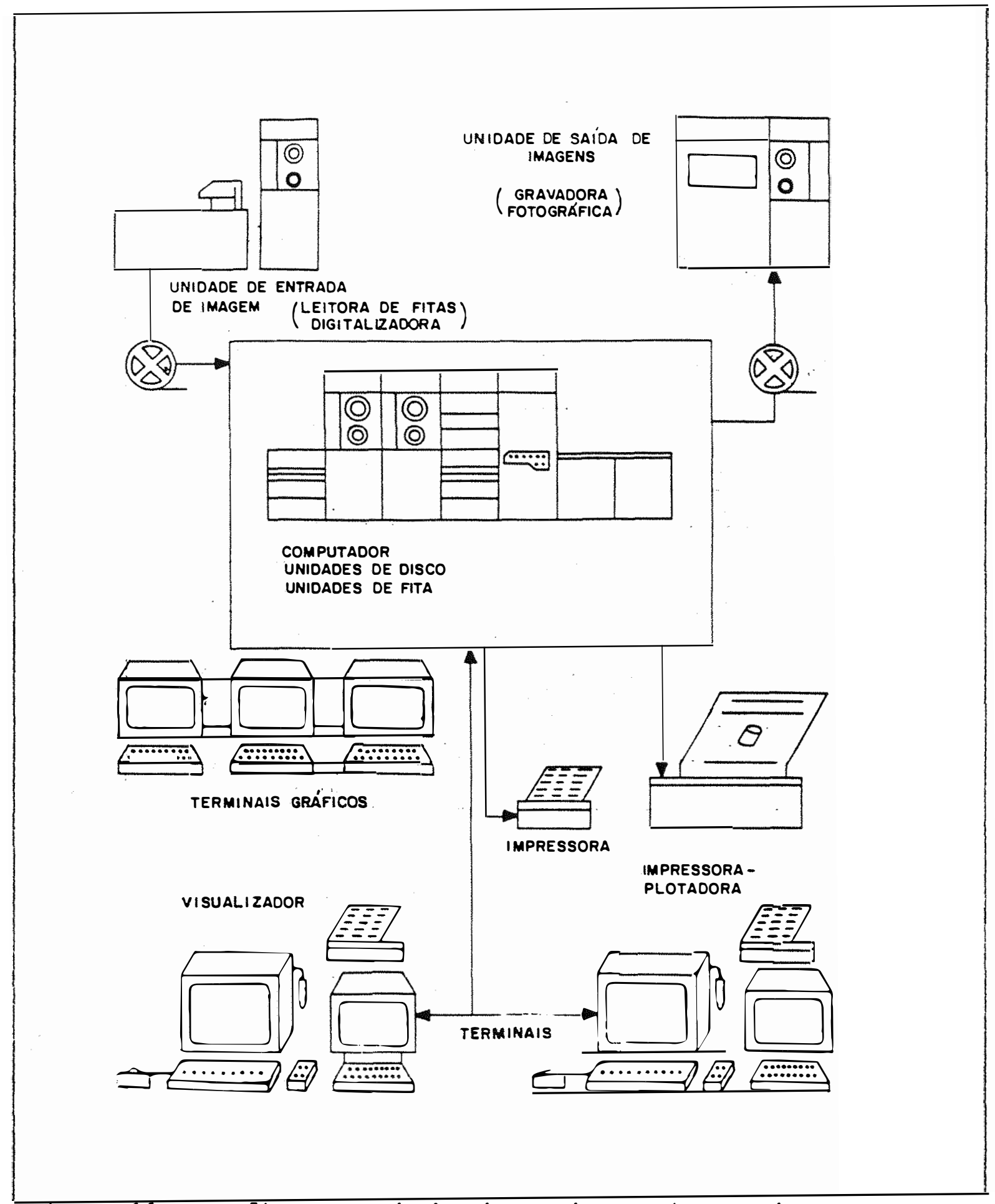

Figura 10 - Configuração do hardware de um sistema de processamento de imagens digitais.

Fonte: HABERĂCKER (1984). 
memória RAM de $32 \mathrm{MB}$; monitor colorido de $15^{\prime \prime}$ e placa RASTEROPS de alta resolução de 24 bytes; Eita DAT de 8 mm (fita gravadora de vídeo comum) para gravar as imagens tratadas; impressora colorida (à jato de tinta) TECTRONIX; impressora comum, e terminal gráfico.

\subsection{Métodos.}

Em conformidade com os objetivos da pesquisa, a Ease operacional constou dos seguintes itens:

- definição dos lotes em exploração agrícola com a cultura definida para a pesquisa;

- delimitação das áreas base do trabalho em cada lote;

- coleta dos dados culturais: tipo de solo, tipo do preparo efetuado para o plantio, qualidade da semente plantada, aspecto fitossanitário e manejo de irrigação adotado;

- coleta de dados fitotécnicos: indice de área foliar, cobertura vegetal e ângulo de inserção da folha no caule;

- mediçoes radiométricas a campo;

- aquisição e tratamento de imagens digitais de satélite;

- tabulação, análise de dados, conclusão e redação final.

\subsubsection{Ações de campo}

\subsubsection{Coleta de dados}

As etapas de coletas de informaçoes de campo, seguiram as fases do ciclo fenológico da cultura, assim esquematizadas:

a) FASE 1 - coleta de dados feita no intervalo de 8 a 15 dias pós-germinação (16/05/92). Nesta fase a planta apresenta-se com 3 a 5 folílos. 
b) FASE II - coleta de dados feita no intervalo de 40 a 50 dias pós-germinação (23/06/92). A planta já encontra-se em seu desenvolvimento vegetativo pleno, em média com 50 folhas.

c) FASE III - coleta de dados feita 70 a 80 dias pós-germinação (30/07/92). A planta encontra-se em fase de Eloraçåo/ Erutificação.

A FASE IV, programada para a coleta de dados na Ease de senescencia da cultura (Erutos formados, folhas amarelando, etc.), caracterizando o final do ciclo da cultura, não foi realizada por desajuste de programação. A cultura foi colhida antes do periodo planejado pelo plano de cultivo em alguns lotes; e/ou ocorrencia de sobressaida de ervas daninhas em relação a cultura (Eenômeno normal nesta fase da lavoura).

Â realização das operaçôes foi programada para coincidir com a época de passagem do satélite sobre a região. procurou realizar o serviço num espaço máximo de 5 dias úteis. Considerou o dia da passagem como mediano ( $3^{\circ}$ dia) e como limites extremos os dias $1^{0}$ (limite inferior) e $5^{\circ}$ (limite superior), para evitar um hiato das informaçoes.

\subsubsection{Dados fitotécnicos}

\section{a) Indice de área foliar}

Os dados foram coletados com vista ao desenvolvimento de cálculos usando a fórmula 5 de BLACKMAN \& WILSON (1951):

IAF - (NPS $\times$ AF $) / E F$

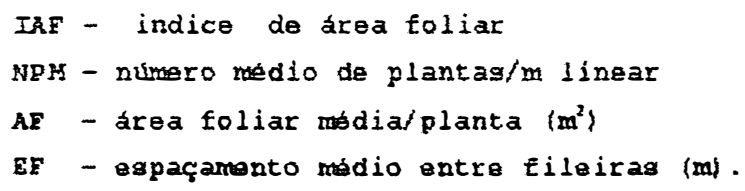

Calculou-se a área foliar (AF) pelo processo de 
"Determinaça da área foliar in vitro no feijoeiro", sem destruiçấo da planta, utilizando o método do círculo circunscrito (GOMIDE \& CASTRO NETO, 1989).

\section{$A=1,1286 \mathrm{C}^{2}$}

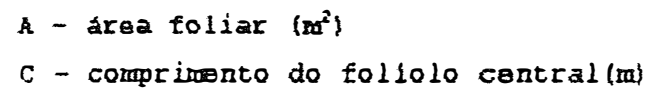

Consistiu em medir no campo apenas o comprimento do foliolo central da folha (cada folha do feijoeiro é composta por 3 foliolos), obtendo-se 0 "C" (figura 11). As medidas foram feitas em 10 plantas, ao acaso, dentro de cada base de trabalho

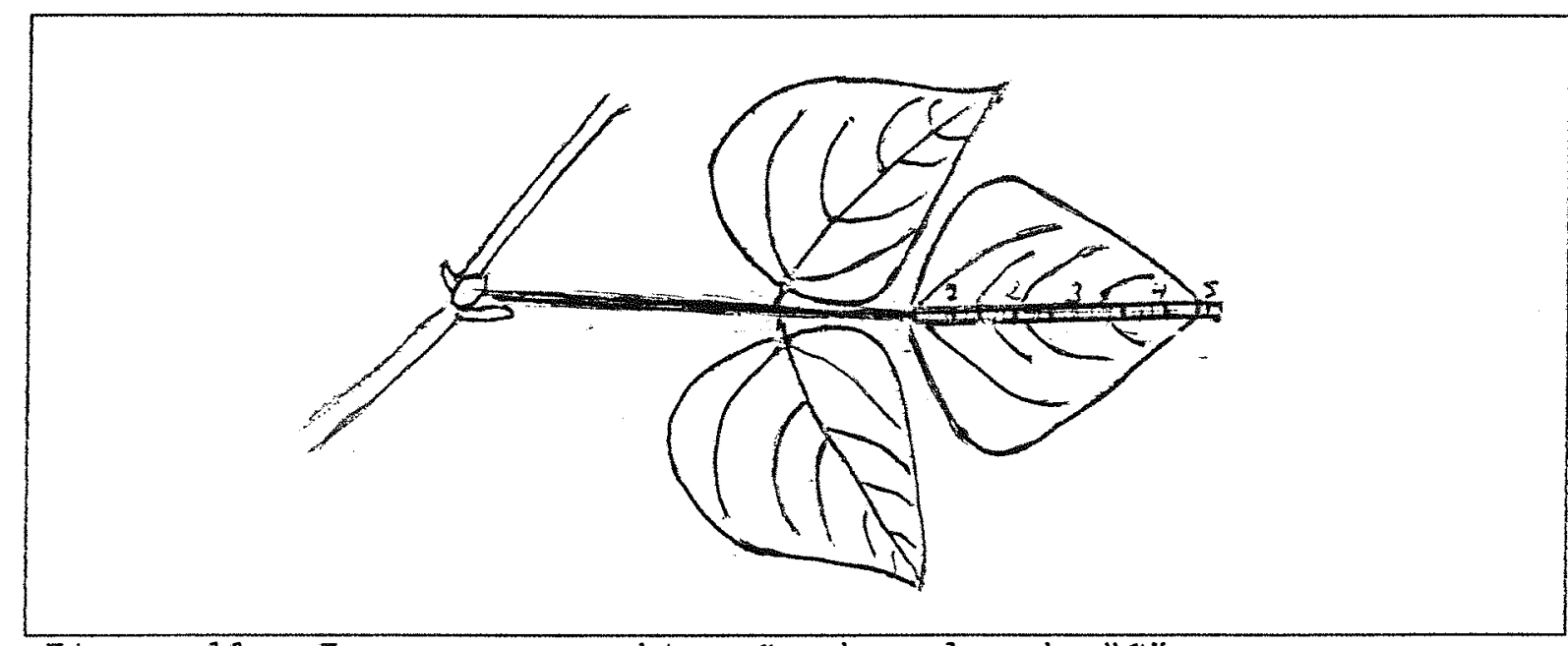

Eigura 11 - Esquema para obtençåo do valor de "C" no campo.

da lavoura, em 308 das folhas, adotando-se um critério de proporcionalidade em função da massa vegetal e do entrelaçamento de cobertura.

Em relaçåo a massa vegetal, assumiu-se que na fase vegetativa adulta da cultura, o volume da concentração de folhas na planta decresce da copa para a base. Adotou-se, entåo, um critério representativo de proporcionalidade para a tomada de dados: fez-se leituras em 158 das folhas da copa; 108 das folhas da subcopa (fase intermediária entre a copa e a base) e 58 das 
folhas basais (figura 12). Essa prática também visou relacionar a tomada de dados com a arquitetura da planta, cujo entrelaçamento das folhas, na sua composição global, tende a proporcionar uma cobertura plena do solo. Os espaços descobertos na copa são recompostos pelas folhas postadas nas camadas inferiores, que se orientam em direção aos feixes de luz que ultrapassaram as partes superiores, intercepta-os, dando uma formação mais completa ao dossel, visto de um plano superior perpendicular ao solo.

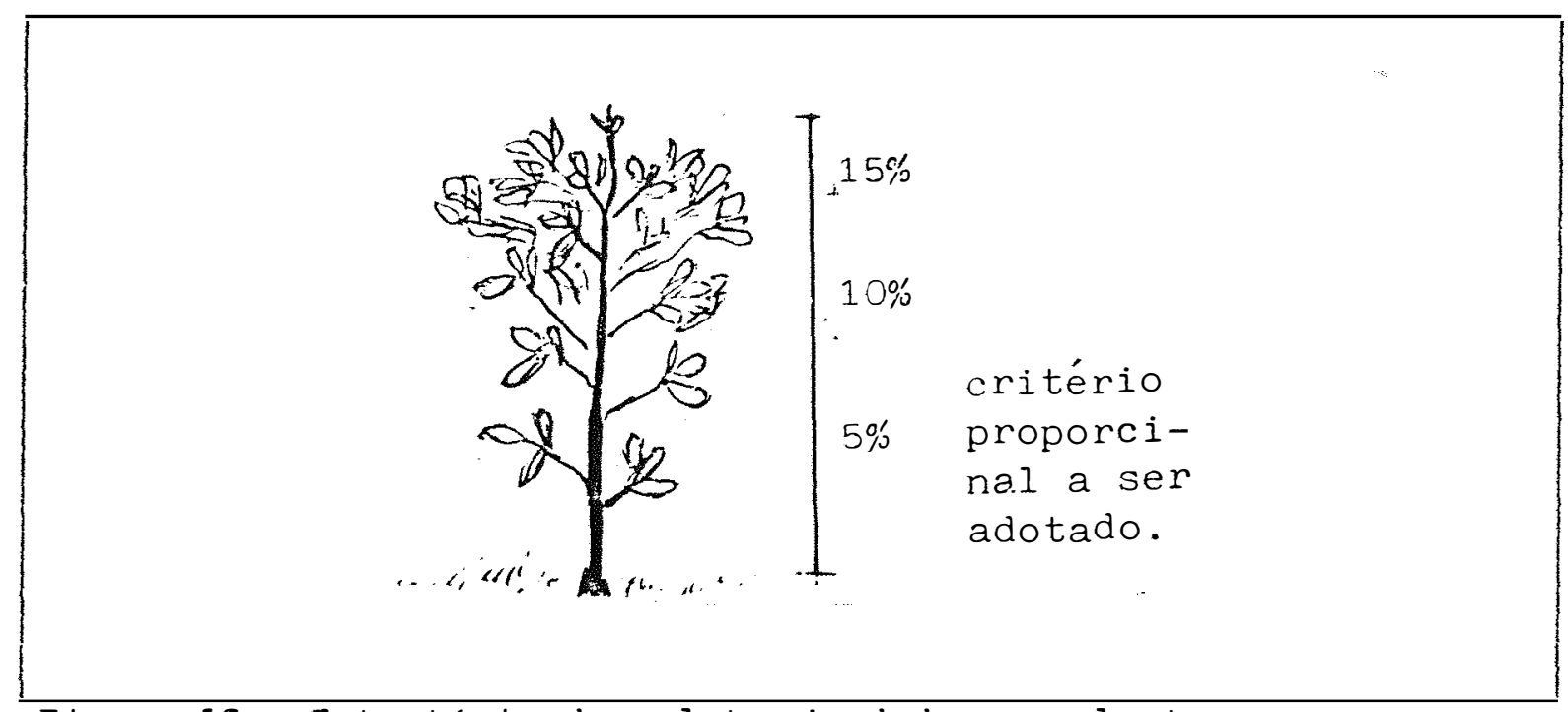

Eigura 12 - Estratégia de coleta de dados na planta.

Para determinar o número médio de plantas por metro linear (NPM) e o espaçamento médio entre fileiras (EE) utilizouse uma trena metálica de 2 metros de comprimento; e um escalimetro de $15 \mathrm{~cm}$ de comprimento para medir " $\mathrm{C}$ ".

A operação de coleta de dados foi repetida em 2 campanhas de campo, em conformidade com o ciclo fenologico da cultura, atendendo as variáveis de intersse necessárias para determinar $O$ IAE (Índice de area foliar), discriminados na formula (5). Os resultados eståo apresentados na Tabela 5. 


\section{b) Cobertura Vegetal (COV)}

Os dados para determinar a evolução da cobertura vegetal foram extraidos de fotografias das bases de estudos, tiradas em cada etapa das operaçoes de campo. As fotografias foram tiradas de uma plataforma móvel adaptável, a pelo menos 3 metros da copa das plantas. Utilizou-se o mastro de acoplagem do radiómetro EXOTEC- modelo $100 \mathrm{BX}$ (vide 3.4.5.) para instalar a máquina fotográfica, prendendo-a numa placa de ferro de apoio, posicionando-a verticalmente para a superficie do solo. Para manusear o equipamento à distância, acoplou-se um "motor driver", com a função de disparar e reposicionar o filme; instalou-se um cabo de $2 \mathrm{~m}$ na extensão do propulsor de disparos para acionálo manualmente; no início das seçôes de fotografias fixava-se a abertura do diafragma, após a focagem.

Com o objetivo de checar os dados extraidos das fotografias, tomou-se no campo o comprimento do trecho de uma fileira considerada (L); o número de plantas dispostas na estensåo da fileira considerada (NP); o espaçamento entre fileiras (EF) e diâmetro da cobertura da planta (fez-se 2 medidas da projeção da copa da cultura na simetria do plano e perpendicularmente entre si). Os dados de campo equipararam-se aos extraidos das fotografias.

Empregou-se a formula 7 para calcular a variável. Os dados encontram-se na tabela $\tilde{b}$.

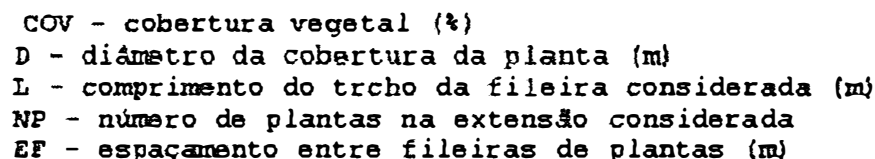




\section{c) Ângulo de inserçăo da folha no caule da planta}

Os dados referentes a esse parâmetro foram coletados nas Fases I e II do ciclo vegetativo da cultura registrando valores medios de $37.5^{\circ}$, em ambas oportunidades. A Ease III foi desconsiderada por não se observar alterações de valores, nas medidas amostrais, em relaçăo às Eases anteriores. A cultura, na Ease de floração e Erutificação, estava bem fechada na sua maioria. Alguns lotes, precocemente, já estavam na Ease IV.

\subsubsection{Leituras radiométricas e tratamentos de dados}

A operação nas 3 bases de cada lote constituiu de: leituras no escuro (objetiva do radiometro Eechada); leituras do PAINEL (calibração); leituras em 5 posiçôes sobre a vegetação em cadia uma das três bases de trabalho de cada lote; e leituras de PRINEL para fechamento da série. Os dados coletados pelo radiômetro såo armazenados em um gravador portátil (POLYCORDER), entäo acoplados por um Eio de 5 metros de comprimento. Estas atividades foram feitas entre 9:00 e 14:00h, quando verifica-se a incidência de alta luminosidade, com os raios solares pouco inclinados em relação ao alvo, céu praticamente isento de nuvens e ventos a velocidades insignificantes. Por ocasião das realizaçôes das duas campanhas de campo, a passagem do satélite ocorreu respectivamente às 9:11 horas (22/05/92) e 10:30 horas $(03 / 07 / 92)$.

No laboratorio, os dados foram transferidos para um microcomputar utilizando o software CROSSTALK. Através de cálculos especificos foram transformados em radiancia e refletância. Os procedimentos de cálculos para a conversão de voltagem em reflectancia foram efetuados empregando equaçðes definidas por NEALE et alii (1989), adaptadas em software para comput ador. 
50.

Equação para calcular ângulo solar zenital para todos alvos:

$$
\cos \theta=\sin 8 \sin \theta+\cos 8+\cos \theta \cos t
$$

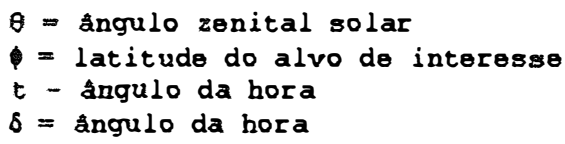

Declinação solar depende da data juliana, J.

E calculada em dois passos:

$k=\pi / 280^{\circ}(0.9683 \mathrm{~J}-78.00878)$ (radianos)

$\delta=\pi / 180^{\circ}(23.4856 \mathrm{sinA}$ (radianos)

Equação para calcular o ângulo da hora

$t=15\left(\pi / 180^{\circ}\right)$ (HVS -12$)$ (radianos)

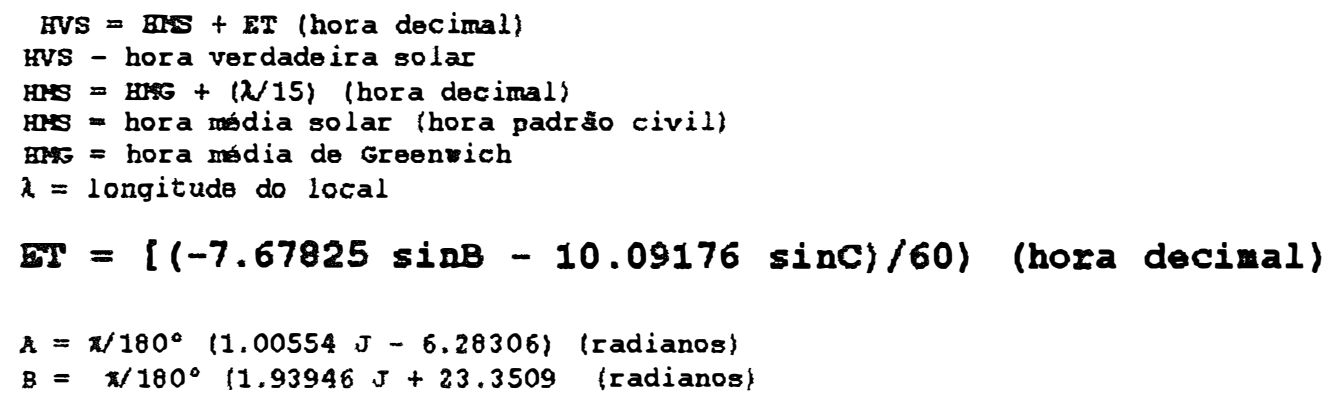

Equaçăo para cálculo da reflectancia calibrada do painel (placa de báriol.

$$
R=\mathbf{a} \theta+\mathbf{a}_{1} \theta+\mathbf{a}_{2} \theta^{2} \mathbf{a}_{9} \theta^{3}
$$

Equaçóes para cálculo da irradiancia (ficando com unidades de rolts do radiómetro) nas horas de leitura do painel, com ue valor para cada banda.

$$
\begin{aligned}
& \operatorname{ETP1}=(\pi \mathrm{TM} 1) /(\mathrm{RI} \cos \theta) \\
& \operatorname{ETP2}=(\pi \mathrm{TM2}) /(\mathrm{R} 1 \cos \theta) \\
& \text { ETP3 }=(\pi \mathrm{TM} 3) /(\mathrm{R} 1 \cos \theta) \\
& \text { ETP4 }=(\pi T M 4) /(R 1 \cos \theta)
\end{aligned}
$$

TM1, TMR, TMB O TM4 - voltagens calculadas. 
51.

Interpolação linear com valores de ETP1, ETP2, ETP3 e ETP4 (irradiáncia), para a hora de medição no alvo:

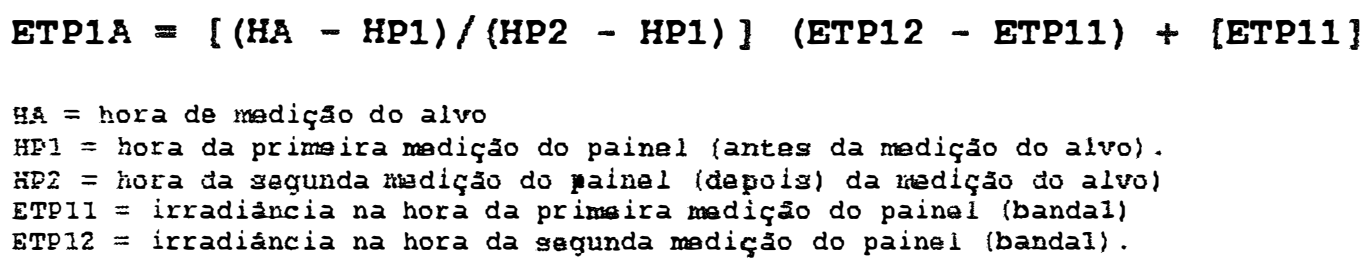

Equacóes para calcular reflectância bidirecional de cada alvo em cada banda.

$$
\begin{aligned}
& \text { R1A }=(\pi T M 1) /(\text { ETP1A } \cos \theta) \\
& \text { R2A }=(\pi T M 2) /(\text { ETP1A } \cos \theta) \\
& \text { R3A }=(\pi T M 3) /(\text { ETP1A } \cos \theta) \\
& \text { R4A }=(\pi T M 4) /(\text { ETP1A } \cos \theta)
\end{aligned}
$$

\subsubsection{Tratamentos de imagens de satélite e obtenção de dados.}

No laboratorio foi feita a leitura da fita COT pelo leitor de fitas SUN, copiando para um arquivo de imagem tipo bil (bandas intercaladas por pixel). A análise visual da imagem no monitor de computador mostrou que o arquivo estava perfeito, sem linhas. Fez-se o programa estatistico de realce. Consiste em fazer uma mudança histogrâmica do arquivo por banda. Daí foi fEito a composiçăo colorida da imagem, onde se definiu a seguinte relaço de banda: HRV-XVI para banda azul; HRV-XV2 para banda verde; e HRV-TV3 para banda vermelha. Com a imagem exposta no monitor de computador, foram localizadas as áreas trabalhadas. Atraves de programas especificos para leituras de pixel foram preparados arquivos com essas informaçôes e transformados em arquivos ACCII (American Standart Code Eor Information Interchange) para serem lidos em programas, tipo planilhas eletronicas. Essas informaçôes de pixels correpondem ao nivel de cinza da imagem, relativos às áreas em estudo. Com esses dados foram desenvolvidos os estudos estatisticos do trabalho. 


\subsubsection{Análise dos dados}

Análise de dados constou de:

a) Análise estatistica dos valores de reflectáncias

- Análise estatística dos valores de reflectáncia temporal obtidos a partir dos dados de niveis de cinza extraidos de imagens do satélite spot (REF) e das leituras de radiometria de campo (RAD));

- Análise estatística dos valores de reflectancia obtidos a partir dos dados de niveis de cinza extraidos de imagens do satélite Spot (REF):

- Análise estatística dos valores de reflectancia das leituras temporais de radiometria de campo (RAD).

b) Avaliaçâo gráfica das curvas dos valores de reflectáncia temporal (RFF e RAD).

c) Avaliaçáo dos valores de reflectâncias en função dos dados fitotécnicos:

- Resposta de reflectâncias em funçåo da cobertura vegetal;

- Respostas de reflectancias em funçåo do Indice de área foliar.

- Tratos culturais.

As análises estatísticas foram realizadas empregando o software SAS (Statistical Analysis System), no Departamento de Ciencias Florestais da ESALQ/USP (Piracicaba/SP) e no Departamento de Matemática e Estatística da UnB (Brasilia/DE). 


\section{RESULTADOS E DISCUSSÖES}

\subsection{Tabulação de dados.}

Os dados dos indicadores de interesse da pesquisa, no ambito do planejamento pré-estabelecido foram coletados e tabuiados, seguindo metodologia e procedimentos de calculos expicitados no CapituIo MATERIAIS E METODOS, em tópico especiceico.

Na tabela 3 estăo os valores de reflectancias calculados a partir dos dados dos niveis de cinza extraidos das imagens do satélite Spot, no periodo relativo ao ciclo da cultura com 8 dias e 50 dias pós-germinação. Os dados do periodo referente a 85 dias de pós-germinaçă, correspondente a etapa de transiçăo floraçăo/Erutificaçăo (Ease III) para a etapa final do cicio da cultura (Ease IV), năo foram catalogados devido a nào aquisiçăo da imagem, em razăo de problemas orçamentarios. Nesta oportunidade, Fase III, foram realizadas apenas as leituras radiometricas.

Na tabela 4 estäo valores de reflectsncias oriundos dos dados das leituras radiométricas de campo da cultura de feijäo realizadas aos 8,50 e 85 dias pos-germinaça.

os dados fitotécnicos tabulados referem-se a Indice Areas Eoliar e Cobertura Vegetal. Säo dados medios dos periodos de 8 e 50 dias pós-germinaçåo da cultura (Tabelas 5 e 5). 
54.

Tabela 3 - Valores de reflectancias obtidas a partir de dados extraidos de imagens do satélite spot.

\begin{tabular}{|c|c|c|c|c|c|}
\hline \multicolumn{6}{|c|}{ PERIODO DE LEITURASS EM DIAS PÓS-GERIIINACCKO } \\
\hline & 8 DIAS & & & 50 DIRS & \\
\hline & BANDAS & $1+1$ & & BANDAS & (4) \\
\hline 1 & 2 & 3 & 1 & 2 & 3 \\
\hline 0.1914 & 0.0896 & 0.1275 & 0.1142 & 0.1313 & 0.2014 \\
\hline 0.0914 & 0.0922 & 0.1312 & 0.1201 & 0.1472 & 0.2118 \\
\hline 0.0953 & 0.0967 & 0.1368 & 0.1241 & 0.1529 & 0.2125 \\
\hline 0.0937 & 0.0496 & 0.1532 & 0.1075 & 0.1068 & 0.1857 \\
\hline 0.0978 & 0.0955 & 0.1413 & 0.1123 & 0.1228 & 0.2054 \\
\hline 0.0998 & 0.1044 & 0.1426 & 0.1208 & 0.4850 & 0.2212 \\
\hline 0.0941 & 0.0908 & 0.1263 & 0.1074 & 0.1074 & 0.1538 \\
\hline 0.096 .5 & 0.1032 & 0.1411 & 0.1085 & 0.1085 & 0.2035 \\
\hline 0.1008 & 0.1523 & 0.1450 & 0.1096 & 0.1400 & 0.2140 \\
\hline 0.0908 & 0.0919 & 0.1290 & 0.1164 & 0.1243 & 0.2034 \\
\hline 0.0924 & 0.0984 & 0.1311 & 0.1202 & 0.1342 & 0.2170 \\
\hline 0.0916 & 0.0950 & 0.1320 & 0.1238 & 0.1465 & 0.2229 \\
\hline 0.0965 & 0.0986 & 0.1794 & 0.1104 & 0.1156 & 0.1787 \\
\hline 0.0985 & 0.1036 & 0.1891 & 0.1130 & 0.1253 & 0.1869 \\
\hline 0.1008 & 0.1072 & 0.1993 & 0.1172 & 0.1366 & 0.2119 \\
\hline 0.0932 & 0.0426 & 0.1263 & 0.1163 & 0.1166 & 0.1881 \\
\hline 0.0965 & 0.1032 & 0.1311 & 0.1132 & 0.1238 & 0.2043 \\
\hline 0.0104 & 0.1044 & 0.1504 & 0.1150 & 0.1399 & 0.2141 \\
\hline 0.1144 & 0.1302 & 0.1384 & 0.1051 & 0.1024 & 0.1985 \\
\hline 0.1162 & 0.1324 & 0.1463 & 0.1081 & 0.1120 & 0.2145 \\
\hline 0.1198 & 0.1426 & 0.1558 & 0.1168 & 0.1327 & 0.2341 \\
\hline
\end{tabular}

(*) Dados de cinza em porcentagem.

Tabela 4 - Valores de reflectância obtidos a partir de radiometria de campo.

\begin{tabular}{|c|c|c|c|c|c|c|c|c|}
\hline \multicolumn{9}{|c|}{ PERTODO DE IEITURRS EM DIAS POS-GERMUUACKO } \\
\hline \multicolumn{3}{|c|}{$\begin{array}{c}8 \\
\text { DIAS }\end{array}$} & \multicolumn{3}{|c|}{$\begin{array}{c}50 \\
\text { DIAS }\end{array}$} & \multicolumn{3}{|c|}{$\begin{array}{c}85 \\
\text { DIAS }\end{array}$} \\
\hline & BRNDAS & $1+1$ & & BNNDAS & (\$) & & BANDAS & $1+1$ \\
\hline 1 & 2 & 3 & 1 & 2 & 3 & 1 & 2 & 3 \\
\hline 0.0537 & 0.0283 & 0.2011 & 0.1005 & 0.0180 & 0.7281 & 0.0818 & 0.0240 & 0.2946 \\
\hline 0.0600 & 0.0311 & 0.2011 & 0.1027 & 0.0194 & 0.7427 & 0.0958 & 0.0361 & 0.3040 \\
\hline 0.0828 & 0.0378 & 0.2665 & 0.0994 & 0.0245 & 0.9138 & 0.1079 & 0.0417 & 0.3179 \\
\hline 0.0001 & 0.0000 & 0.0015 & 0.0855 & 0.0064 & 0.7410 & 0.0747 & 0.0431 & 0.2528 \\
\hline 0.0002 & 0.0000 & 0.0016 & 0.0882 & 0.0141 & 0.8610 & 0.0754 & 0.0509 & 0.2536 \\
\hline 0.0003 & 0.0000 & 0.0016 & 0.0916 & 0.0168 & 0.9011 & 0.0821 & 0.0618 & 0.2614 \\
\hline 0.0493 & 0.0267 & 0.1943 & 0.0537 & 0.0057 & 0.1983 & 0.0496 & 0.0111 & 0.1794 \\
\hline 0.0689 & 0.0301 & 0.2161 & 0.0547 & 0.0064 & 0.5850 & 0.0525 & 0.0136 & 0.1866 \\
\hline 0.0703 & 0.0363 & 0.2412 & 0.0588 & 0.0097 & 0.4395 & 0.0540 & 0.159 & 0.1892 \\
\hline 0.0001 & 0.0000 & 0.0012 & 0.0598 & 0.0000 & 0.4227 & 0.0480 & 0.0105 & 0.1742 \\
\hline 0.0000 & 0,0000 & 0.0014 & 0.0638 & 0.0000 & 0.4952 & 0.0496 & 0.0170 & 0.2258 \\
\hline 0.0002 & 0.0000 & 0.0016 & 0.0852 & 0.0000 & 0.4977 & 0.0550 & 0.0292 & 0.2630 \\
\hline 0.0559 & 0.0303 & 0.1958 & 0.0560 & 0.0243 & 0.4601 & 0.0690 & 0.0219 & 0.2403 \\
\hline 0.0616 & 0.0337 & 0.2087 & 0.0589 & 0.0244 & 0.5545 & 0.0715 & 0.0230 & 0.2545 \\
\hline 0.0711 & 0.0397 & 0.2429 & 0.0590 & 0.0245 & 0.6145 & 0.0127 & 0.0242 & 0.2976 \\
\hline 0.0919 & 0.0451 & 0.2978 & 0.0532 & 0.0035 & 0.5085 & 0.0430 & 0.0068 & 0.2132 \\
\hline 0.1020 & 0.0463 & 0.3226 & 0.0533 & 0.0052 & 0.5273 & 0.0461 & 0.0103 & 0.2187 \\
\hline 0.1068 & 0.0552 & 0.3111 & 0.0550 & 0.0070 & 0.5293 & 0.0498 & 0.0109 & 0.2551 \\
\hline 0.1062 & 0.0482 & 0.3367 & 0.0516 & 0.0000 & 0.0410 & 0.0732 & 0.0048 & 0.3084 \\
\hline 0.0996 & 0.0494 & 0.2877 & 0.0605 & 0.0052 & 0.3553 & 0.0781 & 0.0152 & 0.3314 \\
\hline 0.0937 & 0.0422 & 0.0292 & 0.0751 & 0.0070 & 0.4960 & 0.0828 & 0.0152 & 0.3445 \\
\hline
\end{tabular}

(*) Dados de cinza em porcentagem 
Tabela 5 - Dados médios de indice de área foliar.

\begin{tabular}{|c|c|c|c|c|c|c|c|c|}
\hline \multirow[t]{2}{*}{ IOTE } & \multirow[t]{2}{*}{ NPK } & \multirow{2}{*}{$\begin{array}{l}\mathrm{BF} \\
(\mathrm{m})\end{array}$} & \multicolumn{2}{|c|}{ FOI $\quad P$} & \multicolumn{2}{|c|}{ C $\quad(\mathrm{m})$} & \multicolumn{2}{|c|}{$I A F$} \\
\hline & & & $8 d$ & $50 d$ & $8 d$ & $50 d$ & $8 d$ & $50 \mathrm{~d}$ \\
\hline 1 & 15 & 0.50 & 2 & 10 & 0.049 & 0.110 & 0.104069 & 4.096818 \\
\hline 1 & 24 & 0.40 & 2 & 11 & 0.049 & 0.095 & 0.208138 & 6.722506 \\
\hline 1 & 19 & 0.45 & 2 & 11 & 0.051 & 0.105 & 0.158668 & 5.778996 \\
\hline 1 & 21 & 0.50 & 2 & 10 & 0.042 & 0.110 & 0.107042 & 5.735545 \\
\hline 1 & 18 & 0.45 & 2 & 12 & 0.048 & 0.080 & 0.133153 & 3.467059 \\
\hline 1 & 17 & 0.50 & 2 & 13 & 0.050 & 0.120 & 0.122808 & 7.183313 \\
\hline 1 & 18 & 0.40 & 2 & 11 & 0.055 & 0.095 & 0.196673 & 5.041879 \\
\hline 2 & 19 & 0.50 & 2 & 45 & 0.050 & 0.090 & 0.137256 & 5.210746 \\
\hline 2 & 11 & 0.50 & 2 & 11 & 0.060 & 0.065 & 0.114428 & 1.153937 \\
\hline 2 & 16 & 0.50 & 2 & 11 & 0.050 & 0.075 & 0.115584 & 2.234628 \\
\hline 2 & 19 & 0.50 & 2 & 11 & 0.040 & 0.006 & 0.087844 & 0.016983 \\
\hline 2 & 21 & 0.50 & 2 & 11 & 0.042 & 0.007 & 0.107042 & 0.025549 \\
\hline 2 & 12 & 0.50 & 2 & 15 & 0.046 & 0.007 & 0.073373 & 0.022854 \\
\hline 2 & 13 & 0.50 & 2 & 12 & 0.051 & 0.006 & 0.097706 & 0.012676 \\
\hline 3 & 24 & 0.50 & 2 & 10 & 0.050 & 0.075 & 0.173376 & 3.047220 \\
\hline 3 & 14 & 0.50 & 2 & 11 & 0.055 & 0.075 & 0.122375 & 1.955300 \\
\hline 3 & 17 & 0.50 & 2 & 12 & 0.050 & 0.070 & 0.122808 & 2.256297 \\
\hline 3 & 15 & 0.50 & 2 & 10 & 0.056 & 0.070 & 0.135927 & 1.659042 \\
\hline 3 & 20 & 0.50 & 2 & 13 & 0.050 & 0.075 & 0.144480 & 3.301155 \\
\hline 3 & 14 & 0.50 & 2 & 9 & 0.065 & 0.070 & 0.170920 & 1.393595 \\
\hline 3 & 16 & 0.50 & 2 & 12 & 0.045 & 0.075 & 0.093623 & 2.437776 \\
\hline 4 & 25 & 0.50 & 3 & 19 & 0.055 & 0.096 & 0.327789 & 9.881119 \\
\hline 4 & 20 & 0.50 & 3 & 17 & 0.060 & 0.082 & 0.312077 & 5.160320 \\
\hline 4 & 24 & 0.50 & 3 & 18 & 0.045 & 0.110 & 0.210652 & 11.798840 \\
\hline 4 & 23 & 0.50 & 3 & 15 & 0.045 & 0.111 & 0.201875 & 9.594782 \\
\hline 4 & 19 & 0.42 & 3 & 20 & 0.055 & 0.080 & 0.296571 & 6.535131 \\
\hline 4 & 21 & 0.40 & 3 & 17 & 0.045 & 0.070 & 0.230400 & 4.935650 \\
\hline 4 & 22 & 0.45 & 3 & 19 & 0.055 & 0.110 & 0.320505 & 12.684960 \\
\hline 5 & 15 & 0.50 & 2 & 27 & 0.060 & 0.075 & 0.156038 & 3.237671 \\
\hline 5 & 12 & 0.50 & 2 & 10 & 0.055 & 0.110 & 0.104892 & 3.277454 \\
\hline 5 & 16 & 0.50 & 2 & 13 & 0.051 & 0.095 & 0.120254 & 4.237216 \\
\hline 5 & 18 & 0.50 & 2 & 15 & 0.045 & 0.075 & 0.105326 & 3.428123 \\
\hline 5 & 17 & 0.50 & 2 & 16 & 0.050 & 0.120 & 0.122808 & 8.641001 \\
\hline 5 & 15 & 0.50 & 2 & 17 & 0.040 & 0.065 & 0.069350 & 2.431851 \\
\hline 5 & 16 & 0.50 & 2 & 15 & 0.042 & 0.080 & 0.081556 & 3.467059 \\
\hline 5 & 14 & 0.40 & 4 & 11 & 0.051 & 0.103 & 0.263055 & 2.654467 \\
\hline 6 & 19 & 0.40 & 4 & 19 & 0.050 & 0.083 & 0.343140 & 4.609727 \\
\hline 6 & 14 & 0.50 & 4 & 8 & 0.045 & 0.085 & 0.163840 & 7.016870 \\
\hline 6 & 13 & 0.40 & 4 & 14 & 0.045 & 0.090 & 0.190172 & 1.826526 \\
\hline 6 & 14 & 0.50 & 4 & 15 & 0.040 & 0.105 & 0.129454 & 4.159455 \\
\hline 6 & 13 & 0.50 & 4 & 13 & 0.050 & 0.085 & 0.187824 & 5.225982 \\
\hline 6 & 25 & 0.50 & 4 & 18 & 0.055 & 0.105 & 0.262231 & 2.756098 \\
\hline 7 & 28 & 0.30 & 4 & 19 & 0.055 & 0.105 & 0.815830 & 6.719120 \\
\hline 7 & 25 & 0.45 & 2 & 17 & 0.045 & 0.101 & 0.162540 & 8.510885 \\
\hline$i$ & 19 & 0.45 & $\hat{2}$ & 18 & 0.046 & 0.100 & 0.129082 & 6.654426 \\
\hline$?$ & 27 & 0.35 & 2 & 13 & 0.050 & 0.090 & 0.175440 & 8.577360 \\
\hline$?$ & 23 & 0.40 & 2 & 16 & 0.055 & 0.101 & 0.251305 & 5.772305 \\
\hline 7 & 22 & 0.50 & 2 & 15 & 0.060 & 0.115 & 0.228856 & 8.289251 \\
\hline 7 & 26 & 0.35 & 2 & 17 & 0.050 & 0.104 & 0.165120 & 9.850965 \\
\hline
\end{tabular}

Lote - numaro do lote base de trabaiho

NPM - numero de plantas por metro linear (metro - $m$ )

EF - exnacemento entre fileiras de plantio (m)

FOLip - numero de folhas por planta $(9 \mathrm{~d}, 50 \mathrm{~d}$ : 8 a 50 dias pós-germinaçăo

IRE - Lndice de área foliar

C - comprimento do foliolo central da folha de feijăo (m - metro)

d - dias pós-germinaçáo 
56.

Tabela 6 - Dados médios de cobertura vegetal da cultura.

\begin{tabular}{|c|c|c|c|c|c|c|c|}
\hline IOTE & $\begin{array}{r}\text { DATA } \\
\text { (dias) }\end{array}$ & $\overline{B A S E}$ & $\begin{array}{c}D \\
\text { (m) }\end{array}$ & NP & $\frac{E F}{\langle m i n}$ & $\underline{\underline{L}}$ & $\begin{array}{l}\text { COV } \\
(8)\end{array}$ \\
\hline \multirow{4}{*}{1} & 8 & 1 & 0.20 & 9 & 1.1 & 2.3 & 11.17565 \\
\hline & 8 & 2 & 0.15 & 4 & 1.1 & 2.3 & 2.79391 \\
\hline & 8 & 3 & 0.20 & 7 & 1.1 & 2.3 & 8.61217 \\
\hline & 8 & 1 & 0.20 & 9 & 1.1 & 2.2 & 11.68364 \\
\hline \multirow[t]{3}{*}{2} & 8 & 2 & 0.20 & 8 & 1.1 & 2.2 & 10.38554 \\
\hline & 8 & 3 & 0.20 & 7 & 1.1 & 2.2 & 9.07273 \\
\hline & 8 & 1 & 0.20 & 7 & 1.0 & 2.4 & 9.16300 \\
\hline \multirow[t]{3}{*}{3} & 8 & 2 & 0.15 & 9 & 1.4 & 2.4 & 4.73343 \\
\hline & 8 & 3 & 0.20 & 8 & 1.4 & 2.4 & 7.48000 \\
\hline & 8 & 1 & 0.20 & 9 & 1.0 & 2.4 & 11.78100 \\
\hline \multirow[t]{3}{*}{4} & 8 & 2 & 0.20 & 12 & 1.0 & 2.4 & 15.70800 \\
\hline & 8 & 3 & 0.20 & 9 & 1.0 & 2.4 & 11.78100 \\
\hline & 8 & 1 & 0.20 & 14 & 1.0 & 2.4 & 18.32600 \\
\hline \multirow[t]{3}{*}{5} & 8 & 2 & 0.15 & 18 & 1.0 & 2.3 & 13.82987 \\
\hline & 8 & 3 & 0.20 & 9 & 1.0 & 2.4 & 11.78100 \\
\hline & 8 & 1 & 0.20 & 14 & 1.0 & 2.4 & 18.32600 \\
\hline \multirow[t]{3}{*}{6} & 8 & 2 & 0.15 & 8 & 1.0 & 2.4 & 5.89050 \\
\hline & 8 & 3 & 0.15 & 9 & 1.0 & 2.4 & 6.62681 \\
\hline & 8 & 1 & 0.30 & 10 & 1.1 & 2.4 & 26.77500 \\
\hline \multirow[t]{3}{*}{3} & 8 & 2 & 0.35 & 10 & 1.1 & 2.4 & 36.44375 \\
\hline & 8 & 3 & 0.30 & 9 & 1.1 & 2.4 & 24.09750 \\
\hline & 50 & 1 & 0.55 & 9 & 1.1 & 2.4 & 84.51587 \\
\hline \multirow[t]{3}{*}{1} & 50 & 2 & 0.55 & 4 & 1.1 & 2.3 & 37.56261 \\
\hline & 50 & 3 & 0.55 & 7 & 1.1 & 2.3 & 65.73457 \\
\hline & 50 & 1 & 0.55 & 9 & 1.1 & 2.2 & 88.35750 \\
\hline \multirow[t]{3}{*}{2} & 50 & 2 & 0.55 & 8 & 1.1 & 2.2 & 78.54000 \\
\hline & 50 & 3 & 0.55 & 7 & 1.1 & 2.2 & 68.72250 \\
\hline & 50 & 1 & 0.50 & 7 & 1.0 & 2.4 & 57.26875 \\
\hline \multirow[t]{3}{*}{3} & 50 & 2 & 0.55 & 9 & 1.4 & 2.4 & 88.88344 \\
\hline & 50 & 3 & 0.65 & 8 & 1.4 & 2.4 & 79.00750 \\
\hline & 50 & 1 & 0.50 & 9 & 1.0 & 2.4 & 73.63125 \\
\hline \multirow[t]{3}{*}{4} & 50 & 2 & 0.50 & 12 & 1.0 & 2.4 & 98.17500 \\
\hline & 50 & 3 & 0.50 & 9 & 1.0 & 2.4 & 73.63125 \\
\hline & 50 & 1 & 0.45 & 14 & 1.0 & 2.4 & 92.77538 \\
\hline \multirow[t]{3}{*}{5} & 50 & 2 & 0.40 & 18 & 1.0 & 2.3 & 98.34574 \\
\hline & 50 & 3 & 0.50 & 9 & 1.0 & 2.4 & 73.63125 \\
\hline & 50 & 1 & 0.45 & 14 & 1.0 & 2.4 & 92.77538 \\
\hline \multirow[t]{3}{*}{6} & 50 & 2 & 0.50 & 8 & 1.0 & 2.4 & 65.45000 \\
\hline & 50 & 3 & 0.50 & 9 & 1.0 & 2.4 & 73.63125 \\
\hline & 50 & 1 & 0.55 & 10 & 1.1 & 2.4 & 89.99375 \\
\hline \multirow[t]{2}{*}{$?$} & 50 & 2 & 0.55 & 10 & 1.1 & 2.4 & 89.99375 \\
\hline & 50 & 3 & 0.55 & 9 & 1.1 & 2.4 & 80.99438 \\
\hline
\end{tabular}

Lote - número do lote base de trabalho

DATŔ - dias pós-germinaçăo

BASE - base de trabalho no lote

D - diamestro da copa da planta (m)

NP - número de plantas dentro de cada base escolhidas ao acaso

$E F$ - espaçamento entre filoiras do plantio (m - motro)

I - comprimento linear do trecho da fileira analisado (m - metro)

cov - cobertura vegetal (\$ - porcentagem). 
57.

\subsection{Análise estatistica dos valores de reflectáncia.}

\subsubsection{Análise estatistica dos palores temporais de} reflectância (RAD; RED)

Analisou-se as respostas de reflectancias temporais extraidas a partir dos valores de niveis cinza da imagem do satélite spot (REF) e dos valores das leituras radiométricas de campo ( $R A D$ ), nas bandas 1,2 e 3 referente aos periodos de 8 e 50 dias pós-germinação da cultura (Tabelas 3 e 4). Assumiu-se como variável dependente a RESPOSTA de REELECTÄNCIA (RESP) representada pela expressão:

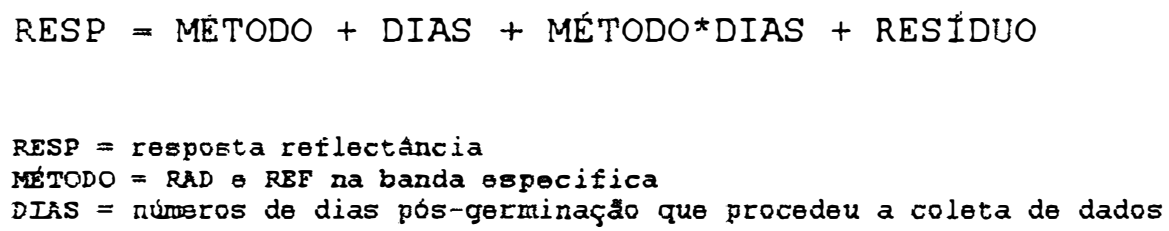

Formulaçåo de hipóteses

Hipótese da nulidade (Ho); Hipotese alternativa (Ha)

Ho: $R A D=R E F ;$ ou Ho: RAD - REF = 0

Ha: RAD $\neq$ REF; OU Ha: RAD - REF $\neq 0$

Ho: Leit8 dias = Leit50 dias; Leit8 dias - Leit50 dias = 0

Ha: Leit8 dias $\neq$ Leit50 dias; Ha: Leit8 dias - Leit50 dias $\neq 0$

\subsubsection{Análise de variância - Teste "E"}

As RESPOSTAS de REFLECTANCIA das variaçoes analisadas nas faixas de dominio das Bandas 1, 2 e 3, atraves do teste "F", mostraram-se significiativas para os niveis de probabilidade 18 e 58, indicando a existencia de diferenças entre as médias dos paråmetros. A nivel de probabilidade de 58 os Testes "F" apresentaram altamente significatıvos. Em razåo disso, 
rejeitam-ze as hipoteses de nulidade (Ho) e aceitam-se as hipote $\mathrm{hes}$ alternativas.

Apicicando-se o Teste de Tukey identificou-se os Indicadores que melhor sobressairam sobre os demais na Eaixa de dominio das BANDAS observadas e nas fases da cultura determinadas.

Teste de Tukey para os dados da faiza de domínio da BANDA 1

De acordo com Tabela 7 as Causas de Variaçåo (C.V) METODO (RAD, REE) e DIAS foram significativos aos niveis de probabilidade de 18 e 5\%. No nivel de probablidade de 58 mostraram altamente significativos. A interação METODO*DIAS não foi significativa a nenhum dos niveis submetidos.

Tabela 7 - Teste "F" para as médias das interaçðes.

\begin{tabular}{|llllrl|}
\hline C.V. & G.L. & S.G. & Q.M. & \multicolumn{1}{c|}{. . } & PROB>F \\
\hline MÉTODO & 1 & 0.03626276 & 0.03626276 & 60.54 & 0.0001 \\
DIAS & 1 & 0.00592200 & 0.00592200 & 9.89 & 0.0023 \\
METODO*DIAS & 1 & 0.00017748 & 0.00017748 & 0.30 & 0.5877 \\
RESIDUAL & 80 & 0.04791682 & 0.00059896 & & \\
\hline TOTAL & 83 & 0.09027906 & & & \\
\hline
\end{tabular}

E (tab) $1 \frac{8}{8}=6.96 ; 5 \%=3.97 ; \mathrm{C.V} .=29.25431$

A tabela 8 mostra que houve diferença significativa ao nivel de probabilidade de 58 entre os componente de METODOS (REE E RAD).

Tabela 8 - Teste de Tukey: variável METODO

\begin{tabular}{|llll|}
\hline NETODO & $N$ & MEDIAS & 5 号 \\
\hline REF & 42 & 0.104436 & $A$ \\
RAD & 42 & 0.062881 & $B$ \\
\hline
\end{tabular}

A Tabela 9 mostra que houve diferença significativa ao nivel de probabilidade de 58 entre os dados coletados a 8 e 50 dias pos-germinaçăo. 
Tabela 9 - Teste de Tukey: variável DIAS

\begin{tabular}{|cccc|}
\hline DIAS & N & MEDIAS & $5 \%$ \\
\hline 50 & 42 & 0.092055 & A \\
8 & 42 & 0.075262 & B \\
\hline
\end{tabular}

Tabela de Tukey para os dados da faixa de domínio da BANDA 2

Tabela 10 - Teste "F" para as medias das interaçôes

\begin{tabular}{|c|c|c|c|c|c|}
\hline C.V. & G.L. & S.G. & Q.M. & E. & PROB $>F$ \\
\hline MÉTODO & 1 & 0.22762506 & 0.22762506 & 121.90 & 0.0001 \\
\hline DIAS & 1 & 0.00290637 & 0.00290637 & 1.56 & 0.2158 \\
\hline METODO X DIAS & 1 & 0.01733482 & 0.01733482 & 9.28 & 0.0031 \\
\hline RESIDUO & 80 & 0.14937976 & 0.00186725 & & \\
\hline TOTAL & 83 & 0.39724601 & & & \\
\hline
\end{tabular}

As causas de variação (C.V) MÉTODO*DIAS (RAD e REE) e MÉTODO*DIAS foram altamente significativas aos niveis de probabilidade de 18 e 58. No nivel de probabilidade de 58 mostraram altamente significativos. A variável DIAS näo foi significativa a nenhum dos niveis submetidos (Tabela 10).

A Tabela 11 mostra que houve diferença significativa ao nivel de probabilidade de 58 entre as componentes de MÉTODO (RAD e RAD).

Tabela 11 - Teste de Tukey: variável MÉTODO

\begin{tabular}{|llll|}
\hline MÉTODO & $\mathrm{N}$ & MÉRIAS & 5 客 \\
\hline REE & 42 & 0.123171 & A \\
RAD & 42 & 0.019060 & $\mathrm{~B}$ \\
\hline
\end{tabular}

A Tabela 12 mostra que houve diferença significativa ao nivel de probabilidade de 5 entre os dados coletados a 8 e 50 dias pós-germinação.

Tabela 12 - Teste de Tukey: variável DIAS

\begin{tabular}{|clll|}
\hline MÉTODO & N & MEDIAS & $5 \%$ \\
\hline 50 & 42 & 0.076998 & A \\
8 & 42 & 0.065233 & B \\
\hline
\end{tabular}


Teste de Tukey para os dados da faira de dominio da BANDA 3

As causas de variaçå (C.V.) MÉtodo (RAD e REF), DIAS E METODO^DIAS foram altamente significativas aos niveis de probabilidade de 18 e 58 . No nivel de probabilidade de 58 mostraram altamente significativos (Tabela 13).

Tabela 13 - Teste "F" para as medias das interações

\begin{tabular}{|llllll|}
\hline C.V. & G.L. & S.G. & Q.M. & F. & PROB>F \\
\hline METODO & 1 & 0.82774503 & 0.82774503 & 58.99 & 0.0001 \\
DIAS & 1 & 1.13925365 & 1.13925365 & 81.19 & 0.0001 \\
MÉTODO*DIAS & 1 & 0.63926331 & 0.63926331 & 45.56 & 0.0001 \\
RESIDUO & 80 & 1.12255220 & 0.014003190 & & \\
\hline TOTAL & 83 & 1.72881413 & & & \\
\hline F(tab) : & $18=6.96$ & C.V. $=43.22717$ & & & \\
& $5 \%=3.97$ & & & &
\end{tabular}

Tabela 14 mostra que houve diferença significativa ao nivel de probabilidade de 58 entre as componentes de MÉTODO (RAD e REE).

Tabela 14 - Teste de Tukey: variável MÉTODO

\begin{tabular}{|llll|}
\hline METODO & N & MEDIAS & $5 \%$ \\
\hline REF & 42 & 0.37330 & A \\
RE.D & 42 & 0.17476 & B \\
\hline
\end{tabular}

A tabela 15 mostra que houve diferença significativa ao nivel de probabilidade de 58 entre os dados coletados a 8 e 50 dias pós-germinação.

Tabela 15 - Teste de Tukey: variável DIAS

\begin{tabular}{|clll|}
\hline DIAS & N & MEDIAS & 58 \\
\hline 50 & 42 & 0.39049 & A \\
B & 42 & 0.15757 & B \\
\hline
\end{tabular}

\subsubsection{Discussão de resultados.}

os resultados da análise estatistica dos valores de reflectância temporal, envolvendo as variávis (RAD) e (REF) nas duas Eases do ciclo vegetativo considerado, indicaram diferenças 
entre os elementos em questão. Não verificou-se similaridade nos resultados em nenhuma das faixas de domínio dos três canais analisados.

Entretanto, o canal 3 apresentou os melhores resultados estatisticos ao nivel de 5 \% de probabilidade:

- As médias das respostas de reflectâncias foram superiores àquelas ocorridas nos demais canais;

- Apresentou melhor coeficiente de correlação entre os dados interagidos (canal 1 - r: 0.6859; canal 2 $r: 0.8360)$.

Essas observaçóes comprovam que a faixa de comprimentos de onda do canal 3 é recomendável para o cadastramento de lavouras agricolas.

Em relação à melhor performance de correlação verificada entre os dados, apesar de não alcançar níveis recomendáveis, explica-se pela compensação dos valores de reflectância registrados nas fases distintas da cultura:

- As leituras radiométricas feitas em campo (Tabela 4) na Ease $I$ (8 dias PG) do ciclo vegetativo são de valores numéricos inferiores aos da Ease II (50 dias PG). Debitase $\circ$ fato aos percentuais de cobertura vegetal ( 8 Cov) serem menores na Ease I em relação a Ease II, que encontra-se na plenitude de seu dossel. Na interação desses dados temporais, o modelo de análise atenua estas discrepâncias.

- Já os dados extraídos das imagens do satélite (Tabela 3), apresentaram leituras diferentes nas duas fases distintas do ciclo vegetativo, mas não com diferenças muito elásticos como as ocorridas na variavel RAD. Atribui-se esse comportamento, da pouca diferença entre os valores de leituras, a fatores variados que podem ter contribuido para o mascaramento das informaçôes por ocasião do registro das imagens na área, não destacando os constrastes espectrais. Eis alguns prováveis:

- Lavouras "no mato": a presença de ervas daninhas entre linha de plantio, na Fase I do ciclo vegetativo da cultura, assemelhando a Ease II (dossel pleno), não caracterizando a diferença espectral nas ocasiòes de tomada da imagens. 
- Ventos: a presença de ventos no perído do imageamento pode contribuir para alterar o plano visual da cultura, ao deformar sua arquitetura padrão. A planta inclina-se na direçăo do rumo do vento e exibe a face dorsal da folhagem, influenciando na intensidade de energia refletida.

- Eresença de aerosóis scobre a área de cultivo: a formação de uma camada de aerosóis sôbre o alvo, derivada da mucropulverização da gota d’água pelos batentes dos aspersores, pode contribuir para alteraçós no registro dos dados. A possibilidade do fenômeno na Area de estudos ocorrer é grande por ser o sistema operacional coletivo, de demanda controlada e turno de rega de 2 horas/posição/lote a cada 2 dias, numa jornada diurna de 12 horas.

- Policultura: explora-se numa mesma safra em Eaixas do lote e na prática de regime consorciado, culturas anuais variadas, que podem dificultar a definiçăo do espectro.

A luz destes fatos assume-se que os valores médios próximos das variáveis explicam a correlação obtida.

\subsubsection{Análise estatistica dos valores temporais de reflectâncias (RBF).}

Eez-se uma análise comparativa dos valores de REELECTANCIA nas Bandas 1,2 e 3 obtidos a partir dos niveis cinza extraidos das imagens spot de 8 e 50 dias pós-germinaÇão (tabela 3). A expressão representativa da RESPOSTA DE REFLECTÂNCIA é:

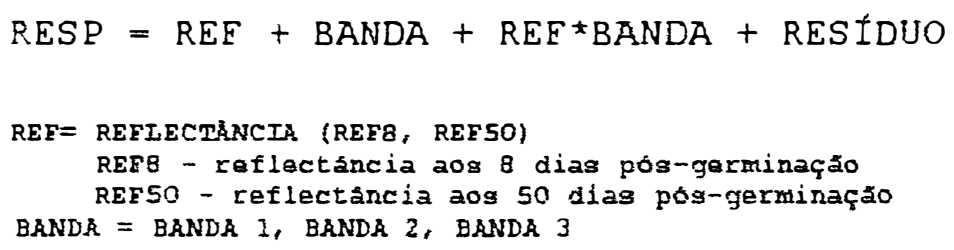


Formulaçåo de hipoteses

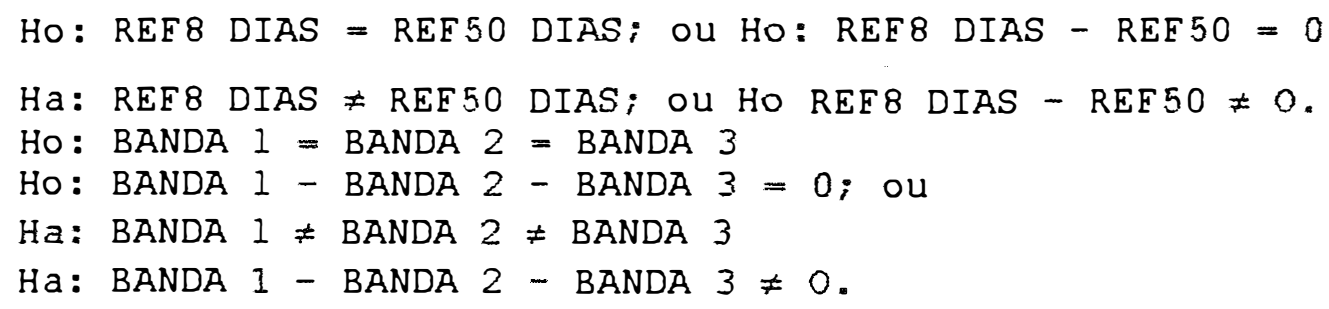

\subsubsection{Análise de variáncia - Teste "E"}

A RESPOSTA DE REELECTÂNCIA do teste "E" mostrou significativa para os niveis de probabilidade de 18 e 58 , indicando a existéncia de diferenças entre as médias dos parâmetros. A nivel de probablidade de 58 o teste "F" apresentouse altamente significativo. Em razão disso, rejeitam-se as hipóteses de nulidade (Ho) e aceitam-se as hipóteses alternativas (Ha).

\subsubsection{Teste de Tukey}

Através do Teste de Tukey identificam-se os indicadores que melhor sobressaem sobre os demais, dentro do universo analisando.

$$
\text { As variáveis (REFB, REF50) e BANDA mostraram-se }
$$
estatısticamente significativas aos niveis de probabilidade de 18 e 58. Houve alta significância no nivel de probabilidade de 58 para ambas variáveis. A interação REF*BANDA não foi significativa aos niveis submeticos (Tabela 16).

Tabela 16 - Teste "F": variável REF

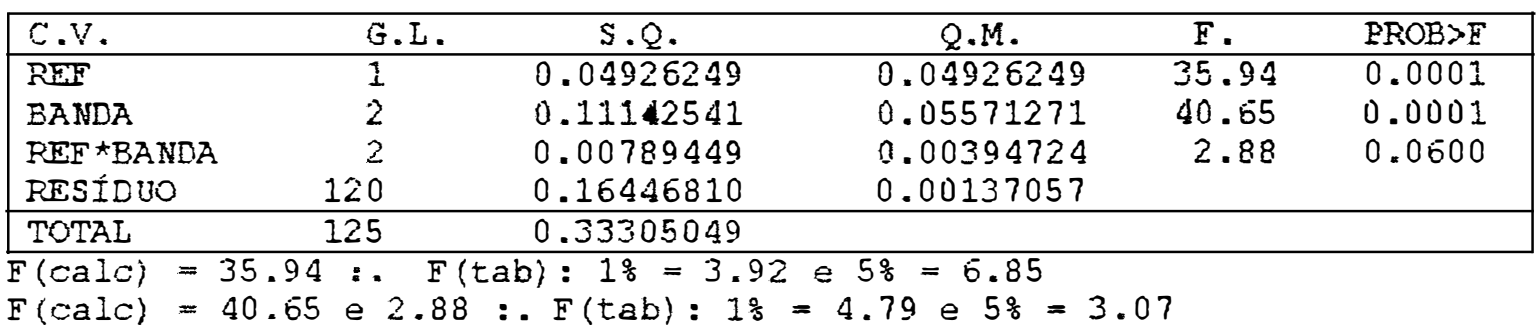


Eela Tabela 17 explicita que houve diferença significativa, ao nivel de probabilidade de 58, da REE\& em relaçăo a REF50.

Tabela 13 - Teste de Tukey: variável REE

\begin{tabular}{|lccc|}
\hline REF & $N$ & MEDIAS & $5:$ \\
\hline REF50 & 63 & 0.15390 & $A$ \\
REFB & 63 & 0.11435 & $B$ \\
\hline
\end{tabular}

A variável Banda 3 (Tabela 18) diferiu significativamente das Bandas 1 e 2 ao nivel de $5 \%$. As Bandas 1 e 2 nao mostraram diferença estatistica significativa entre si.

Tabela 18 - Teste de Tukey: variável BANDA

\begin{tabular}{|c|c|c|c|}
\hline BANDA & $\mathrm{N}$ & MEDIDAS & $5 \%$ \\
\hline BANDA 3 & 42 & 0.17475 & $\bar{A}$ \\
\hline BANDA 2 & 42 & 0.12317 & B \\
\hline BANDA 1 & 42 & 0.10440 & B \\
\hline
\end{tabular}

\subsubsection{Discussão de resultados.}

Na análise estatistica da variável temporal reflectância (REE) nas Bandas 1, 2 e 3, os valores registrados na Fase I do ciclo vegetativo da cultura foram superiores aos da Fase I, confirmando os resultados do item 4.2.1. A cultura em sua fase vegetativa plena propiciou melhores respostas espectrais. Esses resultados, entretanto, não se apresentaram expressivos de uma Ease para outra.

A Banda 3 destacou-se das demais. 


\subsubsection{Análise estatistica dos valores temporais de reflectancia (RAD).}

Analisou comparativamente a REELECTÂNCIA nas Bandas 1,2 e 3 dos dados radiométricos coletados em campo nos dias 8,50 e 85 pós-germinação (RAD8, RAD50 e RAD85 (Tabela 4). A expressão representativa da RESPOSTA de REFLECTÄNCIA é:

RESP $=$ RAD8 + BANDA $=$ RAD BANDA + RESIDUO

Formulação de hipóteses

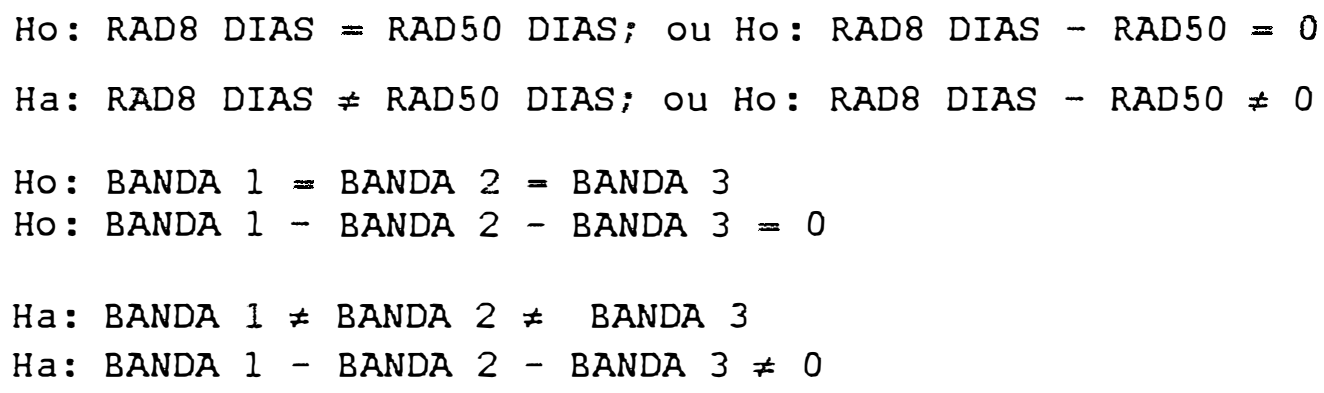

\subsubsection{Análise de variância - Teste "F"}

Pelo teste "F" a RESPOSTA DE REFLECTÂNCIA (Bandas 1, 2 e 3), mostrou significativa para os niveis de probabilidade 18 e 58, indicando a existência de diferenças entre as médias dos parâmetros. A nivel de probabilidade de 58 o teste "E" mostrouse altamente significativo. Em razão disso, rejeita-se as hipóteses de nulidade (Ho) e aceita-se as hipóteses alternativas (Ha).

\subsubsection{Teste de Tukey para as médias das interações}

\footnotetext{
Atraves do Teste Tukey de identificam-se os indicadores que melhor se sobressaem sobre os demais, dentro do universo analisado.
} 
As variáveis de REFLETÄNCIA (RAD8, RAD50 e RAD85), BANDA (BANDA 1, 2 e 3) e a interaçăo (RAD*BANDA) mostraram-se estatisticamente significativas aos niveis de 18 e 58 de probabilidade. Houve alta significancia para todas as variáveis objeto da análise ao nivel de probabilidade de 58 . A interaçáo RAD*BANDẢ nåo foi significativa aos niveis submetidos (Tabela 19).

Tabela 19 - Teste de Tukey para as médias das interaçóes

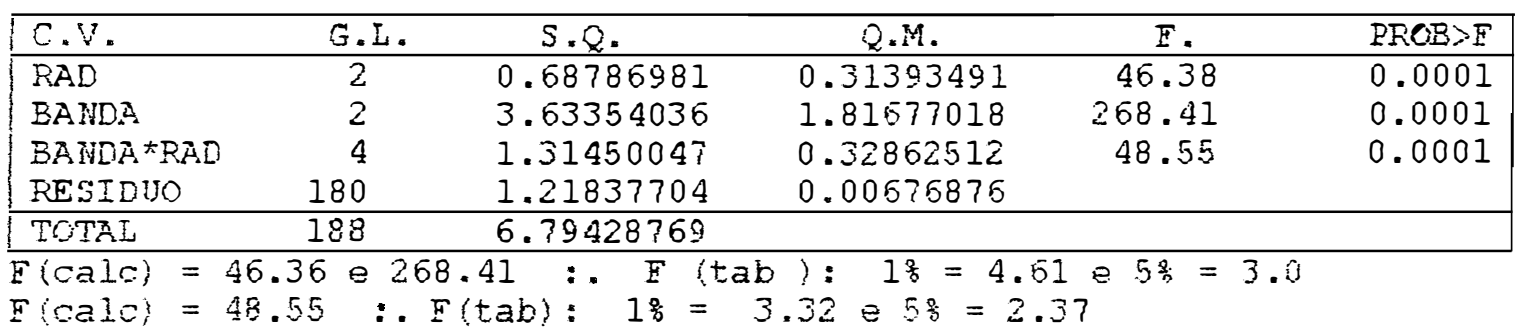

Pela Tabela 20 a RAD5 diferiu significativamente ao nivel de 58 de probabilidade de RADB e RA85. Estas, RADB E RAD85 nao mostraram diferencas signıficativas estatisticamente no nivel de 58 de probabilidade.

Tabela 20 - Teste de Tukey: variável RAD

\begin{tabular}{|llll|}
\hline RAD & $N$ & MEDIDAS & $5 \frac{5}{8}$ \\
\hline RAD50 & 63 & 0.2191 & A \\
RAD85 & 63 & 0.1153 & $B$ \\
RAD8 & 63 & 0.0884 & $B$ \\
\hline
\end{tabular}

As variáveis BANDAS $(1,2$ e 3) diferiram estatisticamente entre si, ao nivel 5 o de probabilidade (Tabela 21).

Tabela 21 - Teste de Tukey: variável BANDAS

\begin{tabular}{|llll|}
\hline BANDA & N & MEDIDAS & 58 \\
\hline BANDA 3 & 63 & 0.3340 & A \\
BANDA 1 & 63 & 0.0643 & B \\
BANDA 2 & 63 & 0.0204 & $\mathrm{C}$ \\
\hline
\end{tabular}




\subsubsection{Discussâo de resultados.}

- resultado estatistico da análise da variável reflectância (RAD) nas Bandas 1, 2 e 3, nas 3 fases vegetativas da cultura (8, 50 e 85 dias PG) apresentou a melhor correlação entre os dados (r: 0,9059). As respostas de reflectancias das leituras feitas nas fases I e III, năo mostraram estatisticamente diferenças significativas entre si, mas diferiram das leituras registradas nas Ease II.

A razăo da similaridade verificada nas fases extremas (Eases I e II), pode ser atribuida d baixa porcentagem da cobertura vegetal presente nestes periodos na lavoura, resultando numa resposta espctral similar estatısticamente.

$\mathrm{Na}$ Fase I do ciclo vegetativo da cultura, os espaços entre fileiras de plantio encontravam-se cobertos por vegetaçăo seca (restos de lavoura da safra anterior, ervas daninhas em estágio de macegas, em razão de tratos culturais executados), solo descoberto, etc., cujos espectros assemelham-se com 0 estágio da Fase III (final do ciclo da cultura). Nesta fase a lavoura encontra-se com as folhas amarelecidas, secas, desfolhadas, com as faixas entre fileiras tomadas por ervas daninhas e/ou com solo exposto nos locais que fá havia sido realizada a colheita e/ou coberto com restos da cultura.

Esse quadro assemelha-se com o da Fase I, podendo contribuir para o mascaramento das informaçoes.

\subsection{Avaliaçao gráfica das curvas dos valores de reflectan- cia temporal (REF e RAD).}

Traçou-se a curva de reflecância de cada lote, plotando os valores de RAD e REF dos períodos de 8 e 50 dias pósgerminaçăo. As curvas eståo representadas em gráficos (Figuras 13 e 14; e de IA a 10, no APENDICE 1). Trabalhou-se com dados médios do universo amostral de cada lote (Tabela 22). 
Tabela 22 - Dados médios de reflectância (REF, RAD)

\begin{tabular}{|c|c|c|c|c|c|}
\hline \multirow{3}{*}{ LOTES } & \multirow{3}{*}{ BANDAS } & \multicolumn{4}{|c|}{ DIAS POS-GERMINACQX゙O } \\
\hline & & \multicolumn{2}{|c|}{8 DIAS } & \multicolumn{2}{|c|}{50 DIAS } \\
\hline & & RAD * & REF * & RAD * & REF \\
\hline 1 & 1 & 0.0630 & 0.09333 & 0.10050 & 0.11940 \\
\hline 1 & 2 & 0.0324 & 0.09280 & 0.02060 & 0.12600 \\
\hline 1 & 3 & 0.2229 & 0.13180 & 0.79480 & 0.20410 \\
\hline 2 & 1 & 0.00020 & 0.09680 & 0.08830 & 0.11940 \\
\hline 2 & 2 & 0.00000 & 0.08316 & 0.01240 & 0.14380 \\
\hline 2 & 3 & 0.00156 & 0.13970 & 0.83430 & 0.20850 \\
\hline 3 & 1 & 0.06280 & 0.09713 & 0.05570 & 0.11350 \\
\hline 3 & 2 & 0.03103 & 0.11540 & 0.00720 & 0.11860 \\
\hline 3 & 3 & 0.12720 & 0.13740 & 0.57420 & 0.19040 \\
\hline$q$ & 1 & 0.00001 & 0.09300 & 0.06960 & 0.12010 \\
\hline 4 & 2 & 0.00000 & 0.10740 & 0.00000 & 0.13500 \\
\hline 4 & 3 & 0.00140 & 0.13170 & 0.47330 & 0.21440 \\
\hline 5 & 1 & 0.06280 & 0.09860 & 0.05790 & 0.11350 \\
\hline 5 & 2 & 0.03450 & 0.10310 & 0.02440 & 0.12580 \\
\hline 5 & 3 & 0.21580 & 0.18920 & 0.54300 & 0.19250 \\
\hline 5 & 1 & 0.10023 & 0.06670 & 0.05380 & 0.11480 \\
\hline 6 & 2 & 0.04820 & 0.08340 & 0.00520 & 0.12070 \\
\hline 5 & 3 & 0.31050 & 0.13590 & 0.52170 & 0.20210 \\
\hline 7 & 1 & 0.09980 & 0.11680 & 0.06240 & 0.11000 \\
\hline ? & 2 & 0.04660 & 0.13550 & 0.00410 & 0.11570 \\
\hline 7 & 3 & 0.21780 & 0.14680 & 0.29740 & 0.21570 \\
\hline
\end{tabular}

(*) Dados de cinza em porcentagem. 


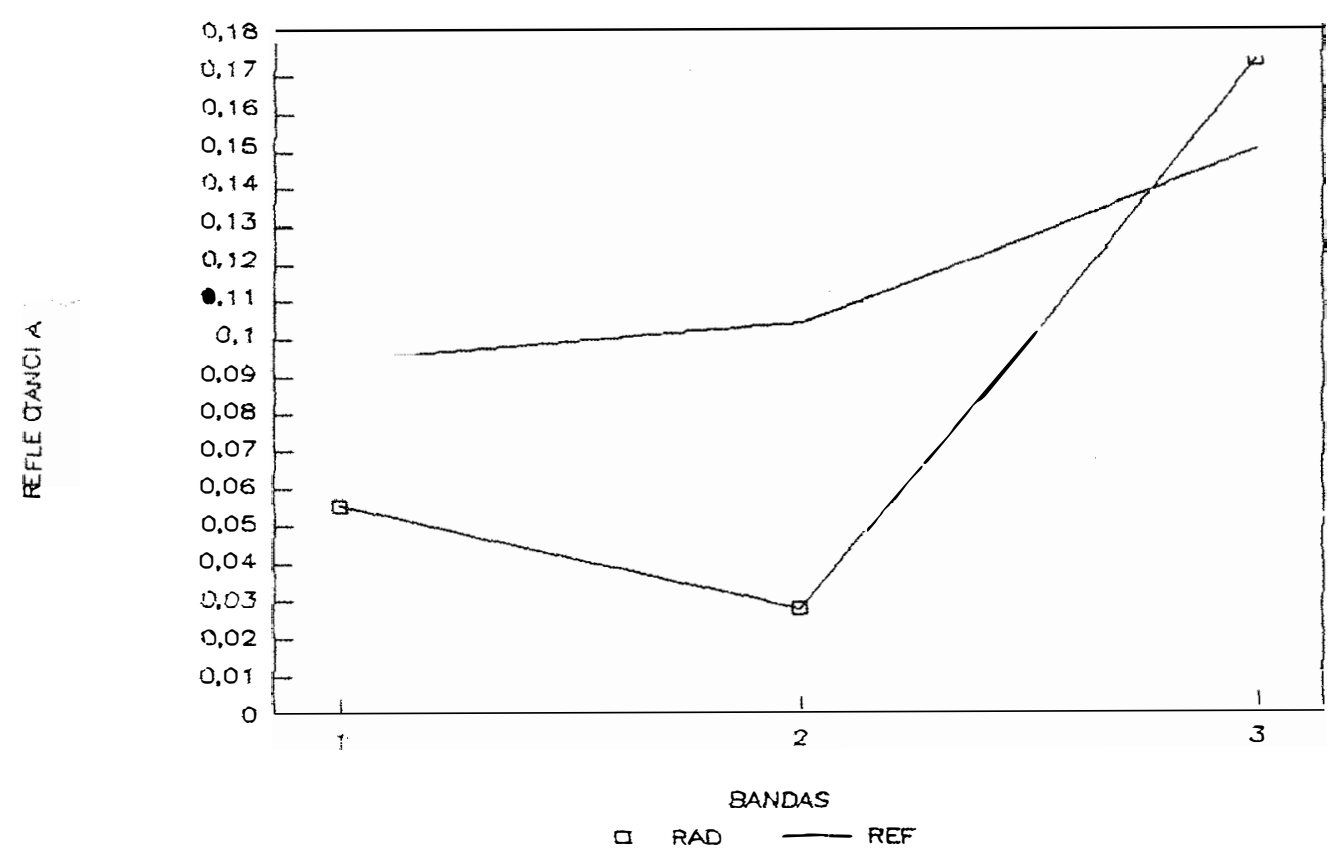

Figura 13 - Curvas da reflectāncias médias dos 7 lotes ( 8 dias PG)

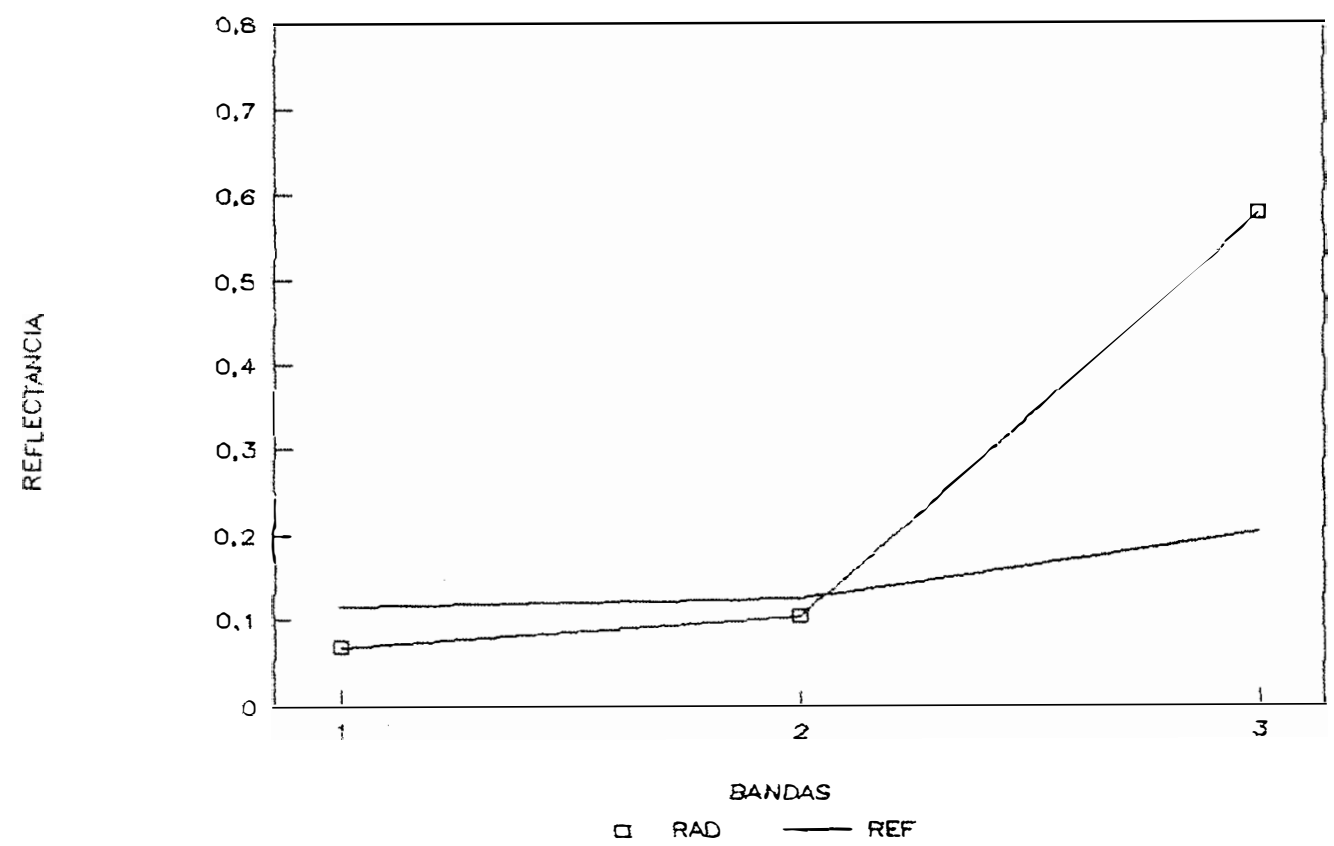

Figura 14 - Curvas da reflectāncias médias dos 7 lotes ( 50 dias $P G)$ 


\subsubsection{Discussão de resultados.}

As curvas gráficas referentes aos valores de reflectâncias temporais (REF e RAD), das Fases I e II do ciclo da cultura, nas Bandas 1, 2 e 3, representadas em gráficos, apresentaram as seguintes características básicas:

- O comportamento das curvas mostrou-se uniforme, dentro de uma proporcionalidade de uma Fase para outra.

- As diferenças significativas indicadas nas análises estatísticas são confirmadas.

\section{Comportamento das curyas de reflectâncias da Fase I}

Os valores médios de reflectâncias (RAD) foram superiores aos valores de reflectancias (REF) em todos os lotes estudados, conforme representado na Eigura 13.

Dentro da Eaixa de dominio da Banda 3 (APENDICE 1), as curvas de reflectâncias dos valores de radiometria foram superiores às curvas de reflectância dos valores de cinza dos lotes I, III, V, VI e VII (Figuras lA, IE, II, $1 \mathrm{~L}$ e IN). Nos lote II e IV (Figuras IC e IG) as curvas de reflectancias dos valores de radiometria foram inferiores às curvas de reflectâncias dos valores de cinza.

Essa inversão de valores pode ser atribuida à baixa resposta espectral ocorrida em razão da presença de cinzas e restos de culturas secas no lote. Para Eacilitar o preparo do terreno com vistas à safra seguinte, os restos de cultura da safra anterior foram submetidos a uma "chamuscada", cuja operaçåo mecanizada (gradagem) seguinte não incorporou a contento os subprodutos da ação praticada (detritos vegetativos restantes e as cinzas).

A influencia desta situação no espectro de reflectància ficou bem caracterizado nas curvas. 


\section{Comportamento das curvas de reflectâncias da Fase II}

Na Ease II, também analisando na Banda 3, a variável curva de reflectância dos valores de radiometria (RAD) destacouse mais que as curva de reflectância dos valores cinza (REF). A Figura 14, representando todos os valores dos lotes analisados, sintetiza essa afirmação.

As diferenças temporais das curvas de reflectânncias (RAD) foram mais elásticas entre si que as curvas de reflectâncias (REF) nas mesmas condições (APÊNDICE 1). 0 acréscimo observado da Fase I para a Fase II, em razão do incremento do dossel, não foi tåo expressivo.

os efeitos do estado da superficie do solo nesta Fase não foram registrados pelos dados de reflectância (RAD) face à evoluçăo da cobertura vegetal da cultura sôbre praticamente todo o terreno.

\subsection{Avaliação gráfica das curvas dos valores de reflectância em função de dados fitotécnicos.}

A avaliação da influência dos dados fitotécnicos na resposta espectral da cultura, foi feita através de gráficos (curvas de reflectâncias) e de regressão linear.

a) Gráficos - trabaihou-se com as variáveis porcentagem de cobertura vegetal (COVo) e indice de área foliar (IAF REE) alusivas aos periodos de 8 e 50 dias pos-germinação. Adotouse as informaçðes da Banda 3 em razåo de responder melhor ao espectro de culturas agricolas. os três pontos orientadores da confecçăo do gráfico, comandados pela abscissa, referem-se a dados fitotécnicos médios registrados nas 3 bases campo de cada lote.

b) Regressão linear - a análise não foi feita individualmente por lote. Trabalhou-se, de uma só vez, com todos os dados dos 7 lotes em estudo, obedecendo as fases temporais das 
informaçôes. Correlacionou-se 21 dados fitotécnicos (COV\&; IAF 8 ) e 21 de reflectância (REF; RAD), em valores médios.

A variável de ângulo de inserção da folha no caule da planta não foi analisada neste contexto por apresentar os mesmos valores médios nas duas fases de ciclo vegetativo considerada. Situação similar também foi detectada no parâmetro lâmina de irrigação. Ambos assuntos estão abordados em comentários no final deste capitulo.

\subsubsection{Curvas de reflectâncias en função da cobertara vegetal.}

As variáveis COV, RAD e REE, estampadas na Tabela 23 deram suporte na confecçäo dos gráficos e das regressöes lineares. Os resultados, curvas espectrais e equaçốs matematicas, caracterizam a influência da percentagem de cobertura vegetal (COV8) na resposta espectral. As Figuras 15 e 16 representam, em cada uma das Fases analisadas, as respostas espectrais do universo de dados dos 7 lotes estudados. Individualmente as curvas espectrais de cada lote, por Fase, estǎo representadas pelas Figuras de $2 \mathrm{~A}$ a 20 (APENDICE 2). 
Tabela 23 - Dados médios temporais de cobertura vegetal (COV) e de reflectância (RAD, REE) da lavoura de feijåo

\begin{tabular}{|c|c|c|c|c|c|}
\hline$\overline{\text { LOTE }}$ & $\overline{D A T A}$ & $\overline{B A S E}$ & $\begin{array}{c}\mathrm{COV} \\
\frac{8}{6}\end{array}$ & $\begin{array}{c}\mathrm{RAD} \\
\star\end{array}$ & $\begin{array}{c}\text { REF } \\
\star\end{array}$ \\
\hline 1 & 8 & 1 & 2.79 & 0.2011 & 0.1312 \\
\hline 1 & 8 & 2 & 8.89 & 0.2665 & 0.1368 \\
\hline 1 & 8 & 3 & 11.17 & 0.2011 & 0.1275 \\
\hline 2 & 8 & 1 & 9.08 & 0.0016 & 0.1426 \\
\hline 2 & 8 & 2 & 10.38 & 0.0016 & 0.1413 \\
\hline 2 & 8 & 3 & 11.68 & 0.0015 & 0.1352 \\
\hline 3 & 8 & 1 & 4.73 & 0.2161 & 0.1411 \\
\hline 3 & 8 & 2 & 7.78 & 0.2412 & 0.1450 \\
\hline 3 & 8 & 3 & 9.16 & 0.1943 & 0.1263 \\
\hline 4 & 8 & 1 & 11.38 & 0.0012 & 0.1290 \\
\hline 4 & 8 & 2 & 11.78 & 0.0016 & 0.1352 \\
\hline 4 & 8 & 3 & 15.70 & 0.0014 & 0.1311 \\
\hline 5 & 8 & 1 & 11.78 & 0.2429 & 0.1913 \\
\hline 5 & 8 & 2 & 13.82 & 0.2087 & 0.1891 \\
\hline 5 & 8 & 3 & 18.32 & 0.1958 & 0.1794 \\
\hline 6 & 8 & 1 & 5.89 & 0.3226 & 0.1311 \\
\hline 6 & 8 & 2 & 6.62 & 0.3111 & 0.1504 \\
\hline 6 & 8 & 3 & 18.32 & 0.2978 & 0.1263 \\
\hline 7 & 8 & 1 & 24.09 & 0.0292 & 0.1558 \\
\hline 7 & 8 & 2 & 26.77 & 0.3367 & 0.1384 \\
\hline 7 & 8 & 3 & 36.44 & 0.2877 & 0.1463 \\
\hline 1 & 50 & 1 & 37.56 & 0.7427 & 0.2118 \\
\hline 1 & 50 & 2 & 65.73 & 0.9138 & 0.2125 \\
\hline 1 & 50 & 3 & 84.51 & 0.7281 & 0.2014 \\
\hline 2 & 50 & 1 & 68.72 & 0.9011 & 0.2212 \\
\hline 2 & 50 & 2 & 78.54 & 0.8610 & 0.2054 \\
\hline 2 & 50 & 3 & 88.35 & 0.7410 & 0.1857 \\
\hline 3 & 50 & 1 & 57.26 & 0.4983 & 0.1538 \\
\hline 3 & 50 & 2 & 79.00 & 0.6395 & 0.2140 \\
\hline 3 & 50 & 3 & 88.88 & 0.5850 & 0.2035 \\
\hline 4 & 50 & 1 & 73.63 & 0.4270 & 0.2034 \\
\hline 4 & 50 & 2 & 73.63 & 0.4977 & 0.2229 \\
\hline 4 & 50 & 3 & 98.17 & 0.4952 & 0.2170 \\
\hline 5 & 50 & 1 & 73.63 & 0.6145 & 0.2119 \\
\hline 5 & 50 & 2 & 92.77 & 0.4601 & 0.1787 \\
\hline 5 & 50 & 3 & 98.34 & 0.5545 & 0.1869 \\
\hline 6 & 50 & 1 & 65.45 & 0.5273 & 0.2043 \\
\hline 6 & 50 & 2 & 73.63 & 0.5293 & 0.2141 \\
\hline 6 & 50 & 3 & 92.77 & 0.5085 & 0.1881 \\
\hline$?$ & 50 & 1 & 89.99 & 0.0410 & 0.1985 \\
\hline 7 & 50 & 2 & 89.99 & 0.3553 & 0.2145 \\
\hline 7 & 50 & 3 & 80.99 & 0.4960 & 0.2341 \\
\hline
\end{tabular}




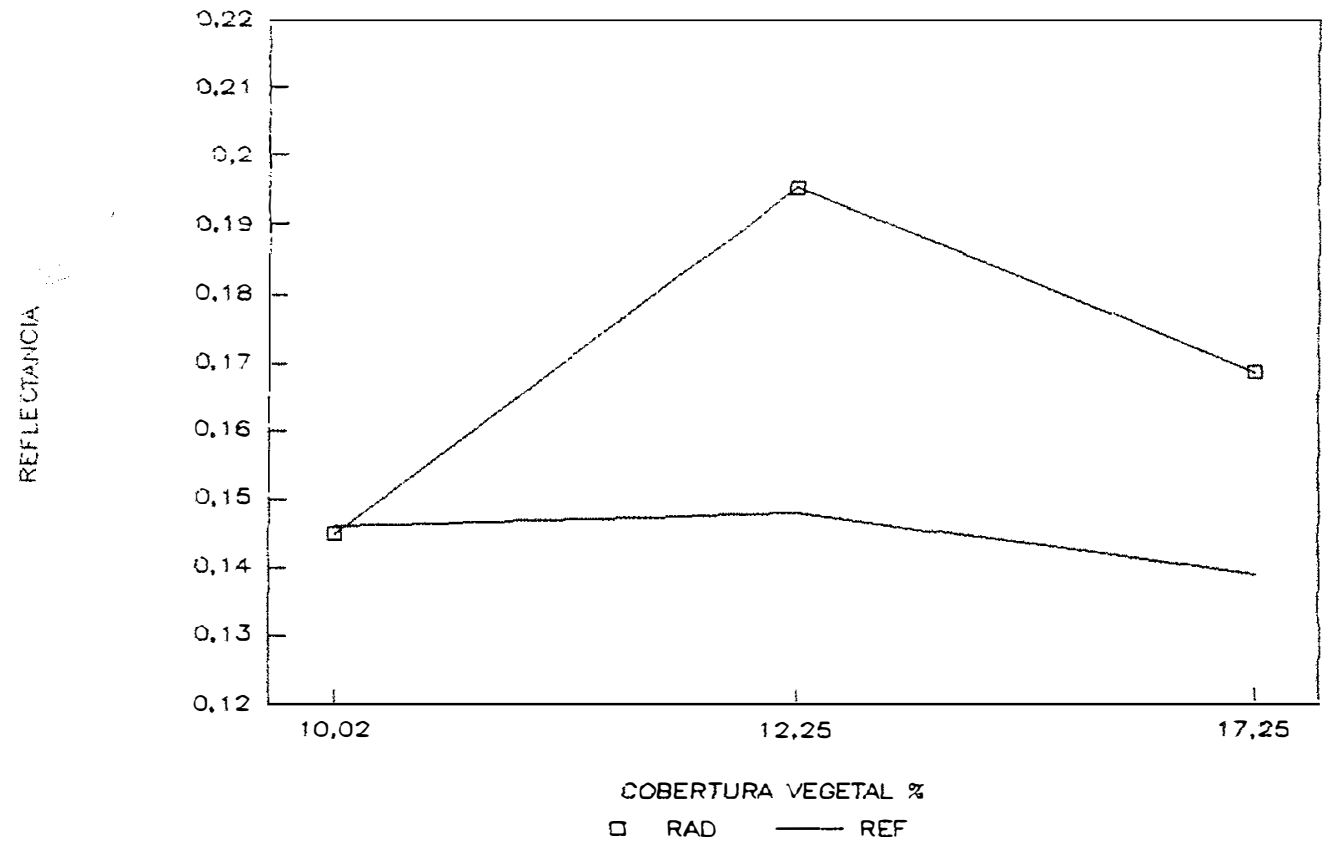

Figura 15 - Curvas médias de reflectāncias em função da cober tura vegetal ( 8 dias PG)

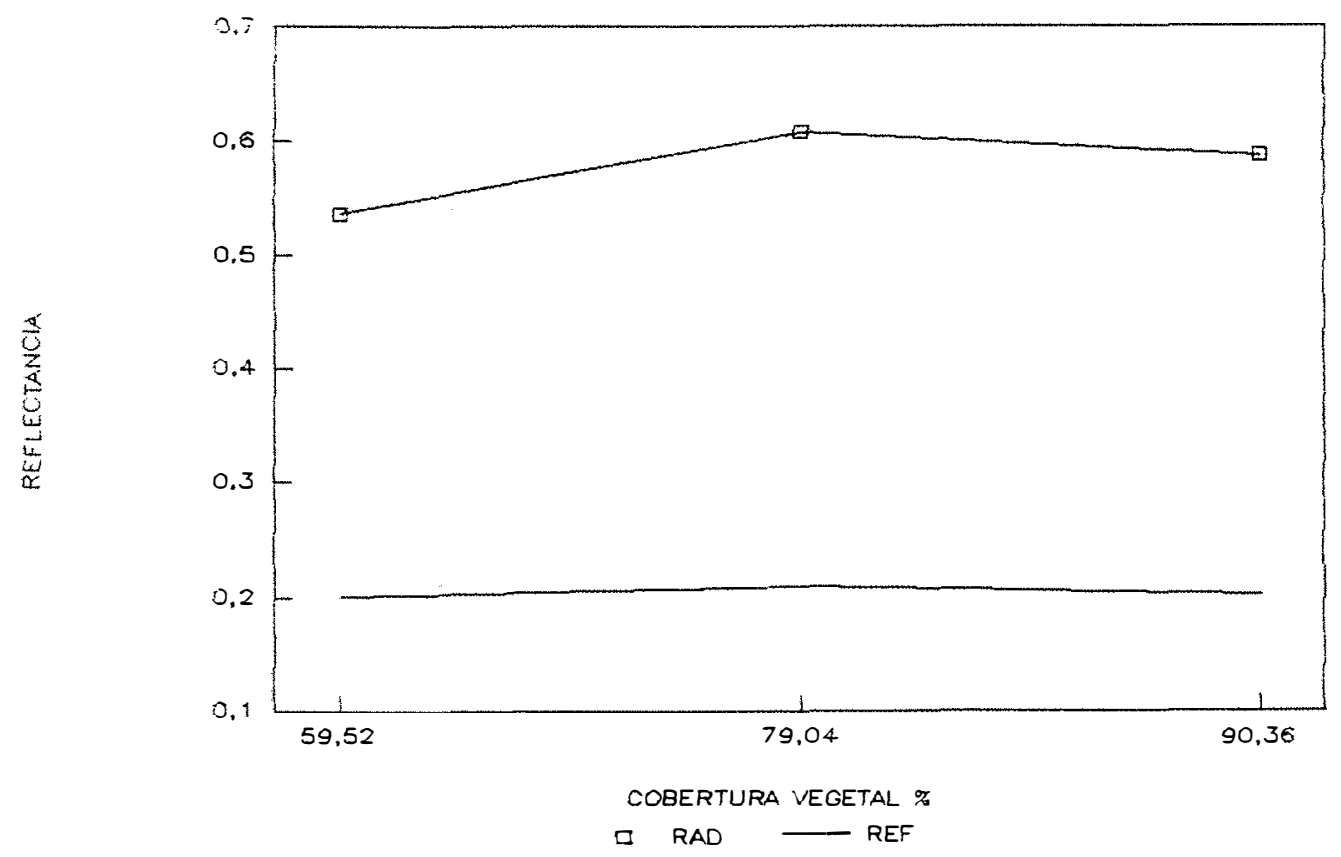

Figura 16 - Curvas médias de reflectāncias em função da cober tura vegetal ( 50 dias PG) 


\subsubsection{Discussão de resultados.}

a) Gráficos - as curvas de reflectáncias geradas referem-se aos dados da faixa de comprimentos de onda da Banda 3 .

$\mathrm{Na}$ Fase I, as curvas de reflectancia (RAD) apresentam-se superiores às curvas de reflectancia (REF) de um modo geral. A Figura 15, que corresponde a média das informaçסes de todos os 7 lotes observados, caracteriza bem esse comportamento. orientando-se pelo APENDICE 2: as Figuras $2 \mathrm{~A}, 2 \mathrm{E}$, $2 I, 2 L$ e $2 \mathrm{~N}$ (lotes I, III, V, VI e VII), também seguem a mesma postura da Figura 13; nas Figuras $2 \mathrm{C}$ e $2 \mathrm{G}$ (lotes II e IV) as curvas de reflectancias (RAD) foram menores que as de reflectancias (REF), chegando em alguns casos a anularem-se em razåo do fenômeno já comentado em 4.3.1.

Em relaça às curvas de reflectancia representativas da Fase II, observou-se:

- A curva de reflectancia (RAD) acusou com destaque $a$ influencia da cobertura vegetal na resposta do espectro. A Figura 16, que representa a resposta média dos 7 lotes estudados, evidencia bem o fato. Também em todos os casos, quando os lotes foram analisados separadamente, mostrou-se bem superior em relaçåo às curvas de reflectância (REF). Estas tiveram acréscimo de ganhos sobre a similar da Fase I, porém sem a dimensão, em termos proporcionais, verificados nas curvas de reflectancias (RAD) de uma fase para outra (Figuras 2B, 2D, $2 \mathrm{~F}$, $2 J$ e $2 M-A P E N D I C E$ 2).

- Na curva de reflectancia (RAD) da Figura 20 (lote VII - APENDICE 2) verifica-se numa base de trabalho, em comparaça entre fases, que embora o percentual de cobertura vegetal seja alto, a resposta espectral é baixa. Atribui-se o fato à deficiéncia, de tratos fitossanitários na parcela agricola, permitindo o dominio de doenças na lavoura, alterando o visual normal da cultura (folha amareladas, necrosadas, etc). 


\section{b) Regressão linear}

Tabela 24 - Resultado da correlação de dados fitotécnicos e de reflectância

\begin{tabular}{|r|c|c|}
\hline VARIAVEL \& & COEF .CORRELACAO & EQUACCAO \\
\hline COV $\times$ (RAD) $8 \mathrm{~d}$ & 0.30 & $\mathrm{Y}=0.1499 \mathrm{X}+0.001488$ \\
\hline COV $\times$ (REF) 8d & 0.41 & $\mathrm{Y}=0.13804 \mathrm{X}+0.00041$ \\
\hline COV $\times$ (RAD) 50d & 0.50 & $\mathrm{Y}=962537 \mathrm{~d}-0.00490$ \\
\hline COV $\times$ (REF) 50d & 0.29 & $\mathrm{Y}=0.211799-0.00009$ \\
\hline
\end{tabular}

cov - cobertura vegetal; Rad/REE - reflectancias 8d/50d - perlodog pog-germinaça.

Os resultados indicam que a variável porcentagem de cobertura vegetal (COV (RAD) mais que as respostas de reflectâncias (REF), nas duas Eases temporais consideradas. Observa-se também, que não houve uma simetria contributiva de dados, não obtendo por isso, ajustes desejados para as curvas, expressa pelas equaçoes da reta.

\subsubsection{Curvas de reflectancias em funçăo do indice de área foliar.}

Os dados da Tabela 25 são as variáveis IÄE, RÄD e REE, em valores médios, em que baseou-se os gráficos de reflectâncias analisados e as regressões lineares. A reflectância média, nas duas Eases estudadas, estão representadas pelas Figuras 17 e 18. As observações individuais de cada lote estão no AEENDICE 3, representadas pelas Eiguras $3 \pi$ a 30. 
Tabela 25 - Dados temporais médios de indice de área foliar (IAE) e reflectância (RAD, REE) da lavoura de feijão.

\begin{tabular}{|c|c|c|c|c|c|}
\hline LOTE & $\begin{array}{c}\text { DATA } \\
\text { dia }\end{array}$ & BASE & $\begin{array}{l}I A F F \\
(B))\end{array}$ & $\underset{\star}{\mathrm{RAD}}$ & $\underset{\star}{R E F}$ \\
\hline 1 & 8 & 1 & 0.1328 & 0.2011 & 0.1312 \\
\hline 1 & 8 & 2 & 0.1561 & 0.2011 & \\
\hline 1 & 8 & 3 & 0.1597 & 0.2565 & 0.1368 \\
\hline 2 & 8 & 1 & 0.0902 & 0.0016 & 0.1426 \\
\hline 2 & 8 & 2 & 0.1017 & 0.0016 & 0.1413 \\
\hline 2 & 8 & 3 & 0.1258 & 0.0015 & 0.1352 \\
\hline 3 & 8 & 1 & 0.1225 & 0.1943 & 0.1263 \\
\hline 3 & 8 & 2 & 0.1322 & 0.2412 & 0.1450 \\
\hline 3 & 8 & 3 & 0.1402 & 0.2161 & 01411 \\
\hline$q$ & 8 & 1 & 0.2492 & 0.0014 & 0.1311 \\
\hline 4 & 8 & 2 & 0.2754 & 0.0016 & 0.1352 \\
\hline 4 & 8 & 3 & 0.3199 & 0.0012 & 0.1290 \\
\hline 5 & 8 & 1 & 0.0866 & 0.2429 & 0.1913 \\
\hline 5 & 8 & 2 & 0.1125 & 0.1958 & 0.1794 \\
\hline 5 & 8 & 3 & 0.1140 & 0.2087 & 0.1891 \\
\hline 6 & 8 & 1 & 0.1598 & 0.3226 & 0.1113 \\
\hline 6 & 8 & 2 & 0.2550 & 0.3111 & 0.1504 \\
\hline 6 & 8 & 3 & 0.2534 & 0.2978 & 0.1263 \\
\hline 7 & 8 & 1 & 0.1458 & 0.3367 & 0.1384 \\
\hline 7 & 8 & 2 & 0.1969 & 0.0292 & 0.1558 \\
\hline 7 & 8 & 3 & 0.2133 & 0.2377 & 0.1463 \\
\hline 1 & 50 & 1 & 5.4090 & 0.7281 & 0.2014 \\
\hline 1 & 50 & 2 & 5.7572 & 0.7427 & 0.2118 \\
\hline 1 & 50 & 3 & 6.1128 & 0.9138 & 0.2125 \\
\hline 2 & 50 & 1 & 0.0021 & 0.8610 & 0.2054 \\
\hline 2 & 50 & 2 & 0.1142 & 0.9011 & 0.2212 \\
\hline 2 & 50 & 3 & 1.6942 & 0.7410 & 0.1857 \\
\hline 3 & 50 & 1 & 1.91 & 0.6395 & 0.2140 \\
\hline 3 & 50 & 2 & 2.4801 & 0.5850 & 0.2035 \\
\hline 3 & 50 & 3 & 2.5012 & 0.4983 & 0.1538 \\
\hline 4 & 50 & 1 & 7.5 & 0.4270 & 0.2034 \\
\hline 4 & 50 & 2 & 8.0649 & 0.4952 & 0.2170 \\
\hline 4 & 50 & 3 & 3.0607 & 0.4977 & 0.2 \\
\hline 5 & 50 & 1 & 3.2575 & 0.4601 & 0.1787 \\
\hline 5 & 50 & 2 & 3.8326 & 0.5545 & 0.1869 \\
\hline 5 & 50 & 3 & 4.42 & 0.5085 & 0.1881 \\
\hline 6 & 50 & 1 & 4.6927 & 0.5273 & 0.2043 \\
\hline 6 & 50 & 2 & 4.7376 & 0.5293 & 0.2141 \\
\hline 6 & 50 & 3 & 7.1748 & 0.3553 & 0.2145 \\
\hline 7 & 50 & 1 & 7.1748 & 0.3553 & 0.2145 \\
\hline 7 & 50 & 2 & 7.1748 & 0.3553 & 0.2145 \\
\hline 7 & 50 & 3 & 8.2457 & 0.4960 & 0.2341 \\
\hline
\end{tabular}




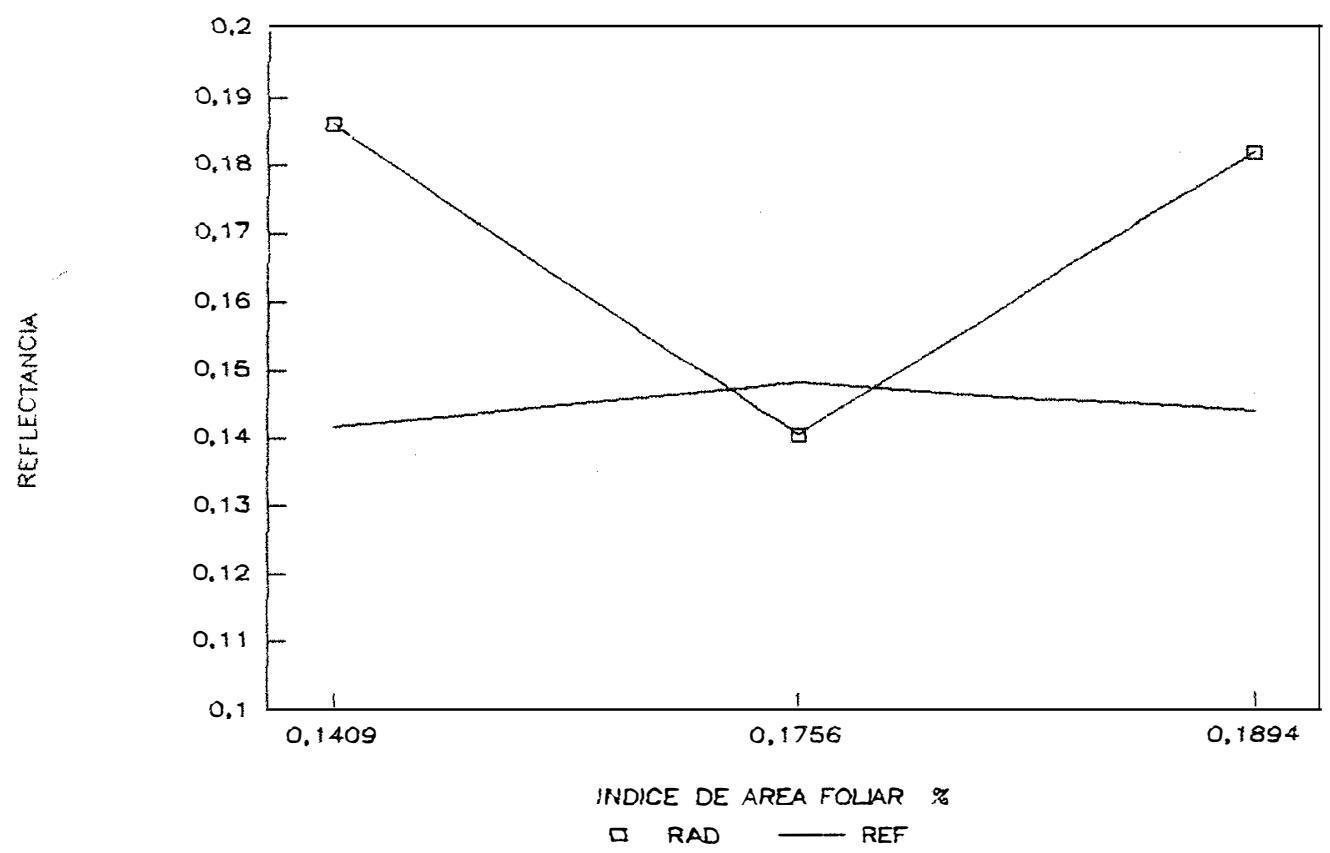

Figura 17 - Curvas médias de reflectâncias dos 7 lotes em função do indice de área foliar (8dias PG)

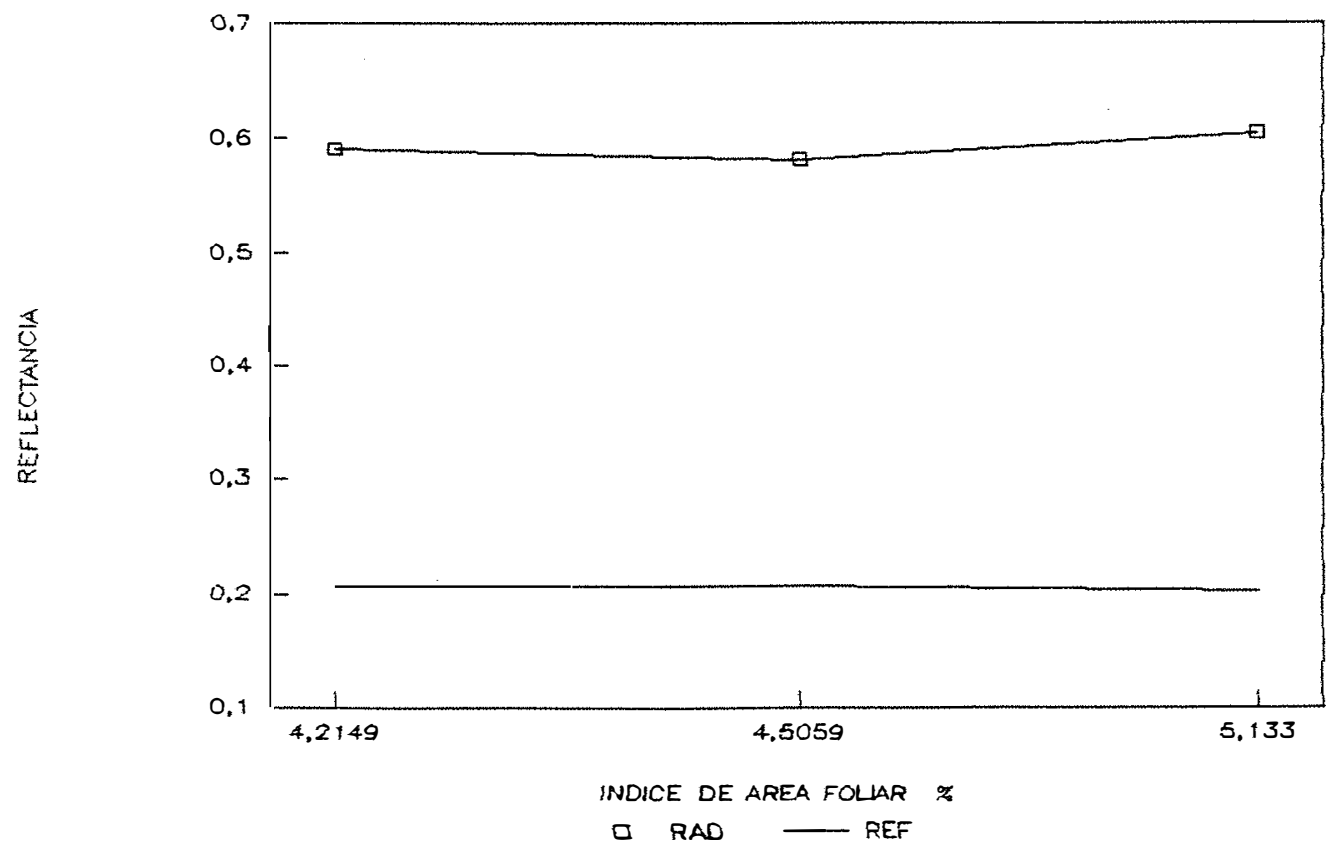

Figura 18 - Curvas médias de reflectâncias dos 7 lotes em função do indice de área foliar (50 dias PG) 


\subsubsection{Discussáo de resultados}

a) Gráficos - Seguindo o raciocínio anterior, as curvas de reflectancias referem-se aos dados de faixa de domínio da Banda 3, por razōes já explicitadas neste capitulo.

\section{Comportamento das curvas de reflectancias na Eases I}

A resposta espectral média dos dados dos 7 lotes estudados, mostrou-se mais expressiva na reflectancia (RAD) que na reflectância REF, expressa na Figura 17. A reflectância (REF), pouco influenciada pela covs teve um comportamento espectral uni forme.

Orientando-se pelo APENDICE 3: i) Os lotes I, II, $V$ e VI (Figuras 3A, 3G, $3 I$ e 3L) apresentaram curvas de reflectancias dos valores de leituras radiômetricas (RAD) bem superiores às curvas de reflectancias obtidas a partir dos valores de níveis dos valores de cinza (REF); ii) As respostas espectrais aos indices de área foliar, dentro da variável especifica, foram em média homogêneas; iii) Nos lotes II e IV (Figuras $3 \mathrm{C}$ e $3 G$ ) as curvas de reflectancias (RAD) foram inferiores às curvas de reflectancias (REF), em razăo da supremacia da tonalidade dos restos de cultura "chamuscada" no lote, já comentado anteriormente. As curvas de reflectancias não mostraram sensiveis ao fato. Mantiveram a performance de homogeneidade; iv) A curva de reflectancia (RAD) apresentou alterada, com desvio em relaçăo ao seu comportamento normal observado nesta fase no lote VII (Figura 3N). O fato deve-se a deficéncias de tratos culturais dispensados à cultura, cujos reflexos săo registrados também na Fase II.

\section{Comportamento das curvas de reflectância na Fase II}

A resposta espectral média da área de estudos foi mais acentuada na reflectancia (RAD) do que na reflectância $\{R E F\}$. Considerada a distensao entre os valores das duas 
variáveis (RAD, REE), as curvas apresentaram-se com uma performance mais uniforme (Figura 18).

Orientando-se pelo ANEXO - Os lotes I, II, V e VI (Eiguras 3R，3D， $3 \mathrm{~J}$ e 3M) apresentaram curvas de reflectancias (RAD) em niveis de respostas mais destacadas que as curvas de reflectâncias (REE). No lote VII esse comportamento não é seguido, conforme já caracterizado em parágrafo anterior.

b) Regressão linear

Tabela 26 - Resultado da correlaçăo de dados fitotécnicos e de reflectância

\begin{tabular}{|c|c|c|}
\hline VARIÄVEL & COEE . CORRELAC AO & EQUACCAO \\
\hline IAF $x(R A D) 8 d$ & 0.37 & $Y=0.21246 \mathrm{X}-0.25689$ \\
\hline (REF) 8d & 0.63 & $y=0.16417 \mathrm{X}-0.11775$ \\
\hline IAF $X$ (RAD) 50d & 0.74 & $Y=0.75104 \mathrm{X}$ \\
\hline (REFF) $50 \mathrm{~d}$ & 0,64 & $Y=0.191707$ \\
\hline
\end{tabular}

- comportamento da curva nos resultados espectrais da EASE I, apresentou-se mais ajustado a reflectância (REF) que na reflectância (RAF). Isso deve-se ao fato da maior sensibilidade no registro das leituras radiométricas em relaçăo as informaçōes das imagens de satélite neste estágio inicial da cultura.

Na Ease II o ajuste da curva para as duas variáveis (RAD, REE) foi mais uniforme, embora longe do nivel de correlação desejado. Houve evoluçăo da Ease I para a Ease II. A uniformidade da cultura neste estágio (Ease II), contribuiram para a redução das variaçōes dos dados.

\subsubsection{Tratos culturais.}

A razăo de ser da atividade agrícola na regiåo semi-árida, onde o presente trabalho foi desenvolvido, é a pratica de irrigaçăo. Entretanto, em razåo do padråo operacional de manejo de irrigaçăo adotado ser coletivo, o parâmetro lâmina de água para irrigaçăo, por ser constante em todas as fases da 
Iavoura, nåo permitiu controlar e/ou simular fatores de interesse da pesquisa. Como, por exemplo, alterar a dotação de água para alguns dos lotes trabalhados em níveis distintos, induzindo a planta a adaptaçoes fisiológicas características à situação submetida.

As recomendações técnicas inobservadas no início da condução da safra, execetuando 2 lotes agrícolas já mencionados, näo chegaram a comprometer expressivamente as lavouras:

- O plantio de sementes nåo certificadas e adubações abaixo da recomendada foram supridas com adubaçŏes de cobertura posteriores.

- As respostas a falta de controle fitossanitário surgiram em reboleiras na Ease vegetativa da cultura, alastrando em alguns casos no final do ciclo, quando a safra já estava garantida.

- Os lotes que receberam um razoável controle de ervas daninhas até o perfeito complemento do dossel, não tiveram necessidade da repetição da prática, a partir daí, até a colheita. A cobertura vegetal abafa o mato. Aqueles outros que assim năo procederam, sofreram uma competição acirrada até o Einal do ciclo, o que contribuiu para mascarar as respostas espectrais.

Äs Eiguras 19, 20 e 21 ilustram Eases distintas do trabalho.

A Eigura 19 mostra a imagem Spot da área onde foram executados os trabalhos de campo, na escala 1:40.000, registrada por pcasiăo da Ease II do ciclo da cultura. Sobrepondo a malha divisoria de lotes na Eigura, tèm-se um idéia do aspecto Fundiario do terreno.

$\tilde{A}$ s Eiguras 20 e 21 săo fotografias da lavoura de Eeijăo nos estágios vegetativos das Eases I e II. 


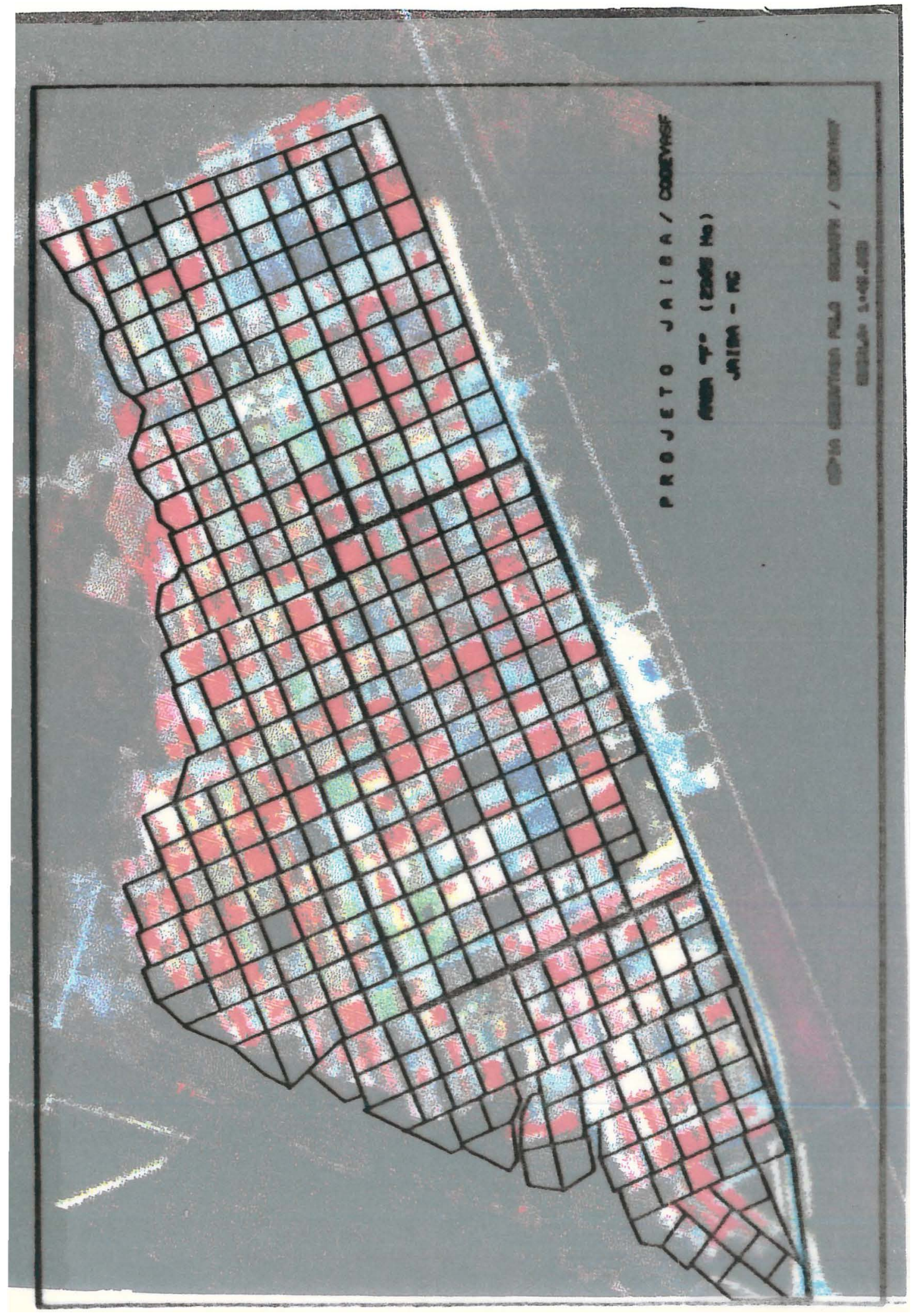

1
0
0
0

0
$\pi$
0
0
0

ก

$\frac{0}{\square}$

$\stackrel{1}{+}$

도

4 .

40

(1) 0

4.

임 움

0 न

r

(1) न्न

م 0

은

0 .

न 0

ช 10

年

(4) 0

$+4$

임 음

$\sigma \pi$

(1) 늑

10

ช

0

$+10$

مُ

E

(1). 담

으

吕

$a$

곡

है

I斤 


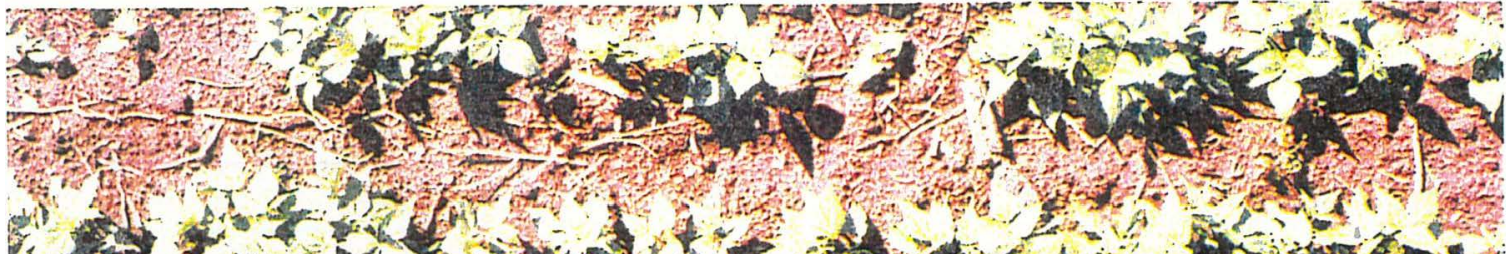

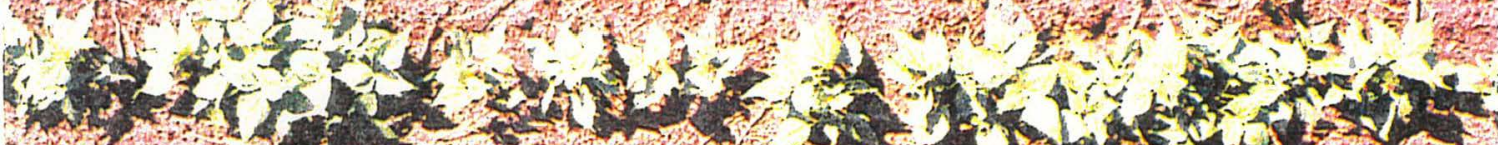

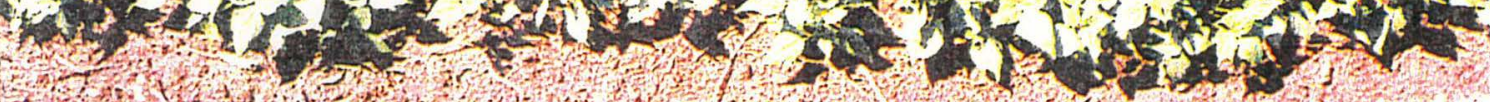

r.

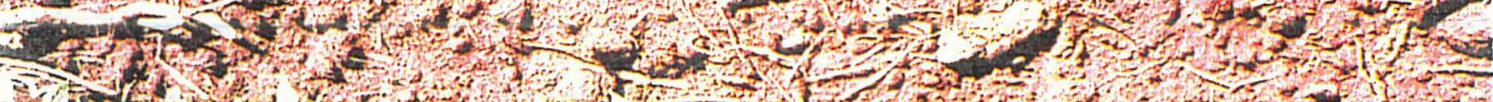

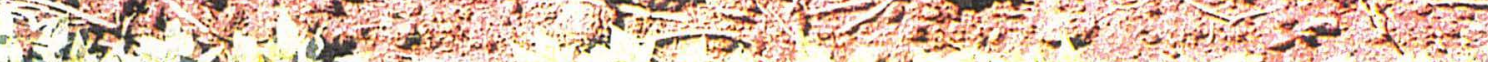

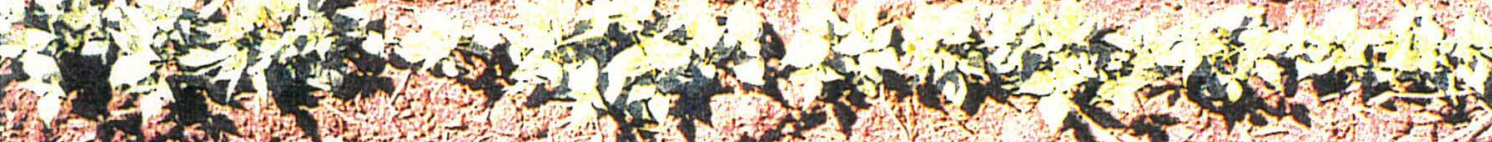

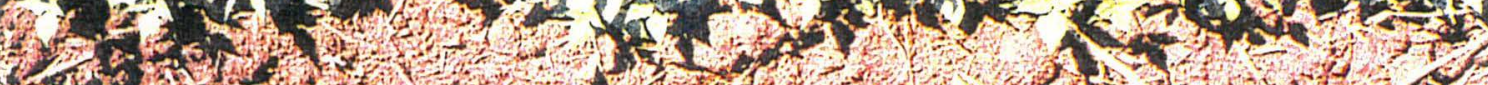

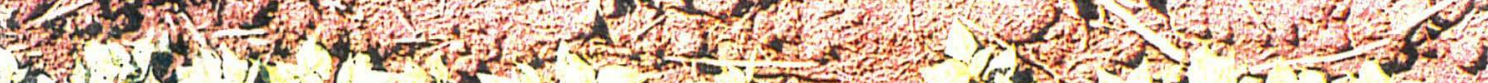

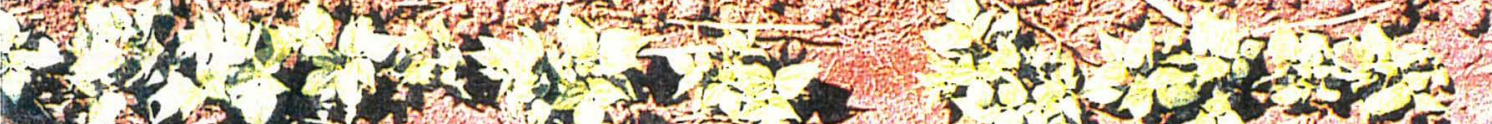

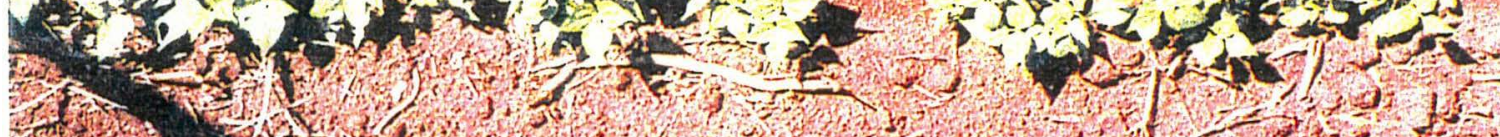
(1)

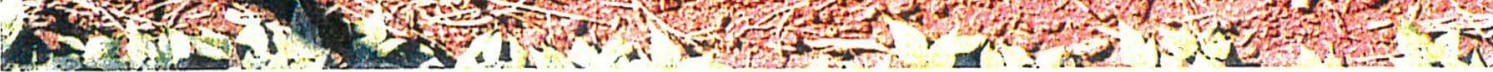

Figura 20 Cultura de feijão na Fase I $(8$ dias após a

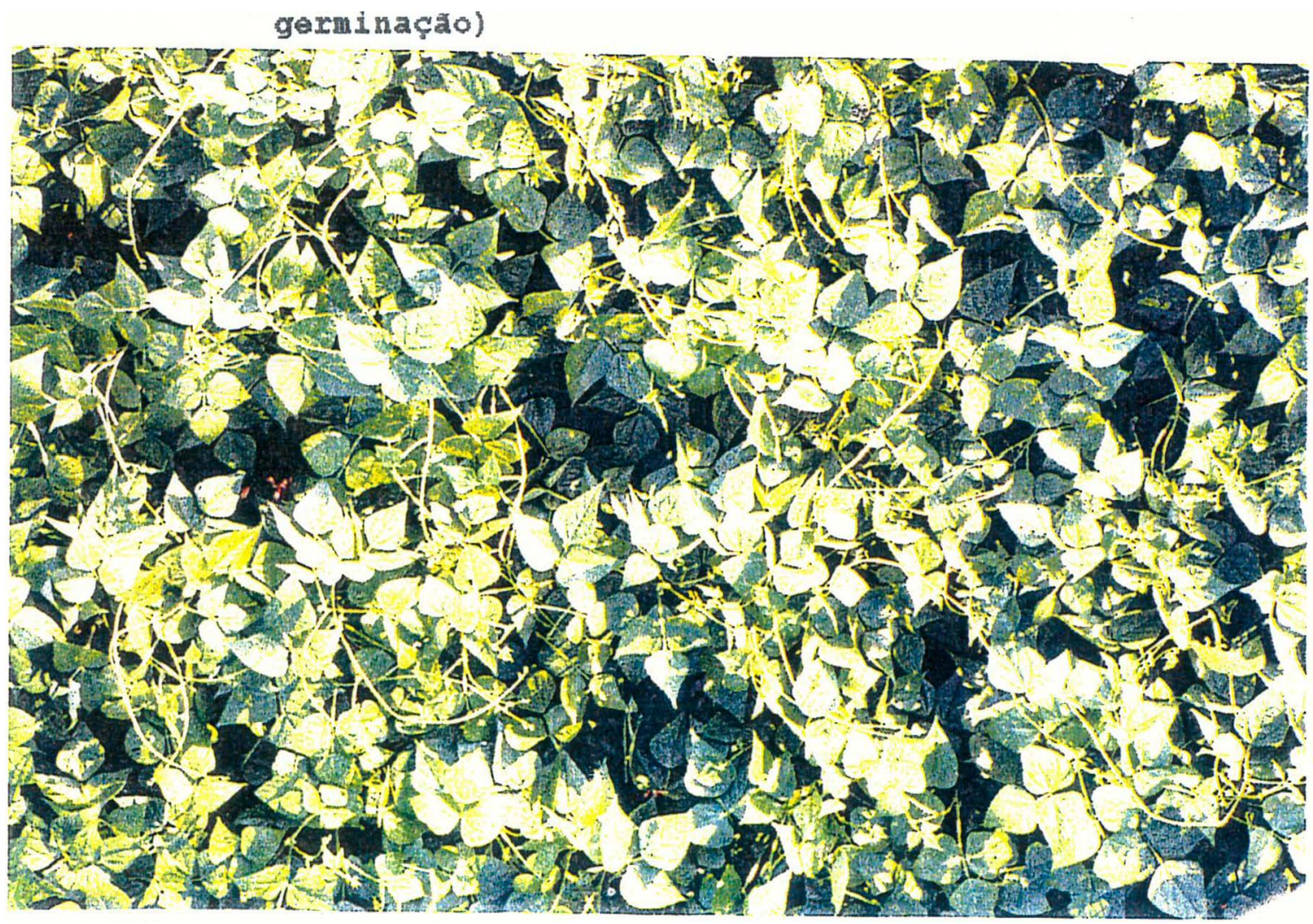

Figura 21 Cultura de feijăo na Fase II (50 dias após a germinação) . 
84.

\section{CONCLUSÕES E RECOMENDAÇÕES.}

A proposta de testar dados digitais de satélites correlacionados à radiometria de campo e fatores fitotécnicos da cultura de Eeijão, no âmbito de um campo de produção agricola, alcançou os objetivos propostos.

A peculiaridade da área de estudo, onde não se teve - controle de fatores influentes nos resultados perseguidos, contribuiu com muitos fundamentos importantes para o segmento. Confirmaram-se constatações de outros trabalhos pesquisados, 0 que dá embasamento ao desemolvimento de novos conceitos a respeito do assunto.

A Iuz desses fatos, o trabalho permite enunciar as seguintes conclusões:

- A correlação entre dados de níveis de cinzas extraidos de imagens dos satélite spot e da radiometria de campo não foi satisfatoria.

- Os dados de radiometria de campo são mais sensíveis às variaçōes dos fatores fitotécnicos que os dados obtidos a partir das imagens. 
- levamento e acompanhamento de áreas agricolas irrigadas pode ser feito com sucesso empregando sensoriamento remoto orbital.

- o cadastramento e identificação de culturas de ciclo anual exploradas em áreas agrícolas sob regime de irrigação, exig̣e serviços de apoio de campo periódico. A orientação do mercado consumidor promove rotatividade na atividade.

- o conhecimento do plano de cultivo, no caso de areas irrigadas com culturas anuais, e fundamental ao serviço de monitoramento e identificação de lavouras.

Para aprimorar a metodologia seguida neste trabaIho, recomenda-se:

- Repetir a pesquisa em pólos de irrigação durante um ano agricola, possibilitando analisar mais de um safra zogricola.

- Conduzir a pesquisa com mais de um tipo de cultura visando a observação de contrastes.

- Identificar as coordenadas geográficas de todos os pontos onde são feitas as leituras de radiometria de campo, no ato da operaçäo. A pratica visa aumentar o grau de confiabilidade quando for relacionar analiticamente dados dos pontos comuns das leituras de radiometria de campo e das informaçôes extraídas de imag̣ens de satélites.

- Controlar todos os Eatores pertinentes ao processo produtivo, nas glebas selecionadas para a pesquisa, evitando a interferência indesejada nos resultados. 
86.

- Eornecer lâminas de água diferenciadas para lotes determinados dentro do universo da pesquisa, com o objetivo de buscar parâmetro diferenciadores em situações distintas. 


\section{REFERÈNCIAS BIBLIOGRÁFICAS}

ADAMOLI; J.; FUKUHARA; M.; SILVA, J.A. Aplicaçăo de técnicas de sensoriamento remoto no estudo de queimadas de pastagens nativas da regiăo de cerrados. In: SIMPOSITO BRASILEIRO DE ¿ENGORIAMENTO REMOTO, 2., Brasilia, 1982. Anais. Brasilia, ONPQ/INPE, 1982. V.1, p. 811-20.

AL-ABBAS, A.H.; BARR, R.; HALL, J.D.; CRANE, F.L.; BAUMGARDNER, M.F.spectra of normal and and nutrient deficiente maize leaves. Agronomy Journal, Madison, 59: 16-20, 1974.

BATISTA, G.T.; CHEM, S.C.; DALLEMAND, J.F.; TARDIN, A.T. Spot data for discrimination in Southern Brasil. In: INSTITUTo DE EESQUISAS ESPACIAIS. spot-1 - First in fight results. Tolouse, National Center Space Study, 1986. E 20921.

BAUER, M. E ; VANDERBILT, V.C.; ROBISON, B.E.; DAUGHTRY, S. T. Spectral properties of agricultural crops and soils mesasured from space, aerial, field and laboratory sensors. In: INTERNATIONAL CONGRESS OF RHOTGGRAMMETRY, 16., Hamburg, 1980. Eroceding. Hamburg, 1980. p.56-73.

BLACKMAN, G.E.\& WILSON, G.L. Physilogical estudies in the anaiysis of plant enviroment. VII. An analysis of the differential effects of light intensity on net assimilation rate, leaf area ratio and relative growth rate of different species. Annals of Botany, Toronto, 15(59): 373-408, 1951. 
BUNNIK, N.J.J. The multispectral reflectance of shortware radiotion by agricultural crops in relation with their morphological and optical properties. Mildelingen Landbouwhogeschool Wageningen, 78-81: (Communications Agricultural University Wageningen, The Netherlands). 1978. $176 \mathrm{p}$.

CASTRO, R.M. Análise de crescimento do amendoinzeiro (Arachis hipogea L.) com relação a infestação de pragas. In: ESCOLA SUPERIOR DE AGRICULTURA "LUIZ DE QUEIROZ"- ESALQ/USP. Piracicaba, 1974. Anais. Piracicaba, ESALQ-USP, 1974. VOL. 31, p. 207-15.

CLEVER, J.G.P.W. The derivation of a simplified reflectance model for the estimation of leaf index. Remote sensing of Enviromment, New York, 25: 53-69, 1988 .

COHEN, B.W. Response of vegetation indices to changes in three measures of leaf water stress. AMERICAN SOCIETY OF PHOTOGRAMMTRY ENGINEERING \& REMOTE SENSIG, FaIIs Church. $57(2):$ 195-202, Eeb. 1991.

COLWEL, R.N. (ed). Manual of remote sensing. American Society of Photogrametry, Ealls Church, 1983. v.2. $1232 \mathrm{p}$.

CURRAN, P.J. Principles of remote sensing. New York, Longman Scientific \& Thechnical, 1985. 282p.

DEPARTAMENTO DE AGUA E ENERGIA ELÉTRICA. plano estadual de recursos hidricos; primeiro plano do Estado de São Paulo sintese. São Paulo, Conselho Estadual de Recursos Hídricos, 1990. 120p. 
EPAMIG/EMBRAPA. Levantamento de reconhecimento detalhado dos solos do Distrito Agroindustrial de Jaíba - Minas Gerais. Belo Horizonte, 1976. 242p. (EPAMIG. Boletim Ténico, 54)

EEHIEHANIO, J. C. N. Dados TM/Landsat-5 no estudo das culturas de trigoo e feijāo. Piracicaba, 1988. 141p. (Doutorado - Escola Superior de Agricultura "Luiz de Queiróz"/USE).

EORMAGgIO, A. R. Caracteristicas agronomicas espectrais para sensoriamento remoto de trigo e feijāo. Piracicaba, 1989. 163p. (Doutorado - Escola superior de Agricultura "Luiz de Queiroz", USP).

GAREIA, G.J. Sensoriamento remoto. In: -.m.-.-. G.J. Infravermelho termal. Såo Paulo, Nobel, 1982. Cap.5, p.15781.

GATES, D.M.; KEEGAN, H.J.; SCHELETER, J.C.; WIEDNER, V.R. Spectral properties of plants. Applied Optics, 4: 11-20. 1965.

GIMRARZEVISKY, P. ERTS-1 imagery in kiophical studios. In: CANADIAN SYMMPOSIUM ON REMOTE SENSING, 2., Ontario, 1974. ontario, 1974. p.391-403.

GOMIDE, M.B. \& CASTRO NETO, P. Determinaça da area foliar in vitro" do feijoeiro (Phaseculus vulgaris L.). CIËncIA $\mathbf{E}$ PRÁTICA, Lavras. 13(2):117-227, maio/ago. 1989.

HABER ĀCHER, E. Digital Image Processing. Müchen, Eachnochusle. 1984. 20 p. 
HADY, M.A.ABDEL; SAMIE, A.G.; ABDEL; EL KANSAS, I.A.; AYOUB, A.S.; SAAD, A.O.Llandsat digital data processing for estimation of agricultural land in Egypt. In: INTERNATIONAL SYMPOSIUM OF REMOTE SENSING OF ENVIRONMENT, 17., Michigan, 1983. Annals. Michigan, Environment Research Institute Michigan, 1983. p.753-69.

HOEFER: R.M. Biological an physical considerations in applyning computer-aided analysis techniques to remote sensor data. In: SWAIN, P.H.; DAVIS, S.M. (ed.). Remote sensing; the qualitative approach. New York, McGraw-Hill. 1978. P. 228289 .

HOEFER, R.M. \& JOHANNSEEN, C.J. Ecological potentials in spectral signature analysis. In: JOHNSON, P.L. Remote sensing in ecology. Athens, University of Georgia Press, 1969. p.116.

HOWARD, J.A. \& LANTIER, D. Vegetation classification, land systems and mapping sensing spot multispectral data-preliminary results. In: EAO. SPOT I - Eirst in-flight results. Toulouse, National Center Space Study, 1985. p.137-49.

HUETE, A.R.. Soil-dependent spectral response in a developing plant canopy. Agronomy Journal, Madison, 79:61-8, 1987.

INSTITUTO NACIONAL DE METEOROLOGIA. Dados climatológicos do posto de Mocambinho - Projeto Jaíba - Série 1976/1985. Brasilia, Ministério da Agricultura, 1986. p.12-3.

LEPOUTRE, D. \& CAVEDON, A.D Programa do PRONI de cartografia e de teledeteçăo para monitoramento de áreas irrigadas. In: SIMPÓSIO ERANCO-BRASILEIRO SÔBRE IRRIGAÇÃO, Rio de Janeiro, 1987. Programa nacional de irrigaçäo-PRONI. Rio de Janeiro, PRONI, 1987. C.AP. 6, p.2-3. 
KEEGAN, H.J.; SCHLETER, J.C.; HALL, W.A.; HAAS, G.M. Spectrophotometric and calorimetric study od diseased and rust-resisting cereal crops. In: National Bureau of Standarts Report, 4591. 1981.

KNIELING, E.B. Ehysical and physiological basis for reflectance of visible and near-infrared radiation from vegetation. Remote Sensing of Enviromment, Madison, 1: 155-9, 1970.

KOFELER, F.N. Identificação da cultura de cana-de-açucar (Saccharum spp), através de fotografias aéreas infra-vermeihas coloridas e dados multiespectrais do satélite Landsat. Eiracicaba, 1982. 234p. (Doutorado - Escolas Superior de Agricultura "Luiz de Queiroz" (USE).

MADEIRA. NETTO, EUKUHARA, M.; EXEINOZA, W. Assinaturas espectrais de quatro variedades de soja. In. SIMPÓSIO BRASILEIRO DE SENSORIAMENTO REMOTO, 2., Brasilia, 1982. Anais. Brasilia, CNEq/INPE, 1982. V.1, p.919-27.

MELLO, A.F.; SILVA,P.A.; VERDIN,J.P; GALVÃO, W.S.; CAVALCANTI, C.A.B. Projeto Rio Verde Grande. Programa PAS. Publicaçăo ininterna. CODEVASE. Biblioteca, 1991. $87 \mathrm{p}$.

MENDONYA, E.J. Sensoriamento remoto aplicado a agricultura; principios básicos, metodologia e aplicaçoes. São José dos Campos, INEE/CNEq, 1981. 81P. (INEE, 2225-MD/012).

MISRA, P.H. \& WHEELER, S.G. Crop classification with Landast miltispectral scanner data. In:-.-.-.. Pattern recognition. Pergamon, 1978. Cap.7, p.1-13. 
MOREAU, J.P.; BOISSARD, P.; BONHOMME, R. Caractérisation des malaies type jaunisse gràce aux mesures de réflectance. In: COLLOQUE INTERNATIONAL SIGNATURES SPECTRALES D'OBJETS EN TÊLEDETECTION, 5. Avignon, 1981. Annales. Avignon, 1981. p.5461.

MOREIRA, M.A. Uso da expansăo direta para áreas de soja e milho através de dados multiespectrais e temporais do Landsat/TM. In: SIMPÓSIO BRASILEIRO DE SENSORIAMENTO REMOTO, 6., Manaus, 1990. Anais. Manaus, 1990. V. 3, p.781-90.

NEALE, C.M.U.; BAUSH, W.C.; HEERMAN, D.E. Development of reflecreflectance-based crop coefficients for corn. Transactions of the American Society of Agricultural Engineers, Falls Chuch, $32(6): 1989$.

NOVO, E.M.L. Sensoriamento remoto; principios e aplicaçóes. Săo Paulo, Edgar Bücher, 1989. 308p.

PINTO, S.A.E.; NOVO, E.M.L.M.; NIERO, M. Metodologia de coleta de dados radiometricos de campo em diferentes tipos de cobertura de solo. In: SIMPÓSIO BRASILEIRO DE SENSORIAMENTO REMOTO, 2. Brasilia, 1982. Anais. Brasilia, CNPq/INPE, 1982. V.1, P.22738.

ROCHA, J.V. Estimativa de áreas de uso agricola do solo através de imagens de satélite e sistema de informação geográfica (SIG). In: CONGRESSO BRASILEIRO DE ENGENHARIA AGRICOLA, 12. Ilheus, 1993. Anais. Ilheus, CPLAC, 1993. v.5, p.374-83. s

SILVA, A.F. Avaliação do potencial hídrico do rio Gorutuba (MG) . Eiracicaba, 1989. 84p. (Mestrado - Escola Superior de Agricultura "Luiz de Queiroz"/USP) . 
STEEFEN, C.A.; LORENZZETTI, J.A.; STECH, J.L.; SOUZA, R.C.M. sensoriamento remoto; princípios físicos; sensores e produtos e sistema Landsat. Såo José dos Campos, INPE, 1981. 81p.

SWAIN, P.H.; DAVIS, S.M. ed. Remote sensing; the quantitative approach. New York, Mac Graw-Hill, 1978. 395p.

THELIN, G.P. \& HEIMES, F.J. Mapping irrigated cropland from Landsat data for determination of water use from the high plains aquifer in parts of Colorado, Kansas, Nebaska, New Mexico, Oklahoma, South Dakota, Texas e Wyoming. Buletin. US Geological Survey. 1987. N 1400c, C1-C38.

THIRUVENGADACHARI, $S$. Irrigated agriculture in Cumbum vailey in south India: a Landsat study. In: INTERNATIONAL SYMPOSIUM ON REMOTE SENSING OF ENVIRONMENT, 17., Michigan, 1983. Annals. Michigan, Environment Research Institute Michigan, 1983. p. 389-97.

THOMAS. J.R.; NAMKEN, L.N.; OERTHER. G.F.; BRAOWN. R̃.G. Estimating leaf water content by reflectance measurements. Agronomy Journal, Madison, 63: 845-7, 1972.

WININGS, S.B.; COOK. P.W. et HANUSCHAK. Agristars dclc aplications project: 1982 corn and soybens area estimates for Iowa and Illinois. In: INTERNATIONAL SYMPOSIUM SYMPOSIUM ON REMOTE BENSING OF ENVIRONMENT, 17., Michigan, 1983. Annals. Michigan, Environment Research Institute Michigan, 1983. p.741-51.

VALÉRIO FILHO, M. Identificaçao de areas irrigadas através de imagens digitais TM/LANDSAT. In: CONGRESSO NACIONAL DE IRRIGAGÃO E DRENAGEM, 7, Brasilia, 1986. Anais. Brasilia, ABID, $1986 . V 3$, P.991-102. 
VALERIO EILHO, M.; RODRIGUES, R.L.V.; CAVEDON, A.D. Imagens TM/Landsat aplicadas ao planejamento da agricultura irrigada. In: SIMPÓSIO BRÁSILEIRO DE SENSORIAMENTO REMOTO, 5, Natal, 1988. Anais. Natal, INPE, 1988. V.1, P.170-9.

VERDIN, J. \& SILVA, P.A. Manual de instruçóes - Radiômetro Erotech Modelo $100 \mathrm{BX}$. SFGRAPH, Brasilia, CODEVASE, 1989. $32 \mathrm{p}$.

VETTORAZZI, C.A. (ESALQ/USP. LER 838 - Sensoriamento Remoto Aplicado a Recursos Naturais). Anotaços de aula, 1991.

VETTORAZZI, C.A. Sensoriamento remoto orbital. Piracicaba: ESALQ - Departamento de Engenharia Rural, 1992. $134 \mathrm{p}$. (Ditática, 2).

ZIMMERMANN, M.J.O.; ROCHA, M.; YAMADA, TSUIOSH. Cultivo do Eeijoeiro; fatores que afetam as produtivades. Piracicaba, Associaça Brasileira para Pesquisa da Potassa e do Fosfato, 1988. 58p. 
95.

APENDICE 1 - Gráficos de reflectâncias temporais (8 dias PG e 50 dias PG) dos 7 lotes estudados. 


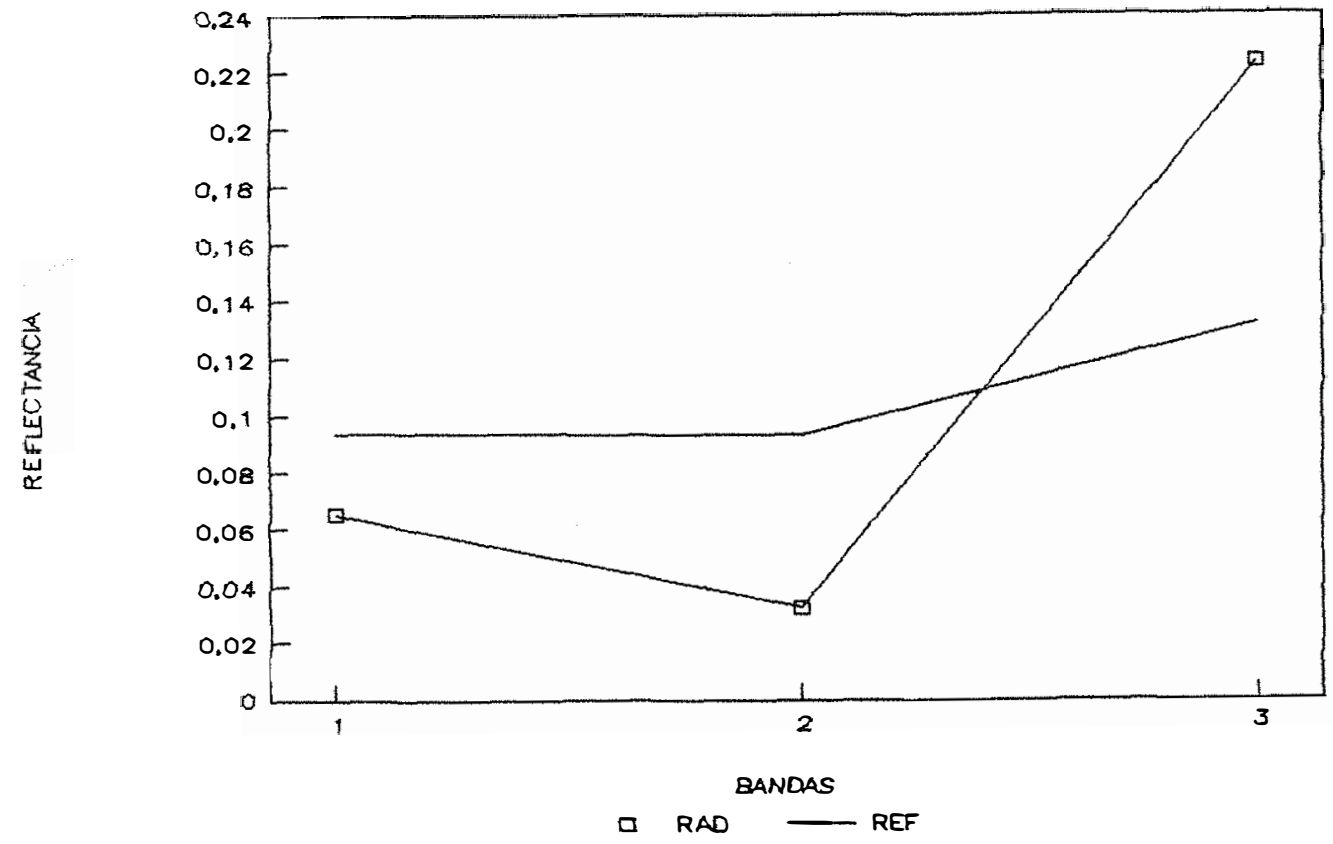

Figura $1 A$ - Curvas de reflectāncias do lote I ( 8 dias PG)

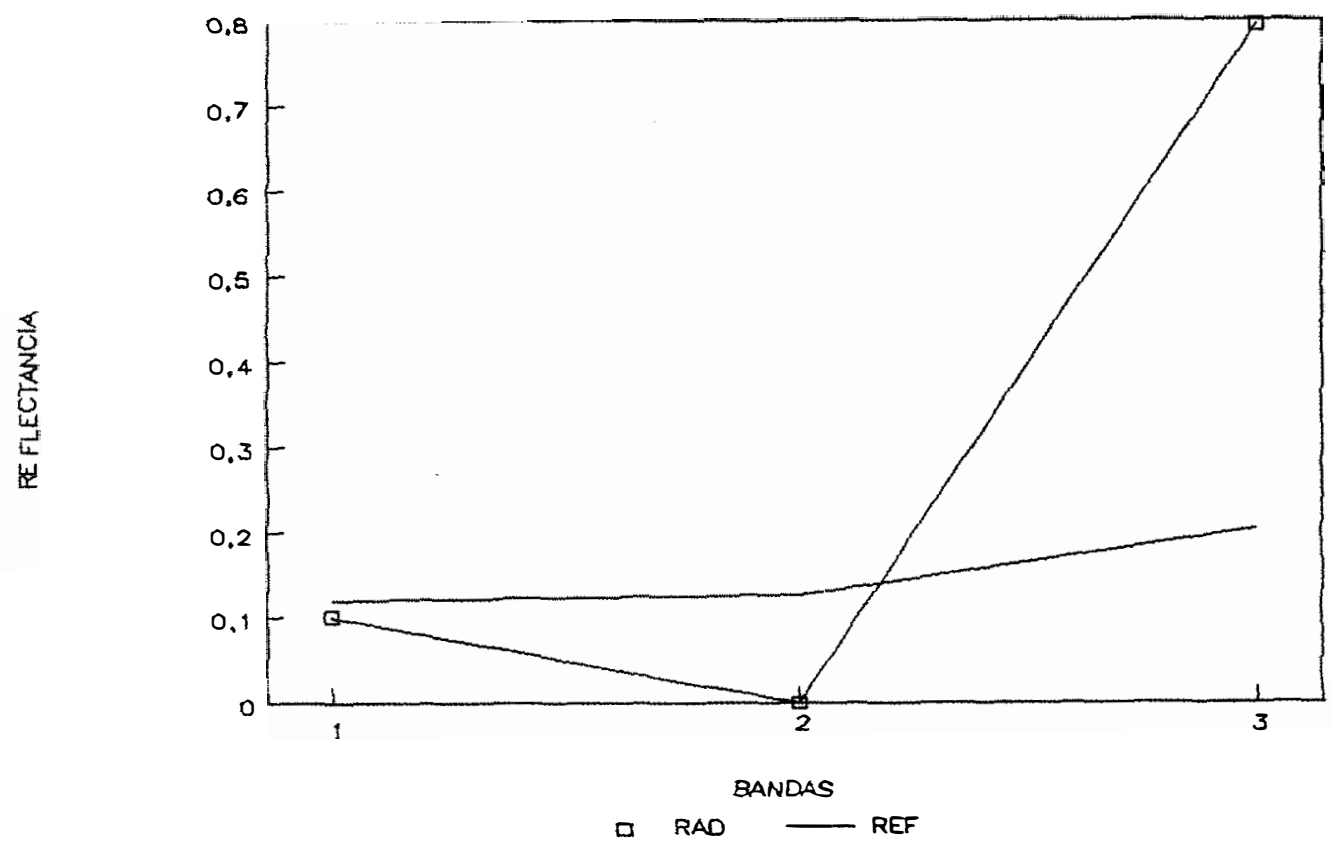

Figura 1B - Curvas de reflectāncias do lote I (50 dias PG) 


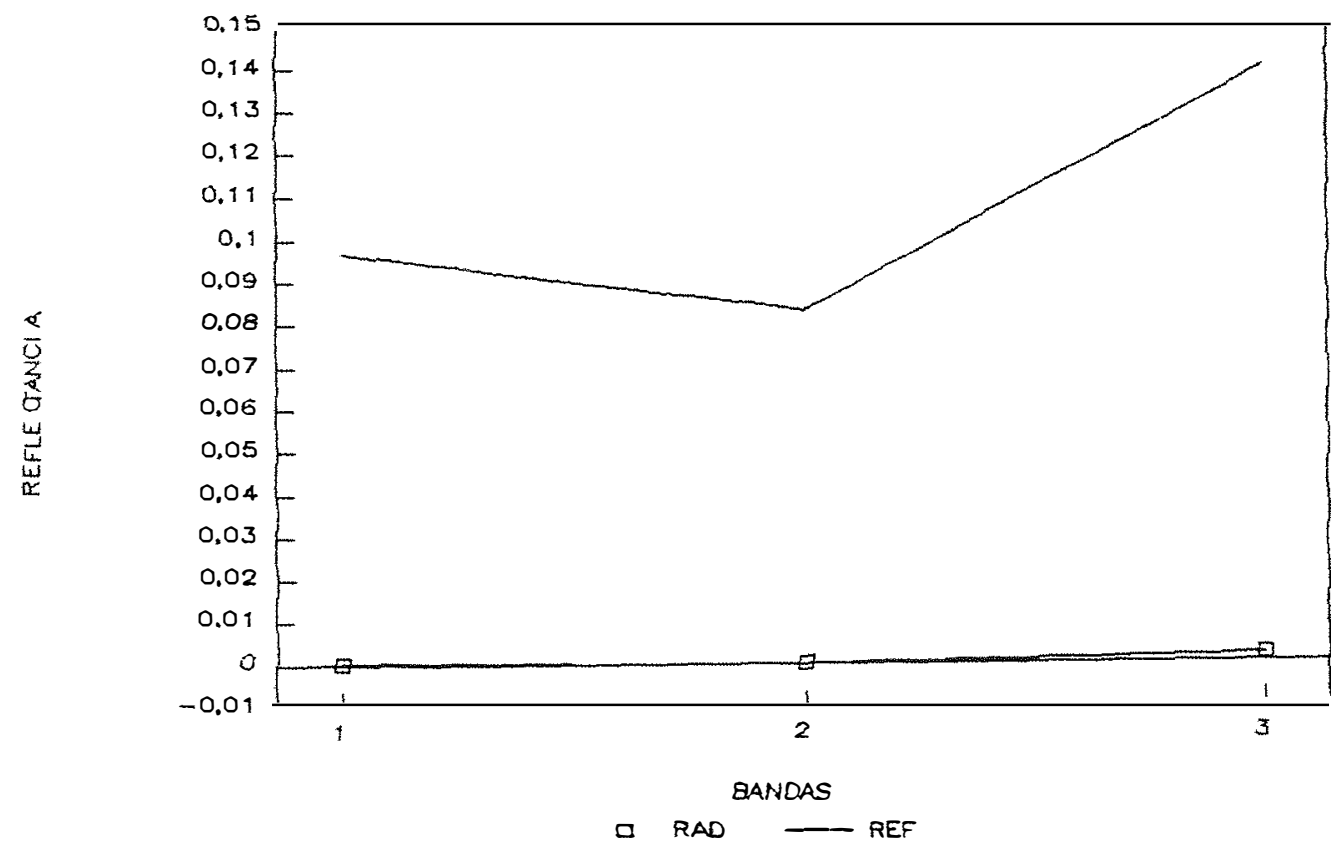

Figura 1C - Curvas da reflectāncias do lote II (8dias PG)

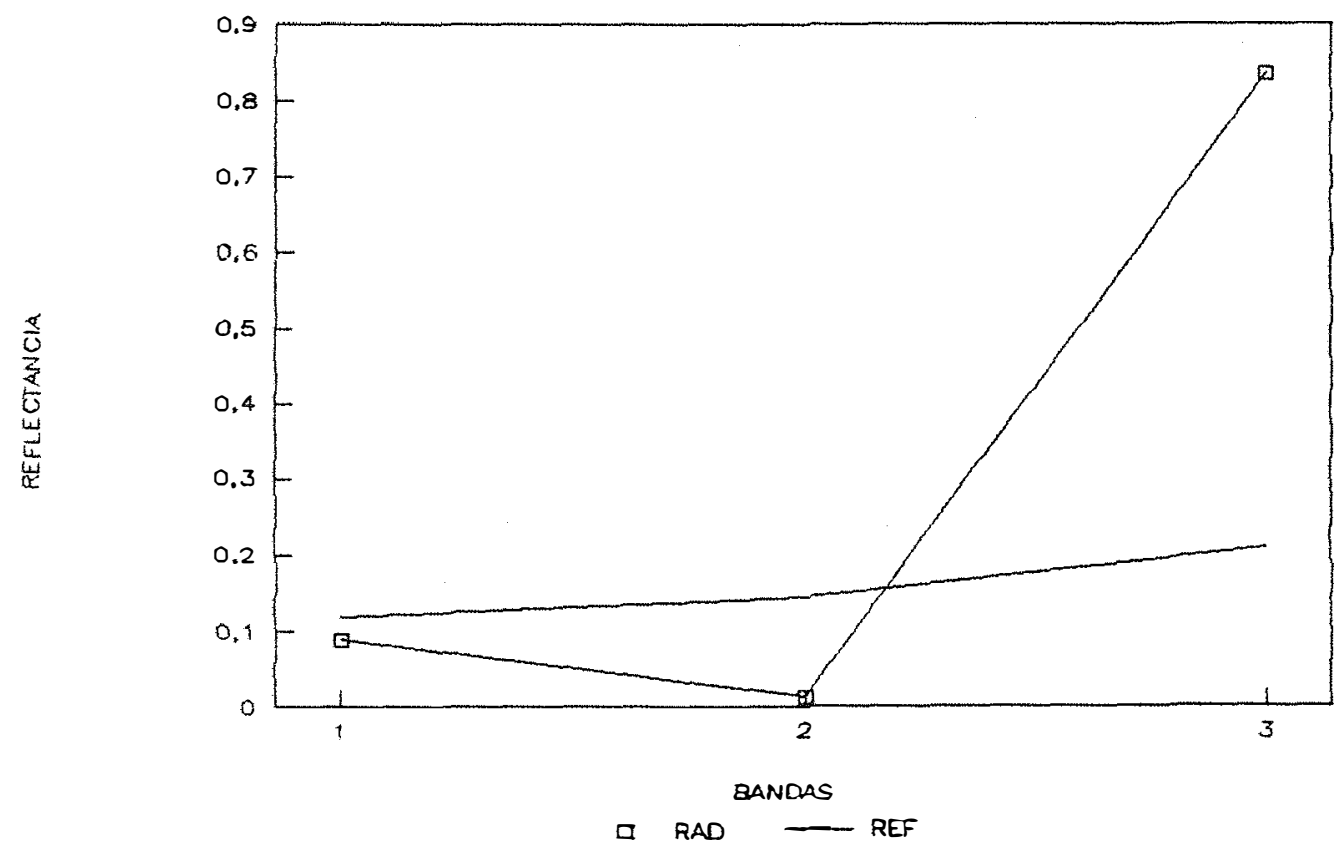

Figura 1D - Curvas da reflectâncias do lote II (50 dias PG) 


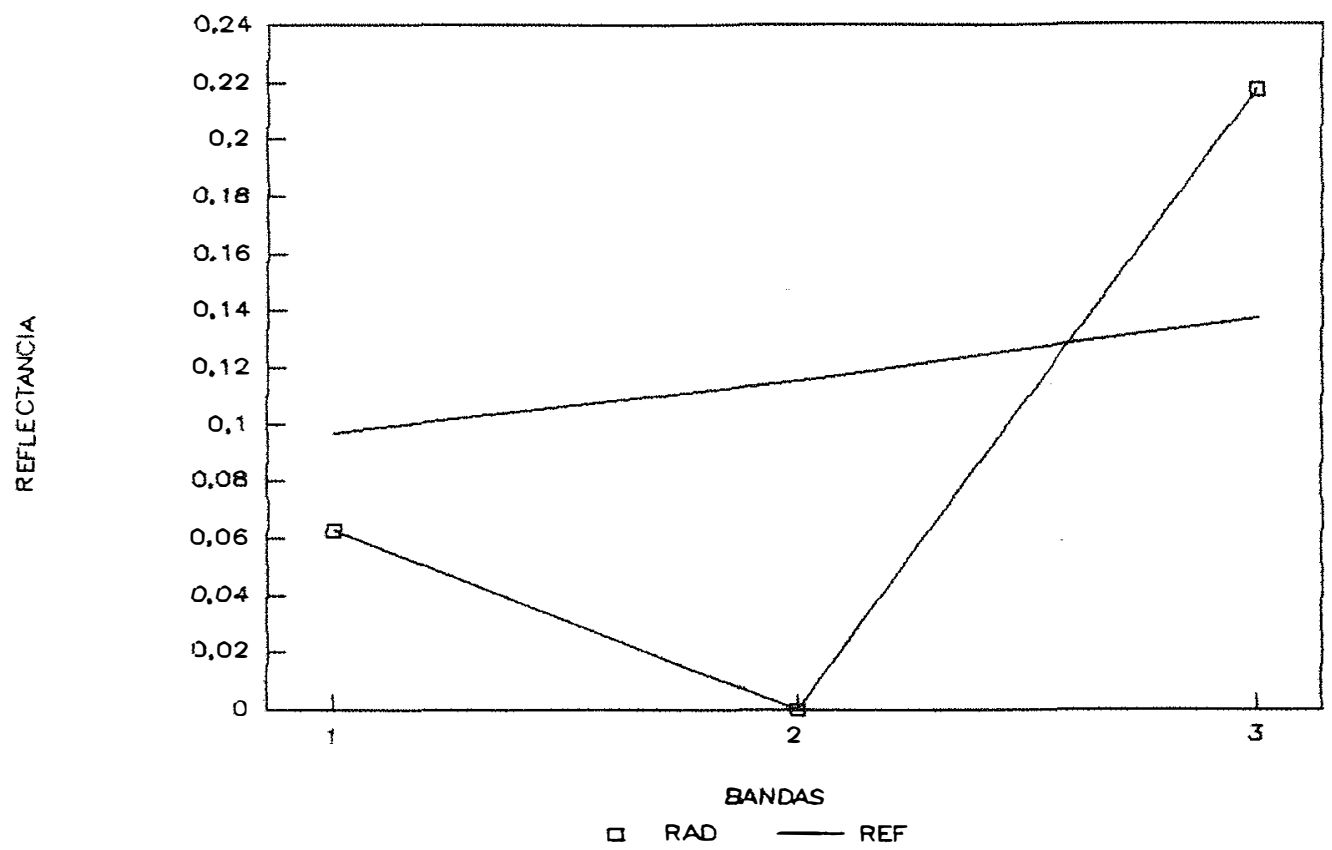

Figura 1E - Curvas da reflectāncias do lote III (8dias PG)

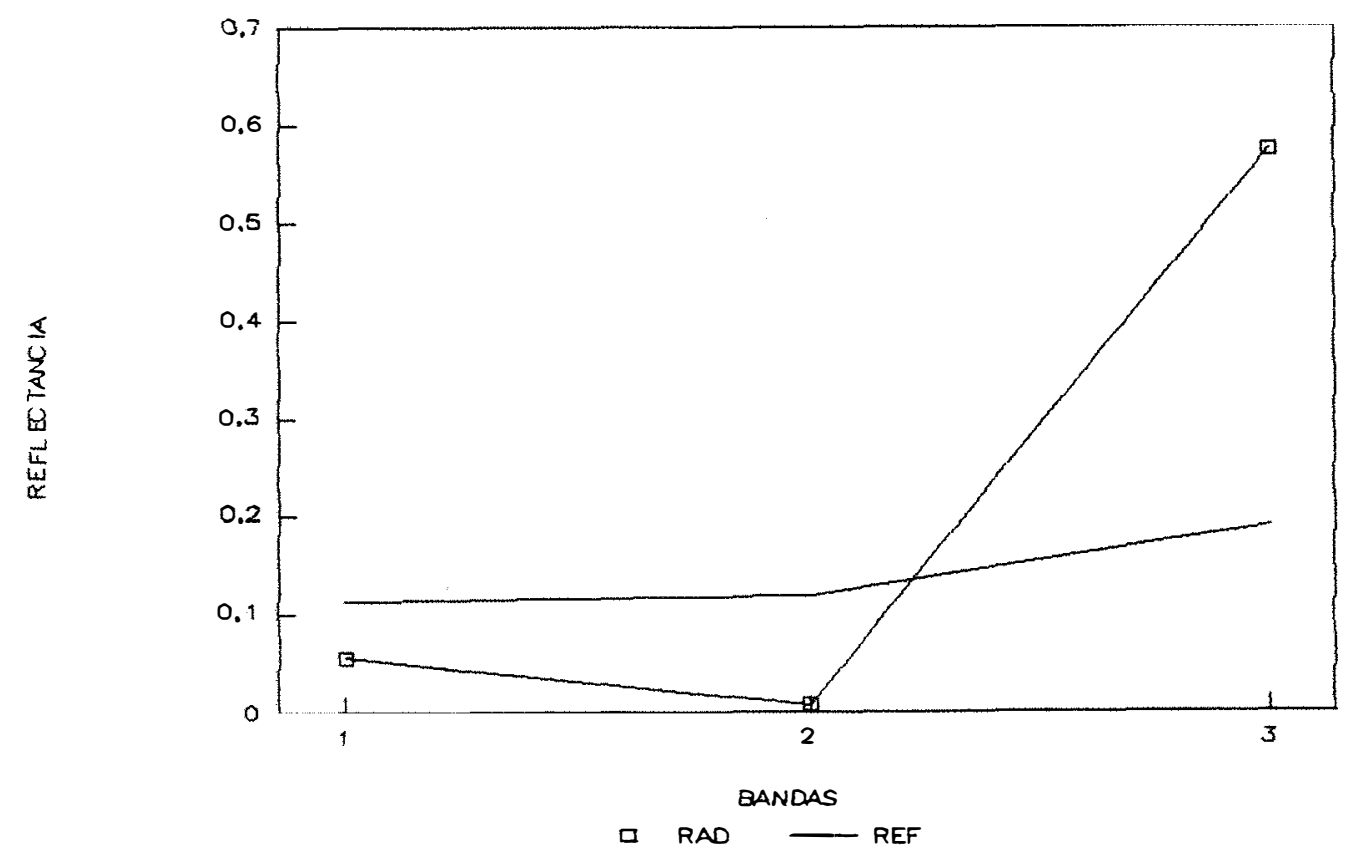

Figura 1F - Curvas da reflectāncias do lote III (50 dias PG) 


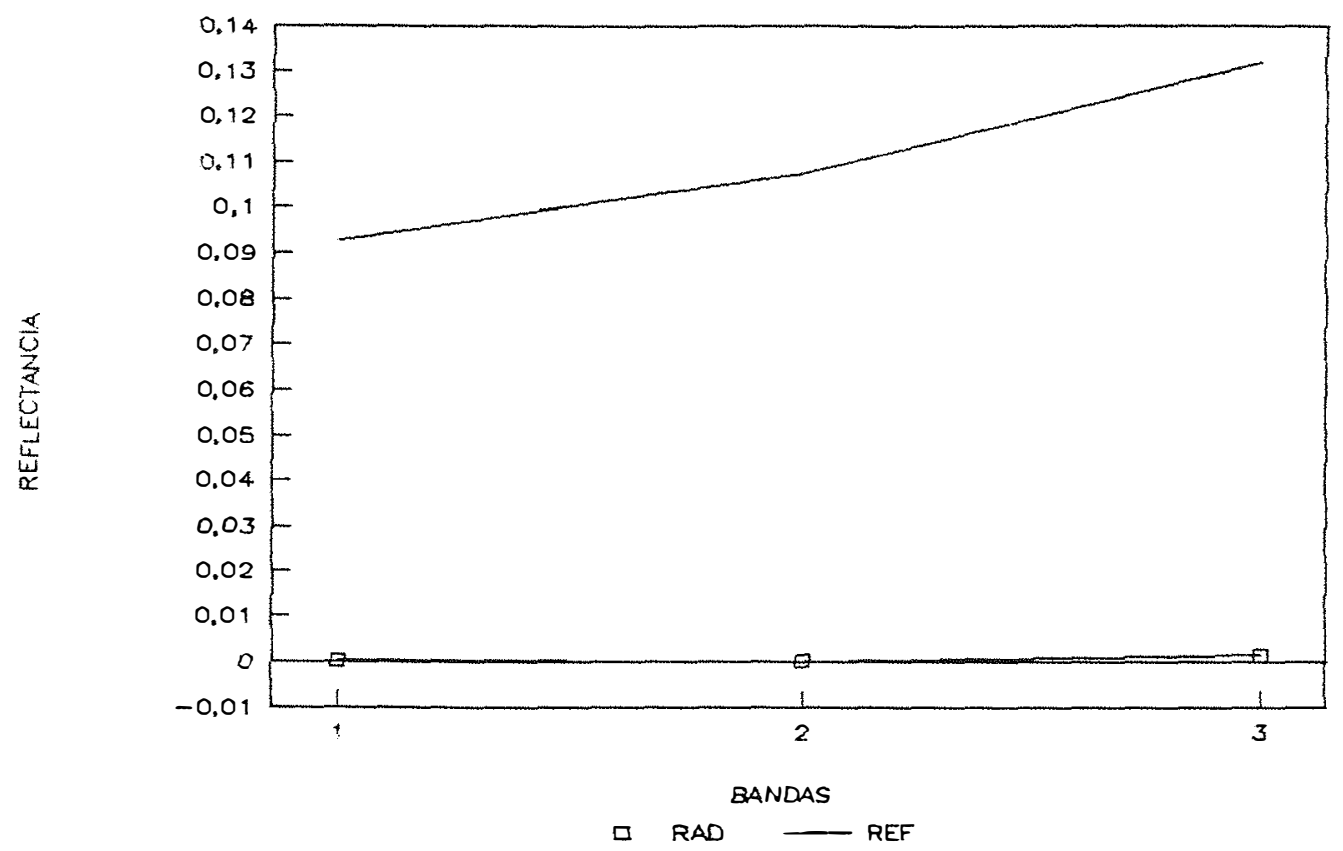

Figura 1G - Curvas da reflectāncias do lote IV ( 8 dias PG)

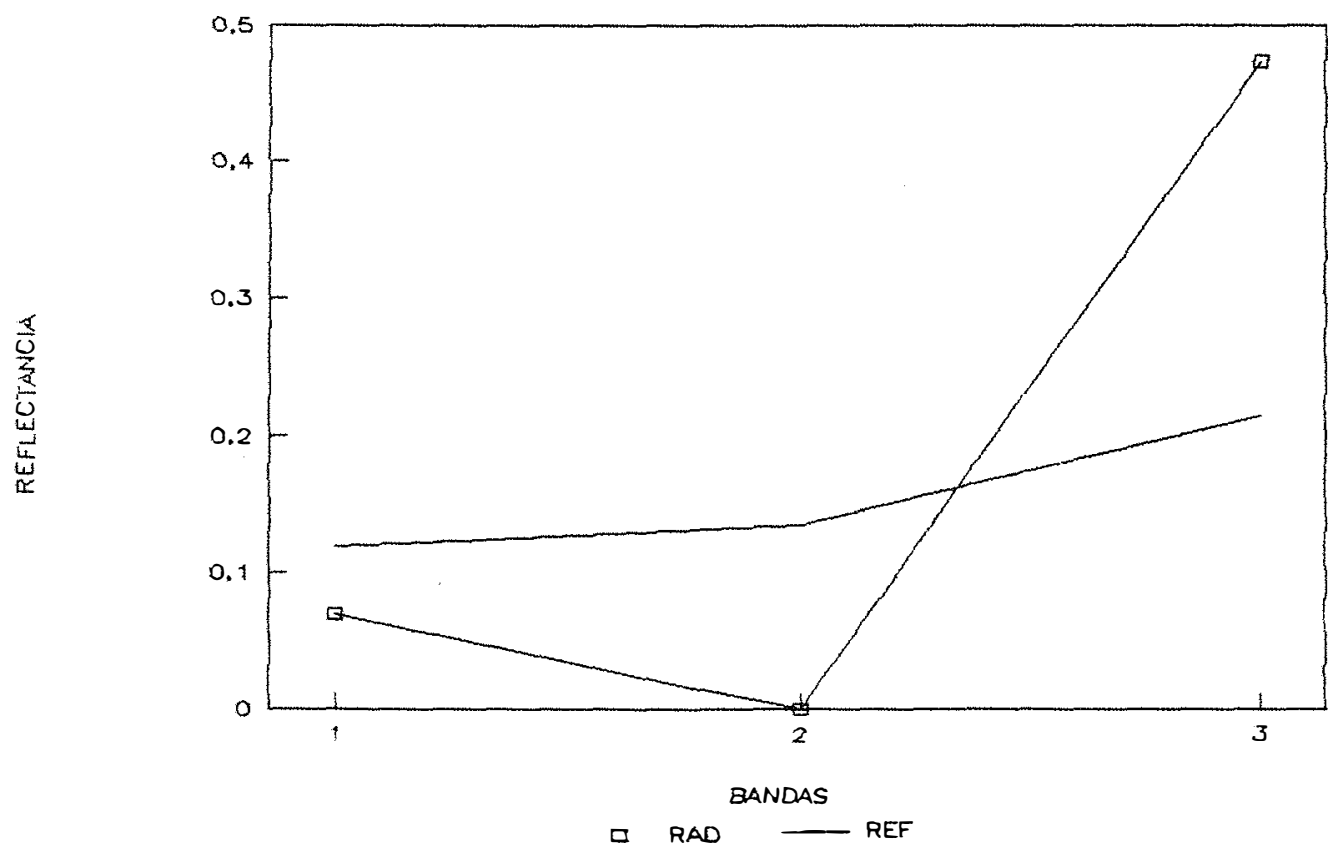

FIgura 1H - Curvas da reflectāncias do lote IV (50 dias PG) 


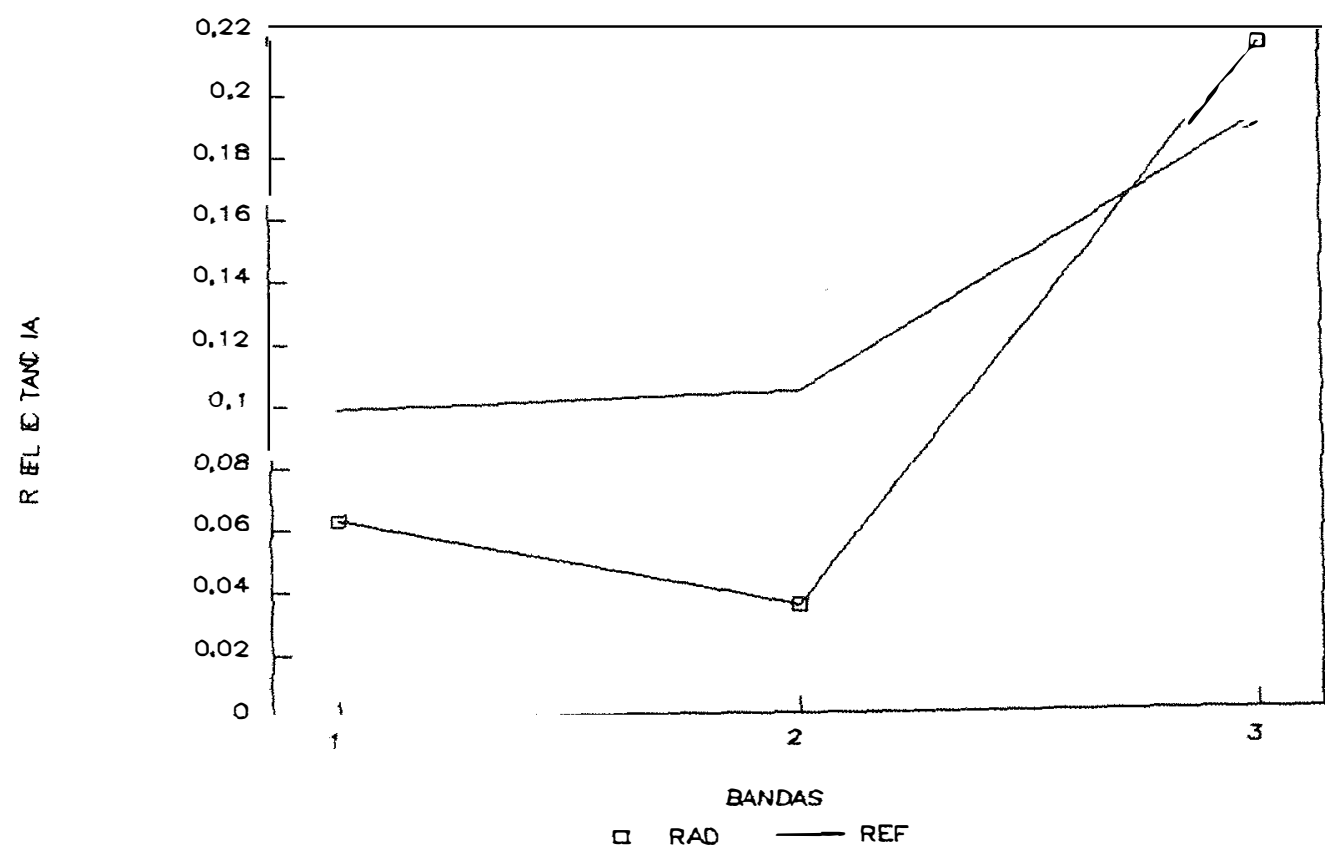

Figura $1 I$ - Curvas da reflectāncias do lote V(8 dias PG)

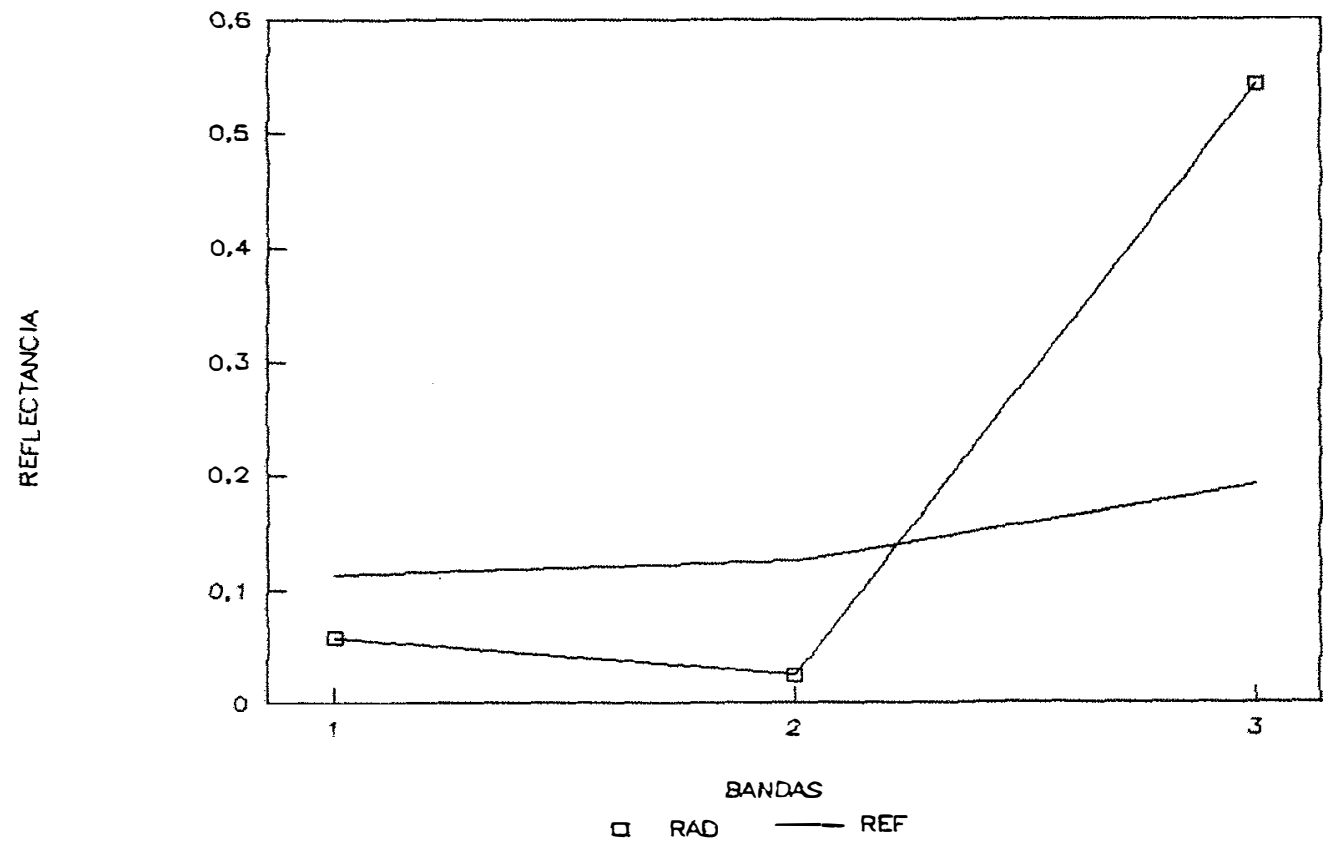

Figura $1 \mathrm{~J}$ - Curvas da reflectâncias do lote V (50 dias PG) 


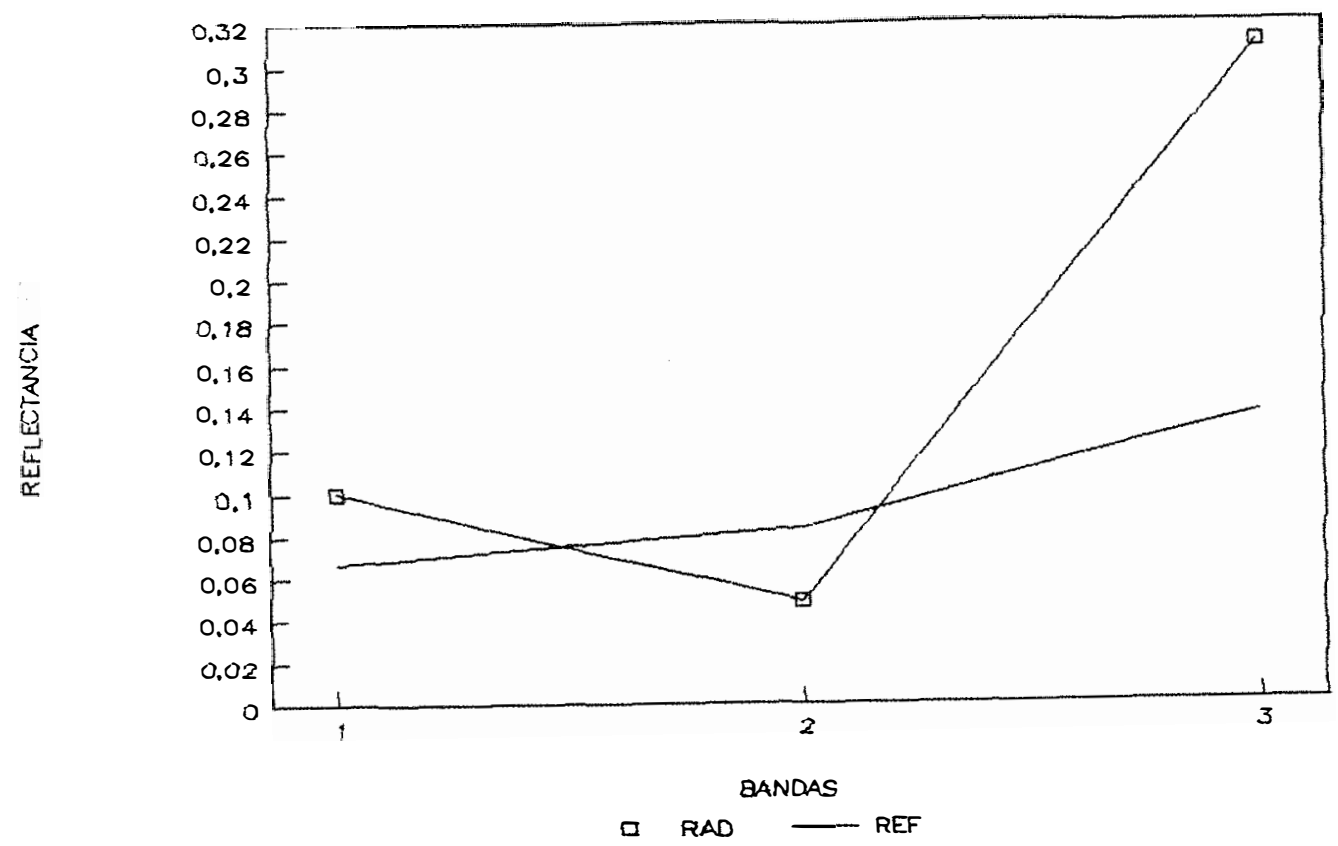

Figura 1L - Curvas da reflectāncias do lote VI ( 8 dias PG)

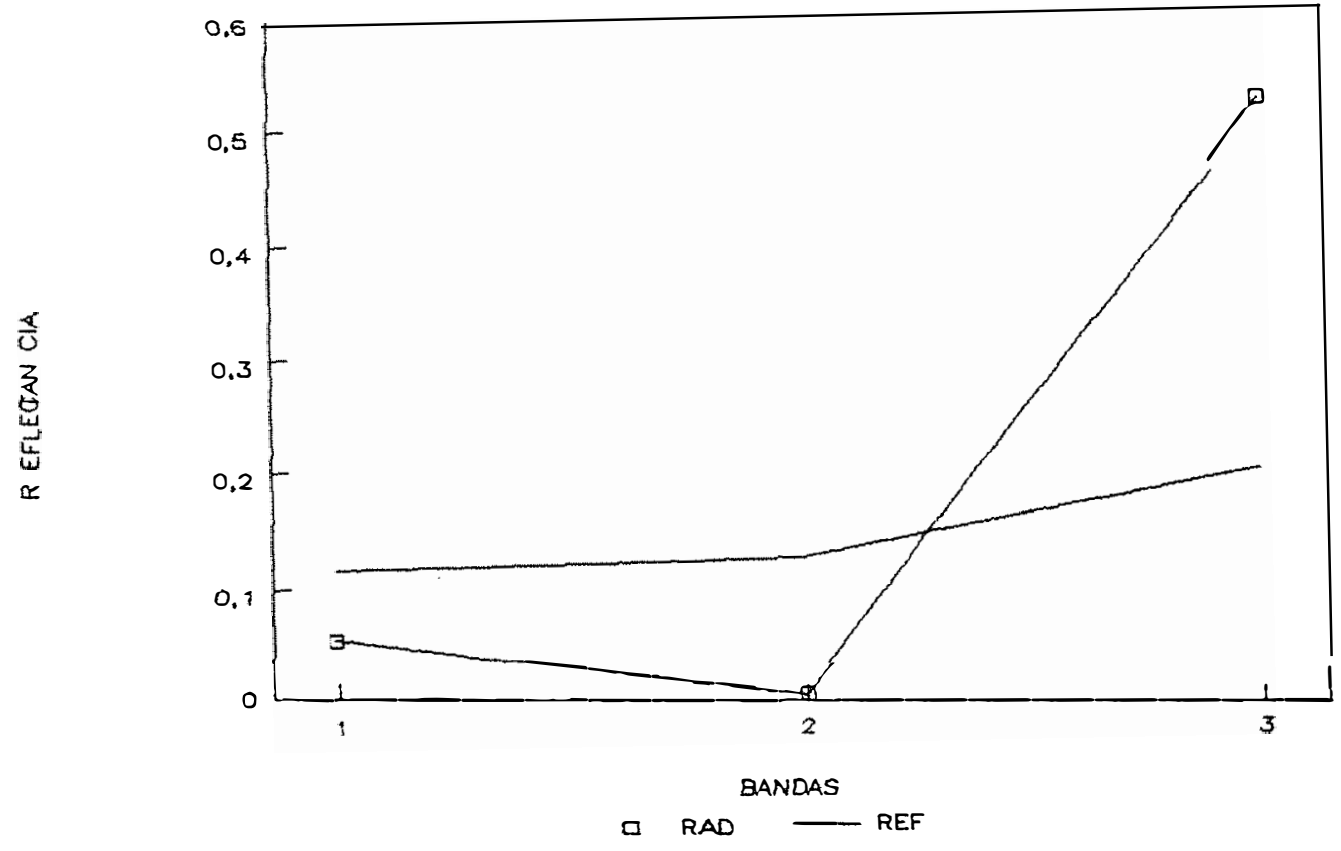

Figura 1M - Curvas da reflectāncias do lote VI (50 dias PG) 


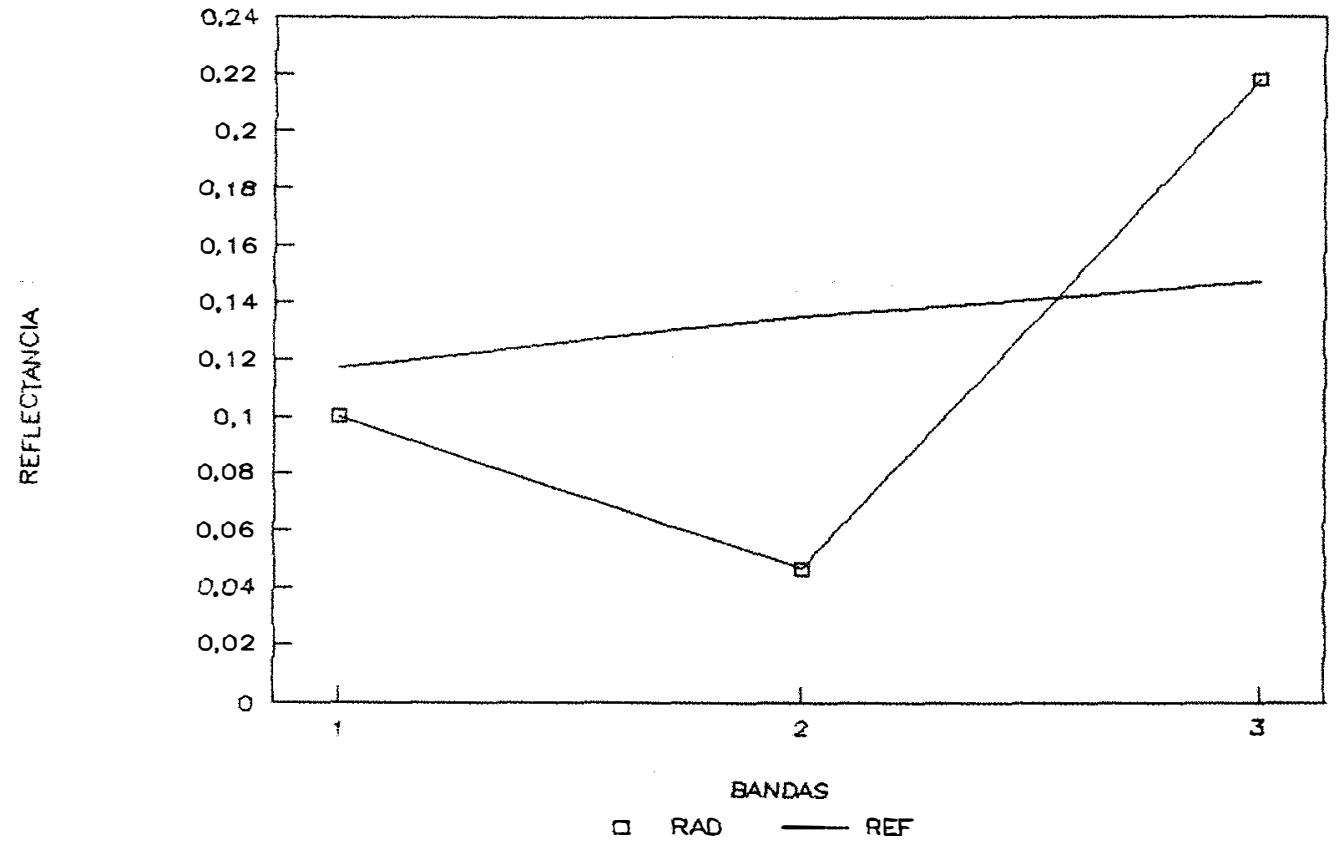

Figura $1 N$ - Curvas da reflectāncias do lote VII (8dias PG)

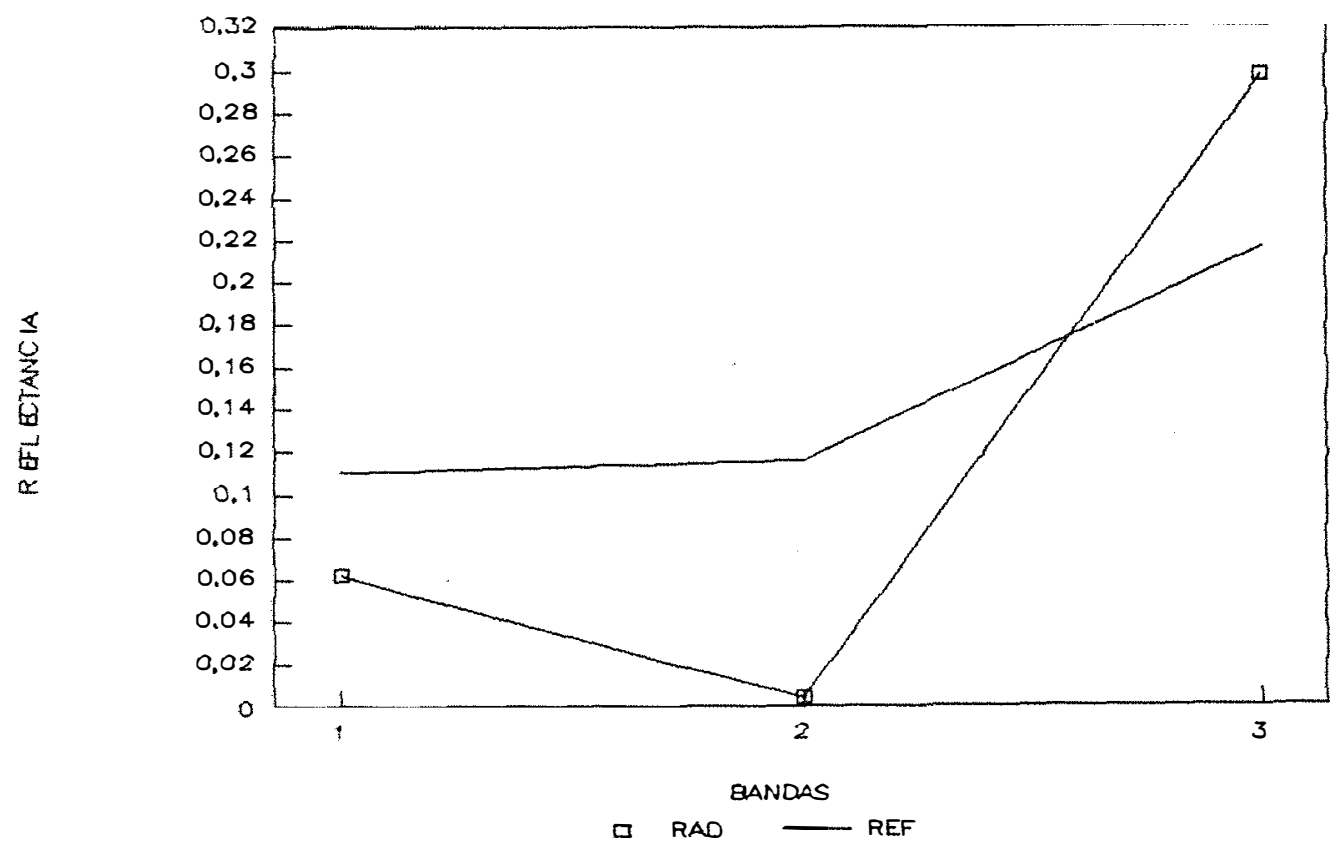

Figura 10 - CUrvas da reflectāncias do lote VII (50 dias PG) 
103.

APÊNDICE 2 - Gráficos de reflectancias temporais 18 dias PG e 50 dias PG) dos 7 lotes estudados em função da cobertura vegetal. 


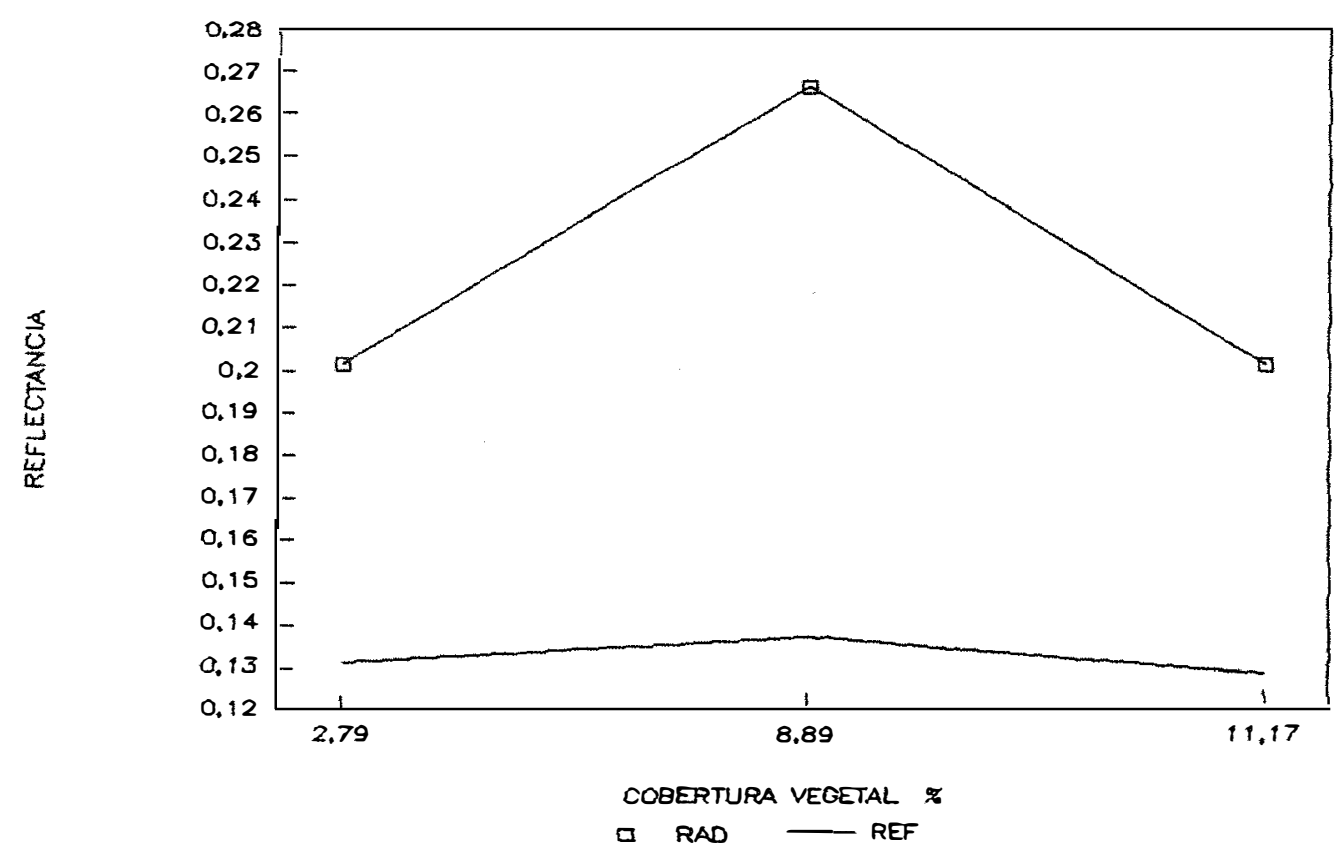

Figura 2A - Curvas de reflectāncias em função da cobertura vegetal. Lote I ( 8 dias PG)

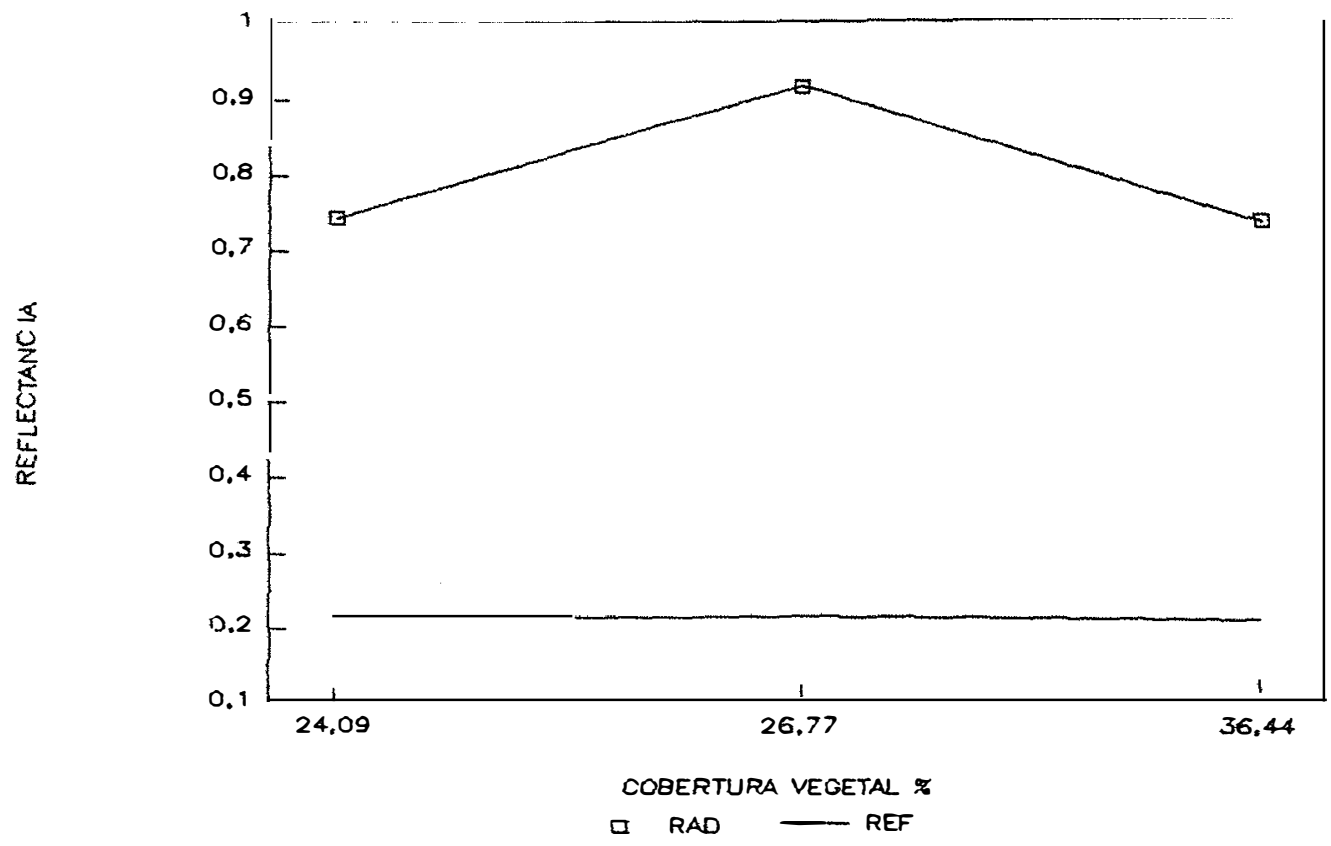

Figura 2B - Curvas de reflectāncias em função da cobertura vegetal. Iote I (50 dias PG) 


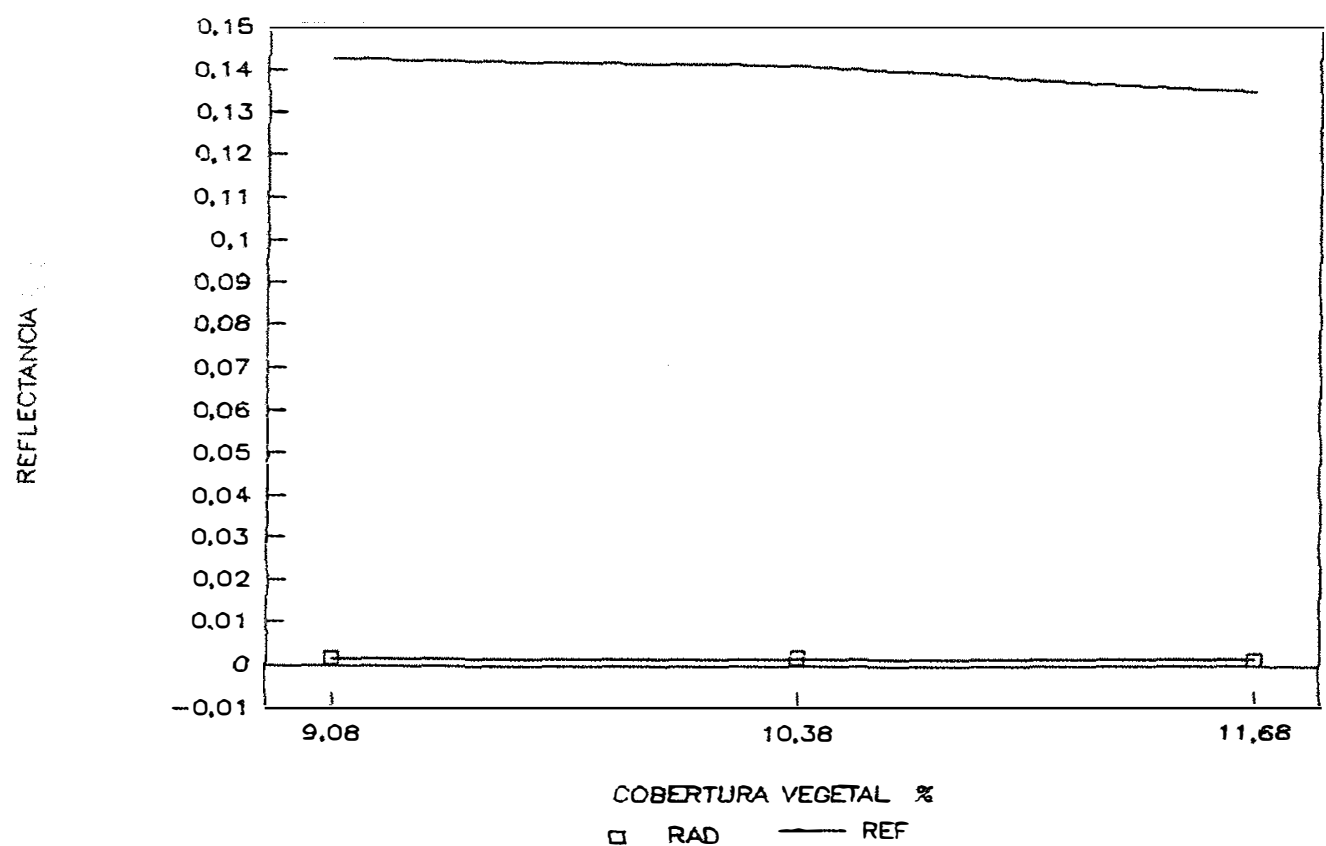

Figura 2C - Curvas de reflectāncias em função da cobertura vegetal. Lote II ( 8 dias PG)

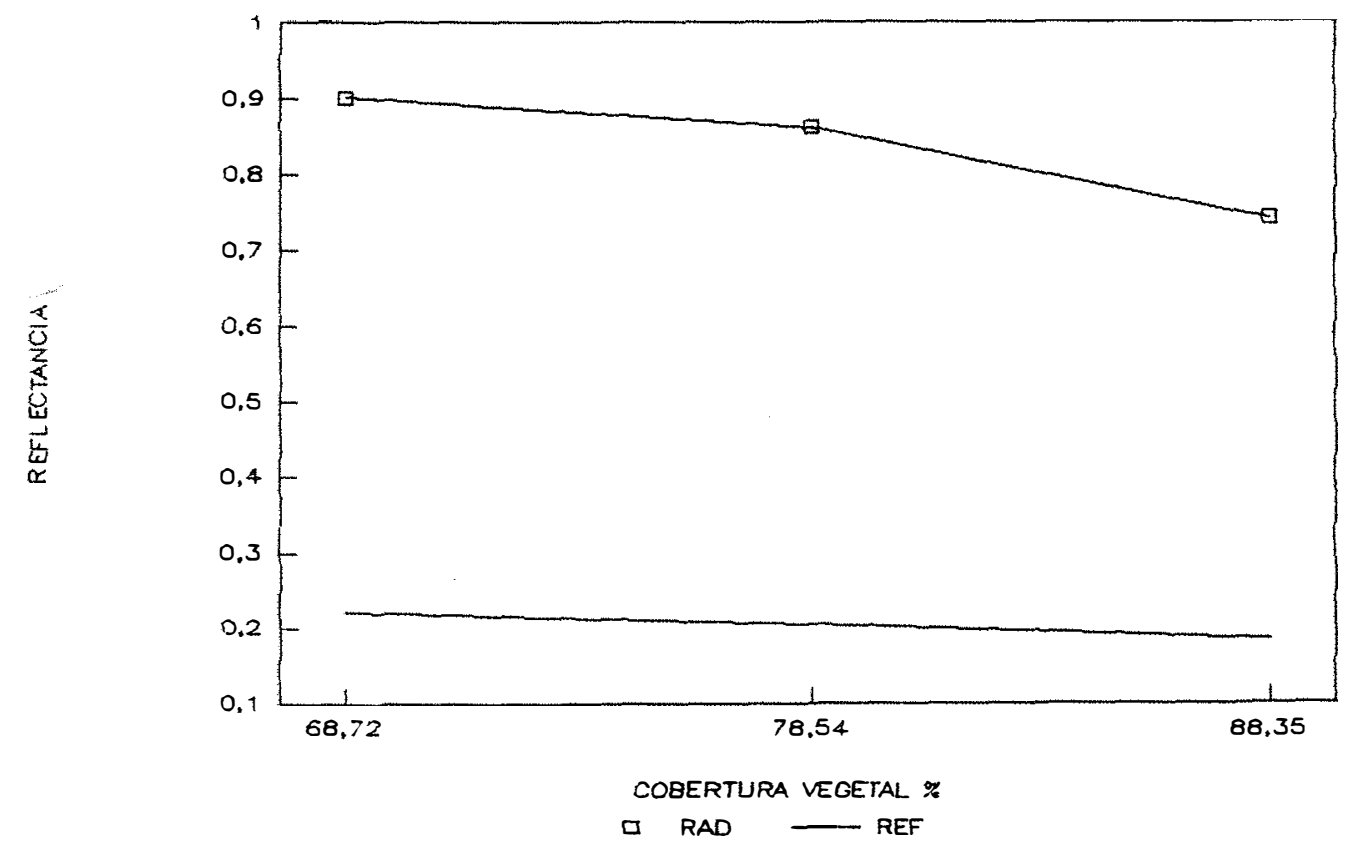

Figura 2D - Curvas de reflectāncias em função da cobertura vegetal. Lote II (50 dias PG) 


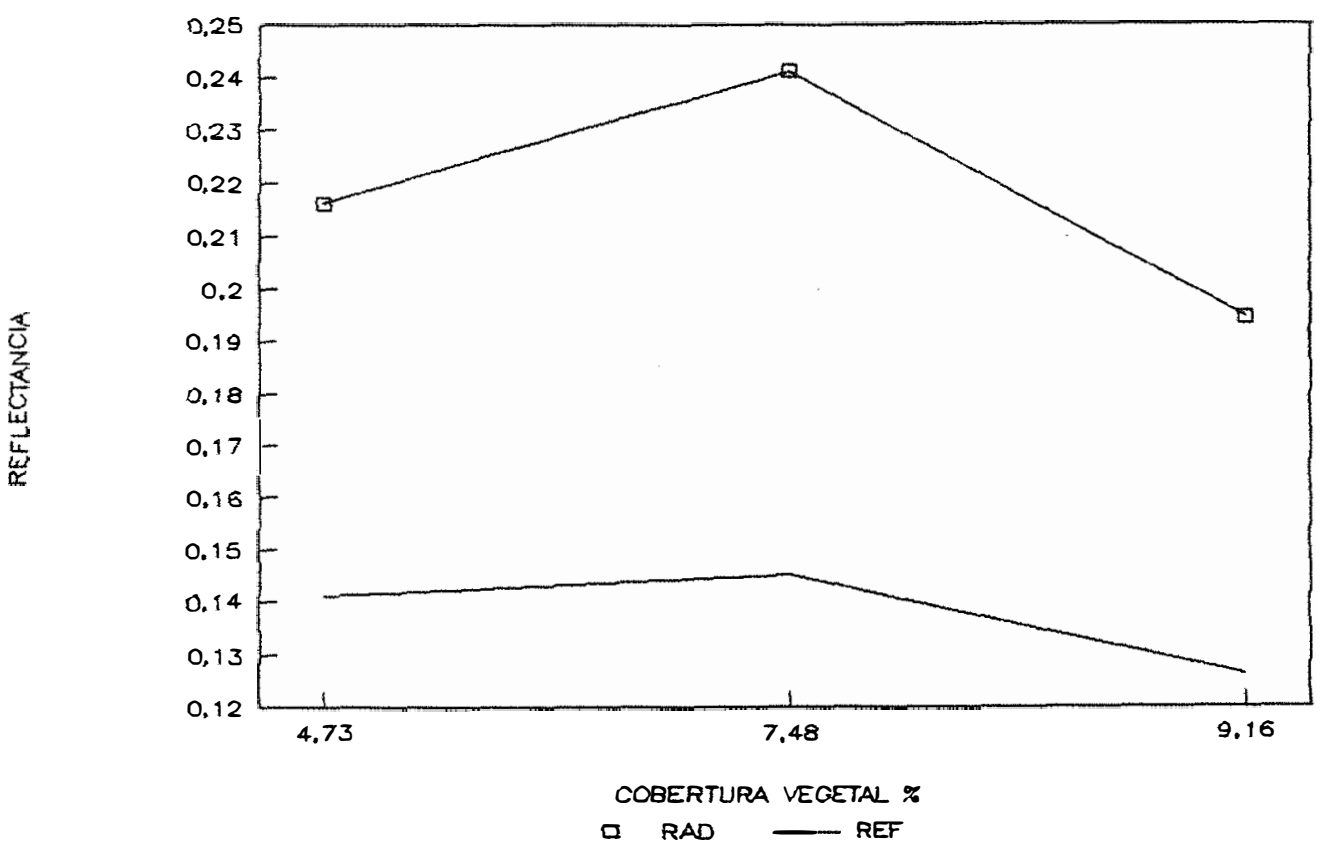

Figura 2E - Curvas de reflectâncias em função da cobertura vegetal. Lote III ( 8 dias PG)

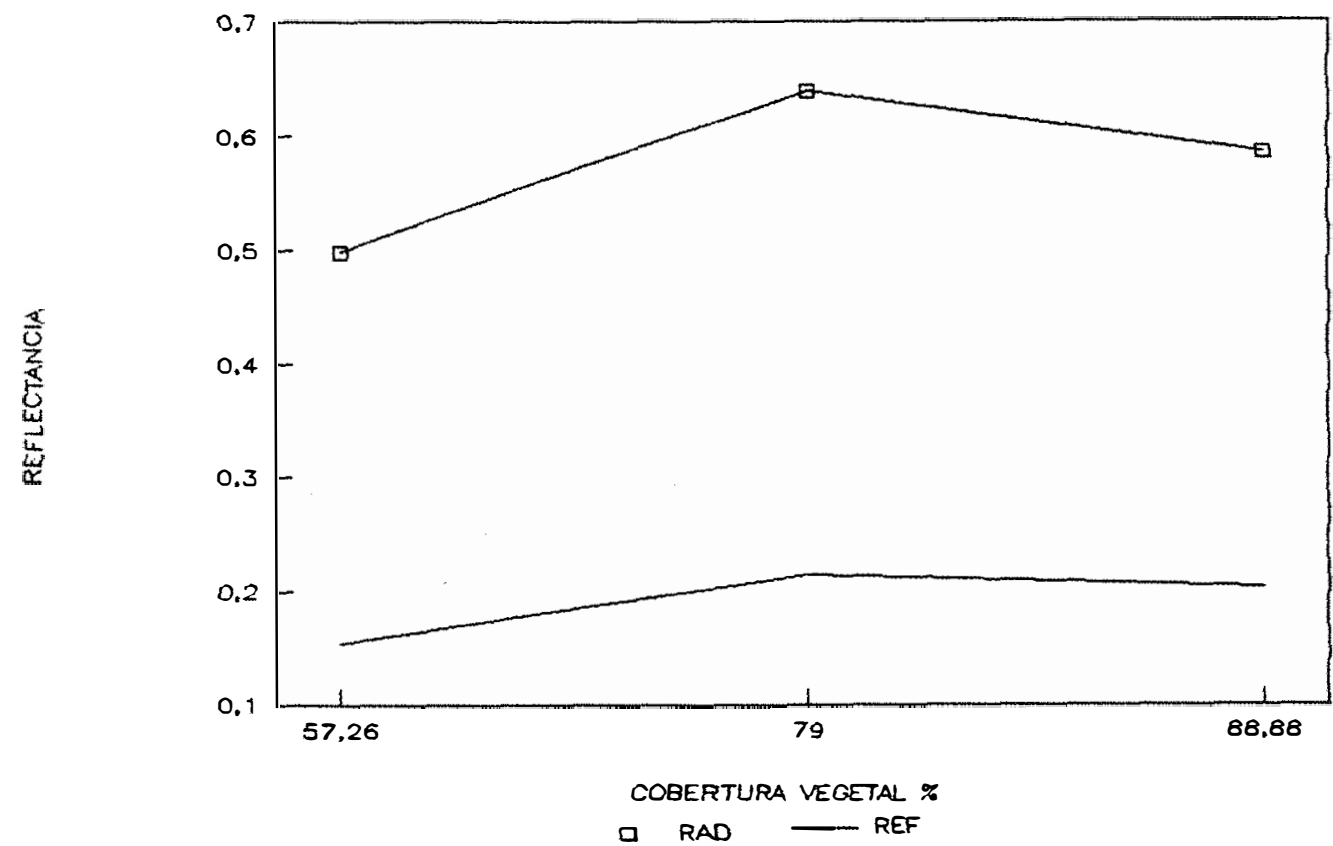

Figura $2 F$ - Curvas de reflectâncias em função da cobertura vegetal. Lote III (50 dias PG) 


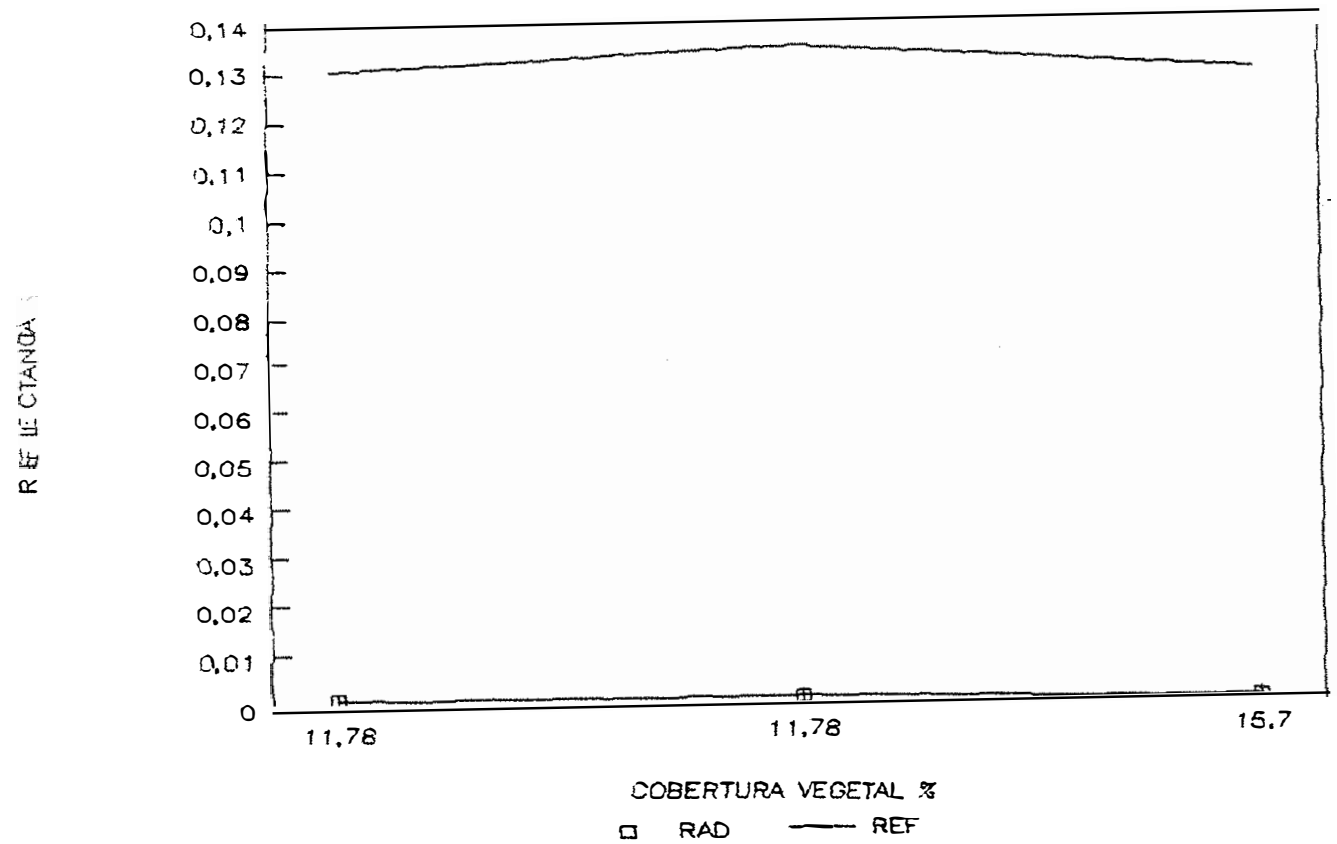

Figura 2G - Curvas de reflectāncias em função da cobertura vegetal. Lote IV ( 8 dias PG)

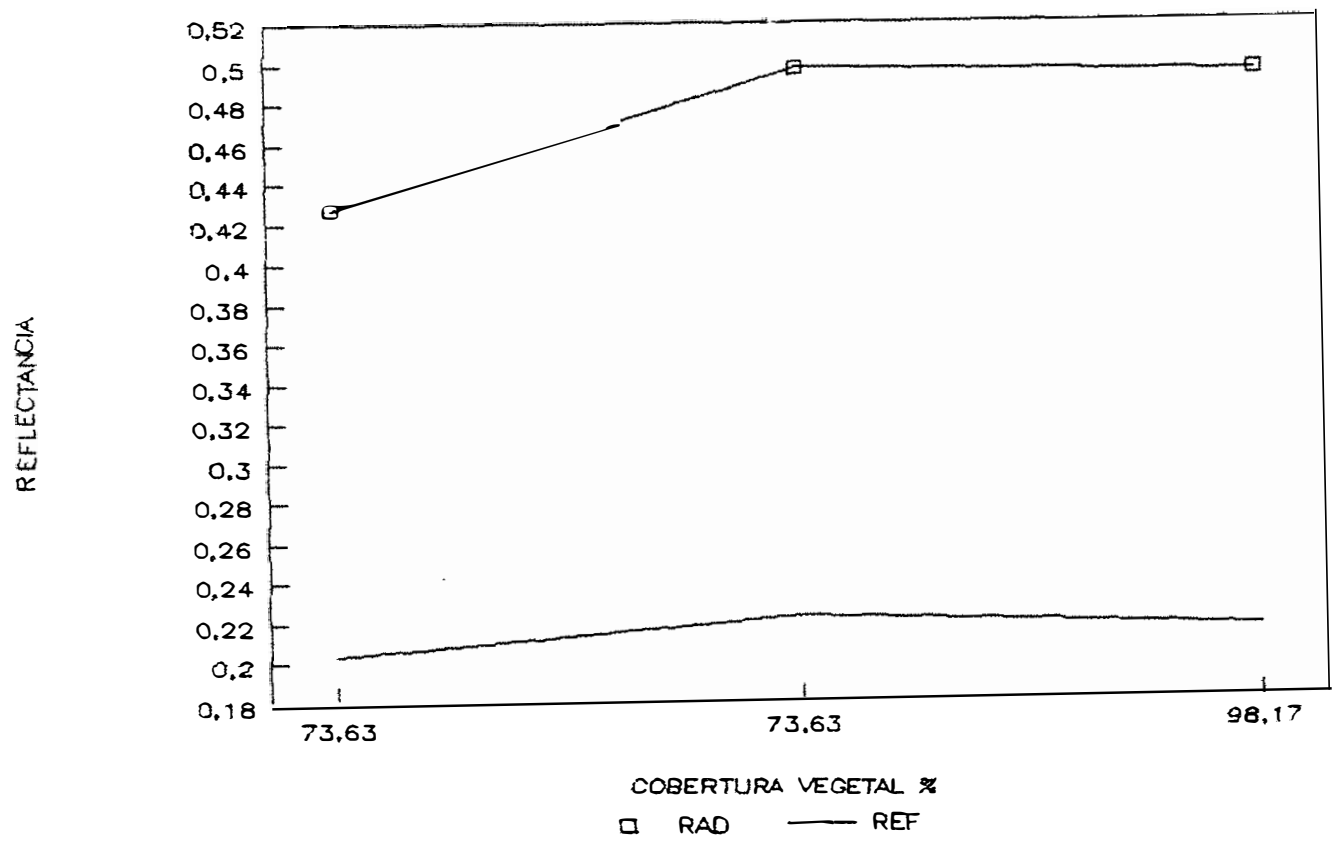

Figura $2 \mathrm{H}$ - Curvas de reflectāncias em função da cobertura vegetal. Lote IV (50 dias PG) 


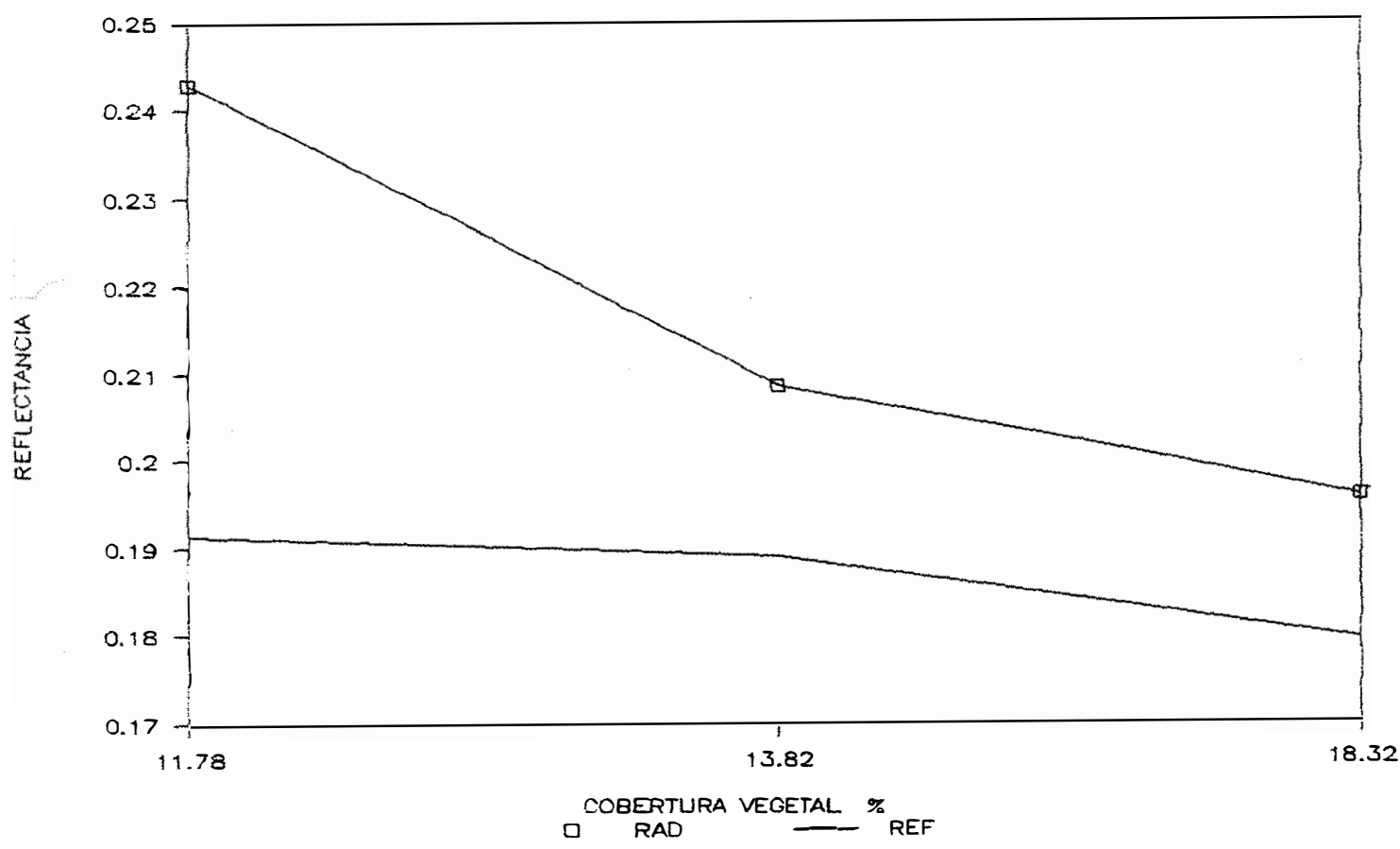

Figura $2 I$ - Curvas de reflectâncias em função da cobertura vegetal. Lote $V(8$ dias $P G)$

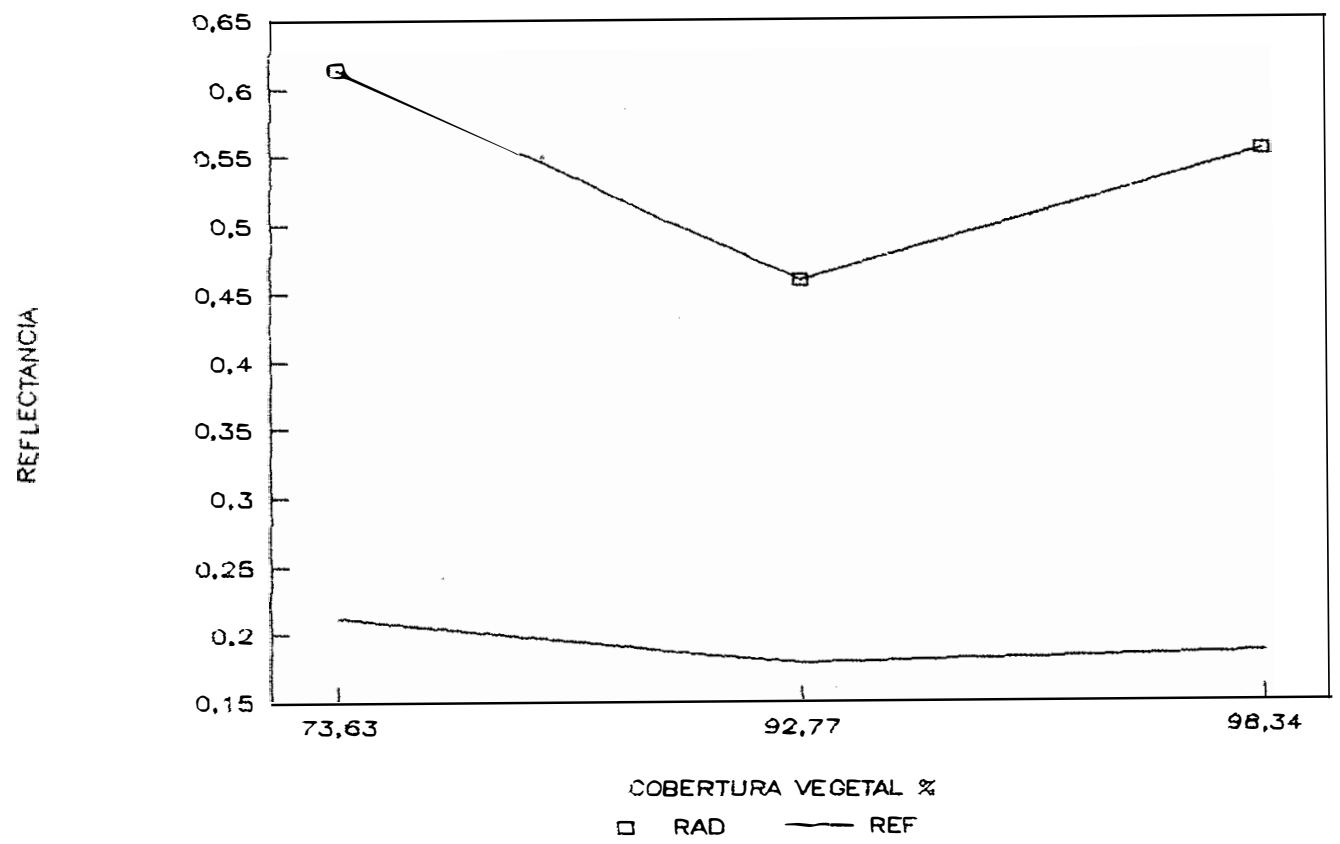

Figura 2J - Curvas de reflectância em função da cobertura vegetal. Lote $V(50$ dias $P G)$ 


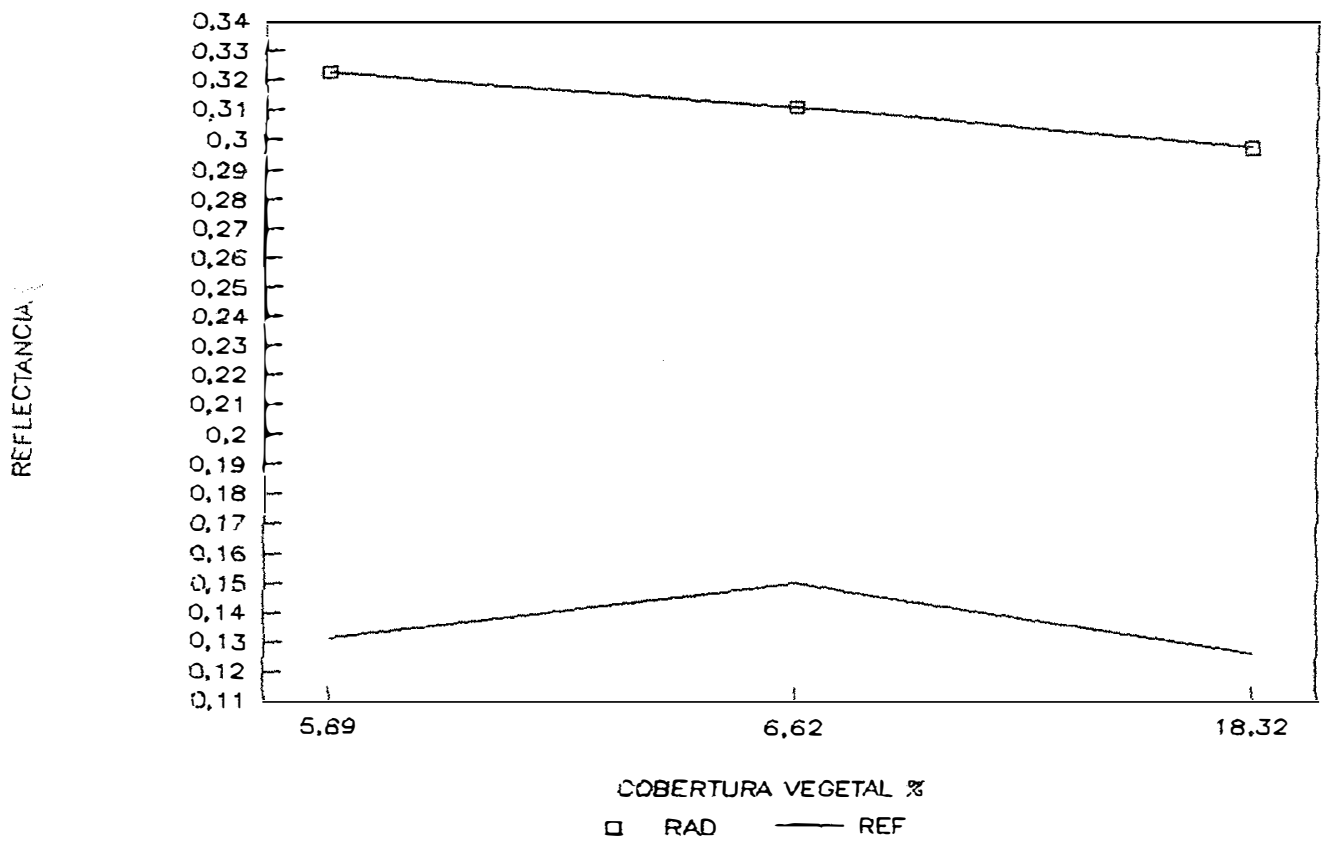

Figura 2L - Curvas de reflectāncias em função da cobertura vegetal. Lote VI ( 8 dias PG)

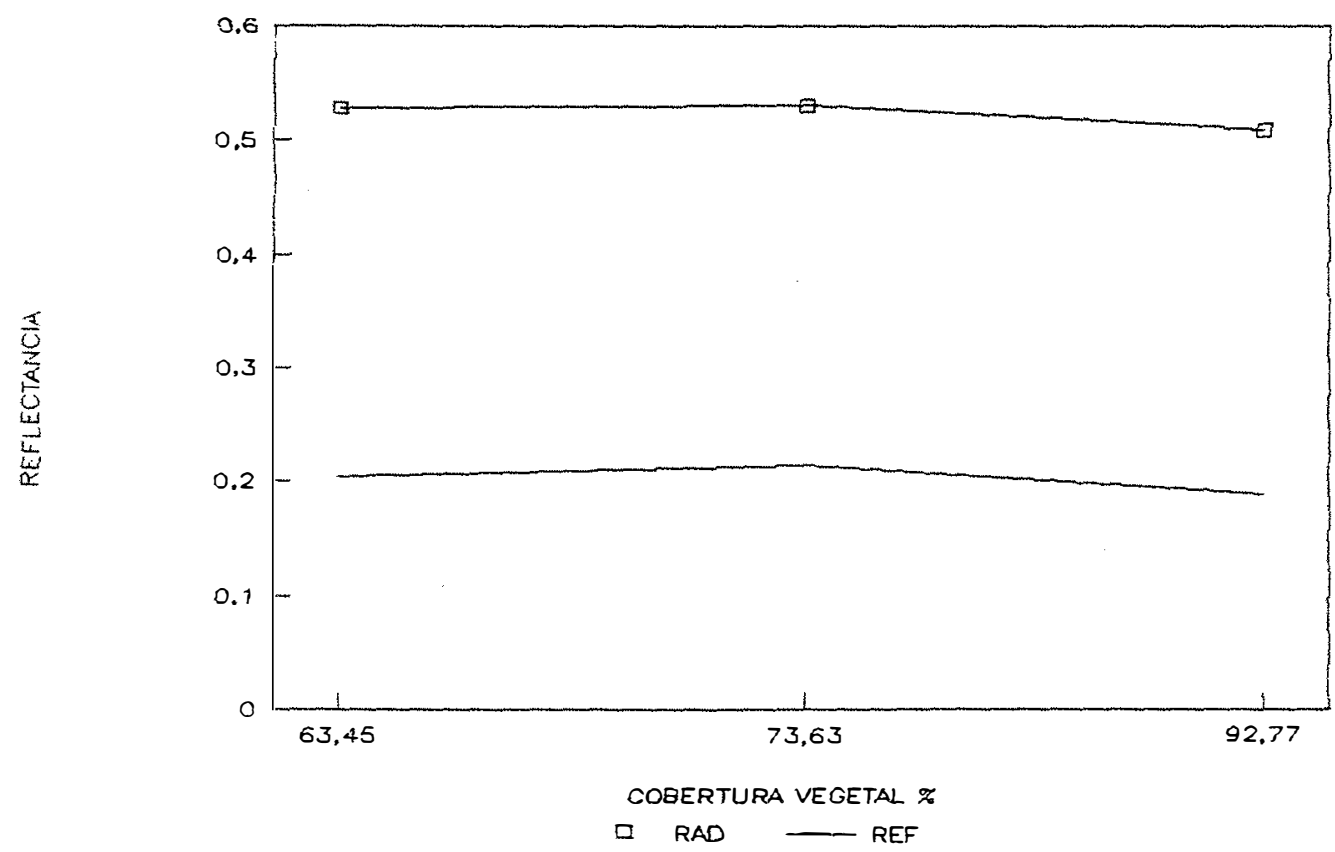

Figura 2M - Curvas de reflectāncias em função da cobertura vegetal. Lote VI (50 dias PG) 


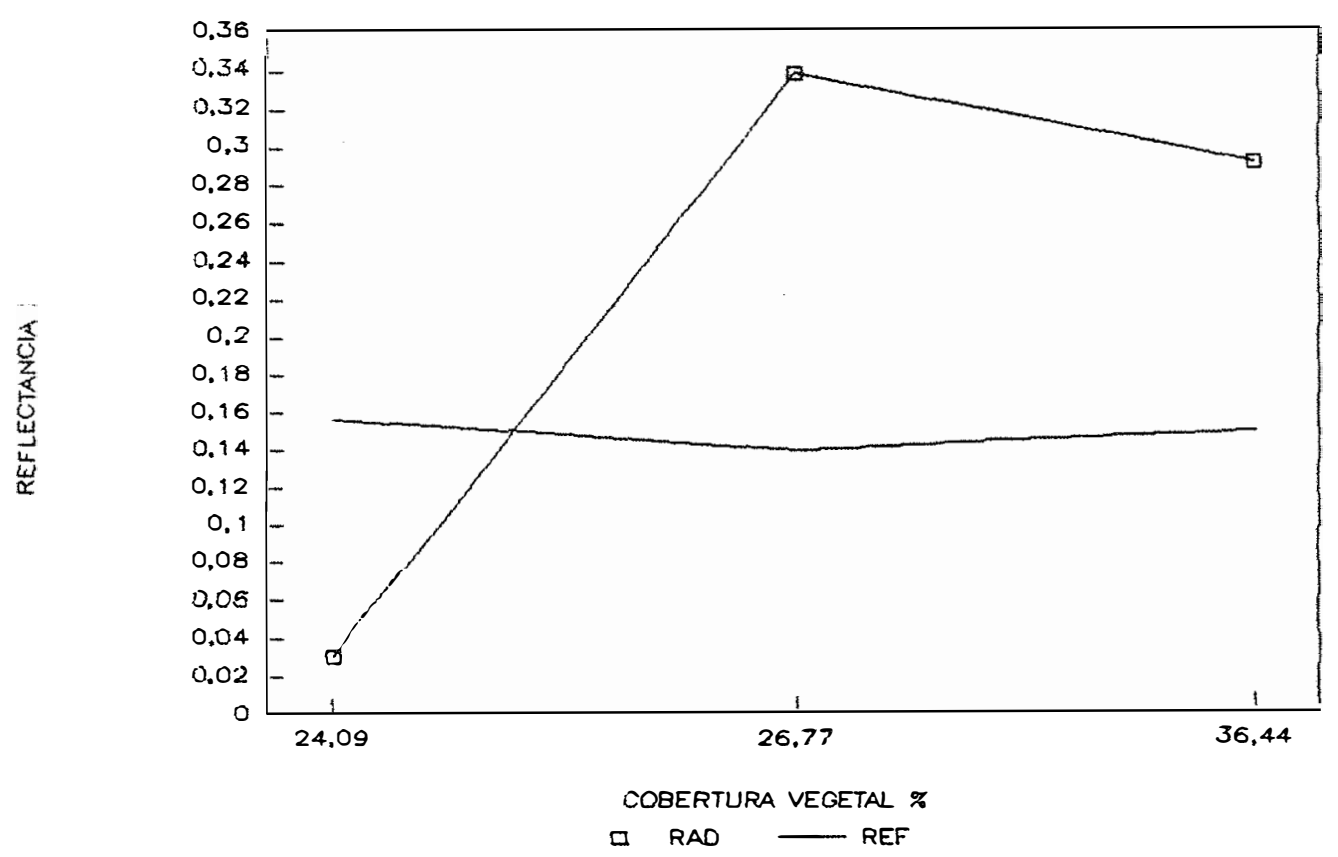

Figura $2 \mathrm{~N}$ - Curvas de reflectâncias em função da cobertura vegetal. Lote VII ( 8 dias PG)

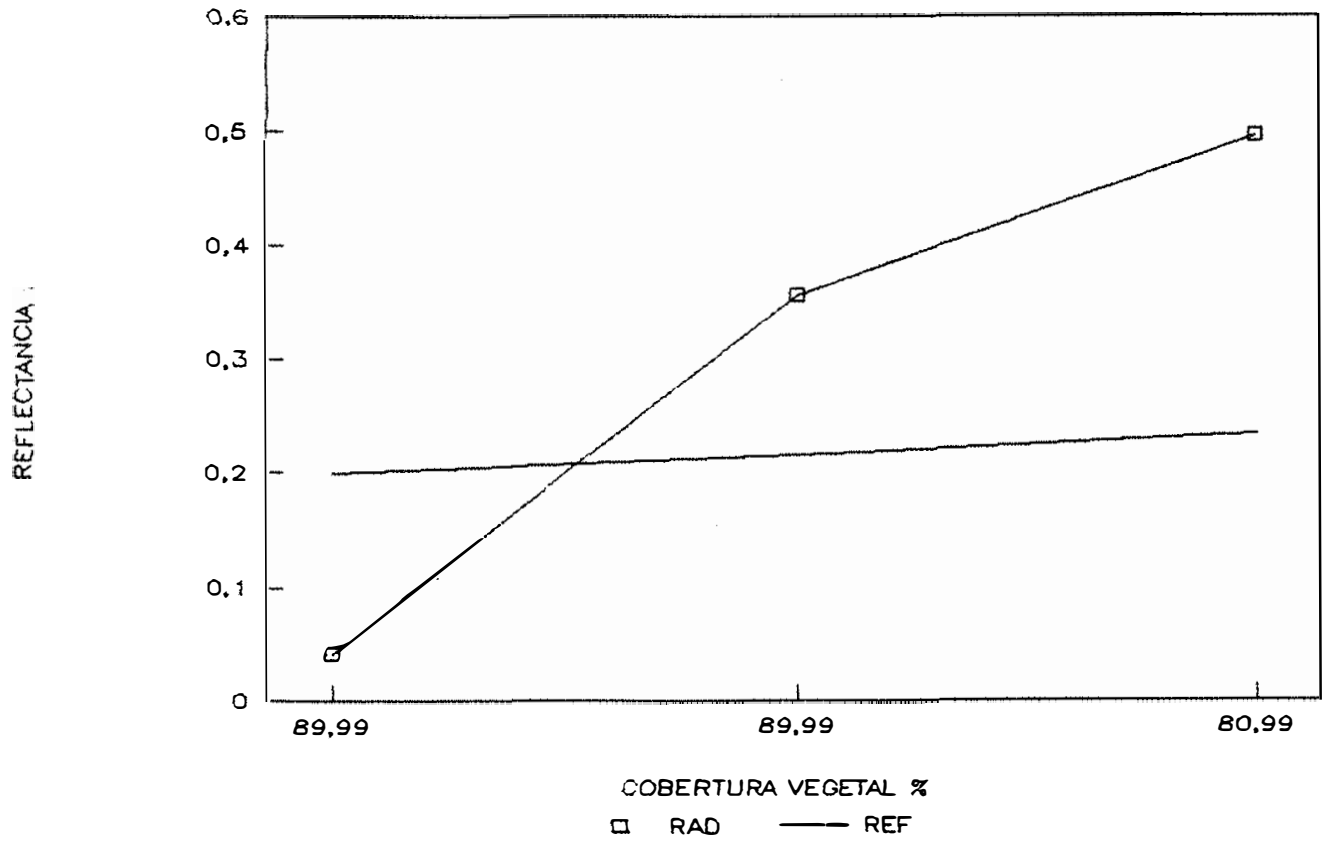

Figura 20 - Curvas de reflectâncias em função da cobertura vegetal. Lote VII (50 dias PG) 
111.

\section{APÈNDICE 3 - Gráficos de reflectâncias temporais 18 dias PG e 50 dias PG) dos 7 lotes estudados em função do indice de área foliar.}


112.

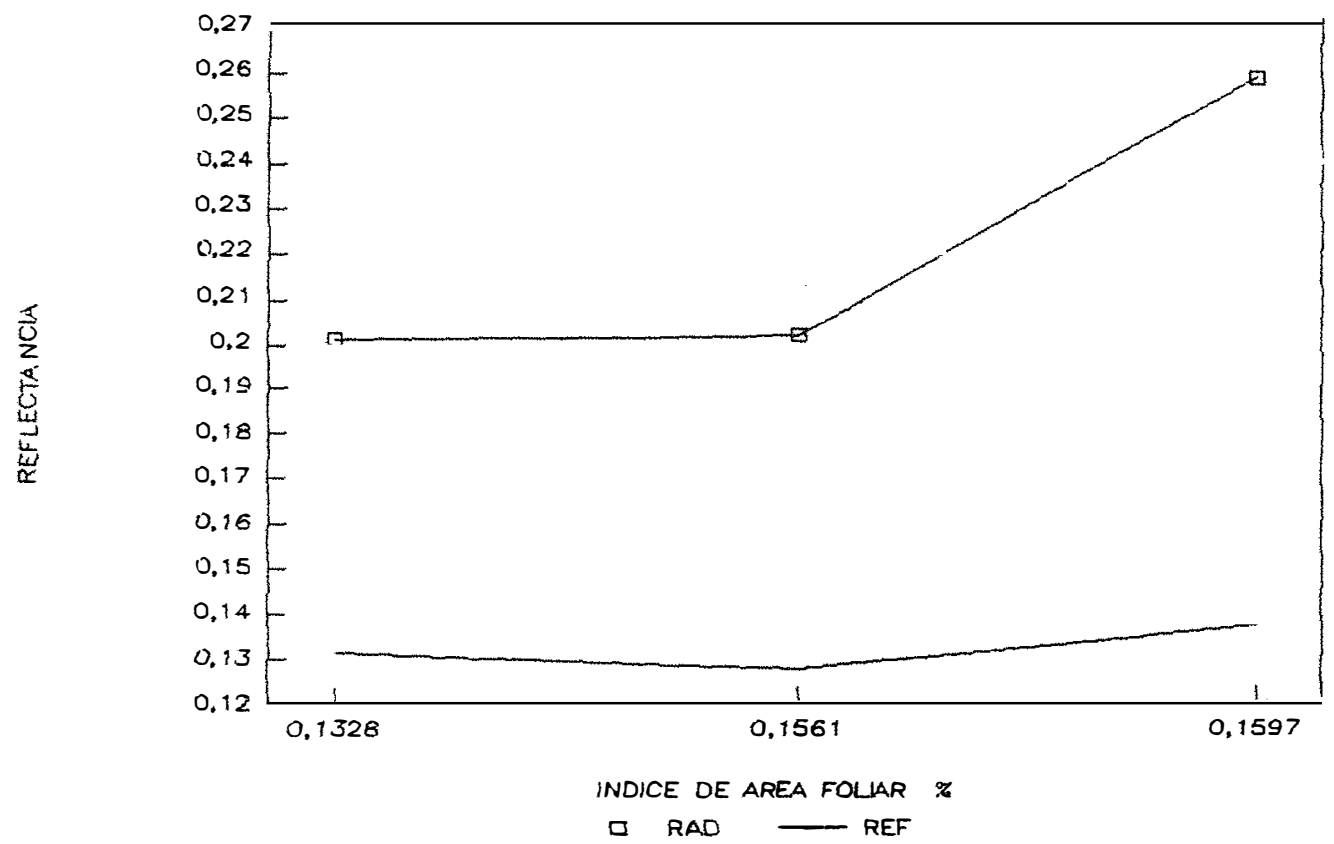

Figura 3A - Curvas de reflectâncias em função do índice da área foliar. Lote I ( 8 dias PG)

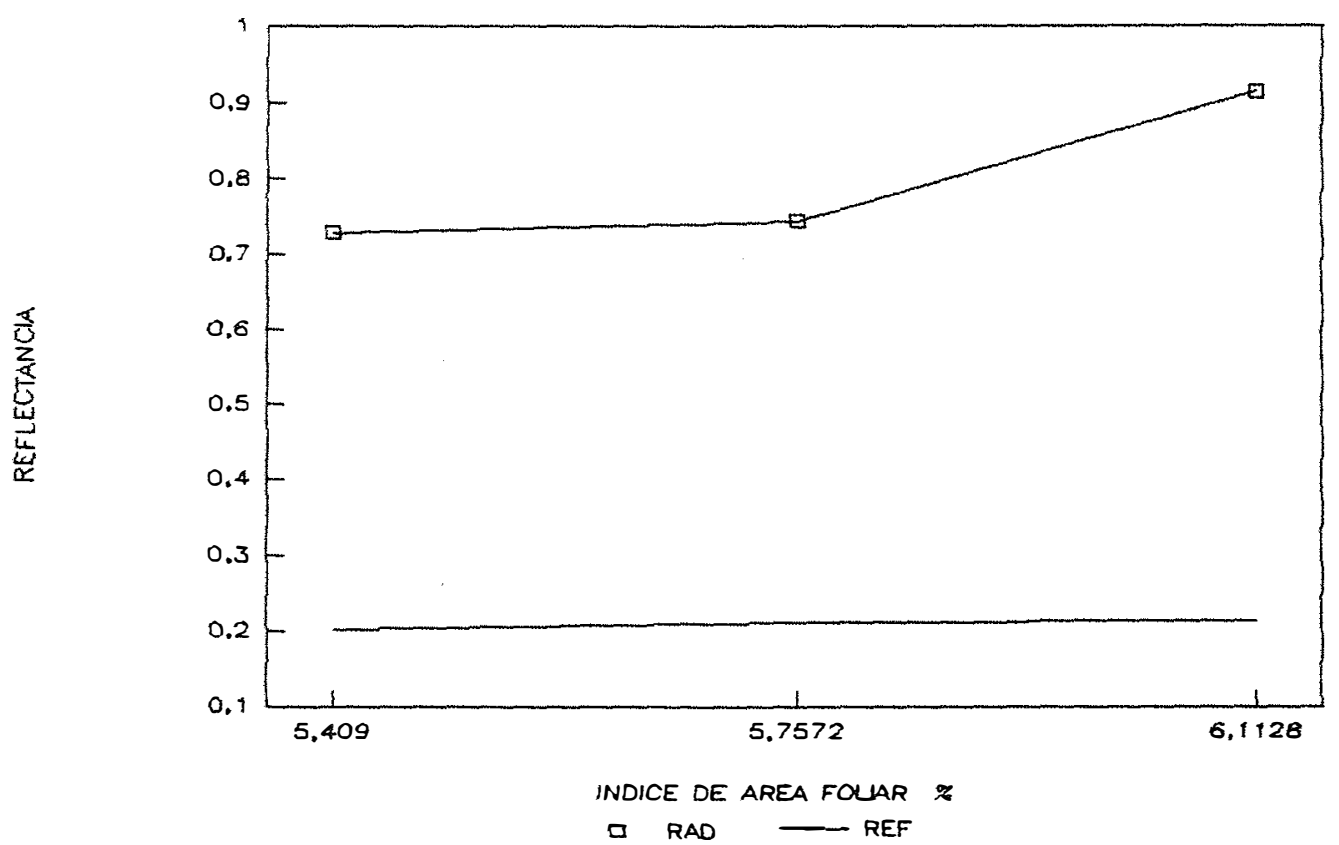

Figura 3B - Curvas de reflectância em função do índice da ārea foliar. Lote $I$ ( 50 dias PG) 
113.

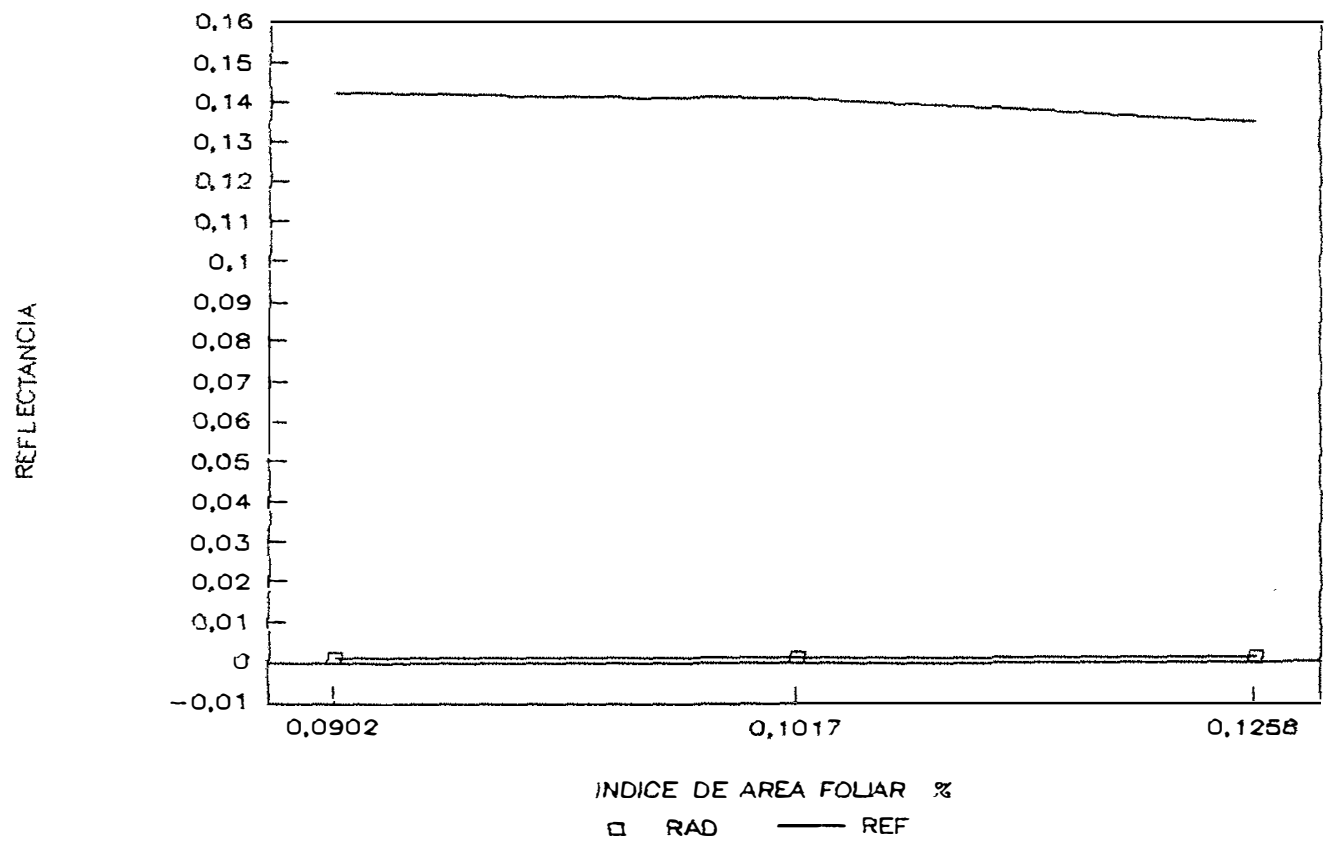

Figura 3C - Curvas de reflectāncias em função do indice de aŕea foliar. Lote I ( $(8$ dias PG)

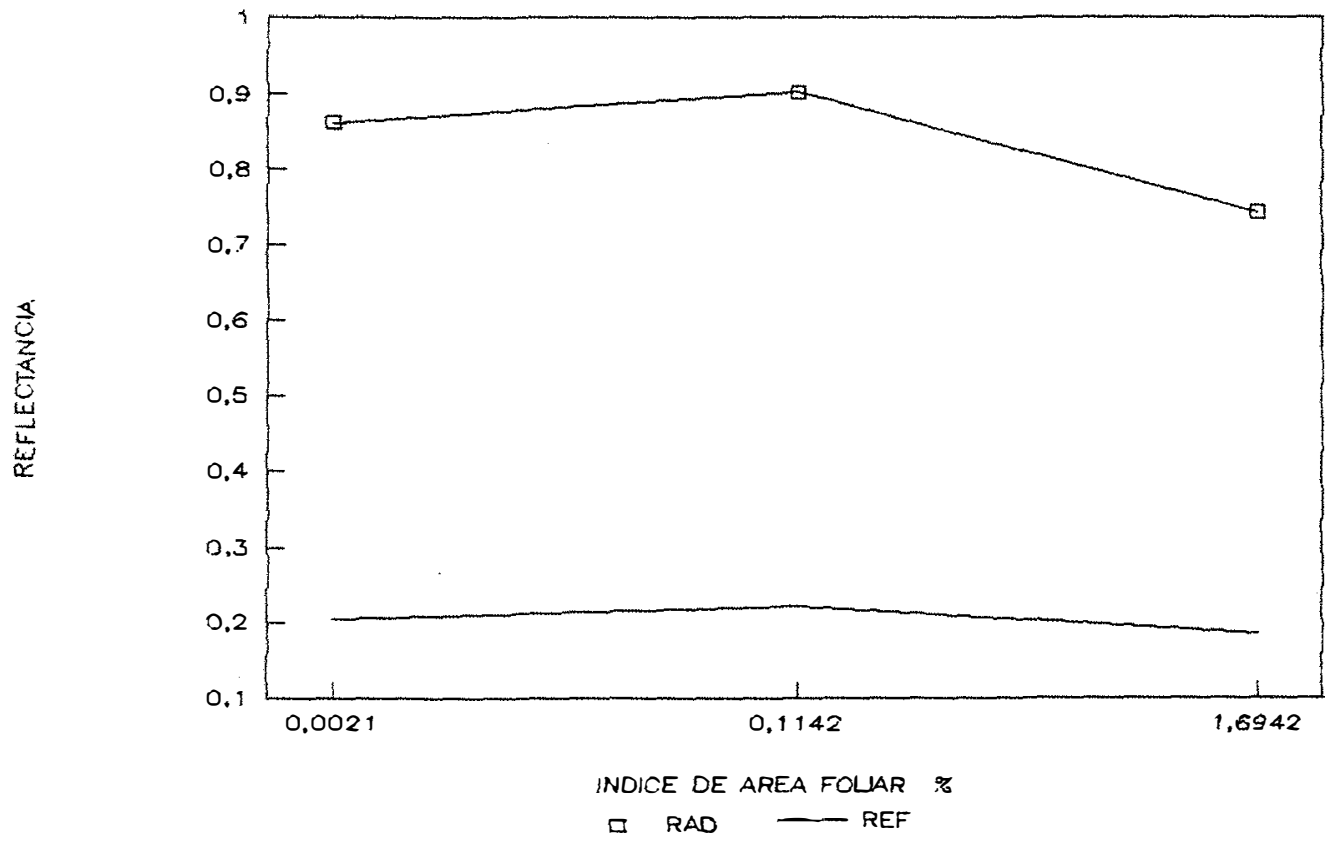

Figura 3D - Curvas de reflectāncias em função do indice de área foliar. Lote II (50 dias PG) 
114.

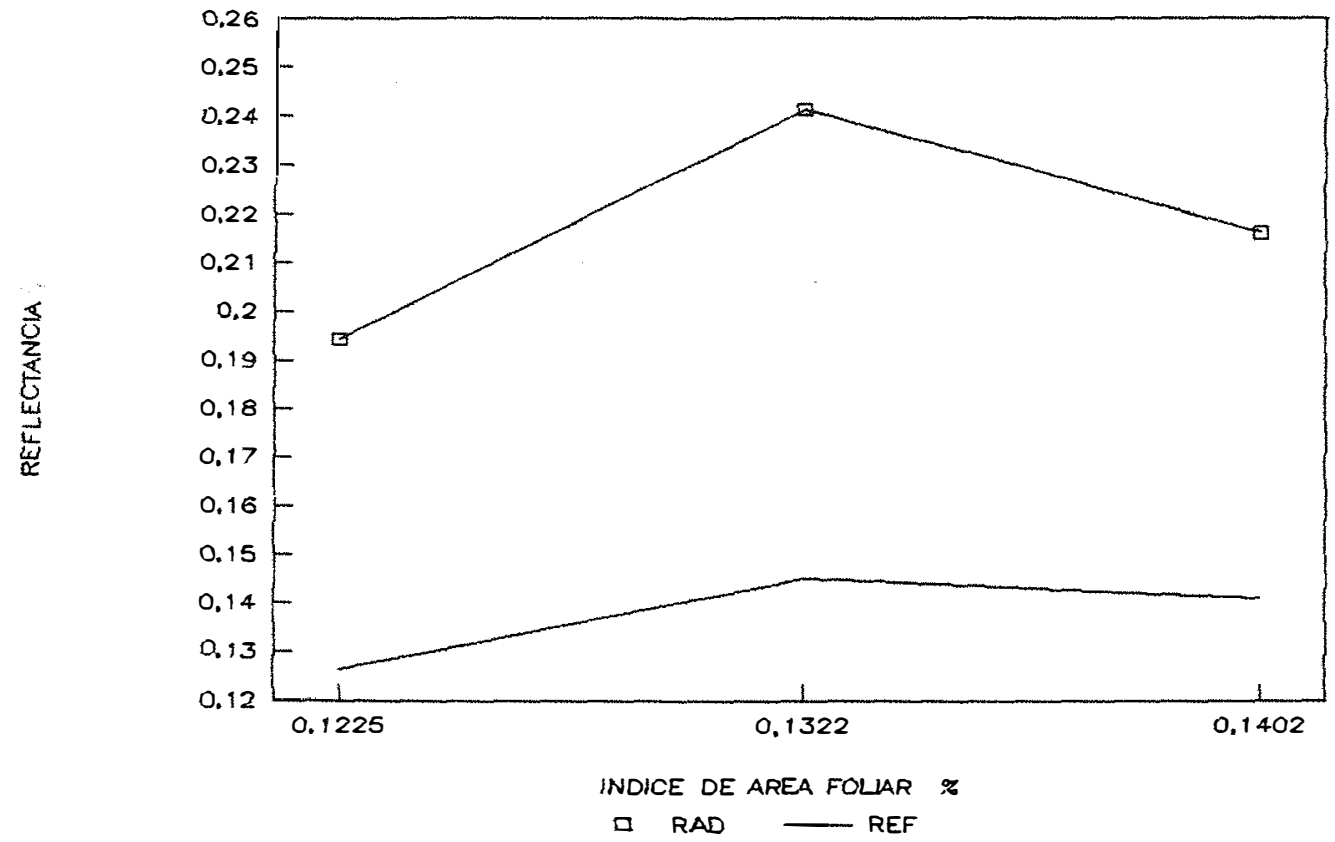

Figura $3 E$ - Curvas de reflectāncias em função do índice da área foliar. Lote III ( 8 dias PG)

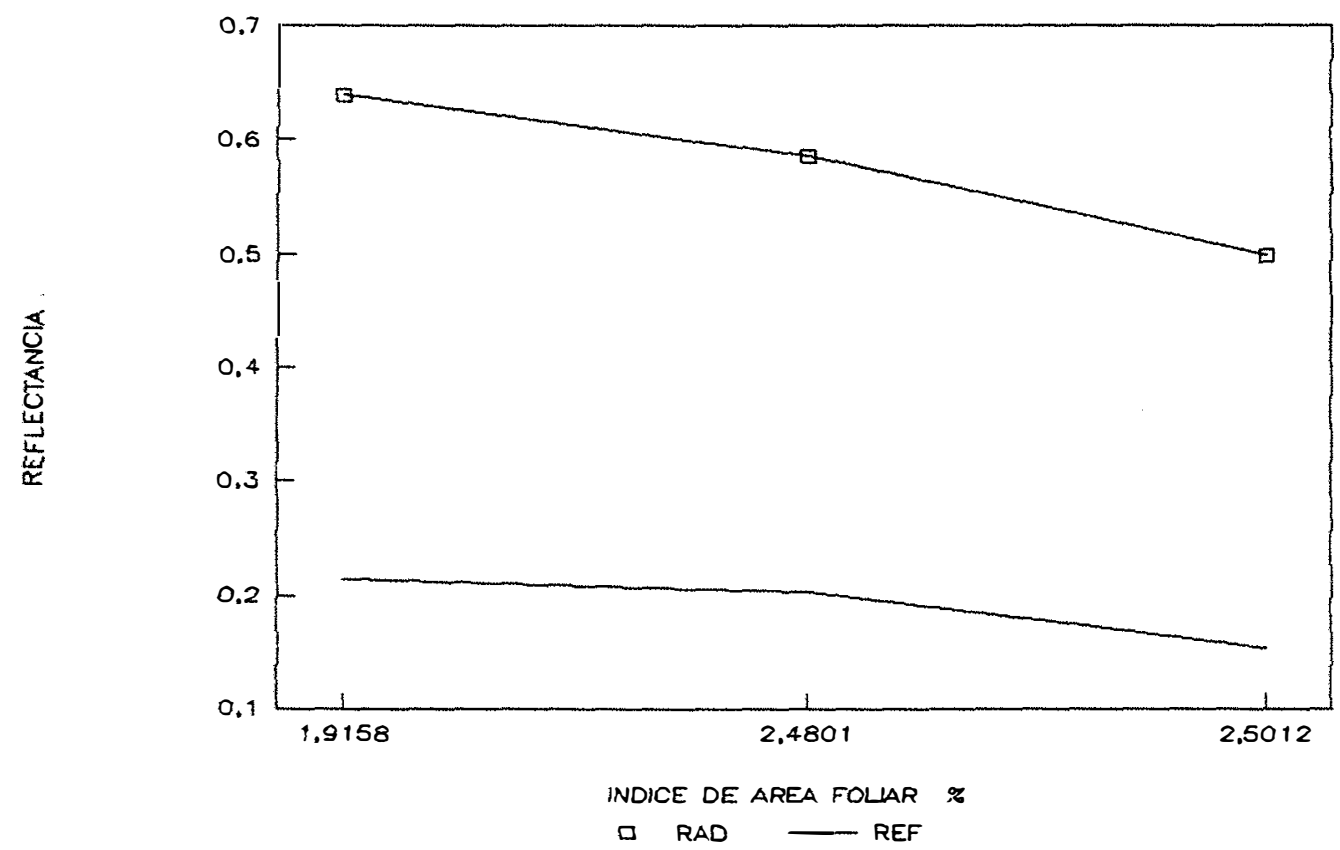

Figura $3 F$ - Curvas de relfectāncias em função do indice da área foliar. Lote III ( 50 dias PG) 
115.

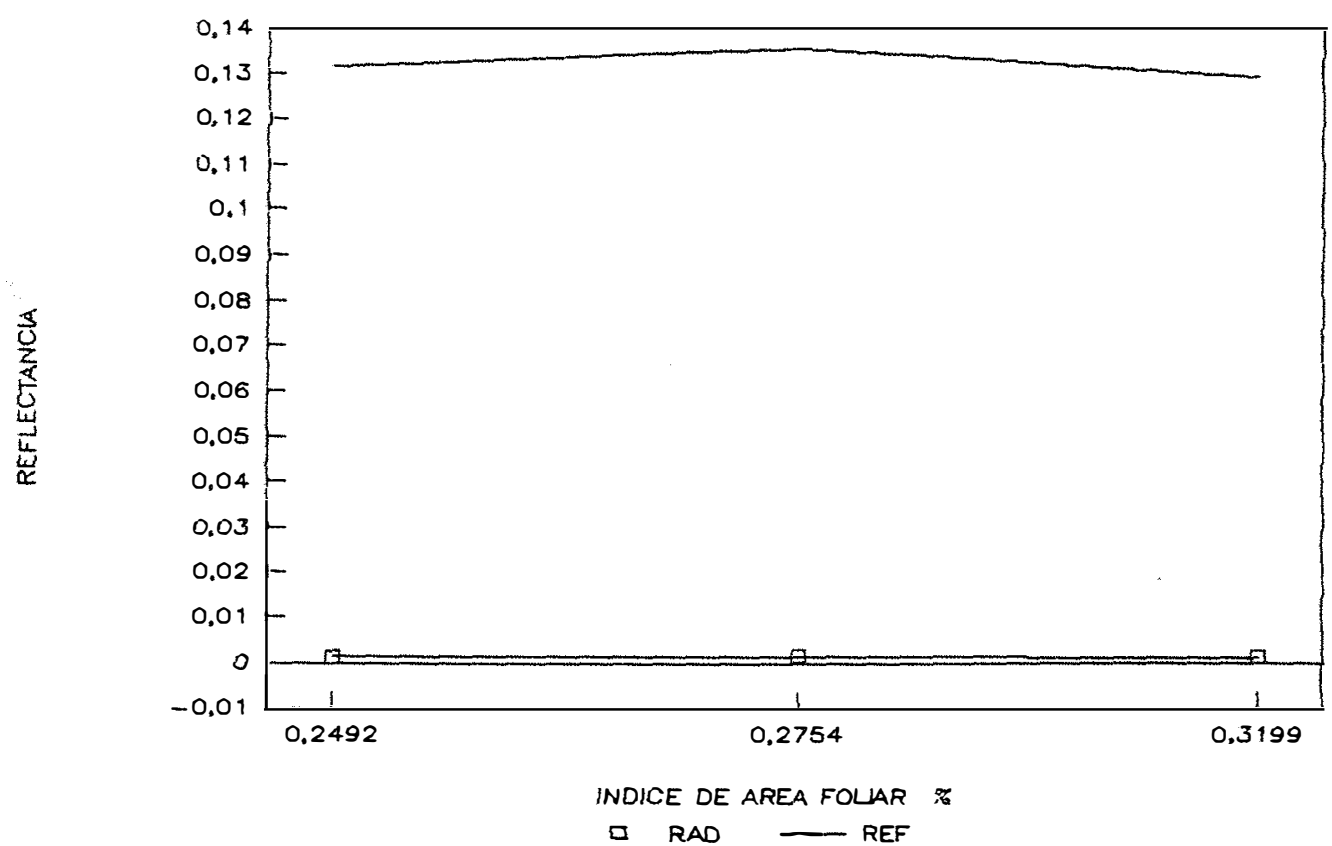

Figura 3G - Curvas de reflectāncias em função do índice da ārea foliar. Lote IV ( 8 dias PG)

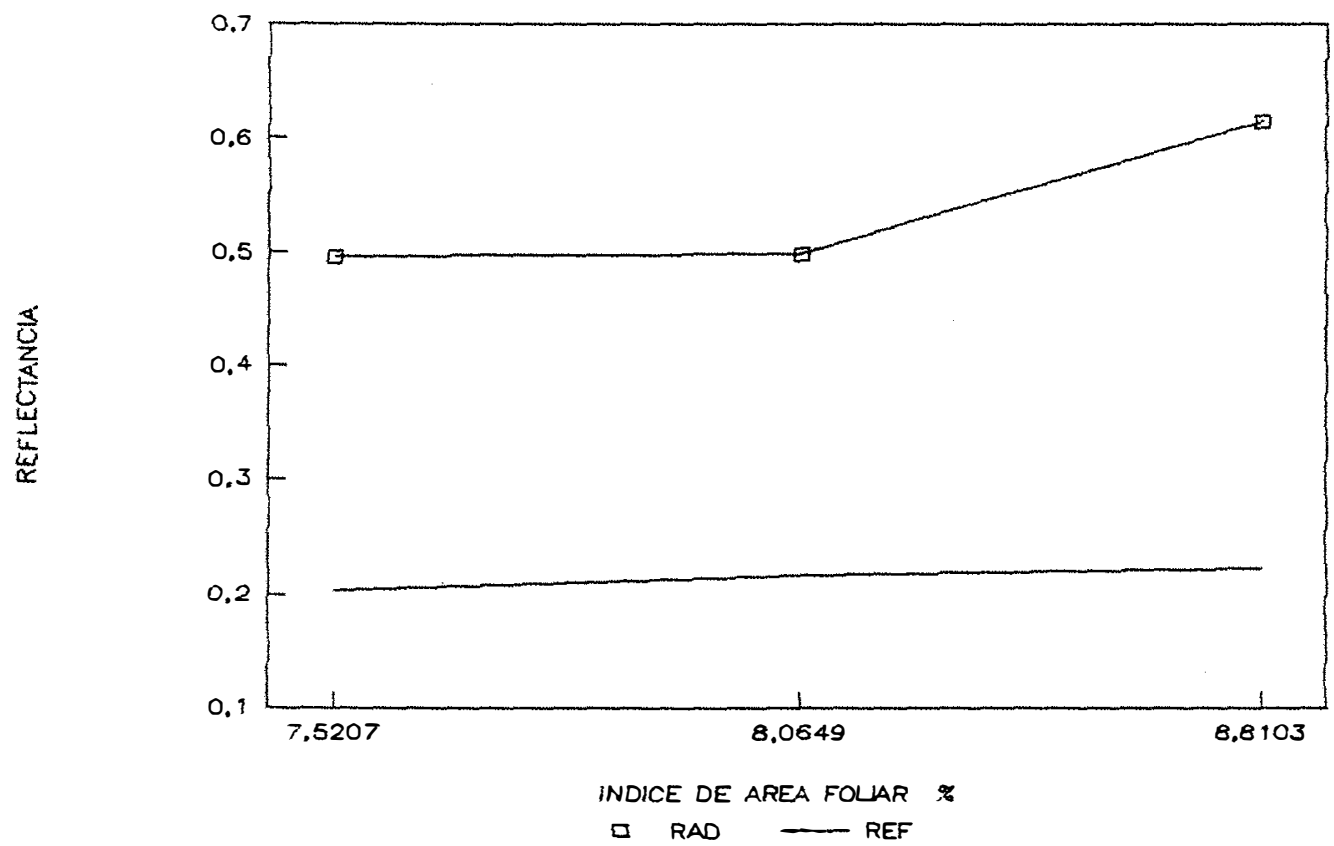

Figura 3H - Curvas de relfectāncias em função do indice da área foliar. Lote IV (50 dias PG) 
116.

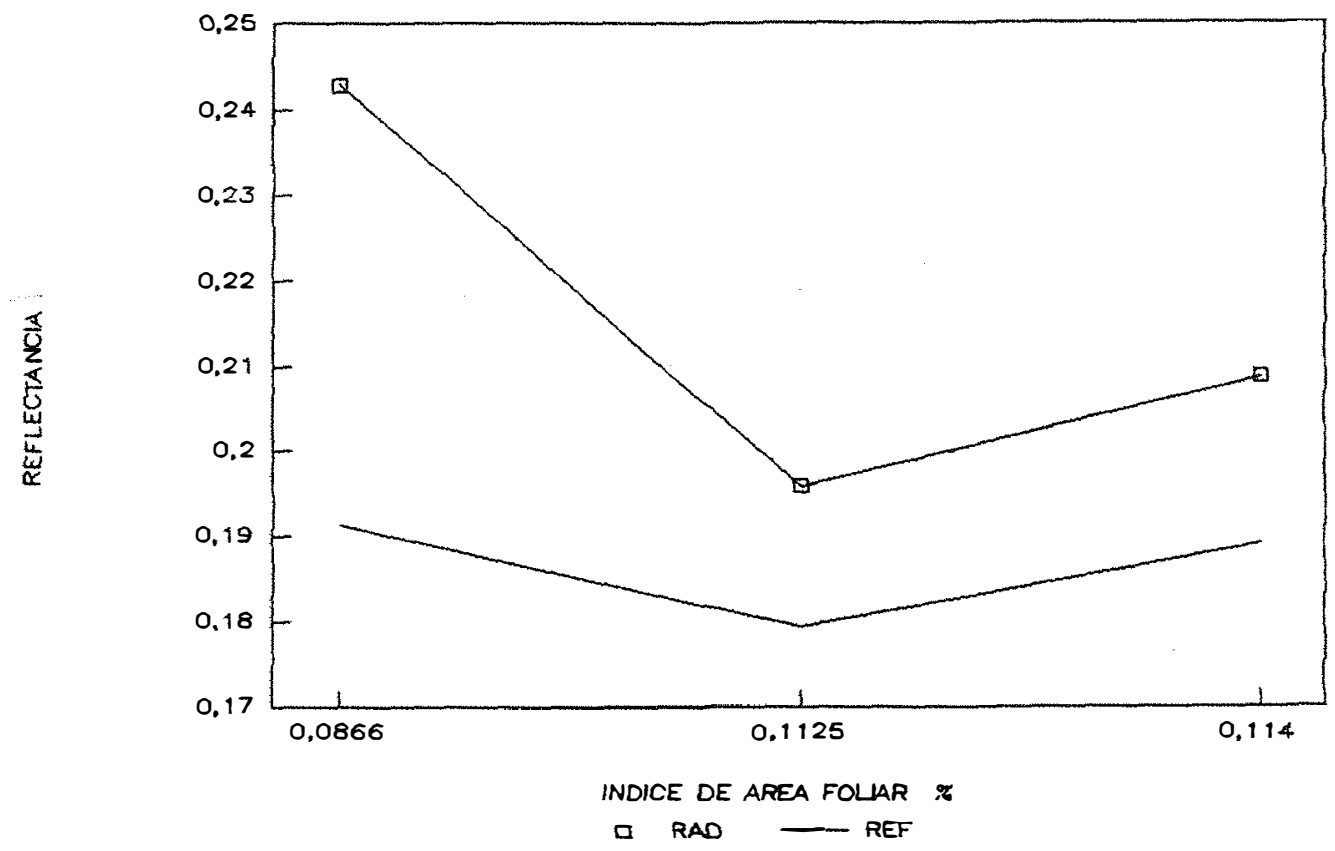

Figura $3 I$ - Curvas de reflectāncias em função do índice da área foliar. Lote $V$ ( 8 dias PG)

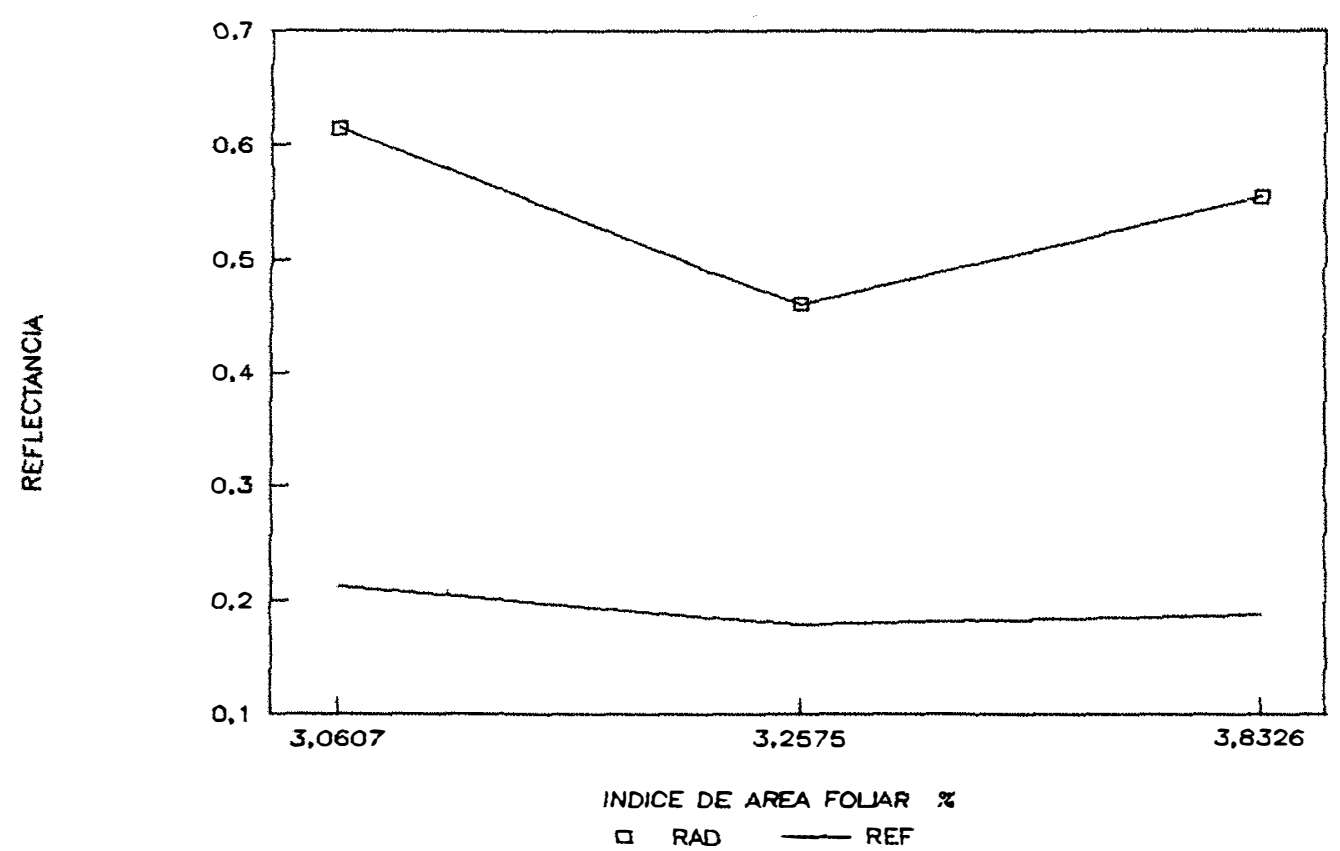

Figura $3 J$ - Curvas de reflectāncias em função do índice da área foliar. Lote $V$ (50 dias PG) 


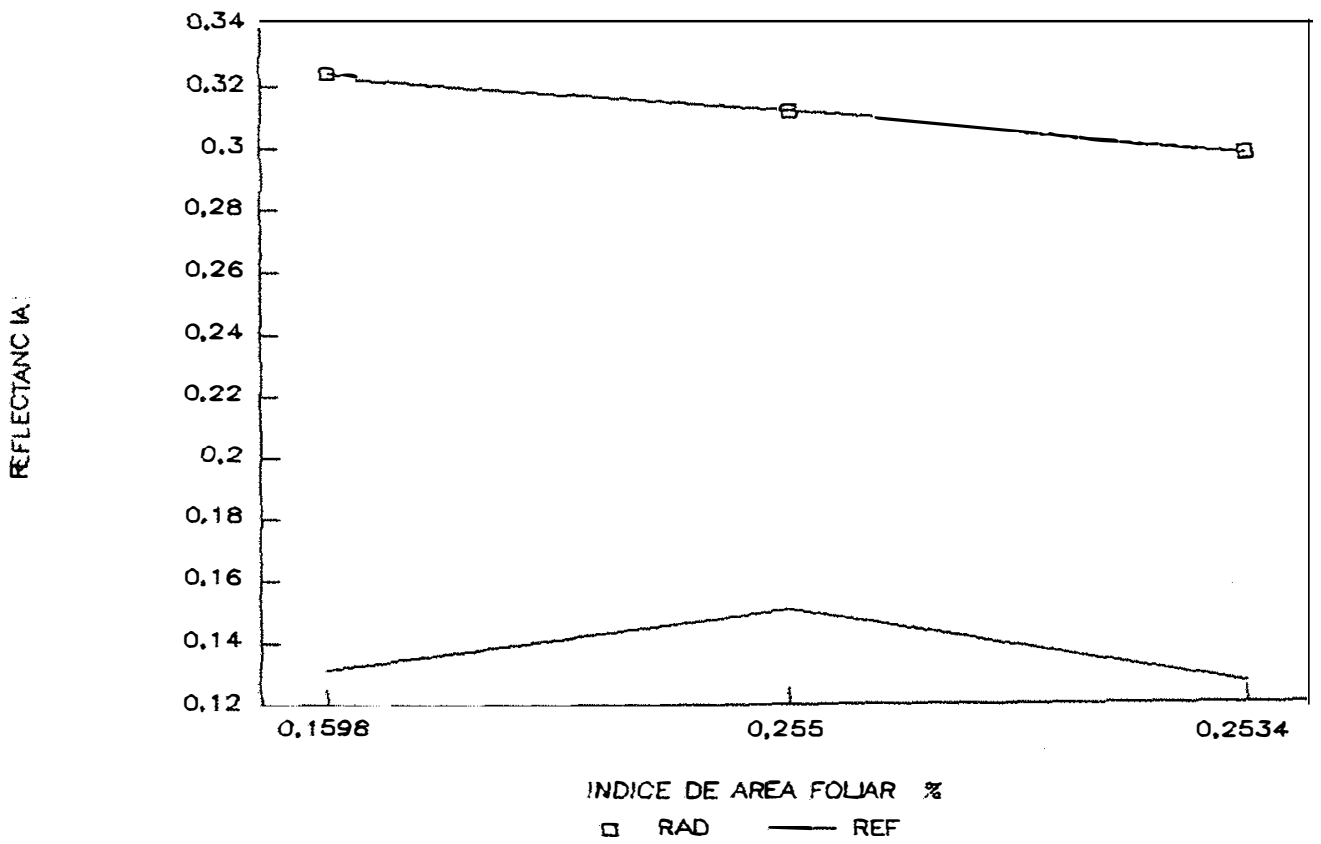

Figura 3L - Curvas de reflectāncias em função do índice de área foliar. Lote VI ( 8 dias PG)

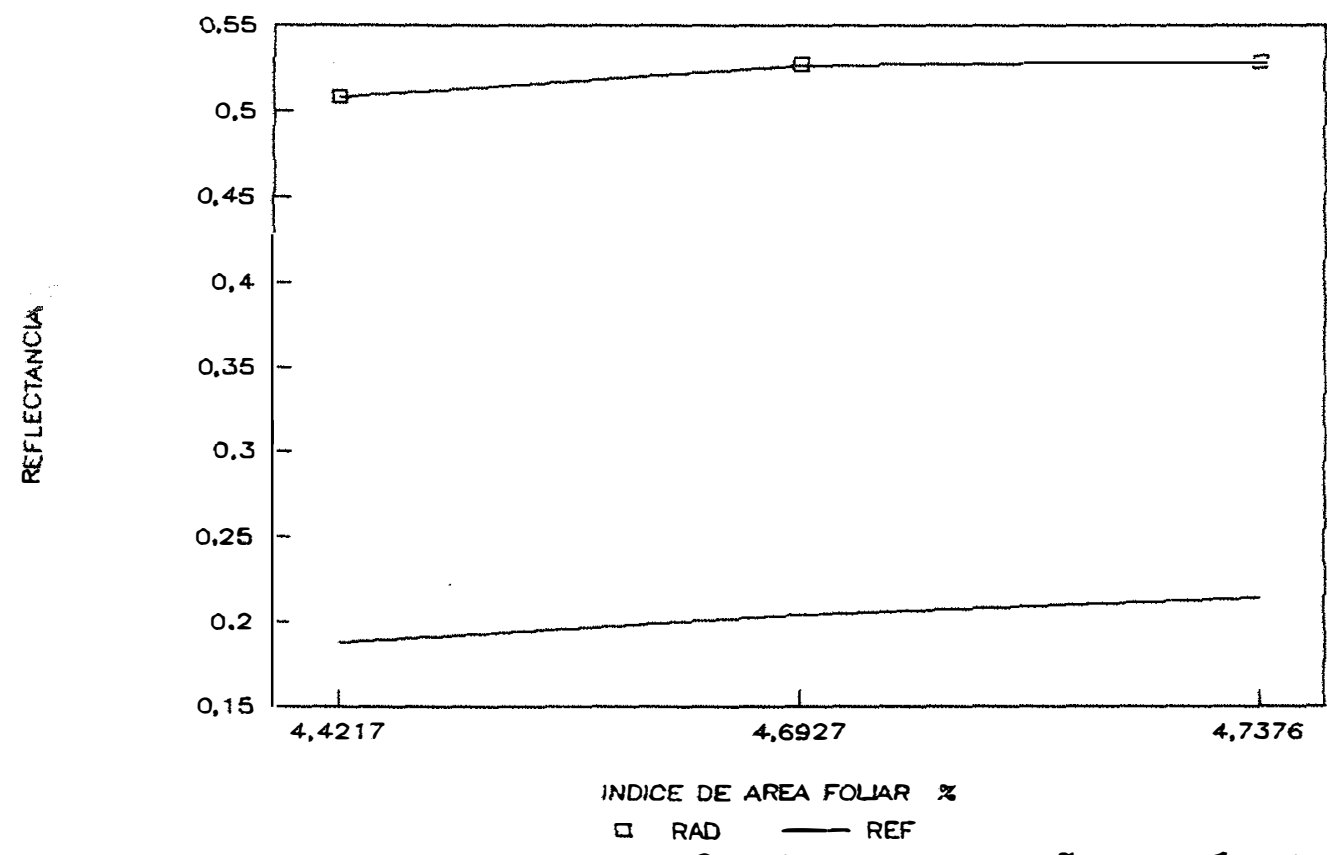

Figura 3M - Curvas de reflectâncias em função do índice de área foliar. Lote VI (50 dias PG) 


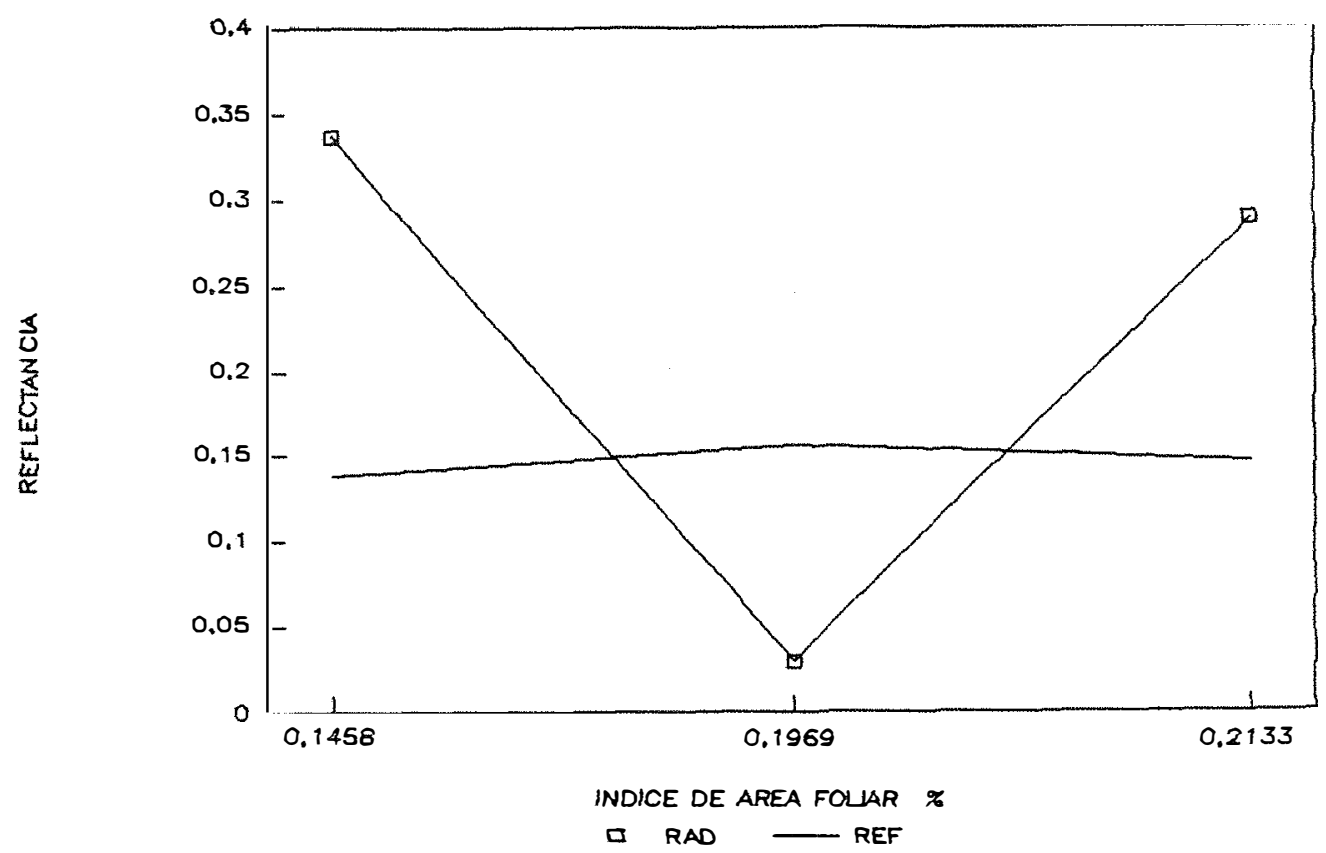

Figura $3 N$ - Curvas de reflectâncias em função do indice da área foliar. Lote VII ( 8 dias PG)

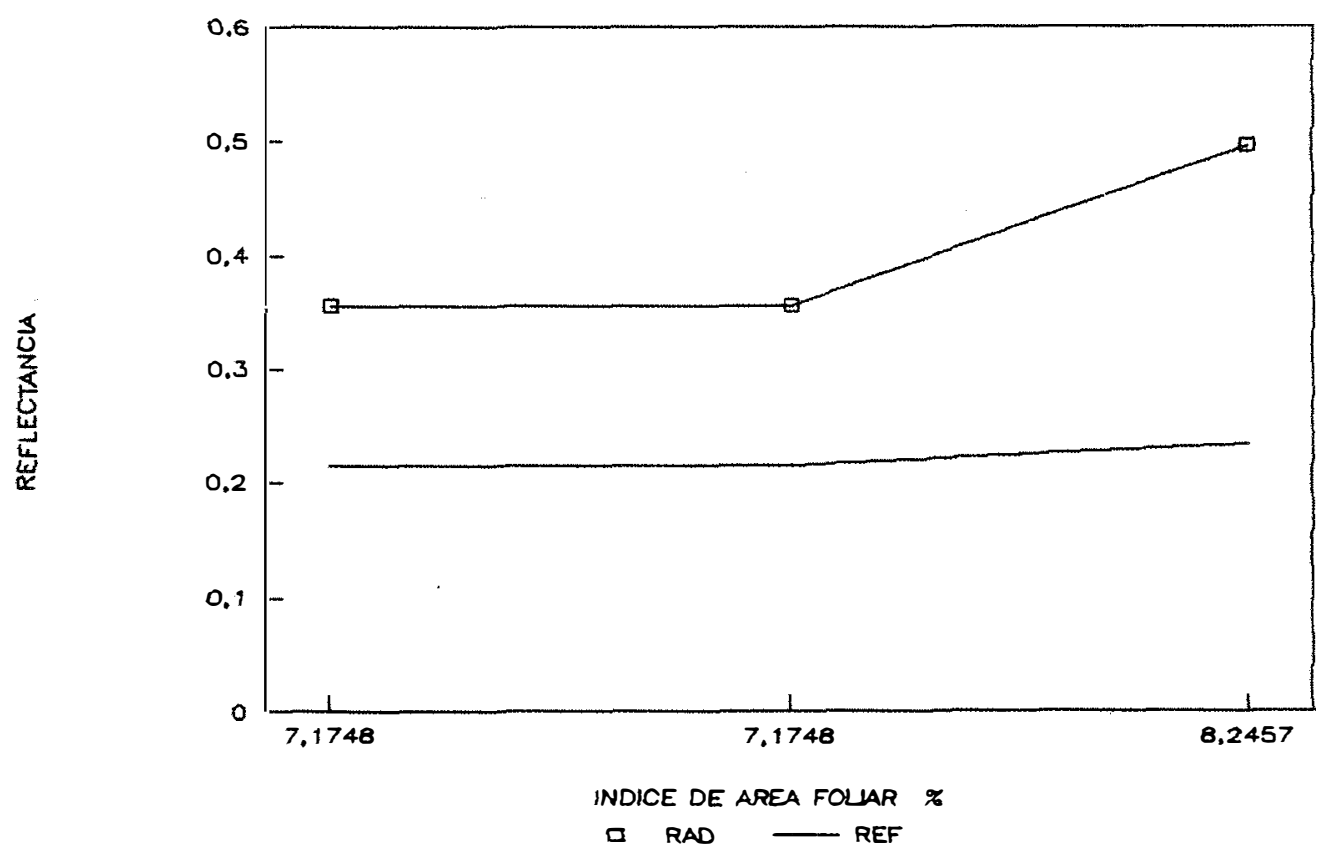

Figura 3 o- Curvas de reflectâncias em função do índice da área foliar. Lote VII (50 dias PG) 